\title{
Hämatophage Dipteren - Makro- und mikroökologische Einflüsse auf ihre Verbreitung
}

\author{
Dissertation \\ Zur Erlangung des Doktorgrades \\ der Naturwissenschaften \\ vorgelegt beim Fachbereich Biowissenschaften \\ der Goethe-Universität \\ in Frankfurt am Main
}

Von

Dorian D. Dörge

aus Mannheim

Frankfurt am Main 2021

(D30) 
vom Fachbereich Biowissenschaften

der Johann Wolfgang Goethe-Universität als Dissertation angenommen.

Dekan: $\quad$ Prof. Dr. Sven Klimpel

Gutachter: Prof. Dr. Sven Klimpel

Prof. Dr. Jörg Oehlmann

Datum der Disputation: 
Für meine Vor- und Nachfahren 


\section{Danksagung}

Mein besonderer Dank geht an meinen Doktorvater Prof. Dr. Sven Klimpel, der mir mit viel Humor, Rat und Tat, Großzügigkeit und einer Vielzahl von Projekten und Exkursionen diese Arbeit ermöglicht hat. Ohne diesen Treibstoff wäre es mir sicherlich nicht gelungen diese Arbeit anzufertigen und abzuschließen.

Bei Prof. Dr. Jörg Oehlmann möchte ich mich bedanken, dass er die Funktion als Zweitgutachter meiner Arbeit übernommen hat.

Sarah Cunze möchte ich für die hervorragend professionelle und jederzeit mögliche Zusammenarbeit sowie die (mehrfache) Korrektur dieser Arbeit danken.

Stefan Zaenker und dem hessischen Höhlenkataster möchte ich dafür danken, dass sie die Daten für das Projekt III ehrenamtlich gesammelt haben und eine Nutzung ermöglichten.

Birgit Nagel und Gabriele Elter möchte ich meinen Dank aussprechen, dafür, dass sie sich so hervorragend um Labor, Organisation und Studenten gekümmert haben und insbesondere auch für die Weihnachtskekse.

Ich danke Katharina Alt, Fanny Eberhard, Sebastian Emde, Raphael Frank, Regina Klapper, Lisa Koch, Judith Kochmann, Thomas Kuhn, Julian Münster, Norbert Peter, Chinhda Sharif, Elke Schleucher und Antje Steinbrink für ein freundschaftliches Arbeitsklima, zahlreiche Ratschläge und zusammen bearbeitete Projekt.

Adrienne Jochum möchte ich für ihre regelmäßigen Hilfestellungen, Ablenkungen und Unterstützung danken.

Meinem besten Freund Taylan Özden möchte ich für die zahllosen Gespräche, Ausflüge und Abende danken, die den Kopf immer mal wieder für andere Dinge freigemacht haben.

Schlussendlich danke ich natürlich auch meinen Eltern, die mich zusätzlich zu sonstiger Unterstützung über die Jahre hinweg regelmäßig daran erinnert haben, dass ich meine Doktorarbeit noch fertig schreiben muss. 


\section{Vorwort}

Die vorliegende Dissertation ist in publikationsbasierter (kumulativer) Form angelegt und gibt einen zusammenfassenden Überblick über den Inhalt und wissenschaftlichen Kontext der von mir in Kooperation veröffentlichten, promotionsrelevanten Publikationen. Die Arbeit beinhaltet drei (ISI-) Publikationen, welche im Anhang aufgeführt sind und unter folgenden Titeln in den jeweiligen Fachzeitschriften veröffentlicht wurden:

I Dörge, D.D., Cunze, S., Klimpel, S.: Incompletely observed - niche estimation for six frequent European horsefly species (Diptera, Tabanoidea, Tabanidae). Parasites \& Vectors 13, 461 (2020)

II Koch, L.K., Cunze, S., Werblow, A. Kochmann, J., Dörge, D.D., Mehlhorn, H., Klimpel, S.: Modeling the habitat suitability for the arbovirus vector Aedes albopictus (Diptera: Culicidae) in Germany. Parasitology Research 115, 957-964 (2016)

III Dörge, D.D., Cunze, S., Schleifenbaum, H., Zaenker, S., Klimpel, S.: An investigation of hibernating members from the Culex pipiens complex (Diptera, Culicidae) in subterranean habitats of central Germany. Scientific Reports 10, 10276 (2020)

Die Einzelpublikationen werden in Kapitel 2 separat zusammengefasst und in Kapitel 3 anschließend übergreifend diskutiert. Im Verlauf dieser Arbeit sind die promotionsrelevanten Publikationen jeweils mit römischen Ziffern nummeriert (Projekt I-III) und dienen an entsprechender Stelle als Querverweise. Sämtliche weiteren Quellen sind dem Literaturverzeichnis zu entnehmen. 


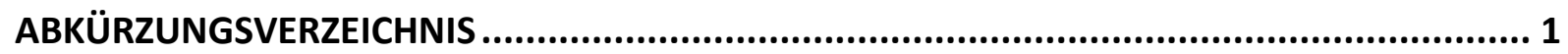

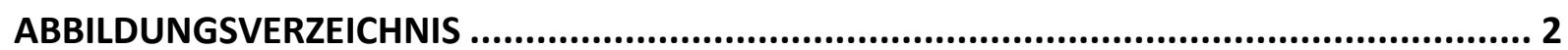

ZIELSETZUNG DER ARBEIT .....................................................................................

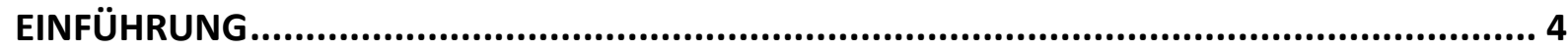

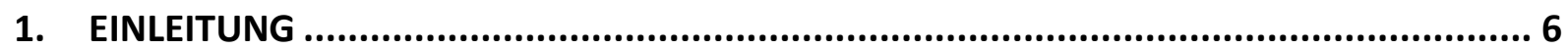

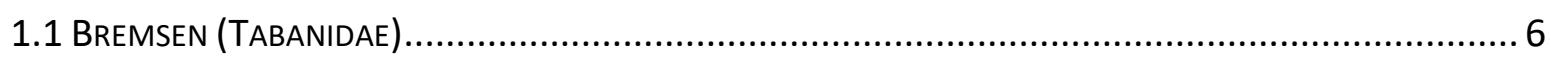

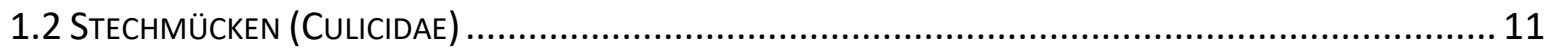

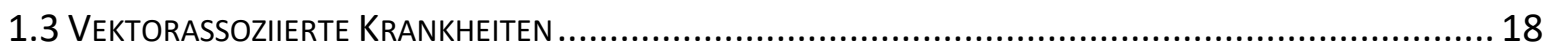

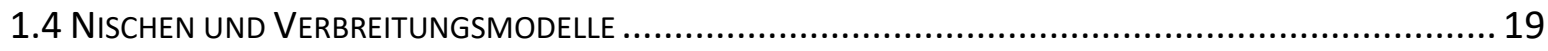

Surface Range Envelope ................................................................................... 22

Maximum Entropy und Klimaprojektion ............................................................... 22

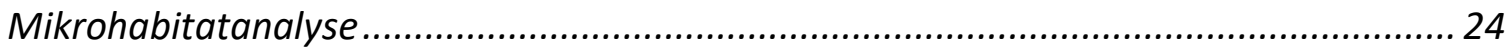

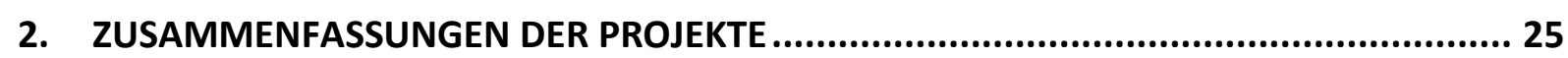

PROJEKT I - UNVOLLSTÄNDIG BEOBACHTET - NISCHENABSCHÄTZUNG FÜR SECHS HÄUFIGE EUROPÄISCHE

BREMSENARTEN (DIPTERA, TABANOIDEA, TABANIDAE) ORIGINALTITEL: INCOMPLETELY OBSERVED - NICHE

ESTIMATION FOR SIX FREQUENT EUROPEAN HORSEFLY SPECIES (DIPTERA, TABANOIDEA, TABANIDAE) .......... 26

Projekt II - Modellierung der Habitateignung für den Arbovirus-Vektor Aedes albopictus

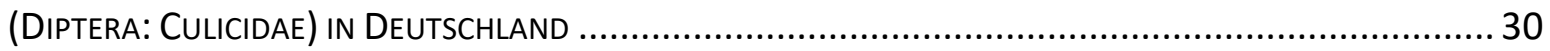

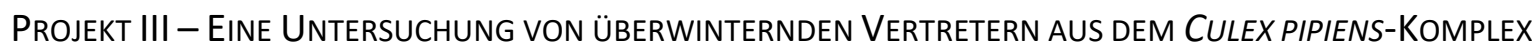

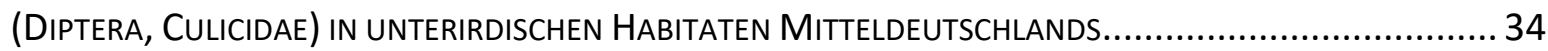

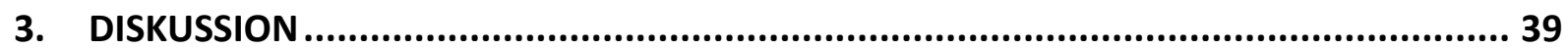

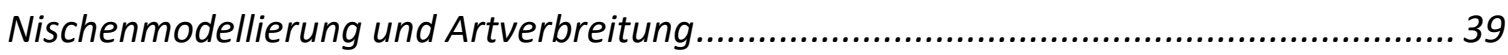

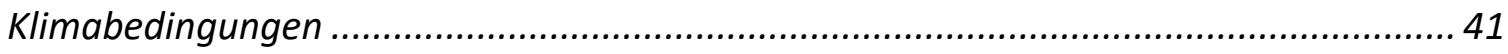

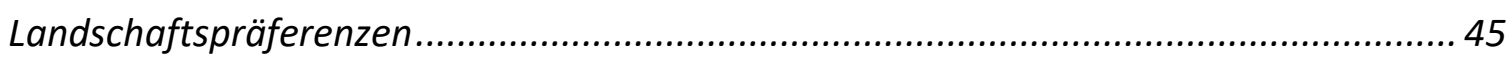

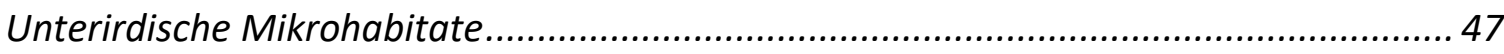

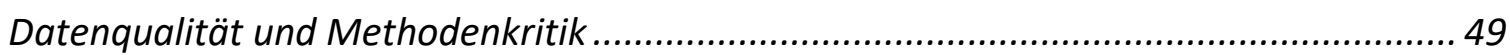

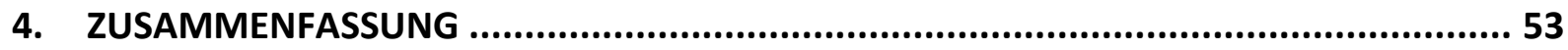

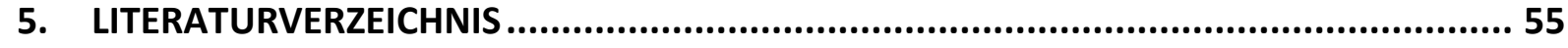

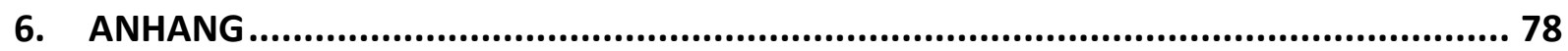

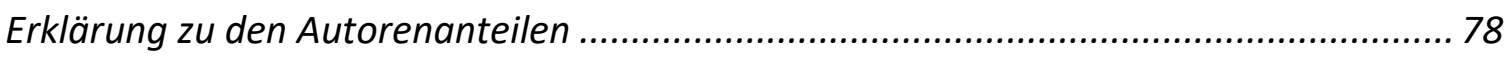

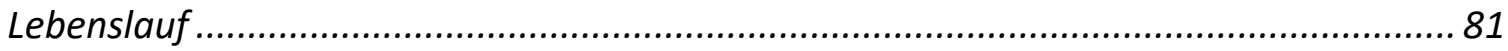

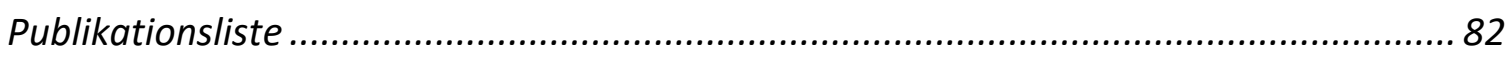




\section{Abkürzungsverzeichnis}

Ae.

Aedes

ca.

circa

${ }^{\circ} \mathrm{C}$

Grad Celsius

$\mathrm{CO}_{2}$

Kohlenstoffdioxid

$\mathrm{CH}_{4} \quad$ Methan

CLC Corine Land Cover

Cx.p. Culex pipiens

et al. et alii

ESA European Space Agency

GCM General Circulation Model

GLM General Linear Model

km Kilometer

$\mathrm{NH}_{3} \quad$ Ammoniak

RCP representative concentration pathway

s. I. sensu lato

s. S. sensu stricto

s. u. siehe unten

SRE Surface Range Envelope

sp. $\quad$ Spezies

spp. Spezies pluralis

ü. N. N. über Normal-Null

z. B. zum Beispiel 


\section{Abbildungsverzeichnis}

Abbildung 1: Innere Phylogenie der Tabaniden (nach Morita et al. 2016).............................. 6

Abbildung 2: Weibchen von Tabanus sudeticus ................................................................. 7

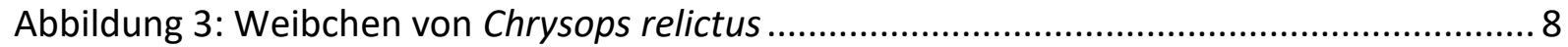

Abbildung 4: Exemplarischer Lebenszyklus einer Bremse mit sechs Larvenstadien ............... 10

Abbildung 5: Innere Phylogenie der Culiciden (nach Harbach und Kitching 1998) ................ 11

Abbildung 6: Männliches Exemplar von Anopheles plumbeus ............................................ 12

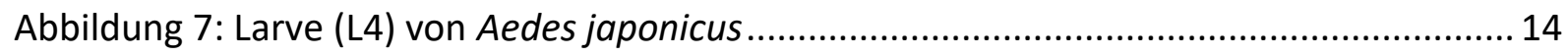

Abbildung 8: Larve (L4) von Anopheles plumbeus mit gedrehtem Kopf............................... 15

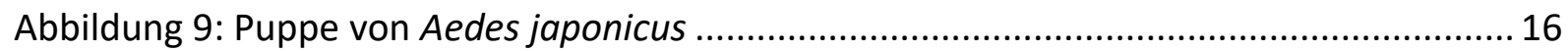

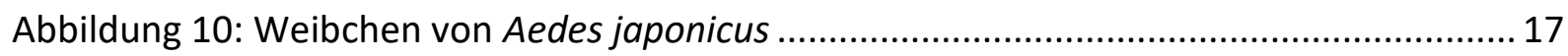

Abbildung 11: Exemplarischer Lebenszyklus einer Stechmücke ........................................ 17

Abbildung 12: Übersicht über die Projekte, genutzte Methoden, Skalen, Aspekte und

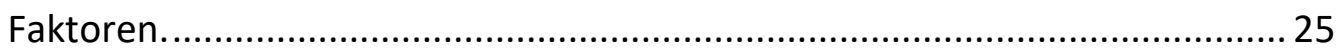

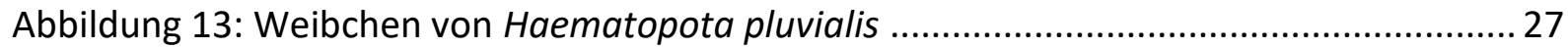

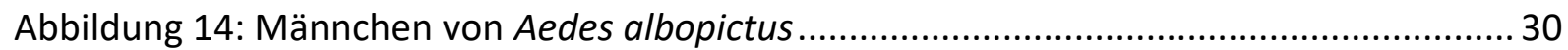

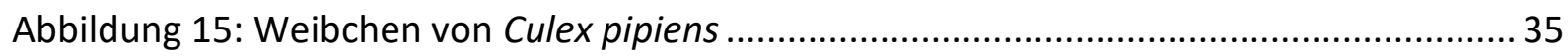

Abbildung 16: Schematische Darstellung und Vergleich der Modellierungsansätze ............... 40

Abbildung 17: Übersicht der untersuchten Faktoren innerhalb der Projekte. ....................... 42

Abbildung 18: Abundanz der überwinternden Mücken in Abhängigkeit der Höhenlage der

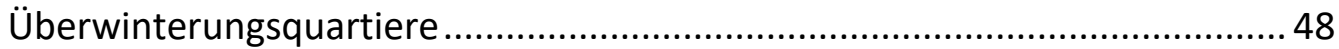

Abbildung 19: Abundanz der überwinternden Mücken in Abhängigkeit der Länge der Überwinterungsquartiere.

Abbildung 20: Übersicht über die Ergebnisse des Einflusses von Landschaft und Klima/Wetter aller drei Projekte. 


\section{Zielsetzung der Arbeit}

Hämatophage Arthropoden, insbesondere Steckmücken, sind aufgrund ihrer Bedeutung als menschliche Krankheitsvektoren und ihrer beschleunigten Ausbreitung im Zuge der Globalisierung ein intensiv untersuchtes und hoch aktuelles Thema in der Forschungslandschaft. Jedoch werden andere wichtige Artgruppen, wie Tabaniden und teilweise wichtige Aspekte der Ökologie der betreffenden Arten wie Überwinterung aktuell wenig bis gar nicht untersucht, meist aus Mangel an entsprechenden, dafür notwendigen Datensätzen. Die durchgeführten Studien stellen einige Möglichkeiten für die Untersuchung der Artökologie und Habitatpräferenzen dar und untersuchen die Verbreitung hämatophager Arthropoden in verschiedenen Größenskalen und Detailebenen. Insbesondere wurden generierte und über längere Zeiträume gesammelte Datensätze genutzt, um, groß- und kleinskalig, zusätzliche Informationen hinsichtlich der Landschaftspräferenzen und anderer ökologisch wichtiger Umgebungsparameter gewinnen zu können und diese statistisch auszuwerten. Zusätzlich wurden drei verschiedene Ansätze der Modellierung angewandt um Habitateignung und Vorkommenswahrscheinlichkeit von Bremsen und Stechmücken in Abhängigkeit der Umweltbedingungen zu bestimmen. In dieser Arbeit soll erörtert werden, welche abiotischen Faktoren auf welchen Ebenen Auswirkungen auf hämatophage Arthropoden haben und mithilfe welcher Untersuchungsmethoden geeignete Ergebnisse erzielt werden können.

Studie I erörtert großflächig (Eurasien) Landschaftspräferenzen und Klimatische Auswirkungen auf die Verbreitung von 6 Arten aus der Familie der Tabaniden, einer sehr mobilen Arthropodengruppe. Hierbei wurden Nischen modelliert und Habitatpräferenzen aus dem aus Literaturdaten generierten Datensatz gewonnen. Studie II fokussiert sich auf die aktuelle und, unter Zuhilfenahme verschiedener Klimaprognosen, die zukünftige Verbreitung einer invasiven Stechmückenart innerhalb Deutschlands. Studie III untersucht einen Artkomplex einheimischer Stechmücken auf seine Überwinterungsstrategien innerhalb hessischer Höhlen als Mikrohabitat und zieht mit der Berechnung vom Überwinterungserfolg abhängiger Landschaftspräferenzen den Kreis zu Studie I und II. 


\section{Einführung}

In Jahrmillionen der Entwicklung und des Zusammenlebens verschiedener Artgemeinschaften innerhalb der Ökosysteme des Planeten haben sich verschiedene Modelle der Interaktion entwickelt. Allesamt sind sie abhängig von Biomasse generierenden Primärproduzenten wie Pflanzen, Algen, Cyanobakterien oder autotrophen Bakterien die aus anorganischen Substanzen Energie gewinnen können (Falkowski und Knoll 2011; Kormondy 1969). In der nächsten Ebene stellen die Primärkonsumenten, also diejenigen Arten die sich von Primärproduzenten ernähren, eine große Gruppe von Arten und eine riesige Masse an Organismen dar, auf denen eine Vielzahl von Ökosystemen basiert (Townsend et al. 2014). Auf diesen Primärkonsumenten aufbauend gibt es die Sekundärkonsumenten, die sich von ihnen ernähren und dadurch auf einem Niveau halten, das verhindert, die Primärproduzenten übermäßig zu verzehren (Townsend et al. 2014). Raubtiere sind die ersten Tiere, die hierbei meistens in den Sinn kommen, jedoch sind diese bei weitem nicht die häufigste Form der Sekundärkonsumenten. Parasitismus ist eine Form der Sekundärkonsumenten und fast jeder freilebende Organismus hat, zumindest Zeitweise, mindestens einen Parasiten, der ihn befällt (Poulin 2006; Lucius et al. 2018). Parasitische Organismen oder Organismen mit parasitischen Stadien stellen dadurch die häufigsten Arten weltweit. Schätzungen zufolge liegt die Prozentzahl der Parasiten zwischen 50\% (Lucius et al. 2018) und 80\% (Zimmer und Curths 2001). Parasitische Lebensweisen ziehen sich durch alle Stämme der Lebewesen, so gibt es zusätzlich zu Viren (Flint 2000; Rohde 2005) parasitische Arten oder Arten mit parasitischen Stadien innerhalb der Pflanzen, Pilze, Protisten, Bakterien und Metazoa. (Press und Graves 1995; Vilcinskas und Götz 1999; Clark und Diamond 2002; Werren et al. 1995; SalgadoMaldonado et al. 2000). Dabei gibt es verschiedene Ausprägungen des Parasitismus. Mit dem Augenmerk auf metazoische Parasiten, die andere Metazoen befallen, können sie in zwei Gruppen unterteilt werden: in Endoparasiten, also innerhalb des Wirtes lebend und in Ektoparasiten - auf dem Wirt lebend. Endoparasiten sind häufig permanente, obligate Parasiten, können also nicht ohne ihren Wirt leben bzw. ihren Lebenszyklus vollenden und sind dadurch von ihm abhängig. Beispiele für diese wären unter vielen anderen Plasmodien (Plasmodium spp.), Bandwürmer (Cestoda) oder parasitische Nematoden (Ascaris spp.) (Thorson et al. 1963; Lucius et al. 2018). Häufig leben Endoparasiten innerhalb des Magens oder Darmlumens oder im Gewebe um den Verdauungstrakt herum (z.B Cestoda, Acanthocephala). Einige Arten wandern jedoch entweder durch die Darmwand hindurch an 
verschiedene Stellen im Körper wie Organe, Gehirn oder Gelenke. (Hendrix und Robinson 2016). Andere Endoparasiten wiederum gelangen durch Wunden oder Einstiche von Blutsaugenden Vektoren in den Blutkreislauf und leben in diesem oder auch innerhalb von Körperzellen (z.B. Leishmania spp., Plasmodium spp.) oder werden als Eier an Schleimhäute aufgebracht in welche die Larven (z.B Oestridae) eindringen (Awasthi et al. 2012; Mota et al. 2001; Bellmann 1999; Haupt und Haupt 1998). Ektoparasiten dagegen verbringen entweder ihren gesamten Lebenszyklus auf dem Wirt und ernähren sich dort von Blut (z.B Läuse), Haaren/Federn (z.B. Mallophaga) oder Haut (z.B. Sarcoptes spp.), es gibt jedoch auch sogenannte temporäre Ektoparasiten, die den Wirt nur aufsuchen um sich von ihm zu ernähren und sich danach wieder zu entfernen (Johnson et al. 2004; Deplazes et al. 2013). Hierbei wären blutsaugende Arten aber auch Gewebefressende Arten (z.B. Neunaugen) genannt. Letztere werden häufig mit Prädatoren vermischt, wobei sich die Ernährungsarten Prädation und Parasitismus hierbei vermischen. Parasiten werden dementsprechend teilweise auch als „Mikroprädatoren“ bezeichnet, also Prädatoren, die ihre Beute nicht oder nur unter besonderen Umständen töten und sich nur von Teilen dieser ernähren (Byers 2009; Lafferty et al. 2008). Eine echte Zwischenstufe zwischen diesen sind parasitoide Gruppen (z.B. Schlupfwespen, Cordyceps-Pilze). Diese nutzen ihren Wirt zur Ernährung, töten diesen allerdings erst entweder bei der Verpuppung oder, bei den Pilzen, vor der Fruchtbildung (Honomichl und Bellmann 1996; Jacobs et al. 1998). Die Krötengoldfliege (Lucilia bufonivora) hat sich vermutlich von einer parasitären Art ähnlich der Oestridae in eine parasitoide gewandelt. Blutsaugende Organismen haben sich ebenfalls in verschiedenen Tiergruppen entwickelt. Hierbei genannt wären Säugetiere (Desmodus rotundus), Vögel (Geospiza difficilis), Insekten (Raubwanzen, Stechmücken, Stomoxys, Bremsen), Krebstiere (Branchiura), Spinnentiere (Ixodes ricinus, Neotrombicula autumnalis) und Egel (Hirudo medicinalis) (Lord 1993; Bowman und Billeb 1965; Honomichl und Bellmann 1996; Jacobs et al. 1998; Westheide et al. 1996; Czihak et al. 1984; Guarneri et al. 2005); (Engelhardt 1989). Von diesen hämatophagen Lebewesen sind vor allem die Gruppen der Zweiflügler (Diptera), der Zecken (Ixodidae) und Raubwanzen (Reduviidae) heutzutage bedeutsam für die Übertragung vieler Krankheiten sowohl auf den Menschen als auch auf Tiere (Danasekaran et al. 2014). Aus der Gruppe der Diptera sind besonders die Stechmücken für Millionen von Infektionen und Hunderttausenden Toten durch übertragene Krankheiten verantwortlich (Benelli und Mehlhorn 2016; Mehlhorn und Benelli 2018). 


\section{Einleitung}

\subsection{Bremsen (Tabanidae)}

Die Bremsen sind eine weltweit, mit Ausnahme der Antarktis, vorkommende Dipterenfamilie mit ungefähr 4450 rezenten, bekannten Arten, die sich in 414 Genera und 9 Triben (Abbildung 1) verteilen (Baldacchino et al. 2014a; Morita et al. 2016; MacAlpine 1981). Sie sind optisch sehr divers (Abbildung 2, Abbildung 3), besiedeln alle Habitate in denen Fließgewässer, stehende Gewässer oder dauerhaft feuchte Böden vorkommen, insbesondere kommen sie jedoch in tropischen und subtropischen Gebieten vor (Morita et al. 2016). Alle Weibchen, mit Ausnahme einiger weniger Arten, saugen Blut (Lane et al. 1983). Hauptsächlich werden große Säugetiere als Nahrungsquelle genutzt, jedoch seltener kleine Säuger, Vögel und Reptilien (Middlekauff und Lane 1980). Häufig werden Menschen als Wirt genutzt (Chvála et al. 1972; Mullen 2019). In Europa sind insbesondere die Gattungen Tabanus und Haematopota und Chrysops relevant und häufig anzutreffen (Chvála et al. 1972; Service 2008). Obwohl Tabaniden diverse Krankheiten und Erreger wie Pferdeanämie, Trypanosomen, Filarien, Anthrax und Tularämie übertragen können (Cheng 1986; Padgett und Jacobsen 2008) und Blutarmut und damit Ertragsverlust bei Weidevieh hervorrufen können (Baldacchino et al. 2014b; Baldacchino et al. 2014a; Foil 1989), werden sie, wohl auch aufgrund deutlich geringerer Zahlen an verursachten Todesfällen, in aktueller Forschung weitaus weniger fokussiert als Stechmücken (Baldacchino et al. 2014a).

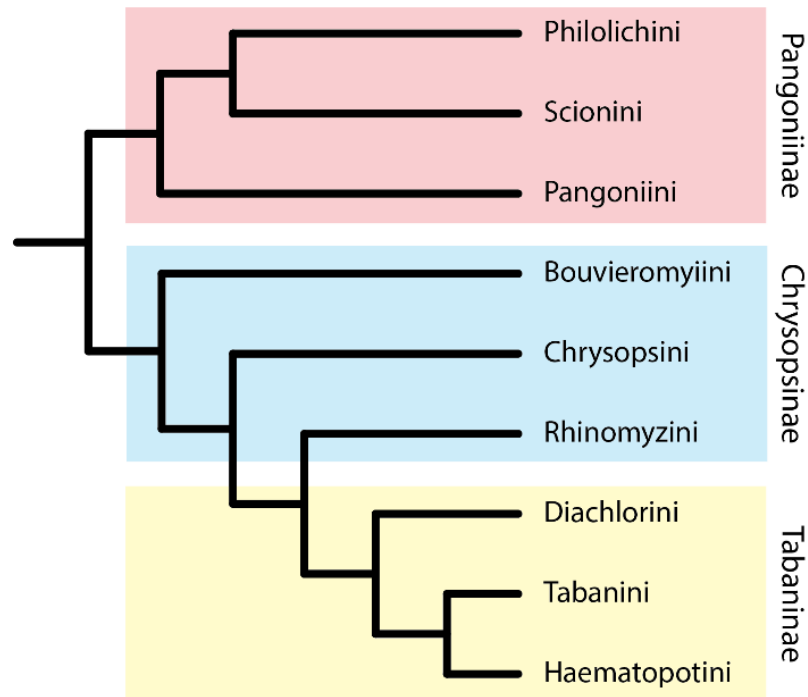

Abbildung 1: Innere Phylogenie der Tabaniden (nach Morita et al. 2016) 


\section{Lebenszyklus der Bremsen}

\section{Paarung}

Die Paarung von Bremsen findet in stehenden, jedoch losen, Schwärmen oder Einzelnen schwebenden Männchen und in, je nach Art, verschiedenen Höhen zwischen wenigen Zentimetern bis zu mehreren Dutzend Metern statt (Mullen 2019; Bailey 1948; MacAlpine 1981). Diese Schwärme umfassen meist nur einige wenige Individuen (Smith et al. 1994). Die verschiedenen Verhaltensweisen sind zwar divers, aber generell immer ähnlich bei den bekannten Arten (Lane 2012;

Chvála und Ježek 1997;

Baldacchino et al. 2014a).

Paarungsschwärme entstehen meist nur bei Sonnenaufgang und bei sonnigem Wetter, einige Männchen stoßen jedoch erst später hinzu oder verlassen den Schwarm vorzeitig oder zwischendurch (Smith et al. 1994; Wilkerson et al. 1985; Bailey 1948)

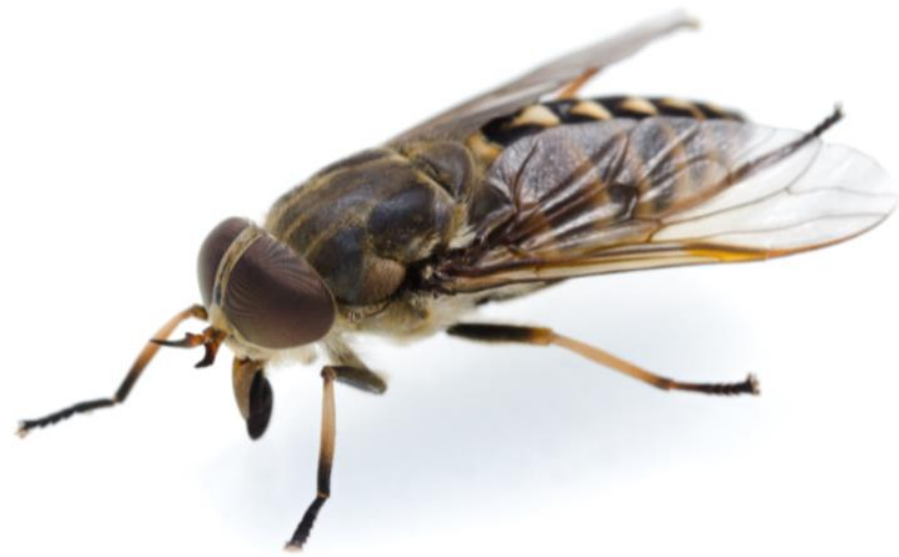

Die Dauer der Schwärme ist abhängig von der Versorgung der Männchen mit Kohlenhydraten aus Pflanzensäften und kann unter optimalen Umständen bis zu 12 Stunden betragen (Mullen 2019; Smith et al. 1994; Bailey 1948). Die Schwärme befinden sich fast ausschließlich in der Sonne, oft auf kleinen Hügeln, in der Nähe von Waldrändern aber auch in Lichtungen oder Korridoren innerhalb des Waldes, seltener jedoch auf offener Fläche (Smith et al. 1994; McAlpine und Munroe 1968). Eine andere Taktik der Männchen ist es, sich auf erhöhte, exponierte Positionen wie Zweige oder Felsen zu setzen und auf vorbeifliegende Weibchen zu warten (Wilkerson et al. 1985; Catts und Olkowski 1972; McAlpine und Munroe 1968). Pheromoneinwirkungen wurden beim Paarungsverhalten vorgeschlagen, jedoch bisher nicht bewiesen (Mullen 2019). Die vergrößerten Augen der Männchen, spezielle Anpassungen an polarisiertes Licht und die generell hohe Fluggeschwindigkeit der Bremsen (kurzzeitig bis $30 \mathrm{~m} / \mathrm{s}$, längere Strecken bis zu $45 \mathrm{~km} / \mathrm{h}$ ) deutet eher auf eine optische Orientierung hin, die jedoch sehr unspezifisch ist, sodass Männchen, jedoch mit hoher Erfolgsquote, alles verfolgen, was in geeigneter Geschwindigkeit und Größe an ihnen vorbeifliegt (Wilkerson und Butler 
1984; Mullen 2019; Wunderer und Smola 1986). Die Verpaarung findet entweder nach einer Verfolgung durch ein Männchen oder durch den Einflug eines Weibchens in einen Paarungsschwarm statt (Bailey 1948; Mullen 2019). Die Paarung findet während dem Flug statt und dauert meist nur wenige Sekunden, entweder innerhalb des Schwarmes oder nach dem Herausfliegen des Pärchens aus dem Schwarm (Mullen 2019; Bailey 1948; Smith et al. 1994; McAlpine und Munroe 1968). Die Paarung konnte bisherig nicht unter Laborbedingungen untersucht werden, deshalb sind Folgeuntersuchungen zu Eiern, Larven und Puppen bisher nicht möglich gewesen. Weibchen suchen hauptsächlich erst nach einem Wirt nachdem sie sich gepaart haben (Mullen 2019). Die Wirte werden anhand von abgesonderten Stoffen und mithilfe von reflektiertem polarisierten Lichtes erkannt (Egri et al. 2012; Mullen 2019). Einige Tage nach der Blutmahlzeit sucht das Weibchen nach einer geeigneten Eiablagestelle, hierbei werden von vielen Arten Gewässer ebenfalls durch die Reflektion polarisierten Lichtes aufgespürt (Egri et al. 2012; Mullen 2019).

\section{Eier}

Die Eier der Tabaniden sind länglich oval und meist zwischen 1-2,5 mm lang (Cheng 1986; MacAlpine 1981). Sie werden in ein- bis mehrschichtigen Gruppen von bis zu 1000 Eiern, selten auch einzeln, an verschiedene Substrate in der Nähe von hauptsächlich stehenden Gewässern abgelegt (Cheng 1986). Meist werden über dem Wasser hängende oder stehende Pflanzenteile gewählt. Hierbei gibt es keine Muster, die einzelne Gattungen von anderen trennen würden, die Art und Weise der Eiablage ist Art- und Ortabhängig, so werden an dünnen Pflanzenteilen Eier auch in einer Linie abgelegt, während sie an breiteren Stellen als breitere Gruppe abgelegt werden (MacAlpine 1981; Graham und Stoffolano 1983). Die Anzahl der gelegten Eier ist Abhängig von der Art und der Größe der

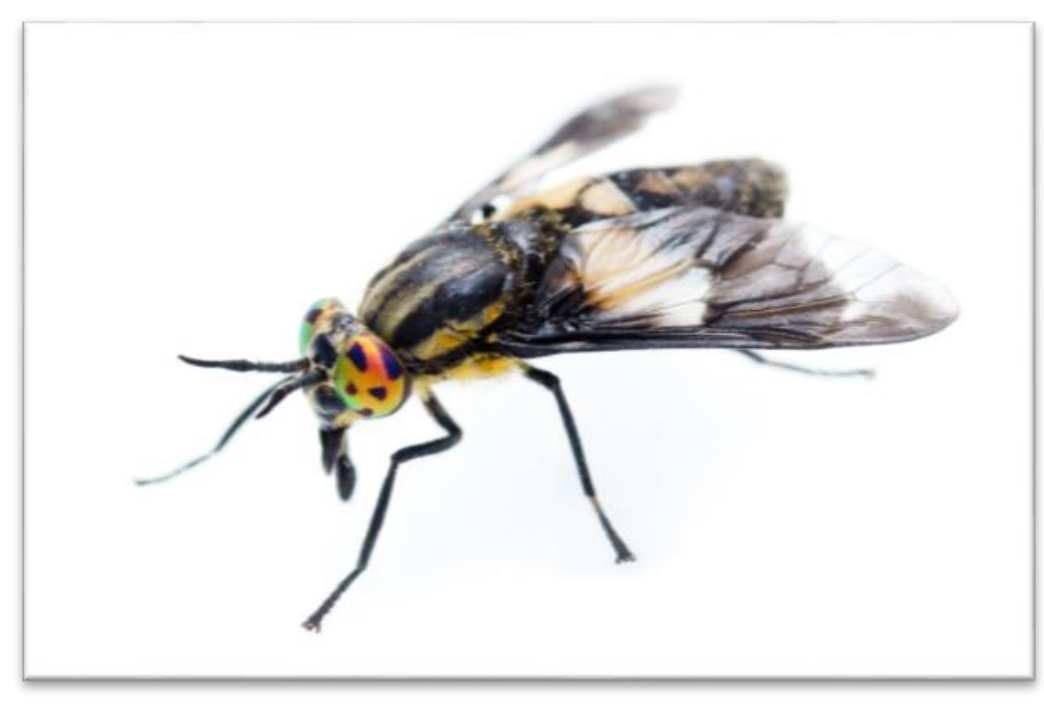

Abbildung 3: Weibchen von Chrysops relictus vorherigen Blutmahlzeit (Mullen 2019). Die Eier sind meist hell gefärbt und dunkeln mit der Zeit nach, vermutlich härten sie in dieser Zeit aus und die dunkle Farbe schützt vor UV- 
Strahlung, ähnlich der Eier von Stechmücken (Graham und Stoffolano 1983). Arten, die nicht auf Gewässer angewiesen sind, legen die Eier auf feuchten Boden, Pflanzenmaterial oder auch Dung. Für die Einteilung der Eiablage wurden drei ökologische Gruppen erschaffen: Die rheophile/subrheophile Gruppe, die Eier an Fließgewässer ablegt, die hydrobionte/hemihydrobionte Gruppe, die Eier bevorzugt an stehende, nur langsam fließende Gewässer oder im Uferbereich ablegt und die edaphobionte Gruppe, die Eier unabhängig von Gewässern terrestrisch ablegt, es gibt jedoch auch Zwischenformen (Andreeva 1982; Andreeva et al. 2009). Fälle von Weibchen, die das Gelege bewachen, gibt es für die Art Goniops chrysocoma, dies wurde jedoch bei keiner anderen Art beobachtet (Schwardt 1934). Die Embryogenese dauert, je nach Art und Temperatur, zwischen 2 und 21 Tagen, läuft jedoch bei höheren Temperaturen und Luftfeuchtigkeit (Chvála et al. 1972; Mullen 2019).

Larven

Die Larven besitzen eine Zahnstruktur an der Kopfkapsel, mit der sie die Eihülle beim Schlupf durchstoßen und haben einen zylindrischen Körperbau mit elf Segmenten, Pseudopodien mit Borsten und ansonsten ohne besondere Anhängsel (Lane 2012; Cheng 1986). Die geschlüpften Larven fallen in das Gewässer oder bewegen sich in das artspezifisch präferierte Gebiet (Gewässer, Schlamm, Pflanzenstreu, Dung, verrottendes Material) und häuten sich einmalig kurz nach dem Schlupf ohne vorher Nahrung aufzunehmen, wodurch sie den Eizahn verlieren (Mullen 2019). Anschließend beginnen sie mit der Nahrungssuche. Sie ernähren sich oftmals prädatorisch und erbeuten andere Larven (auch Larven der eigenen Art), Würmer und andere Invertebraten innerhalb ihres Habitates, vermutlich ernähren sie sich teilweise auch von Detritus (Fairchild 1969; Baldacchino et al. 2014a).

Manche Arten bewohnen Salzmarschen (MacAlpine 1981). Es wurden ebenfalls Larven und Puppen gefunden, die innerhalb von Phytotelmen von Bromelia sp. lebten (Zillikens et al. 2005). Insgesamt haben bekannte Tabanidenarten zwischen 6 und 13 Larvenstadien (Baldacchino et al. 2014a). Tabaniden verbringen bis zu 3 Jahre als Larve, können aber auch mehrere Generationen pro Jahr haben. Dies ist abhängig von der Art und ihrer Größe, Klima, Frostperioden und Nahrungsangebot. In Gebieten mit besonders langen Frostperioden verlängert sich diese Zeit vermutlich zusätzlich. 


\section{Puppen}

Aquatisch lebende Larven suchen zur Puppenhäutung trockenere Gebiete unter Laub, Ästen oder Steinen auf (Chvála et al. 1972). Larven, die terrestrisch leben, verpuppen sich unter Laubstreu oder vergraben nahe der Oberfläche, manche Arten sogar in austrocknendem Schlamm (Chvála et al. 1972; Tremlett 1964). Das Puppenstadium ist, anders als bei Stechmücken, nach Aushärtung der Cutilcula inaktiv und fast unbeweglich. Das Stadium dauert, je nach Art und Temperatur, zwischen 4 und 21 Tage (Cheng 1986).

\section{Imagines}

Das Geschlechterverhältnis der aus den Puppen schlüpfenden adulten Bremsen ist ungefähr gleich. Wie bei Stechmücken, schlüpfen die Männlichen Bremsen ebenfalls vor den weiblichen (Chvála et al. 1972). Die Imagines haben eine Größe von 6-30 mm (MacAlpine 1981). Nicht alle Arten sind Anautogen sondern einige sind dazu fähig, Eier auch ohne vorherige Blutmahlzeit zu produzieren und zu legen (Kniepert 1980; MacAlpine 1981). Die Imagines beider Geschlechter haben einen Saugrüssel, mit dem sie Pflanzensäfte aufnehmen. Honigtau wird ebenfalls von Pflanzenläusen aufgenommen (Kniepert 1980). Zusätzlich sind einige Arten bedeutende Bestäuber verschiedener Pflanzenarten (McKeever und French 1997; Karolyi et al. 2014). Nur die Weibchen nutzen diesen Saugrüssel ebenfalls, um aus der mit den Mandibeln erzeugten Wunde bei den Wirten bis zu 0,5 $\mathrm{ml}$ Blut zu saugen (McKeever und French 1997; Kniepert 1980; Foil und Hogsette 1994). Die meisten Adulti leben maximal einen Monat (Foil und Hogsette 1994; Chvála et al. 1972).

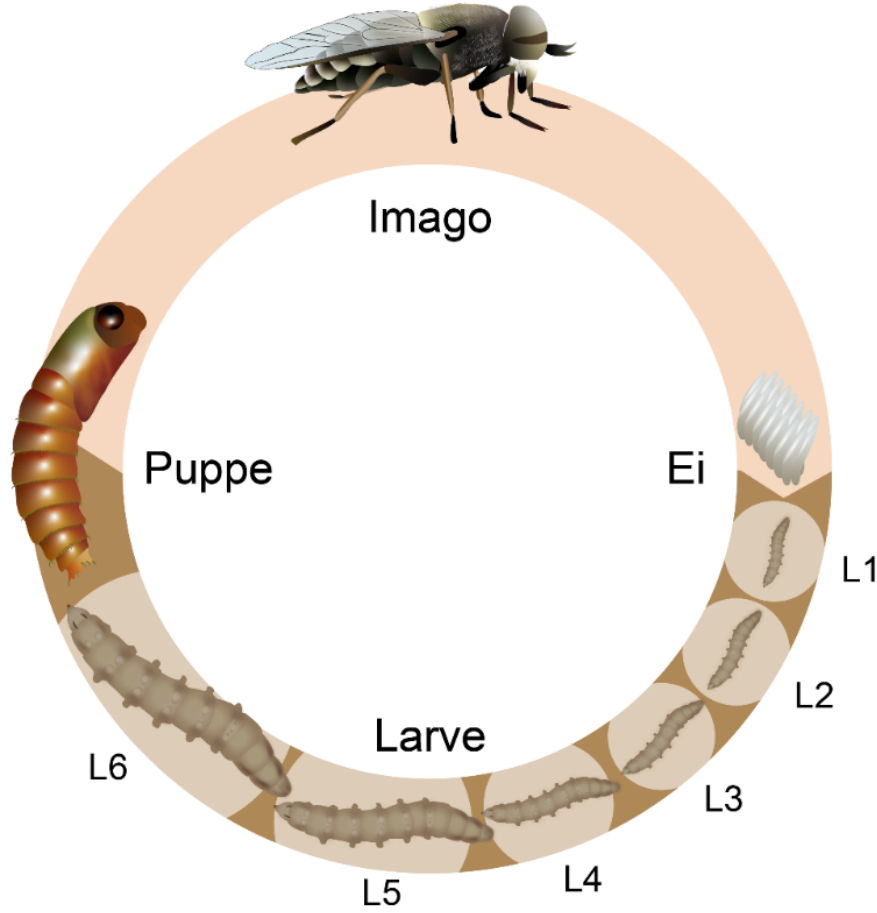

Abbildung 4: Exemplarischer Lebenszyklus einer Bremse mit sechs Larvenstadien 


\subsection{Stechmücken (Culicidae)}

Die Stechmücken sind eine weltweit, mit Ausnahme der Antarktis, vorkommende Dipterenfamilie mit 3582 rezenten, bekannten Arten (Harbach 2020), die sich innerhalb der Culicinae in in 11 Triben (Abbildung 5) und 110 Genera verteilen (Catalogue of Life 2019; Harbach 2020). Neue Untersuchungen teilen die Anophelinae in 3 Genera auf (Harbach 2020). Sie besiedeln alle Habitate in denen Wasseransammlungen zumindest zeitweise vorkommen, insbesondere kommen sie jedoch in tropischen und subtropischen Gebieten vor (Rueda 2007). Alle Weibchen, mit Ausnahme der Gruppe Toxorhynchitini, saugen Blut (Schreiber 2007; Becker et al. 2010), wobei es ebenfalls Arten gibt, die zumindest in einer Generation Eier legen können ohne vorher Blut gesaugt zu haben (Briegel 1969). Hierbei werden hauptsächlich Säugetiere und Vögel, aber auch Reptilien und selten Amphibien als Nahrungsquellen genutzt (Molaei et al. 2008). Insbesondere nutzen nur relativ wenige Gruppen den Menschen hauptsächlich als Wirt. Hier wären vor allem die Gattungen Anopheles, Aedes und Culex genannt, die zusammen fast 2300 Arten beinhalten (Catalogue of Life 2019). Aufgrund ihres Vektorpotenzials und den dadurch noch heute großen Zahlen an Toten (Jährlich über 800.000 Todesfälle; (Winegard 2019) haben sie eine große Bedeutung für die menschliche Gesundheit und werden daher im besonderen Maße erforscht.

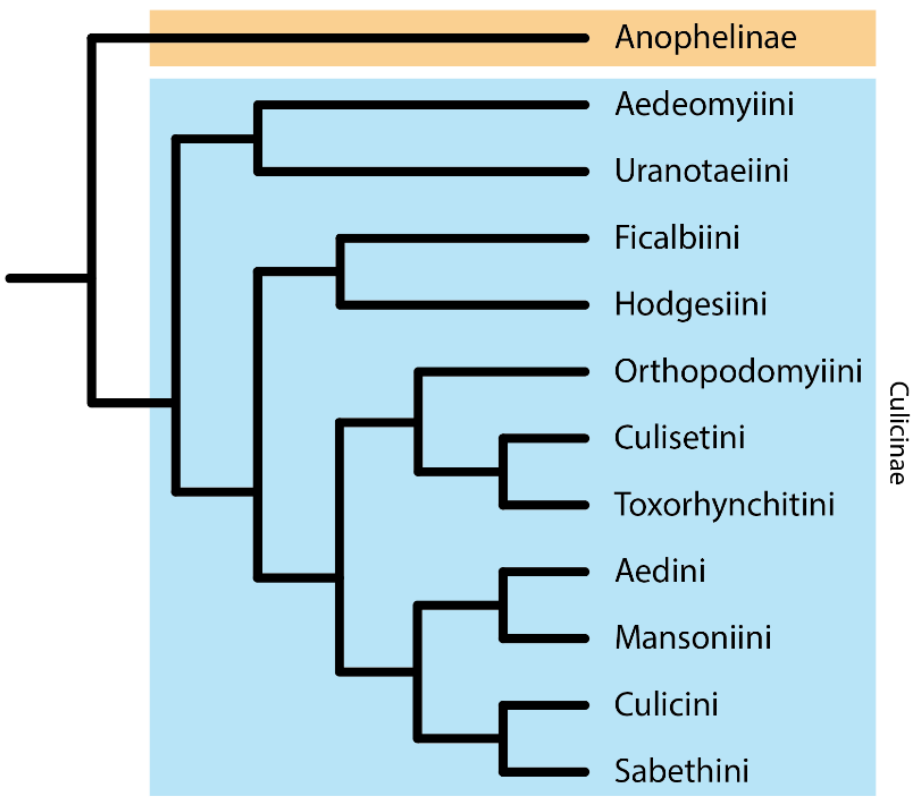

Abbildung 5: Innere Phylogenie der Culiciden (nach Harbach und Kitching 1998) 


\section{Lebenszyklus der Stechmücken}

\section{Paarung}

Die Paarung von Stechmücken findet häufig zur Dämmerungszeit in feststehenden, bis zu mehreren Metern hohen Schwärmen statt (Charlwood et al. 2002). Die Orientierung und Bildung dieser Schwärme ist abhängig von verschiedenen Faktoren wie Landmarken, Pflanzenbewuchs, Gelände aber auch die Nähe zu einem potentiellen Wirt für die Weibchen (Charlwood et al. 2002; Becker et al. 2010). Hierbei können, je nach Populationsdichte und Art, bis zu mehreren Tausend hauptsächlich männliche Individuen in einem Schwarm zusammenkommen (Fawaz et al. 2014). Zur Vorbereitung auf dieses, oft stundenlang andauernde, Fliegen, müssen sowohl die Männchen als auch die Weibchen (in geringerem Maße) genügend Kohlenhydratreserven aufbauen, die sie durch Nektar generell und im Vorfeld zur Paarung aufnehmen (Villiard und Gaugler 2015). Manche Weibchen von Arten aus der Gruppe der Anophelinae saugen bereits vor der Paarung Blut (Rowland 1989). Einige Arten sind stark auf dieses Schwarmverhalten angewiesen und paaren sich nicht unter einer bestimmten Individuenzahl innerhalb des Schwarmes (Becker et al. 2010). Während die Männchen innerhalb des Schwarmes umherfliegen,

Abbildung 6: Männliches Exemplar von Anopheles

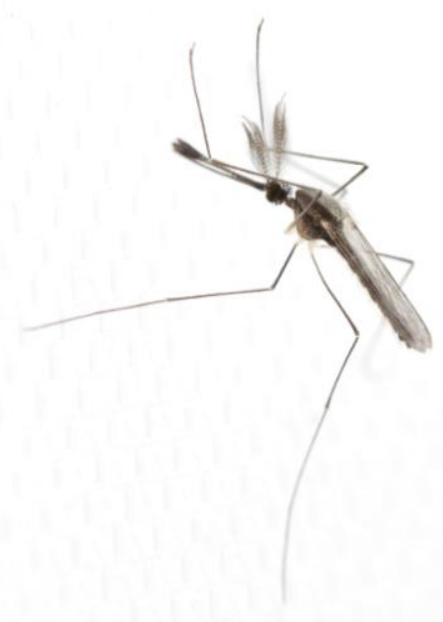
plumbeus schütten sie Pheromone aus und stellen bestimmte Summfrequenzen ein, die den Schwarm zusammenhalten und die Weibchen anlocken (Fawaz et al. 2014; Arthur et al. 2014). Dadurch angelockte Weibchen fliegen in den Schwarm (Cator et al. 2009). Die Weibchen haben eine niedrigere Summfrequenz und werden dadurch von den Männchen lokalisiert (Tripet et al. 2004). Sobald sie auf ein oder mehrere Männchen treffen, orientieren sie sich gegenseitig an den Summtönen, hierfür nutzen sie das sogenannte Johnston'sche Organ am zweiten Glied der Antenne (Cator et al. 2009; Brogdon 1994; Lapshin und Vorontsov 2017), die bei den Männchen besonders vergrößert ist (Abbildung 6). Vermutlich wählen die Weibchen aus den interessierten Männchen den passenden Partner aus, jedoch wurde auch berichtet, dass 
größere Männchen bei einigen Arten mehr Paarungserfolg hatten (Yuval et al. 1993). Es gibt jedoch auch Berichte, dass größere Weibchen ebenfalls einen höheren Paarungserfolg haben als kleinere. Nun verlässt das Weibchen während der Paarung mit dem Männchen den Schwarm, nach der Paarung sucht es entweder einen geeigneten Wirt für die Blutmahlzeit oder paart sich erneut. Die Wirte werden mithilfe des vom Wirt ausgeatmeten $\mathrm{CO}_{2}$, Körperwärme und sonstigen ausgesonderten, flüchtigen Stoffen lokalisiert (Service 2008). Manche Arten paaren sich mehrfach (Yuval und Fritz 1994). Bei einer anderen Art der Paarung warten paarungsreife Männchen auf die Weibchen, während diese kurz vor der Häutung aus der Puppe stehen (Downes 1966). Hierbei sitzen sie neben dem Gewässer oder sogar direkt auf der weiblichen Puppe (Benelli 2015). Während Männchen mehrere Tage benötigen um paarungsreif zu werden, sind weibliche Stechmücken oft direkt nach der letzten Häutung paarungsfähig (Becker et al. 2010).

Eier

Nachdem die Eibildung nach 2-5 Tagen, abhängig von der Temperatur, abgeschlossen ist, wird ein geeignetes Eiablagegebiet vom Weibchen gesucht (Thavara et al. 2004; Becker et al. 2010) Die Eier werden von den Weibchen, je nach Art, entweder direkt auf die Wasseroberfläche gelegt oder an den Rand von Wasseransammlungen oder feuchten Boden (Day 2016). Bei Arten, die Eier direkt auf die Wasseroberfläche oder an den Wasserrand legen, wird das Gewässer nach Größe und anderen, hauptsächlich olfaktorisch wahrgenommenen Eigenschaften ausgewählt. Hauptsächlich Stoffe, die beim Verfall organischen Materials entstehen $\left(\mathrm{NH}_{3}, \mathrm{CH}_{4}, \mathrm{CO}_{2}\right)$ deuten auf ausreichende Nahrungsquellen hin und locken die Weibchen an (Bentley und Day 1989). Hierbei können auch Prädatoren durch Detektion von Kairomonen oder ähnlichen Stoffen vermieden werden. Wasseransammlungen mit bestimmten Eigenschaften wie bereits vorhandenen Larven der gleichen Art, ausgebildeter Mikrofauna oder geeigneter Nährstoffkonzentration werden dabei bevorzugt (Bentley und Day 1989; Becker et al. 2010; Millar et al. 1994). Die Eier werden, je nach Art, entweder einzeln oder zusammen gebündelt in sogenannten Eischiffchen abgelegt (Mattingly 1976). Einzelne schwimmende Eier werden von Arten der Anophelinae gelegt, während viele Arten der Culicinae die Eier mithilfe der Auswölbungen in der Eierstruktur aneinander befestigen. Hierbei haben die Eier ein hydrophiles Ende, das sich mit der Wasseroberfläche verbindet, während der Rest der Eistruktur wasserabweisend ist. So wird ein umkippen des Paketes verhindert (Hinton 1968). Arten die ihre Eier in feuchten Boden in Überflutungsgebieten 
legen, müssen besonders darauf achten, dass die Eier vom umgebenden Boden oder Moos bis zum Überflutungsereignis lange genug feucht gehalten werden. Hierbei werden die Eier gezielt in kleine Senken in der Nähe von Gewässern mit Moos oder feuchtem, lehmigen Überflutungsboden abgelegt, da hier die Wahrscheinlichkeit der Überflutung am höchsten scheint (Schäfer und Lundström 2006; Gjullin et al. 1950). Ein Weibchen kann bis zu 500 Eier legen (Becker et al. 2010). Die Embryogenese beginnt mit der Ablage der Eier, hierbei kann sich jedoch eine Diapause (genetisch bestimmt) oder eine Ruhephase (von Außenfaktoren bestimmt) aktivieren, die die weitere Eientwicklung zeitweise stoppt (zur Überdauerung des Winters oder der Trockenzeit) (Vinogradova 2007; Farnesi et al. 2017; Parker 1986). Die weitere Entwicklung dauert, Art- und temperaturabhängig, 2-8 Tage. Hierbei ist die Entwicklung schneller, je höher die Temperatur ist und bei Überflutungsarten generell langsamer (Becker et al. 2010). Der Schlupf der Larven erfolgt nach der Embryoentwicklung sofort oder, bei überwinternden Eiern oder Überflutungsarten, nach speziellen Stimuli wie sinkenden oder steigenden Wassertemperatur und verstrichener Zeit seit der Überflutung (Parker 1986; Livdahl und Edgerly 1987; Becker et al. 2010).

\section{Larven}

Alle Stechmückenlarven haben vier Häutungsstadien, wobei sich immer nur die Kopfkapsel nach jeder Häutung verfestigt und der Thorax und das Abdomen mitwachsen, die Kopfkapsel wird daher auch zur Bestimmung des Larvalstadiums genutzt (Deslongchamps und Tourneur 1980). Es gibt dabei drei verschiedene Gruppen, die sich in ihrer Morphologie und ihren Anpassungen unterscheiden. Alle besitzen einen dreigeteilten Körper (Kopf, Thorax und Abdomen). In Ruhe befinden sie sich zur Atmung direkt an der Wasseroberfläche (Abbildung 7, außer Mansoniini) und können sich langsam mithilfe der Haarkämme am Kopf vorwärtsbewegen oder bei

Störungen durch Zusammenziehen

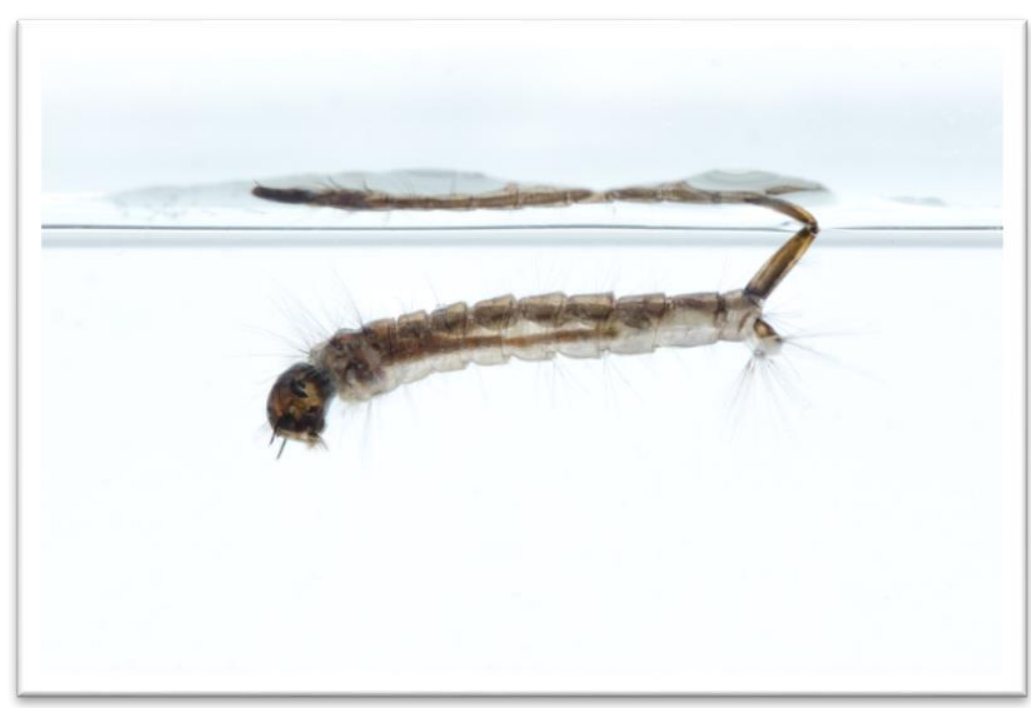

Abbildung 7: Larve (L4) von Aedes japonicus des Abdomens in tieferes Wasser abtauchen (Sih 1986; Pucat 1965). Hierbei treiben sie 
anschließend mit kleineren Schläge des Abdomens wieder an die Wasseroberfläche. Die Larven der Culicinae besitzen am achten Abdominalsegment einen Atem-Siphon, während die Anopheleslarven hier Lappen mit Tracheenöffnungen besitzen (Azari-Hamidian und Harbach 2009; Sallum et al. 2020). Die dritte Larvenform der Mansoniini besitzt einen Siphon, der adaptiert ist die Luftleitbündel von Wasserpflanzen zu penetrieren um eine halbsessile, permanent submerse Lebensweise zu ermöglichen (Rueda 2007). Alle Larven ernähren sich hauptsächlich von Detritus, Mikroorganismen und Algen. Culicinae-Larven strudeln mit Haarkämmen an der Kopfkapsel Nahrungspartikel zur Mundöffnung und können damit sowohl von der Wasseroberfläche, in der Wassersäule aber auch vom

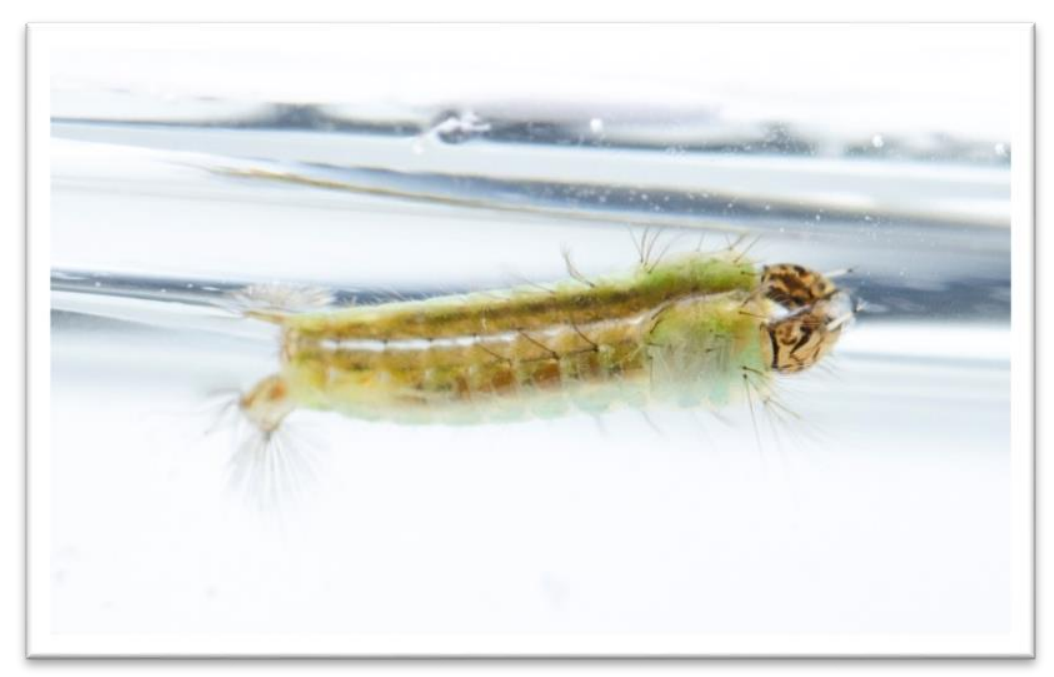

Abbildung 8: Larve (L4) von Anopheles plumbeus mit gedrehtem Kopf

Bodensubstrat Nahrung aufnehmen. Die Kämme sind ebenfalls stabil genug, um kleinere Stücke von abgestorbenen Organismen abzutrennen (Merritt et al. 1992; Yee et al. 2004; Becker et al. 2010). Larven der Anophelinae befinden sich permanent an der Wasseroberfläche und können ihren Kopf um $180^{\circ}$ drehen um Nahrung von der Wasseroberfläche aufzunehmen (Merritt et al. 1992, Abbildung 8). Einige Larven aus den Gruppen Aedes, Culex, Toxorhynchites und Toxophora sind prädatorisch lebend und ernähren sich hauptsächlich von anderen Mückenlarven (Trpis 1972; Jin et al. 2006; Becker et al. 2010).

\section{Puppen}

Das Puppenstadium dauert meist nur wenige Tage, ist jedoch abhängig von der Umgebungstemperatur (Trpis 1972; Al-Jaran und Katbeh-Bader 2001). In dieser Phase werden, wie bei anderen holometabolen Insekten innere Organstrukturen aufgelöst und umgewandelt (Rolff et al. 2019). Die Puppe besitzt einen prominenten Cephalothorax mit Atmungshörnern und ein Abdomen mit gespaltenem Paddel am Ende. Durch das halbtransparente Exoskelett lassen sich die Beine, Antennen und Flügel des Adulten Tieres erkennen (Becker et al. 2010). Die Puppen der meisten Arten hängen, ähnlich der Larven, meist regungslos unter der Wasseroberfläche (Abbildung 9), hierbei durchstoßen die 
Atemhörner diese, wie auch der Larvalsiphon durch einen Ring aus hydrophoben Strukturen (Becker et al. 2010). Nur die Gruppe der Mansoniini hat, ähnlich der Larven, modifizierte Atemhörner um in die Luftleitbündel submerser Pflanzen anzustechen (Belkin 1962). Während des Puppenstadiums wird keine Nahrung oder Flüssigkeit aufgenommen. Sie sind in der Lage sich bei Störung schnell durch Kontraktion des Abdomens in tieferes Wasser zu bewegen. Sie treiben danach wieder regungslos zurück an die Oberfläche oder bewegen sich, bei weiterer Störung, zufällig in verschiedene Richtungen unter Wasser (Awasthi et al. 2012; RodríguezPrieto et al. 2006). Die Puppen sind robust gegen Austrocknung und die Adulti schlüpfen auch, wenn sie am Gewässerrand stranden oder das Gewässer austrocknet (Becker et al. 2010). Sobald die Stechmücke in der Puppe schlupfbereit ist, pumpt sie

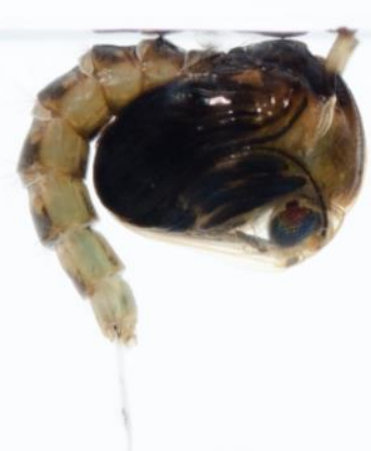

Abbildung 9: Puppe von Aedes japonicus

Luft zwischen den Intercuticulären Raum und ihren Mitteldarm, um die Thoraxkapsel der Puppe entlang einer dorsal gelegenen Sollbruchstelle zu sprengen (Spielman und D'Antonio 2004; Becker et al. 2010). Die Puppen der Mansoniini trennen dabei vorher die Verbindung zu der Wasserpflanze, um zur Oberfläche zu steigen (Belkin 1962). Langsam bewegt sich das Adulte Tier, durch weitere Luftaufnahme, aus der Hülle, sobald die ersten Beine aus der Puppe gelöst sind, werden diese zur Stabilisation auf der Wasseroberfläche positioniert (Becker et al. 2010). Nach dem Schlupf wird die Hämolymphe durch die Beine gepumpt, die sich dadurch ausstrecken. Die Tiere sind während der gesamten Schlupfdauer, bis die Flügel ausgehärtet sind und sie abfliegen können, einfache Beute für Räuber aber auch anfällig Windstöße, die die Puppen und halb geschlüpften Adulti umwerfen können. Sobald die Tiere abfliegen, benötigen sie noch etwa einen Tag, um ihren Metabolismus einzustellen (Becker et al. 2010).

\section{Imagines}

Männliche Stechmücken benötigen für die Entwicklung der Geschlechtsorgane und zur Paarungsvorbereitung etwa ein bis zwei Tage länger, schlüpfen daher auch vor den Weibchen (Mahmood et al. 1997; Souza et al. 2019; Becker et al. 2010). Diese Verkürzung der 
Entwicklungszeit wirkt sich in einer geringeren Körpergröße der Larven, Puppen und Adulti aus, was jedoch auch auf alle Larven zutrifft, die aus Prädationsdruck, Überbevölkerung oder anderen Gründen eine schnellere Entwicklung durchlaufen (Alto und Juliano 2001; Schäfer und Lundström 2006). Die adulten Mücken leben meist nur wenige Tage bis Wochen, je nach Art und Habitat, hierbei überdauern die Weibchen (Abbildung 10) meist deutlich länger, als die Männchen und können auch monatelang in unterirdischen (Höhlen-) Systemen überwintern (Becker et al. 2010; Maharaj 2003; Denlinger und

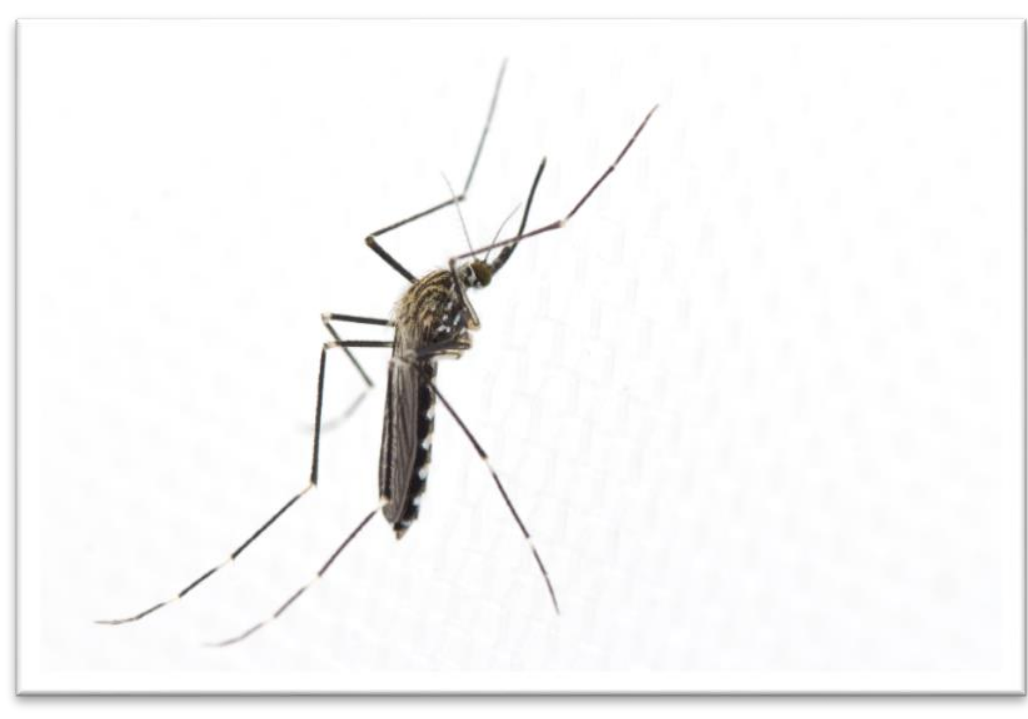

Abbildung 10: Weibchen von Aedes japonicus Armbruster 2014; Benoit und Denlinger 2007). Stechmücken benötigen für die Entwicklung vom $\mathrm{Ei}$ zum Adulten Tier, je nach Art und Temperatur, zwischen 6 und 60 Tagen (Becker et al. 2010). Hierbei entwickeln sich, je nach Art, unter $10^{\circ} \mathrm{C}$ und über $30^{\circ} \mathrm{C}$ fast keinerlei Tiere mehr, die Entwicklungszeit steigt exponentiell mit sinkender Temperatur (Becker et al. 2010; Shelton 1973).

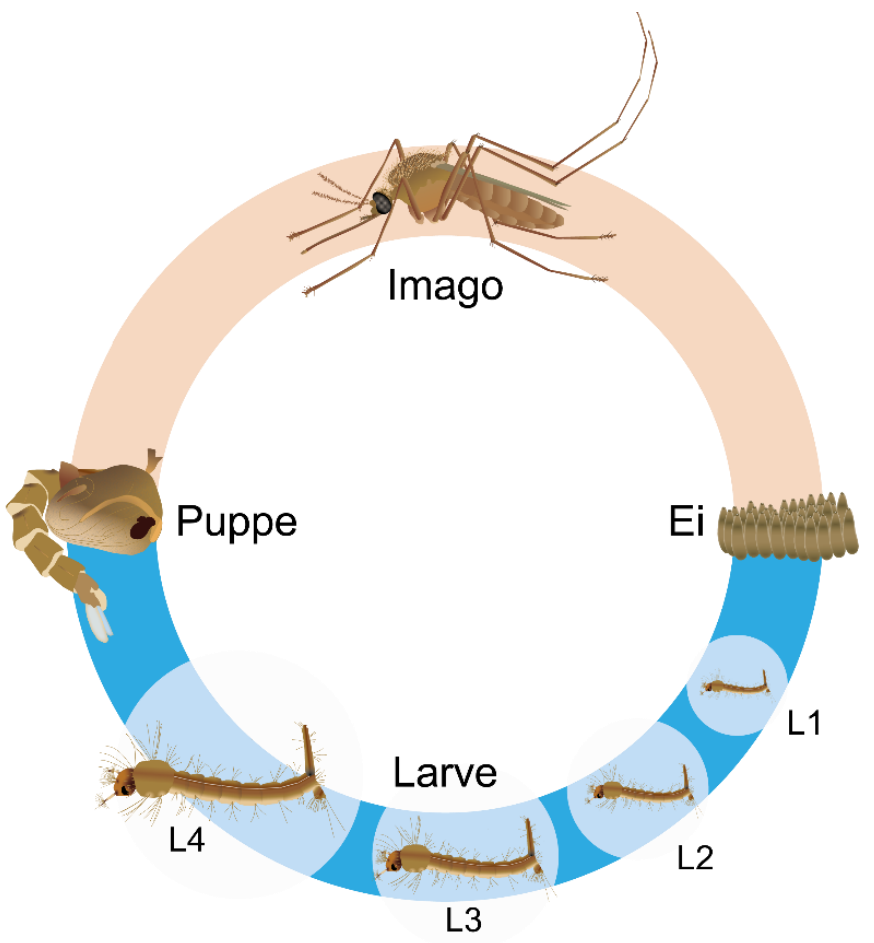

Abbildung 11: Exemplarischer Lebenszyklus einer Stechmücke 


\subsection{Vektorassoziierte Krankheiten}

Hämatophage Arthropoden sind bereits seit der Antike als Krankheitsüberträger bekannt. Zu dieser Zeit wurden jedoch erst einfache Zusammenhänge zwischen dem Massenauftreten von Stechmücken, Sumpfgebieten und Epidemien von Fiebererkrankungen erkannt (Service 1978). Zahlreiche schriftliche Aufzeichnungen für die Bekämpfung oder die Abwehr von Läusen, Flöhen, Stechmücken oder Bettwanzen sind vorhanden (Service 1978). Heute ist bekannt, dass Hämatophage Arthropoden eine Vielzahl von Krankheitserregern übertragen und verantwortlich für eine Vielzahl an Infektionen und Todesfällen weltweit sind.

Mit der Medizinischen Entomologie hat sich ein großes Forschungsfeld alleinig auf deren Erforschung spezialisiert (Mullen 2019). Weltweit sind 14 bedeutende vektorübertragene Krankheiten bekannt, die durch hämatophage Arthropoden übertragen werden. Davon sind hämatophage Insekten jährlich mit über 200 Millionen Infektionen und über 700.000 Toten für die meisten Infektionen und Toten verantwortlich (WHO 2020). Insbesondere die Vielzahl der Individuen und Arten ermöglicht eine solch effektive Übertragung dieser Krankheiten in fast allen Lebensräumen. Im Zuge von sich ändernder Raumnutzung, Klimaveränderungen, globaler Personenvernetzung und globalem Handel werden Krankheitserreger zunehmend häufiger aus ihren Ursprungsgebieten heraus in andere Teile der Welt verschleppt (La Rocque et al. 2011). Ebenso verbreiten sich die passenden Vektoren und Reservoirwirte, zumindest zeitweise, in andere Gebiete auf dem Planeten, hierbei ist die Verbreitung von Krankheitserregern, die entweder generalistisch oder auf den Menschen spezialisiert sind in besonderem Maße möglich (Kilpatrick 2011). Dadurch entstehen außerhalb des Ursprungsgebietes neu erschlossene Zonen, in denen sich die Krankheiten ausbreiten können, da zumindest ein Vektor und ein Endwirt vorhanden sind (Shahhosseini et al. 2018; Bagnarelli et al. 2011). Für Tabaniden wurde die Übertragung auf dem natürlichen Wege für folgende Krankheitserreger und Krankheiten nachgewiesen: infektiöses Pferdeanämievirus, Rinderleukämievirus, klassische Schweinepest, Rinderpest, Hepatitis-C-Virus, Anaplasma marginale, Bacillus anthracis, Francisella tularensis, Besnoitia besnoiti, Trypanosoma theileri, T. evansi, T. vivax, Loa loa. Für folgende Krankheiten und Erreger ist eine Übertragung experimentell nachgewiesen oder wurde berichtet: Stomatitis vesicularis, Chlostridium chauvoei, Pasteurella multocida, Borrelia burgdorferi, Brucella spp., Listeria monocytogenes, Erysipelothrix rhusiopathiae, Haemoproteus metchnikovi, Trypanosoma equiperdum, T. congolense, T. brucei brucei, Dirofilaria roemeri, Elaeophora schneideri (Krinsky 1976; Foil 
1989). Bei Stechmücken wurden, auch aufgrund der größeren Bedeutung für die menschliche Gesundheit, eine Vielzahl von Krankheiten und Erregern festgestellt. Die wichtigsten hierbei sind Malaria (Plasmodium spp.) Denguefieber, West-Nil-Virus, Gelbfieber, Chikungunya, verschiedene Filariosen, Francisella tularensis, Dirofilaria spp., Japanische Encephalitis, La Crosse Encephalitis und Zika-Fieber (WHO 2020).

\subsection{Nischen und Verbreitungsmodelle}

Die Verbreitung von Arten, egal ob Vektor, Wirt, Reservoirwirt oder Krankheitserreger, ist abhängig von diversen Einflussfaktoren. Diese Einflussfaktoren sind hauptsächlich klimatisch, es gibt jedoch vielzählige weitere Einflüsse von z. B. Wasserverfügbarkeit, Pflanzenbewuchs, Höhenlage und Nahrungsverfügbarkeit (Townsend et al. 2014). Über manche Arten, die nicht im Fokus wissenschaftlichen Interesses stehen, ist wenig über die genaue Verbreitung bekannt. Ihre Verbreitung wird oftmals unterschätzt. Auch können sich durch globale Veränderungen die Verbreitungsgebiete mit der Zeit verändern. Es ist gerade für Abschätzung von Risiken, Konkurrenz zwischen Arten, Krankheitsausbreitung oder Ausbreitung von invasiven Arten von Bedeutung, eine möglichst genaue Einschätzung der realen Verbreitung einer Art zu erhalten. Als bedeutende Ansätze diese Verbreitungen zu schätzen haben sich verschiedene Modelle zur Berechnung von Nischen gezeigt, welche inzwischen häufig genutzt, viel diskutiert und stetig verbessert werden (Hirzel und Le Lay 2008; Sillero und Barbosa 2021).

Diese Ökologische Nischenmodellierung (eng. Ecological Niche Modelling $=$ ENM) kommt inzwischen regelmäßig zur Anwendung um zum Beispiel Ausbreitungen invasiver Arten oder von Krankheitserregern in aktueller Zeit oder mit Zukunftsprognosen vorherzusagen und kann damit beitragen, bedrohte Tierarten zu schützen, Epidemien einzudämmen oder die Verbreitung heimischer Arten mit begrenzten Fundpunkten realistisch vorherzusagen (Mays et al. 2018; Li et al. 2017; Walsh und Webb 2018). Die von Hutchinson (1957) geprägte fundamentale Nische kann modelliert werden (Guisan und Thuiller 2005) und mit der Weiterentwicklung der Modelle können inzwischen auch andere Teile der Nische (z. B. Ausbreitung, Populationsdynamiken) in die Berechnungen miteinbezogen werden (Carey 1996; Peng 2000). Die fundamentale Nische einer Art besteht nur aus den abiotischen Faktoren, die in einer Modellierung als Grundlage dienen können (u. A. Klima, Relief, Wasserzugang, Bodenzusammensetzung, Lichteinstrahlung; Hutchinson 1957). Jede Art hat jedoch im Ökosystem ein bestimmtes Habitat oder eine Reihe von Habitaten, die ihren 
artspezifischen Ansprüchen genügt und in denen sie auch tatschlich vorkommt. Alle diese Habitate zusammengefasst ergeben die realisierte Nische dieser Art (Hutchinson 1957). Die anderen Faktoren, die diese Nische beeinflussen sind Wechselwirkungen mit anderen Arten, also biotische Faktoren (Wittig und Streit 2004; Soberón 2007; Pulliam 2000). Als Kritikpunkt an der Nischenmodellierung wird angesetzt, dass, durch den Mangel an notwendigen biotischen Faktoren, die modellierte fundamentale Nische deutlich größer sein kann als die realisierte und somit nicht den Tatsachen entspricht (Peterson und Soberón 2012; Soberón 2007). Ein Nachteil der Modellierung ist ebenfalls, dass Ausbreitungshindernisse wie Bergketten oder größere Wasserflächen zwar als nicht habitabel modelliert werden, jedoch dahinterliegende Gebiete als mögliches Habitat gezeigt werden, auch wenn es der Art physikalisch nicht möglich ist, dorthin zu gelangen (Tjaden et al. 2018). Andere Autoren argumentieren, dass die biotischen Faktoren in Vorkommensdaten bereits mit einfließen und somit die modellierte Nische größtenteils der realisierten Nische entsprechen (Guisan und Thuiller 2005).

Wichtig für Modellierungen dieser Art ist die Datengrundlage. Die Qualität dieser Daten bestimmt, wie gut eine Modellierung die Realität wiedergibt (oder ihr zumindest sehr nahe kommt) und ist besonders wichtig für Arten, die nicht häufig berichtet werden (Aubry et al. 2017; Yates et al. 2018; Wiens et al. 2009). Seltene oder kryptische Arten, über die Datensätze mit zu wenig Datenpunkten oder falschen Bestimmungen erstellt werden, bieten ein großes Fehlerpotential (Wiens et al. 2009). Große Datensätze, die oftmals von vielen Personen über einen längeren Zeitraum gesammelt wurden, müssen vor der Nutzung erst bereinigt werden, da sie oft eine mehr oder minder große Stichprobenverzerrung (sampling bias) aufweisen, hierbei werden z. B. Datenpunkte häufiger an Stellen generiert, an denen viele Menschen verkehren, während abgelegene Orte seltener beprobt werden (Dennis und Thomas 2000). Diese Unregelmäßigkeiten müssen vor einer Analyse bereinigt werden (Costa et al. 2010) und inzwischen gibt es mehrere Ansätze für solche Verfahren (Fourcade et al. 2014; GutierrezVelez und Wiese 2020).

Im Zuge des sich ändernden Klimas oder durch Einführung in neue Gebiete breiten sich einige Arten aus, während andere an Gebiet verlieren (Hellmann et al. 2008). Dies geschieht auf aktivem oder passivem Wege. Viele Arten breiten sich aktiv aus, in dem sie neue Gebiete erschließen, in denen noch keine Artgenossen vorkommen. Diese Streifzüge sind von vielen 
revierbesetzenden Säugetieren und Vögeln bekannt (Celis-Murillo et al. 2017). Auch Stechmücken und Bremsen breiten sich aktiv aus (Guagliardo et al. 2014; Hocking 1953), Letztere jedoch haben ein deutlich höheres Potential, große Strecken zurückzulegen (Sheppard und Wilson 1976; Hocking 1953; Mullen 2019). So ist von Bremsen bekannt, dass diese innerhalb von kurzer Zeit Strecken von mehreren Kilometern zurücklegen können, auch ist ihre Fluggeschwindigkeit deutlich höher als die der Stechmücken (Mullen 2019). Stechmücken dagegen haben durch ein eher verstecktes Leben, kleinere Körpergröße und eine langsamere Fluggeschwindigkeit eine deutlich reduzierte Möglichkeit, sich aktiv auszubreiten, über längere Zeit gesehen ist dies aber ebenfalls effektiv möglich (Briegel et al. 2001; Kaufmann und Briegel 2004). Für Stechmücken sind dadurch natürliche Hindernisse und Barrieren wie z. B. Bergketten oder größere Seen bzw. Meerabschnitte effektivere Ausbreitungshindernisse (Verdonschot und Besse-Lototskaya 2014).

Möchte man die Ausbreitung oder Verbreitung von Stechmücken oder Bremsen, zwei sich deutlich voneinander unterscheidenden Gruppen, modellieren, müssen diverse Faktoren berücksichtigt werden. Somit ist die natürliche Ausbreitungsgeschwindigkeit durch die Tiere selbst ein wichtiger Faktor, die Einbeziehung gestaltet sich jedoch bei Tieren, die nur schlecht markierbar oder besenderbar sind und auch nur niedrige Wiedereinfangraten haben besonders schwierig. Bei Bremsen und Stechmücken ist die Wiederfangrate sehr niedrig und macht Untersuchungen zur Verbreitung, insbesondere über größere Gebiete, auf diesem Wege sehr aufwändig (Thornhill und Hays 1972; Reisen et al. 2003). Auch ein passiver Transport durch andere Tiere kommt bei Stechmücken theoretisch in Frage, so können sich Stechmückenweibchen an einer versteckten Stelle eines größeren Säugetieres eine Weile lang festhalten oder ein Eischiffchen oder eine Larve wird z. B. durch einen Wasservogel von einem Gewässer ins nächste getragen. Hierbei würde es sich aber um seltene Ausnahmefälle handeln die bei Analysen nicht berücksichtigt werden können. Ein passiver Transport durch Tiere ist bei Bremsen äußert unwahrscheinlich, da sich die Larven häufig am Grund von Gewässern und am oder im Boden aufhalten und die Eier direkt an Wasserpflanzen geklebt werden. Ein passiver Transport durch den Menschen findet statt, beispielsweise ist es belegt, dass Stechmückenlarven in Autoreifen oder Schnittblumenlieferungen transportiert werden, hierbei ist es lediglich wichtig, dass eine geringfügige Wassermenge transportiert wird (Becker et al. 2010). Ein Transport von Bremsenlarven oder Puppen durch den Menschen ist möglich, wenn Erdmassen oder Ernteerzeugnisse transportiert werden, jedoch nicht belegt. Hierbei 
kämen aber nur Arten in Frage, die während der Larvenstadien keine Gewässer benötigen. Es können also in potentielle Verbreitungsvorhersagen nicht nur die klimatischen Faktoren einfließen, sondern auch die Eigengeschwindigkeit der Tiere und potentielle Routen von menschlichen Transportwegen.

\section{Surface Range Envelope}

Eine "Surface Range Envelope" (SRE) Modell beruht auf Präsenzdaten und nutzt Umweltvariablen an den Fundpunkten, um einen Rahmen um die gesamte Verbreitung der Art vorherzusagen. Sie hat ihren Ursprung in der Nischentheorie und es werden als Grundannahme nur abiotische Faktoren, hauptsächlich klimatische, berücksichtigt (Hutchinson 1957). Es werden hierbei die untersten Minima (z.B. in Temperatur) und die obersten Maxima als Grenzen genutzt, Punkte, die dazwischenliegen werden automatisch als geeignet eingestuft. Für die meisten Faktoren ist dies eine realistische Schätzung. Es ist unwahrscheinlich, dass eine Art bei $10^{\circ} \mathrm{C}$ und $20^{\circ} \mathrm{C}$ auftritt, jedoch bei $15^{\circ} \mathrm{C}$ nicht überleben kann, dies ist die Grundannahme der Vorhersage. Ebenfalls werden andere Interaktionen mit z. B. anderen Arten nicht mitberücksichtigt, es wird nur die fundamentale Nische berechnet. Die realisierte Nische weicht meist davon ab (Austin et al. 1990). Die meisten ökologischen und klimatischen Daten können genutzt werden, jedoch empfiehlt es sich, sich auf die ökologisch relevantesten zu beschränken. Diese werden vom Modell ebenfalls berechnet. Es werden alle ausgewählten Faktoren an den Fundpunkten kombiniert und eine Vorhersage des Auftretens der Art darauf basierend erstellt. Im Gegensatz zu einigen anderen Modellierungsvarianten, benötigt die SRE-Modellierung keine Absence-Daten und kann Ergebnisse nur auf den Vorkommensdaten basierend generieren. Somit ist generell eine hohe Ergebnisqualität gegeben, auch wenn die tatsächliche Verbreitung an den Verbreitungsgrenzen dadurch eher überschätzt wird. Es wird ein Modell erstellt, das alle vorhandenen Parameter miteinbezieht, mit den Vorkommensdaten kombiniert und auf den eingespeisten Raum zurückprojiziert. Als Ergebnis wird eine Karte erstellt, die für jede Rasterzelle die Eignung wiedergibt.

\section{Maximum Entropy und Klimaprojektion}

Das Programm MaxEnt (Abkürzung für Maximum Entropy) kann die Eignung eines Habitates für eine Art basierend auf der bereits bekannten Verbreitung vorhersagen. Es werden in der Modellierung ebenfalls die durch die Umweltvariablen bestimmten Einschränkungen herangezogen, um die Ausbreitungsgrenzen zu bestimmen. Der „Maximum Entropy“-Ansatz 
beschreibt hierbei den Ausgangszustand einer gleichmäßigen Verteilung im Raum, in dem, basierend auf Einschränkungen durch die bekannte Artverbreitung, die Eignung des umliegenden Raumes modelliert wird. Zur Modellierung der potentiellen Artverbreitung wird die bekannte Verbreitung analysiert und die erklärenden Faktoren (z. B. Temperatur oder Niederschlag) aufgenommen, es handelt sich hierbei um eine „presence only“ Analyse, bei der keine Punkte für das Nicht-Vorkommen der Art eingegeben werden müssen. Anschließend werden gleichmäßig verteilte Punkte über das gesamte untersuchte Gebiet generiert, die bekannten Einschränkungen der Art auf diese angewandt und daraus wird die mögliche Artverbreitung berechnet. Funktionen des Algorithmus um Überanpassung zu vermeiden, sind eine unscharfe Anpassung an die Ränder der Umweltvariablen sowie ein Herausrechnen der Variablen, die das Vorkommen gar nicht oder nur sehr schwach verbessern. Desweiteren muss in Modellierungsansätzen beachtet werden, dass verschiedene Arten mit einer Prävalenz abgeschätzt werden müssen, die aufgrund mangelnder Datenlage nicht immer adäquat gewählt werden kann.

Die berechnete Karte zeigt eine Habitateignungswahrscheinlichkeit an, jedoch nicht die Verbreitung der Art, und eignet sich so besonders für Arten, die ihr absolutes Verbreitungsgebiet noch nicht vollständig erschlossen haben, wie z. B. invasive Spezies. Das fertige Modell kann, durch Einspeisung anderer Kartendaten, also entweder anderer Gebiete oder dem gleichen Gebiet mit veränderten Klimavariablen, genutzt werden um die Artverbreitung zukünftig oder in anderen Gebieten vorherzusagen und auch dort Habitateignungskarten zu modellieren (Randin et al. 2006; Sillero 2011). Für die Übertragung der Modellierung auf ein sich änderndes Klima wurde eine große Anzahl an Klimamodellen (global circulation model, GCM) angefertigt, die verschiedene Entwicklungen des zukünftigen Klimas vorhersagen sollen. Diese beziehen verschiedenste Systeme (Ozeane, Vulkansysteme, Wettereffekte) mit ein, die insgesamt das Klima angemessen beschreiben. Um hierbei eine möglichst genaue Vorhersage für die untersuchte Art treffen zu können, sollten diverse Klimavorhersagen mit in die Modellierung einbezogen werden. Diese verschiedenen Szenarien werden als repräsentative Konzentrationspfade (representative concentration pathway, RCP) bezeichnet und beziehen, neben den natürlichen Systemen auch verschiedene Entwicklungen der Weltbevölkerung, Technikfortschritt, Energiequellennutzung und sich dadurch ergebende Auswirkungen auf Treibhausgasemissionen und gesteigerten Strahlungsantrieb. Die von uns genutzten RCP Szenarien sind RCP 2.6, 4.5, 6.0 und 8.5, 
entsprechen dem jeweiligen Wert an Strahlungsantrieb und einer durchschnittlichen Erwärmung der Oberflächentemperaturen von $1^{\circ} \mathrm{C}, 1,8^{\circ} \mathrm{C}, 2,2^{\circ} \mathrm{C}$ respektive $3,7^{\circ} \mathrm{C}$. (Qin et al. 2014).

\section{Mikrohabitatanalyse}

Mithilfe von Mikrohabitaten können Rückschlüsse auf Artpräferenzen, deren potentielle Verbreitung innerhalb eines beliebig kleinen Verbreitungsgebietes und sogar phylogenetische Rückschlüsse zwischen Schwesterarten gezogen werden (Mehrabi et al. 2014; Ficetola et al. 2018). Geeignet ist diese Analyse, wenn weitere abiotische oder biotische Informationen zu den für eine Nischenmodellierung genutzten Vorkommenspunkten einer Art vorhanden sind. Ist ein Organismus mobil und er kann zwischen mehreren Mikrohabitaten wechseln, kann das seine Anfälligkeit für Umweltveränderungen beeinflussen (Huey et al. 1989; Kearney und Porter 2009). Je kleiner diese Habitaträume sind und je mehr Datenpunkte mit Vorkommensoder Abwesenheitsdatenpunkten der untersuchten Art in Kombination mit den Umgebungsfaktoren vorhanden sind, desto genauer kann die Eignung eines Mikrohabitates bestimmt werden. Die in Mikrohabitaten auftretenden Einflüsse auf die Arten können signifikante Auswirkungen auf das Vorkommen oder Nichtauftreten einer Art haben. Diese können größer sein als die großskaligen klimatischen Einflüsse (Huey 1991; Helmuth und Hofmann 2001). Durch die Häufigkeit des Auftretens einer Art innerhalb eines Mikrohabitates können in Kombination mit den Umgebungsfaktoren wie z. B. Sonneneinstrahlung Rückschlüsse auf Toleranzen, Vermeidung oder Präferenzen der Art gezogen werden (Krämer et al. 2012; Vezzani et al. 2005). Mikrohabitate können ebenfalls als Rückzugsorte dienen, die eine Wiederbesiedlung des umgebenden Gebietes nach einem spontanen aber auch langzeitigen Extremereignis (z. B. Waldbrand, Überflutung, Eiszeit) ermöglichen (Hannah et al. 2014; Low-Décarie et al. 2015). Besonders eignen sich hierbei getrennte Inselhabitate oder sonstige räumliche Strukturen, die einen Austausch der Arten zwischen den Habitaten zumindest zeitweise unterbinden. Ein besonders zur Untersuchung geeignetes Mikrohabitat sind Höhlen oder ähnliche Untergrundstrukturen. Besonders troglobionte Arten können effektiv klassifiziert werden, da diese ihren Lebensraum nicht verlassen (Kozel et al. 2019), es können aber auch Arten analysiert werden, die zumindest zeitweise innerhalb der Höhle anzutreffen sind und eine Phase aufzeigen, in der sie dieses Habitat nicht verlassen, z.B. eine Überwinterungsphase. 


\section{Zusammenfassungen der Projekte}

In diesem Kapitel werden die drei Publikationen innerhalb dieser Dissertation zusammengefasst und die wichtigsten Ergebnisse und Diskussionsansätze kurz dargestellt. Die vollständigen Publikationen sind im Anhang angefügt. Die drei Publikationen untersuchen verschiedene hämatophage Dipteren auf ihre Verbreitung und Habitatanforderungen mithilfe dreier passender Modelle in verschiedenen Größenskalen (Abbildung 12). In Kapitel 3 werden die Publikationen anschließend miteinander verglichen um Rückschlüsse auf die Ergebnisse zu ziehen.

\begin{tabular}{|c|c|c|c|}
\hline \multirow[b]{2}{*}{ Artgruppe } & Projekt I & Projekt II & Projekt III \\
\hline & Tabanidae & Culicidae & Culicidae \\
\hline Anzahl Arten & 6 & 1 & 2 \\
\hline Statistisches Modell & $\begin{array}{c}\text { SRE } \\
\text { Surface Range Envelope }\end{array}$ & $\begin{array}{l}\text { MaxEnt } \\
\text { Maximum Entropy }\end{array}$ & $\begin{array}{c}\text { GLM } \\
\text { General Linear Model }\end{array}$ \\
\hline Skala & Kontinental & Land & Bundesland, Mikrohabitat \\
\hline Auflösung & $5^{\prime}$ & $30^{\prime \prime}$ & punktuell \\
\hline Wichtigste Faktoren & Klima, Landcover & Klima, Höhenlage & Wetter, Umgebung \\
\hline Hauptaspekt & Sampling Bias & Zukunftsprojektion & Überwinterung \\
\hline \multicolumn{4}{|l|}{ Detailgrad der Analyse } \\
\hline Größenordnung & & & \\
\hline
\end{tabular}

Abbildung 12: Übersicht über die Projekte, genutzte Methoden, Skalen, Aspekte und Faktoren. 


\section{Projekt I - Unvollständig beobachtet - Nischenabschätzung für sechs häufige}

\section{europäische Bremsenarten (Diptera, Tabanoidea, Tabanidae)}

Originaltitel: Incompletely observed - niche estimation for six frequent European horsefly species (Diptera,

Tabanoidea, Tabanidae)

Weltweit sind 4400 unterschiedliche Arten von Bremsen (Tabanidae) beschrieben (Pape und Thompson 2019; Cheng 1986), von denen mehr als 170 in Europa vorkommen (Chvála et al. 1972). Weibliche Bremsen können durch ihr Fraßverhalten schwere Hautläsionen verursachen (Veraldi und Esposito 2017) und sind in der Lage, verschiedene Krankheiten effektiv zu übertragen (Baldacchino et al. 2014b; Chippaux et al. 2000; Foil 1989; Wiesenhütter 1975). Dazu gehören unter anderen der Augenwurm Loa loa, der Erreger der Loiasis (Cheng 1986; Chippaux et al. 2000; Turkington und Ashby 2007; Padgett und Jacobsen 2008), der Infektiösen Blutarmut der Einhufer (Krinsky 1976; Issel und Foil 1984; Liberato et al. 2019), Trypanosoma theileri (Böse et al. 1987; Dirie et al. 1990) und T. evansi, dem Erreger von Surra, der vor allem Nutztiere befällt (Cheng 1986), aber auch Menschen infizieren kann (Joshi et al. 2005). Weitere übertragbare Erreger sind Spiroplasma (Le Goff et al. 1993; Grulet et al. 1993; Hackett et al. 1996), Tularemie (Bacillus tularensis, Olsufjev und Golovd 1936), Anthrax (Bacillus anthrax) (Krinsky 1976), Mycoplasma bovis (Hornok et al. 2011), die Elch- und Hirsch-Filariose (Elaeophora schneideri, Mullen 2019) sowie die bovine Besnoitiose (Alvarez-García et al. 2013). Viele Arten benötigen langsam fließende oder stehende Gewässer zur Eiablage und als Larvalhabitate. Die Larven leben räuberisch oder von Detritus und suchen trockenen Boden zur Verpuppung. Andere Arten hingegen sind auf trockenere Gebiete spezialisiert und benötigen keine Gewässer, sondern nur feuchten Boden oder Dung von Weidetieren (Cheng 1986; Chvála und Ježek 1997; Bellmann 1999; Liebisch 1987; Chvála et al. 1972). Als Folge der Trockenlegung vieler Feuchtgebiete in Europa (Ellenberg und Dierschke 2010; Schönborn und Risse-Buhl 2013) ist die Zahl der Bremsen stark zurückgegangen (Frouz 2001). Aktuelle Insektizidanwendung und Landnutzung führt zu einem weiteren Rückgang der Zahlen (Mustapha und Hill 1974; Hallmann et al. 2017; Benton et al. 2002; Mazoyer und Roudart 2017). Auch leiden, vor allem in ärmeren Ländern, weiterhin Rinder und andere Nutztiere aufgrund fehlender Schutz- oder Bekämpfungsmöglichkeiten unter großen Befallszahlen, was zu Anämien oder schweren Hautschäden bei den betroffenen Tieren führt (Cheng 1986; Hansens 1979; Maramorosch 1962). Neuere Forschungen innerhalb Europas konzentrieren sich vor allem auf begrenzte Gebiete innerhalb weniger Länder und fokussieren sich auf das 
Auftreten von Bremsen und mögliche Bekämpfungsmaßnahmen (Barashkova und Reshetnikov 2017, 2014) sowie auf ökologische und anthropogene Auswirkungen auf ihre Populationen (Baldacchino et al. 2017). Bis heute gibt es keine standardisierten und wiederholt durchgeführten Monitoring-Protokolle für Bremsen in Eurasien (und auch in anderen Kontinenten), was es schwierig macht, vorhandene Daten zu erfassen, zusammenzustellen und für Berechnungen und Prognosen zu nutzen. Aufgrund der unterschiedlichen Überwachungssysteme in den verschiedenen Ländern werden die Vorkommen entweder über- oder unterschätzt und die Kombination dieser Datensätze ist aufwändig. Aufgrund der fehlenden Überwachung in vielen Ländern ist nicht viel über die komplette Verbreitung bekannt. Da nur Standorte in Westeuropa ausgiebig untersucht wurden, ist die Verbreitung im restlichen Eurasien höchstwahrscheinlich stark unterschätzt. Sechs in Mitteleuropa häufig vorkommende Arten wurden für unsere Studie verwendet: Chrysops relictus und die morphologisch ähnliche Art,

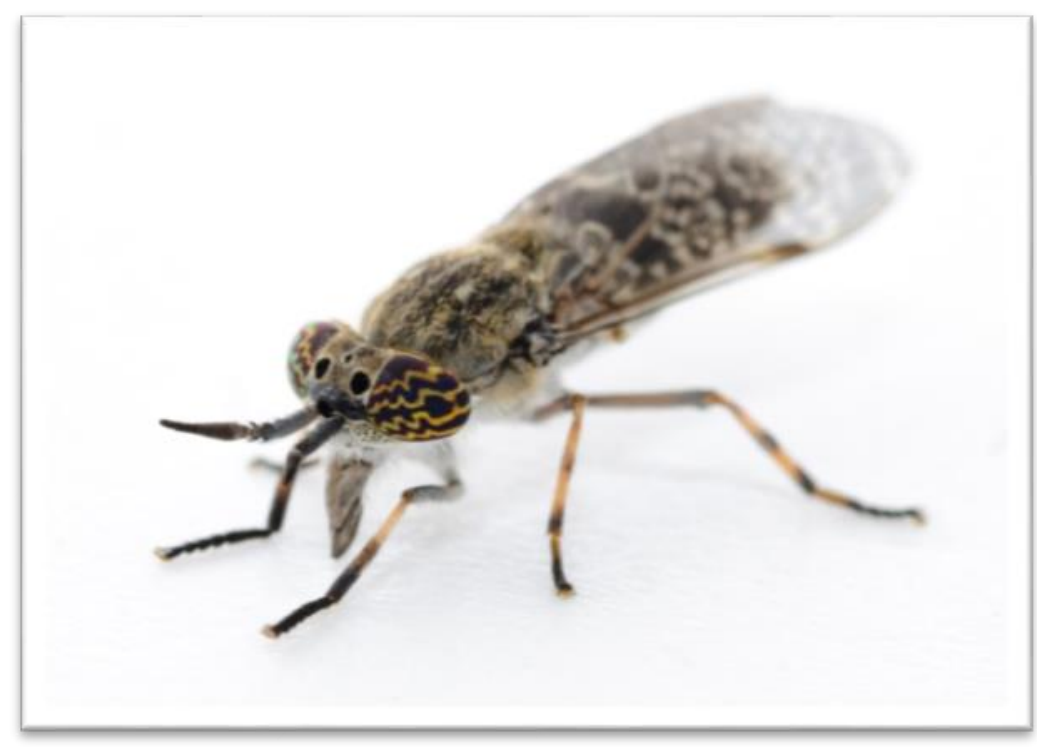

Abbildung 13: Weibchen von Haematopota pluvialis Chrysops caecutiens (Linnaeus

1758), Haematopota pluvialis (Linnaeus 1758, Abbildung 13), Tabanus bromius, Tabanus bovinus und Tabanus sudeticus. Die Tabanus- und Haematopota-Arten sind relativ eurytrop und benötigen nur feuchten Boden zur Eiablage und Larvenentwicklung (Bellmann 1999; Edwards et al. 1939; Burgess et al. 1978; Steinbach et al. 1996; Haupt und Haupt 1998; Andreeva 1982), während Chrysops auf Teiche, Flüsse oder Seen angewiesen ist (Andreeva 1990). Um eine realistische Ausbreitung der Arten zu finden, berechneten wir die klimatische Nische sowie die Landbedeckungszuordnung der Vorkommenspunkte anhand von Literatur und Datenbankdaten, die bis ins Jahr 1990 zurückreichen. Für die Projektion der potentiellen Verbreitung innerhalb Europas und Asiens verwendeten wir ein Ökologisches Nischenmodell (Envelope Model, ENM) mit einem Surface-Range-Envelope (SRE). Um der vorhandenen Stichprobenverzerrung entgegenzuwirken, verwendeten wir diese Methode, da sie besonders 
resistent gegen Über- und Unterrepräsentation von Arten in Datenbanken und Literatur ist. Wir verglichen auch die modellierten Nischen sowie die bevorzugte Art der Landbedeckung und die Anzahl der frostfreien Monate, die für das Vorkommen der sechs Arten erforderlich sind. Für unsere Analyse nutzten wir Daten aus einer umfangreichen Literaturrecherche sowie der GBIF-Datenbank. Die Vorkommensdaten wurden an die räumliche Auflösung (5 Bogenminuten) der Umweltrasterdaten angepasst und auf ein Vorkommen pro Rasterzelle reduziert. Für die Nischenverbreitungsanalyse wurden 8 bioklimatische Variablen, die von WorldClim (Fick und Hijmans 2017) zur Verfügung gestellt wurden, mit einer räumlichen Auflösung von 5 Bogenminuten heruntergeladen. Wir berechneten SREs (Thuiller et al. 2016) für jede Tabanidenart und betrachteten drei Modelle: Das vollständige Modell, 95\% und 90\% aller Vorkommenspunkte. Die Karten wurden in Esri ArcGIS (Environmental Systems 2019) erstellt. Sowohl für die Aktivitätsphasen als auch für die Landbedeckungspräferenzvergleiche wurden Daten aus ESA GlobCover (Arino 2010) gewonnen. Die Landbedeckungskategorien wurden angemessen in 11 Kategorien kombiniert: Ackerland $>50 \%$, Gras-/Buschland, Laubwald, Mischwald, Dichtes Immergrün, Lichtes Immergrün, Mosaikvegetation, Spärliche Vegetation, Anthropogen beeinflusst, Gewässer, Sonstiges. Für T. bovinus, T. bromius und T. sudeticus liegen die 90\%- und 95\%-Modelle sehr nah am vollständigen Modell. Das vollständige Modell schließt für alle Arten Lücken in Mitteleuropa und fügt Gebiete in Finnland und Zentral- und Ostrussland hinzu. Für T. sudeticus schließt das vollständige Modell die meisten Lücken innerhalb der bekannten Verbreitung. Die klimatischen Variablen sind für diese drei Arten relativ ähnlich. Der Vergleich von Landbedeckungstyp und Artenvorkommen zeigt, dass die Kategorie Ackerland von allen Arten gemieden wird. 5 der 6 Arten kommen auf Flächen der Kategorie Gras-/Buschland zwischen dem Doppelten und Dreieinhalbfachen der erwarteten Häufigkeit vor. In der Kategorie „Dichtes Immergrün“ zeigen die Arten $C$. caecutiens und $C$. relictus sowie $T$. bovinus eine negative Abweichung vom Erwartungswert zwischen $60 \%$ und $90 \%$, während T. bromius (30\%) und T. sudeticus (80\%) häufiger vorkommen. In der Anthropogen beeinflussten Kategorie erscheinen die mit Abstand größten Abweichungen vom Erwartungswert, mit positiven Abweichungen zwischen 2,6-5,1-fachem Erwartungswert. Aufgrund der sehr dichten Beprobung in Westeuropa ergibt sich ein verzerrtes Bild, obwohl einige der Arten auch etwa 6000 Kilometer weiter östlich vorkommen. Die Arten sind in Europa relativ häufig und weit verbreitet und dürften daher in vielen Datenerhebungen vorkommen, was sie zu einem geeigneten Beispiel für diese Methodik 
macht. Für das Modell haben wir einer Verzerrung so weit wie möglich entgegengewirkt, indem wir die Anzahl der Proben auf eine pro Gitterzelle reduziert haben. Daher ist es wahrscheinlich, dass alle Arten wirklich den größten Teil der in der Analyse berechneten Nische ausfüllen können. Beim Vergleich der Flächen des 90\%-Modells wird deutlich, dass das bisher bekannte Verbreitungsgebiet aufgrund eines dichten Monitorings in West- und Mitteleuropa sehr klein ist und eine sehr ähnliche Verteilung für alle sechs Arten zu erwarten wäre. Berücksichtigt man das vollständige Modell, ergibt sich ein anderes Bild. Die drei Arten C. caecutiens, $C$. relictus und $H$. pluvialis haben eine viel größere Nische als aus den Daten ersichtlich. T. bovinus und T. bromius haben ähnlich große Nischen, $T$. sudeticus hat die kleinste Verbreitung. Die Ergebnisse unserer Berechnung von T. bovinus liegen sehr nahe an der bekannten Verbreitung. Fünf der sechs Arten kommen in Gebieten mit nur zwei frostfreien Monaten vor, wobei T. sudeticus nur in Gebieten mit mindestens 4 frostfreien Monaten auftritt. Es ist bekannt, dass Bremsen als Larven überwintern und für ihre Entwicklung mehrere Jahre benötigen können (Schnieder et al. 2006). In Mitteleuropa beträgt die Entwicklungszeit zwischen 1 und 3 Jahren. Geht man jedoch von einem Gebiet mit nur zwei frostfreien Monaten pro Jahr aus, könnte sich diese Zahl deutlich erhöhen. Die frosttolerantesten Arten sind C. caecutiens, C. relictus und H. pluvialis mit Vorkommen in Gebieten, in denen die Temperatur auf $-58{ }^{\circ} \mathrm{C}$ sinken kann. Unser Modell basiert auf einer kontinentalen Skala, in der die klimatischen Faktoren am wichtigsten sind, um Verbreitungsmuster zu zeigen (Peterson und Soberón 2012). Die Verbreitung der meisten Tabaniden wird in vielen Gebieten nicht ausreichend überwacht. Das SRE-Modell ist ein effektives Werkzeug, um die Verbreitung von Arten zu berechnen, die in einigen Gebieten gut, in anderen aber schlecht überwacht sind. Unsere Ergebnisse unterstützen die Hypothese, dass die verfügbaren Verbreitungsdaten die tatsächliche Verbreitung der untersuchten Arten unterschätzen. Insbesondere $C$. relictus, $C$. caecutiens und $H$. pluvialis haben eine viel größere berechnete Nische, als die gesammelten Beobachtungen darstellen. Wir schlagen ein standardisiertes Überwachungsprogramm vor, das diese Methodik sowohl für Tabaniden als auch für andere Arten verbessern und validieren kann. Mit Hilfe der Vorhersagen aus diesem Modell können weitere Monitoringprogramme in Gebieten geplant werden, in denen wenige oder keine Beobachtungen aufgezeichnet wurden, um unser Modell zu bestätigen und zu erweitern. 
Projekt II - Modellierung der Habitateignung für den Arbovirus-Vektor Aedes

albopictus (Diptera: Culicidae) in Deutschland

Originaltitel: Modeling the habitat suitability for the arbovirus vector Aedes albopictus (Diptera: Culicidae) in

Germany

Überall auf der Welt sind Stechmücken als Plagegeister bekannt. Aufgrund des fortschreitenden Klimawandels kann sich das potenzielle Verbreitungsgebiet von Arten nach Norden verschieben. Durch den globalen Handel und den Tourismus werden die Arten passiv über große Distanzen transportiert (Becker 2008) und können so auch Standorte außerhalb des alten Verbreitungsgebietes mit neu geeigneten Habitatbedingungen erreichen. Das erneute Auftreten von durch Arthropoden übertragenen Viren in Europa gilt als eine der Folgen der Umverteilung von Arten, wobei tropische Stechmücken als Vektoren für schwere Krankheiten fungieren. Tropische Stechmücken gehören oft zu den Gattungen Anopheles oder Aedes. Eine Stechmückenart, die in den letzten Jahrzehnten in Europa an Aufmerksamkeit gewonnen hat, ist die Asiatische Tigermücke Aedes albopictus (Abbildung 14). Diese Art ist in Asien beheimatet und besitzt eine starke Invasionsfähigkeit (Paupy et al. 2009). Erste Nachweise aus Europa stammen aus dem Jahr 1979 in Albanien, wo sie wahrscheinlich mit Waren auf

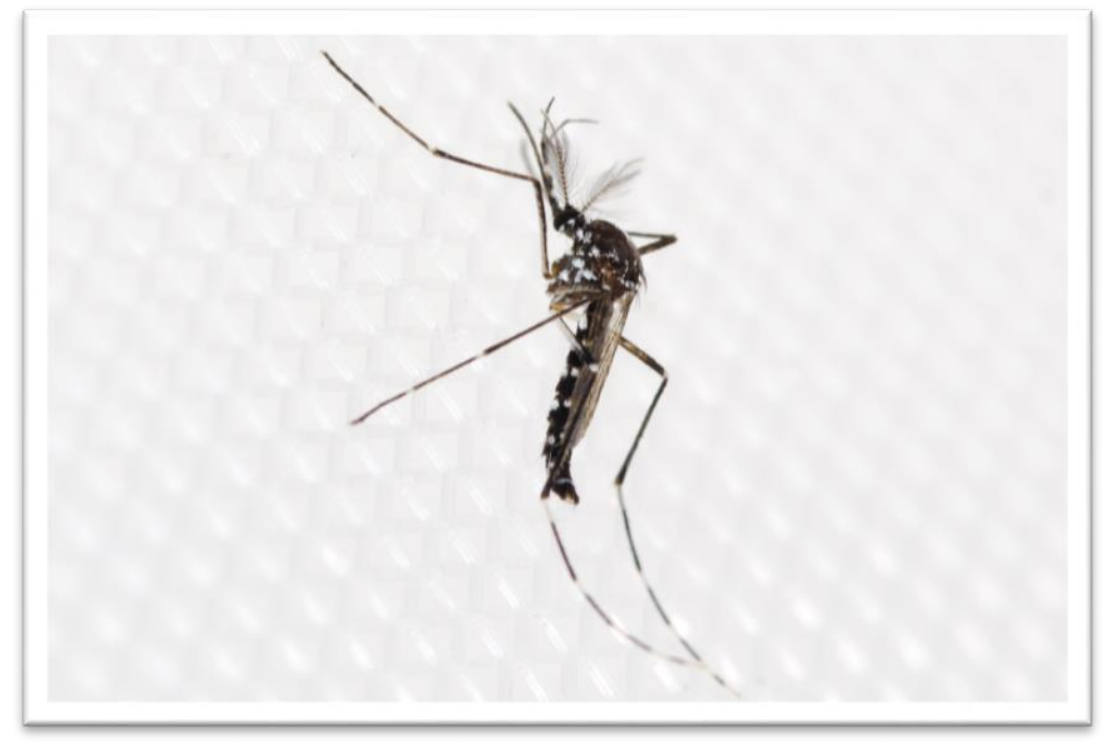

Abbildung 14: Männchen von Aedes albopictus

Schiffen aus China eingeschleppt wurde (Adhami und Reiter 1998). Heute hat die Art in mindestens 12 europäischen Ländern Populationen etabliert (Dalla Pozza G, Majjori G 1992; ECDC 2015a, 2015b; Schaffner et al. 2001; Giatropoulos et al. 2012; Aranda et al. 2006). Aedes albopictus wurde bereits in die Niederlande, Belgien und Deutschland eingeschleppt (Schaffner et al. 2000; Scholte et al. 2007; Becker 2008; Pluskota et al. 2008; Kampen et al. 2013; Werner und Kampen 2015; Di Luca et al. 2017). Trotz mehrfacher Nachweise ist jedoch noch unklar, ob sich die Art in diesen Ländern etablieren konnte (Pluskota et al. 2008; Werner et al. 2012; Becker et al. 2013; Kampen et al. 2013). Es wird angenommen, dass das sich 
ändernde Klima das Risiko einer Etablierung von Ae. albopictus in Nordeuropa, z. B. in Deutschland, erhöht. Generell ist die Art empfänglich für Infektionen mit vielen durch Arthropoden übertragenen Viren und einigen Nematodenarten und kann auch als Überträger dieser fungieren. So wird Ae. albopictus beispielsweise für den jüngsten Ausbruch von Chikungunya in Italien und Dengue in Frankreich und Kroatien verantwortlich gemacht (Rezza et al. 2007; La Ruche et al. 2010; Gjenero-Margan et al. 2011). Im Jahr 2011 initiierten (Becker et al. 2013) ein erstes Überwachungsnetzwerk, das internationale Flughäfen, Häfen und Bahnhöfe als Probennahmestellen einschloss. Allerdings berücksichtigten die Autoren keine Umweltfaktoren, die eine Etablierung der Art begünstigen könnten. Trotz eines prognostizierten globalen Temperaturanstiegs wird es Unterschiede in der Habitateignung für Stechmücken geben, abhängig z. B. von der Höhenlage oder den Niederschlagsmengen. Aufgrund der zu erwartenden zukünftigen klimatischen Veränderungen gehen wir davon aus, dass Ae. albopictus ihr europäisches Verbreitungsgebiet nach Norden ausdehnen und sich somit dauerhaft in Deutschland etablieren könnte. Vor diesem Hintergrund haben wir die ökologische Nischenmodellierung (Environmental Niche Modeling, ENM) eingesetzt, um die aktuelle und zukünftige Habitateignung für Ae. albopictus in Deutschland zu projizieren. Basierend auf einer intensiven Literaturrecherche unter Verwendung der in (Benedict et al. 2007) genannten Referenzen und des Europäischen Zentrums für die Prävention und die Kontrolle von Krankheiten (ECDC 2015a) haben wir eine Fundpunktdatenbank für Europa zusammengestellt. Für die Modellierung verwendeten wir 96 Fundpunkte für Ae. albopictus in Europa. Für die Auswahl der Umweltvariablen folgten wir (Fischer et al. 2011). So wurden vier Klimavariablen, Jahresmitteltemperatur, Mitteltemperatur des wärmsten Quartals, Mitteltemperatur des kältesten Quartals und Jahresniederschlag und die von WorldClim (Hijmans et al. 2005) zur Verfügung gestellte Höhe ausgewählt. Um unser Modell zu trainieren, verwendeten wir Variablen, die die klimatischen Bedingungen zwischen 1950 und 2000 repräsentieren. Es wurde ein Maximum-Entropie-Ansatz verwendet und in der Software MaxEnt implementiert (Phillips et al. 2004; Phillips und Dudík 2008). Diese korrelative und präsenzbasierte ENM-Methode ist ein gut funktionierendes Werkzeug (Elith et al. 2006) das häufig verwendet wird (Hijmans und Graham 2006; Kumar und Stohlgren 2009; Stabach et al. 2009; Trisurat et al. 2009; Reiss et al. 2011; Melaun et al. 2015) Für die Kartierung der Habitateignung von Ae. albopictus in Deutschland unter aktuellen Klimabedingungen wurden WorldClim-Daten aus dem Zeitraum zwischen 1950 und 2000 verwendet. Um die potenzielle 
Habitateignung für Ae. albopictus unter zukünftigen klimatischen Bedingungen in Deutschland darzustellen, projizierten wir die Habitateignung für die Zeiträume 2021-2040, 2041-2060 und 2061-2080. Für die Daten zu den zukünftigen Klimabedingungen standen vier Representative Concentration Pathways (RCP) Szenarien zur Verfügung: RCP2.6, RCP4.5, RCP 6.0 und RCP 8.5 (Qin et al. 2014; Stocker et al. 2013). Wir haben die Daten basierend auf dem globalen Zirkulationsmodell CSIRO-Mk3.6.0 verwendet. Für die Projektionen wurde eine räumliche Auflösung von 30 Bogensekunden verwendet. Nach unserem Modell gibt es in Deutschland bereits zwei Gebiete, die unter den aktuellen klimatischen Bedingungen für Ae. albopictus geeignet sind. Ein Gebiet liegt im Westen Baden-Württembergs um Freiburg und weiter nördlich. Das andere Gebiet ist das Ruhrgebiet in Nordrhein-Westfalen. Die Projektionen für alle betrachteten Zukunftszeiträume unter verschiedenen RCPs zeigen eine Vergrößerung der Gebiete mit geeigneten Habitatbedingungen und weisen ein ähnliches Muster über ganz Deutschland auf. Für die Zukunft werden die besten klimatischen Bedingungen für Ae. albopictus in Norddeutschland sowie in den südöstlichen (Bayern) und südwestlichen Teilen (um Freiburg) modelliert. Bei Betrachtung des RCP 2.6-Szenarios nimmt die modellierte Habitateignung im Vergleich zu den anderen RCPs am wenigsten zu, die höchste Zunahme wird unter dem RCP 8.5 prognostiziert. Die mittlere Temperatur des kältesten Quartals (bio11) wurde als die Variable identifiziert, die am meisten zum Modell beiträgt, gefolgt von der mittleren Temperatur des wärmsten Quartals (bio10). Aedes albopictus findet bis zu einer mittleren Temperatur des kältesten Quartals von $0{ }^{\circ} \mathrm{C}$ geeignete Bedingungen vor, während das Optimum bei etwa $6,5^{\circ} \mathrm{C}$ liegt. Hinsichtlich der mittleren Temperatur des wärmsten Quartals (bio10) kommt die Art in Regionen mit Temperaturen zwischen 17 und $30{ }^{\circ} \mathrm{C}$ (Optimum $24^{\circ} \mathrm{C}$ ) vor. In Bezug auf die Jahresmitteltemperatur (bio01) und den Jahresniederschlag (bio12) kommt die Art bei einer Jahresmitteltemperatur zwischen 10 und $18{ }^{\circ} \mathrm{C}$ (Optimum 14,5 ${ }^{\circ} \mathrm{C}$ ) bzw. zwischen 160-1700 mm (Optimum $1200 \mathrm{~mm}$ ) vor. Der allgemeine Anstieg der modellierten Habitateignung in Deutschland sowie in den Regionen, in denen Ae. albopictus zu erwarten ist, bestätigt andere frühere Ergebnisse von Nischenmodellierungen auf globaler und europäischer Ebene (Benedict et al. 2007; Fischer et al. 2011; Fischer et al. 2014; Kraemer et al. 2015). Darüber hinaus stehen unsere Ergebnisse im Einklang mit den allgemein bekannten Etablierungsschwellen des ECDC für Ae. albopictus (ECDC 2015a, 2015b; Medlock et al. 2015). Nach diesen Schwellenwerten kann die Art in Regionen mit einer mittleren Wintertemperatur von mehr als $0{ }^{\circ} \mathrm{C}$ und einer mittleren 
Jahrestemperatur von mehr als $11{ }^{\circ} \mathrm{C}$ vorkommen (Medlock et al. 2015). Darüber hinaus benötigt die Mückenart für eine optimale Entwicklung, einschließlich Brutplätzen für die Eiablage, mindestens $500 \mathrm{~mm}$ Jahresniederschlag und eine Sommertemperatur von $25-30{ }^{\circ} \mathrm{C}$ (Medlock et al. 2015). Die Asiatische Tigermücke ist eine Art mit einer hohen Konkurrenzfähigkeit und ökologischen Plastizität (Paupy et al. 2009). In einigen Ländern hat Ae. albopictus sogar begonnen, andere bekannte Vektorarten wie die Gelbfiebermücke Aedes aegypti zu verdrängen oder Lebensräume anderer Arten (z. B. Culex pipiens) auszubeuten (Paupy et al. 2009). Einige Laborexperimente zeigten, dass Populationen aus Südeuropa Frostperioden von bis zu $-10^{\circ} \mathrm{C}$ überwinden können (Thomas et al. 2012; Kampen und Werner 2015). Darüber hinaus könnten Präadaptionen an kältere Temperaturen in den Herkunftsgebieten auch eine schnellere Etablierung in kälteren Regionen ermöglichen. (Nawrocki et al. 1987) zeigten bereits, dass Ae. albopictus-Populationen der gemäßigten Zone in Asien während des Eistadiums eine Dormanz aufweisen, die sie von Ae. albopictusPopulationen aus der tropischen Zone Asiens unterscheidet. Es wurde bereits vermutet, dass diese Art neben Ae. aegypti der problematischste Invasor in Europa sein könnte und daher überwacht werden sollte (Zgomba et al. 2008; Medlock et al. 2015). Obwohl Ae. albopictus oft als unbedeutender Vektor für Dengue- und Gelbfieberviren angesehen wird (Tandon und Ray 2000; Eritja et al. 2005; Moutailler et al. 2009; Paupy et al. 2009; Valerio et al. 2010), haben Studien von (Brady et al. 2014) ergeben, dass Ae. albopictus nicht nur ähnliche Verbreitungsmuster wie das Dengue-Virus aufweist, sondern sogar den Primärvektor Ae. aegypti übertrifft. Außerdem kann Ae. albopictus aufgrund seiner Wirtspräferenzen als Brückenvektor fungieren (Medlock et al. 2006). Mehrere frühere Studien wiesen neben einem hohen Anteil an Säugetierblut (einschließlich menschlichem Blut) auch Vogelblut in den Blutmahlzeiten der Stechmücke nach, so dass die Art nicht auf einen obligaten Wirt angewiesen ist (Medlock et al. 2006; Valerio et al. 2010; Faraji et al. 2014). Aufgrund der jüngsten autochthonen Ausbrüche von Krankheiten, die durch Ae. albopictus in anderen europäischen Ländern wie Italien, Frankreich und Kroatien übertragen werden (Vazeille et al. 2008; Paupy et al. 2009; Gould et al. 2010; Gjenero-Margan et al. 2011), könnte die Asiatische Tigermücke auch in Deutschland zu einer großen Gefahr für die menschliche Gesundheit werden. 


\section{Projekt III - Eine Untersuchung von überwinternden Vertretern aus dem Culex}

\section{pipiens-Komplex (Diptera, Culicidae) in unterirdischen Habitaten Mitteldeutschlands}

Originaltitel: An investigation of hibernating members from the Culex pipiens complex (Diptera, Culicidae) in subterranean habitats of central Germany

Stechmücken der gemäßigten Breiten, die zum Culex pipiens-Komplex gehören, sind morphologisch schwer zu unterscheiden. Zu den charakteristischsten Merkmalen gehören die männlichen Genitalien und der Larvalsiphon (Vinogradova 2000). Nach Vinogradova (2000) umfasst der Komplex Culex pipiens pipiens var. pipiens (Linnaeus 1758), den Biotyp Culex pipiens pipiens var. molestus (Forskål 1775), Culex torrentium (Martini 1925), Culex pipiens quinquefasciatus (Say 1823), Culex pipiens pallens (Coquillett 1898), und Culex vagans (Meigen und Wiedemann 1828). Die ersten drei sind in Deutschland häufig anzutreffen. Während dieser Komplex größtenteils aus Stechmücken besteht, die städtische Gebiete in gemäßigten Klimazonen besiedeln (Barr 1967), ist Cx. pipiens (Abbildung 15), einschließlich der Unterarten und Biotypen, möglicherweise die weltweit am häufigsten vorkommende Stechmückenart (Hubálek und Halouzka 1999). Wie viele andere Stechmückenarten übertragen die Mitglieder des Culex pipiens-Komplexes verschiedene Viren wie das West-NilVirus (WNV), das tödliche Epidemien in Ost- und Mitteleuropa ausgelöst hat (Lundström 1999; Hayes 2001; Hubálek 2008) und auch in Asien, Australien, Afrika, der Karibik und Nordamerika bekannt ist (Hubálek 2008). Studien zeigen, dass Culex-Arten kompetente Vektoren sind (Werblow et al. 2013; Hesson et al. 2014; Becker et al. 2010). Dies könnte auch auf $C_{X}$. torrentium zutreffen, eine Art, die in Mitteleuropa weit verbreitet ist (Hesson et al. 2014; Werblow et al. 2013). Da CX. p. pipiens ornithophil ist (Becker et al. 2010; Gomes et al. 2013), spielt die Art eine Rolle bei der Übertragung von WNV innerhalb von Vogelpopulationen, außer in den Vereinigten Staaten, wo sie eine höhere Affinität zum Menschen aufweist und zu einem Brückenvektor wird (Andreadis 2012). Andreadis führt diese Veränderung der Wirtspräferenz auf eine mögliche Abstammung von $C_{x}$. p. molestus zurück und wird analog zur angenommenen Hybridisierung (Lõhmus et al. 2012) betrachtet. Cx. p. molestus ist als mammophil bekannt (Harbach et al. 1984) und zeigt im Vergleich zu Cx. p. pipiens ein anderes Verhalten. Allerdings hat $C x . p$. molestus in einem Untersuchungsgebiet im Westen Portugals kein unterschiedliches Fressverhalten im Vergleich zu Cx. p. pipiens (Gomes et al. 2013) gezeigt. Heute wird allgemein angenommen, dass $C x$. p. molestus an eine unterirdische Umgebung angepasst ist (Knight 1951; Kamura und Bekku 1959; Amara Korba et al. 2016; Kent 
et al. 2007) und autogen, stenogam und homodynamisch ist. Im Gegensatz dazu ist $C x . p$. pipiens anautogen, eurygam und heterodynamisch (Vinogradova 2000; Knight 1951; Kamura und Bekku 1959). Die allgemeine Autogenie und Stenogamie wurden in einem Zuchtexperiment nachgewiesen (Amara Korba et al. 2016). Cx. p. molestus wird oft als eine unterirdische Form von CX. pipiens (Harbach et al. 1984; Kent et al. 2007; Vinogradova und Shaikevich 2007; Sulaiman und Service 1983) angesehen und könnte daher in Höhlen viel häufiger vorkommen. Es wurde theorisiert, dass Hybriden von $C_{x}$. p. pipiens und $C_{x} . p$. molestus existieren und als Brückenvektoren für Arboviren von Vögeln auf den Menschen dienen könnten, da sie Säugetiere und Vögel als Wirte aufsuchen (Huang et al. 2009). Hybride von $C x$. p. molestus und $C x . p$. pipiens könnten daher eine Schlüsselrolle bei der Verbreitung bestimmter zoonotischer Krankheiten wie WNV spielen. Je nach Art können Stechmücken in allen drei Lebensstadien den Winter überleben (Denlinger und Armbruster 2014). Entweder überleben die Eier die kalte Jahreszeit auf trockenem Boden und schlüpfen, sobald die Temperaturen steigen und ausreichend Wasser zur Verfügung

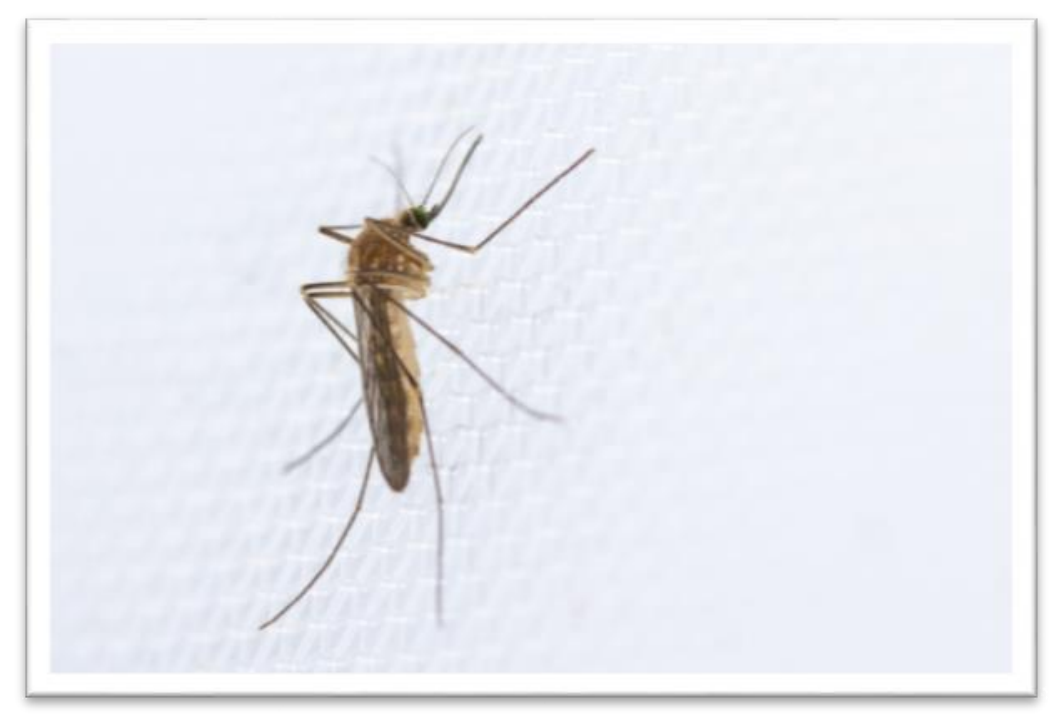

Abbildung 15: Weibchen von Culex pipiens steht, oder sie überwintern als geschlüpfte Larven unter der Eisdecke kleiner Gewässer. Das Diapausieren oder Überwintern der Weibchen in unterirdischen Systemen wie Höhlen oder Minen ist die dritte Möglichkeit. Es wird allgemein angenommen, dass begattete Weibchen von CX. p. pipiens überwintern (Sulaiman und Service 1983; Onyeka und Boreham 1987), während Cx. p. molestus dies nicht tun muss (Spielman 1964; Harbach et al. 1984; Harbach et al. 1985). Die fehlende Diapause von Cx. p. molestus kann entweder als ausgeprägte oder als unterdrückte Homodynamie auftreten (Merdić und Vujičić-Karlo 2005). Nach Kjærandsen (Kjærandsen J. 1993) überwintert Cx. pipiens in Höhlen und höhlenähnlichen Umgebungen. Höhlen werden als thermisch isolierte Systeme angesehen (Badino 2004) und die Temperatur in einer Höhle entspricht permanent ungefähr der durchschnittlichen Jahrestemperatur der umliegenden Region (Barr 1967) und schwankt nur in der Eingangszone. Höhlen werden in 
drei ökologische Zonen unterteilt: die Eingangszone, die Dämmerungszone und die Dunkelzone (Gunn 2004; Kempe und Rosendahl 2008). Es gibt verschiedene Kategorien von Höhlen, die von Höhlen mit fließendem Wasser bis zu fast vollständig trockenen Höhlen reichen (Kempe und Rosendahl 2008). Nach Buffington ist die Höhlenfeuchtigkeit kein ausschlaggebender Faktor für die Wahl eines Standortes zum Diapausieren (Buffington 1972). Ausführlich getestete Reaktionen von $C x$. fatigans auf unterschiedliche Temperaturen und Luftfeuchtigkeiten konnten jedoch die Meidung von unterirdischen Habitaten mit mehr als 95 $\%$ und weniger als $40 \%$ relativer Luftfeuchtigkeit belegen (Thomson 1938). In Anbetracht der noch ungeklärten Struktur des Culex pipiens-Komplexes sowie der Variabilität ihrer biologischen Interaktionen und der mangelnden Kenntnisse innerhalb Deutschlands ist dies die erste Studie, die die überwinternden Mücken in größerem Maßstab einbezieht. Wir untersuchten das gemeinsame Vorkommen der drei in Deutschland vorkommenden Arten des Culex pipiens-Komplexes und prüften, ob räumliche Muster innerhalb des Untersuchungsgebietes auftreten. Außerdem untersuchten wir, ob Temperatur- und Niederschlagsbedingungen in den vorangegangenen Aktivitätsphasen die Anzahl der im Winter gefundenen Mücken beeinflussen. Zusätzlich untersuchten wir, ob die Abundanz innerhalb der unterirdischen Schutzräume über die Wintermonate abnimmt und ob dieses zeitliche Muster von bestimmten unterirdischen Parametern abhängig ist. Ein Datensatz bestehend aus 8750 Individuen aus 698 unterirdischen Standorten diente als Grundlage für unsere Untersuchungen. Die Proben wurden in den Jahren 1991 bis 2014 hauptsächlich in den Wintermonaten gesammelt. Wir untersuchten eine Teilprobe von 727 Mücken aus 52 der 698 verfügbaren Standorte genetisch und verwendeten eine modifizierte Version der von (Rudolf et al. 2013) entwickelten real-time qPCR um vergleichbare Ergebnisse zu erhalten. Hinsichtlich der Verteilungsmuster der Arten wurde der gesamte Datensatz von 1827 Beprobungen und Artenzählungen verwendet. Um die Auswirkungen von Temperatur- und Niederschlagsbedingungen auf die überwinternden Populationen zu untersuchen, führten wir eine Berechnung eines generalisierten linearen Modells (GLM) durch. Da die genaue Anzahl der beobachteten Individuen bei der ursprünglichen Datenerhebung nur bis zu 20 Mücken gezählt wurde, betrachteten wir die Anzahl der überwinternden Mücken als kategorische Variable mit drei Klassen: $f=f e w, s=$ several, $m=$ many. Um die Datenqualität zu maximieren nutzten wir verschiedene Methoden um Autokorrelationen zu vermeiden, dies führte zu einem Datensatz von 271 Proben. Als erklärende Variablen betrachteten wir Temperatur und 
Niederschlag während des Frühlings (März, April, Mai), Sommers (Juni, Juli, August) und Herbstes (September, Oktober, November). Zusätzlich berücksichtigten wir den Probenahmemonat im Winter und die Höhenlage. Die Analyse wurde in R (R Core Team 2013) mit dem Paket VGLM (Yee und Wild 1996; Yee 2015) durchgeführt. Wir testeten mittels eines Chi-Quadrat-Tests auf signifikante Unterschiede in der Häufigkeit der Mücken zwischen den Wintermonaten und die Abhängigkeit von Höhlenparametern wie Feuchtigkeitsgrad, pH Auswirkung des Gesteins und der Höhlenzone. Zusätzlich führten wir weitere Analysen zur Umgebung der Probennahmestellen durch. Die Umgebung der Höhlen wurde mithilfe von Corine Land Cover-Daten (Copernicus Land Monitoring Service 2019) unter Verwendung von ArcGIS Version 10.7 (Environmental Systems 2019) charakterisiert, um mögliche Zusammenhänge aufzudecken. Die molekulare Artbestimmung zeigt ein sympatrisches Vorkommen von $C x$. p. pipiens und $C x$. torrentium in den meisten Habitaten, während es beim Vergleich verschiedener Probenahmejahre keine deutlichen Unterschiede in der Artenzusammensetzung gab. Die Anzahl der gefangenen $C x$. p. pipiens und $C x$. torrentium war von ähnlicher Größe und Verteilung, während die Unterart $C x . p$. molestus bei unseren Beprobungen sehr selten. Das GLM ergab, dass die Abundanz der überwinternden Mücken sowohl von der Höhenlage als auch der Temperatur im Sommer und Herbst und vom Niederschlag aller drei betrachteten Quartale signifikant beeinflusst wird. In unterirdischen Umgebungen, die von einer sauren Gesteinszusammensetzung umgeben waren, gab es während der Wintermonate eine signifikante Abnahme der Mückenhäufigkeit. Die Dunkelzone scheint von überwinternden Stechmücken bevorzugt zu werden, ein Ergebnis das bisher anders bekannt war (Kempe und Rosendahl 2008). Zusätzlich betrachteten wir die Landbedeckungsmerkmale der Umgebung der unterirdischen Standorte. Wir fanden signifikante Unterschiede in der Abundanz der überwinternden Mücken zwischen unterirdischen Unterschlüpfen, die von Laub- und Nadelwäldern umgeben sind, und landwirtschaftlichen Flächen und anthropogen genutzten Flächen, ein häufiges Resultat (Becker et al. 2010; Weitzel et al. 2015; Zittra et al. 2016; Zittra et al. 2017). Wir erbringen den Nachweis, dass die Witterungsbedingungen während der vorangegangenen Aktivitätsphase sowie der Zeitpunkt der Probenahme die Abundanz der Arten innerhalb der Überwinterungshöhlen im folgenden Winter beeinflussen. In den unterirdischen Schutzräumen in Hessen konnte kein räumliches Muster der Artenzusammensetzung festgestellt werden. Ähnliche Ergebnisse zeigten (Rudolf et al. 2013) mit einem 
Stichprobensatz von in Deutschland oberirdisch gesammelten Stechmücken. Für das Bundesland Hessen fanden sie mehr $C_{X}$. torrentium als $C_{X}$. $p$. pipiens und keine Proben von $C_{X}$. p. molestus. Werblow et al. (2014) stellten ein allgemeines Muster von weniger $C x$. torrentium als Cx. pipiens fest. Nach (Hesson et al. 2014) kommen $C_{x}$. torrentium und $C_{x}$. pipiens sympatrisch vor. In Mitteleuropa sind die Verbreitungsmuster der beiden Arten sehr ähnlich (Weitzel et al. 2015; Lühken et al. 2015; Zittra et al. 2016). Insgesamt scheint es, dass CX. torrentium und $C x$. p. pipiens in Mitteldeutschland gleich häufig vorkommen. Wir konnten bei unserer Beprobung ein Hybridisierungsereignis nachweisen. Obwohl mehrere Autoren bereits eine Hybridisierung zwischen Cx. p. pipiens und Cx. p. molestus (Fonseca et al. 2004; Gomes et al. 2009; Andreadis et al. 2011) vermuteten, konnten wir nicht feststellen, welche beiden der drei beprobten Arten hybridisierten. Da ihre genetischen Unterschiede insgesamt sehr gering sind (Kent et al. 2007; Vinogradova und Shaikevich 2007), ist es fraglich, ob diese beiden Arten als verschiedene Unterarten unterschieden werden sollten. Insgesamt bestätigen unsere Ergebnisse die anderen Studien und zeigen, dass es sich bei $C_{x}$. p. molestus nicht um eine unterirdische Unterart handelt, sondern eher um einen Biotyp von $C_{x}$. pipiens, der eine verschobene Nische in Richtung kleinerer Behausungen wie Tierhöhlen hat. Im Datensatz waren lediglich 22 männliche Culex-Mücken. In Anbetracht der sehr geringen Anzahl von Männchen und dem Fehlen von Cx. p. molestus oder Hybridmännchen zeigen die untersuchten hessischen $C x . p$. molestus keine Anzeichen von Homodynamie. Ähnliche Ergebnisse bestätigen unsere Annahme, dass es sich bei $C x . p$. molestus nicht um einen unterirdischen Biotyp von $C x$. p. pipiens handelt oder dass sich unterirdische Habitate besonders für die Hybridisierung eignen (Zittra et al. 2019). Unsere Ergebnisse zeigen einen negativen Effekt im Frühling und einen positiven im Sommer und Herbst, was eine Präferenz für höhere Niederschläge bestätigt, über die bereits berichtet wurde (Zittra et al. 2017; Paz und Albersheim 2008). Je später die Probenahme im Winter, desto weniger Mücken wurden in der Höhle gefunden, was durch eine andere Studie bestätigt wird (Zittra et al. 2019). Bisher war man davon ausgegangen, dass Mücken hauptsächlich in den Eingangs- und Dämmerungszonen überwintern Unsere Studie ergänzt das vorhandene Wissen über die ökologischen Ansprüche dieses Artenkomplexes. Die Standorte, ihre Eigenschaften und die Umgebung sind wichtig für das Vorkommen der Arten und schaffen räumliche Muster. Räumliche und zeitliche Muster sind besonders für Vektorarten wichtig, da sie eine schnellere Einschätzung und Anwendung der notwendigen Vorsichtsmaßnahmen ermöglichen. 


\section{Diskussion}

Im Rahmen dieser Dissertation wurden drei Einzelpublikationen vorgestellt, welche sich mit verschiedenen Aspekten ökologischer Modellierung (Projekt I, II \& III), Habitatpräferenzen (Projekt I, II \& III) und auf verschiedenen Größenebenen von Kontinental (Projekt I) über Länderebene (Projekt II) zu Bundesland und Mikrohabitaten (Projekt III) und den damit zusammenhängenden Datenqualitätsaspekten befassen. In der nachfolgenden Diskussion werden die wichtigsten Ergebnisse und Schlussfolgerungen der Einzelpublikationen aufgegriffen und unter den oben genannten Gesichtspunkten zusammenfassend erörtert. Zukünftige Fragestellungen, welche sich aus den Ergebnissen und Schlussfolgerungen ergeben, werden im Ausblick vorgestellt.

\section{Nischenmodellierung und Artverbreitung}

Nischenmodellierungen sind ein geeignetes Werkzeug, um zukünftige Ausbreitung oder aktuelle Verbreitung von Arten abzuschätzen und auf Lücken in der Überwachung, insbesondere von invasiven Arten aufmerksam zu machen. Um die Verbreitung der ausgewählten Arten zu bestimmen, wurden Nischen generiert und die bisherig bekannte Verbreitung untersucht. Die Modellierung der Nischen erfolgte in Projekt I Mithilfe von Surface Range Envelopes (SRE) in R (Projekt I, Fig. 1) in großem Maßstab mit einem Raster von 5 Bogenminuten. In Projekt II wurden durch die Nutzung eines Maximum Entropy Ansatzes in Maxent (Projekt II, Fig. 1) in mittelgroßer Skala von 30 Bogensekunden die Verbreitung modelliert. In Projekt III wurde keine Verbreitungsmodellierung durchgeführt, die punktuell untersuchten Arten jedoch auf einer Karte dargestellt (Projekt III, Fig. 1) und das Gebiet punktuell und auf kleinskaliger Ebene (einzelne Höhlen) untersucht. Um großflächige, hier über die Kontinente Europa und Asien, Verbreitungen zu bestimmen ist das SRE ein geeignetes Werkzeug. Insbesondere die Unabhängigkeit von einer flächendeckend dichten Datenlage macht es in dem Falle der Tabaniden zur besten Wahl, da Tabaniden weit verbreitet sind, jedoch in den meisten Gebieten entweder schlecht oder Lückenhaft beobachtet werden. Die klare Abgrenzung an den Gebietsrändern zeigt das Modell auf. Das Habitat hat, basierend auf den Ausprägungen an den Fundpunkten, entweder eine Eignung für die untersuchte Art oder nicht, dies wird im Abschnitt „Klimabedingungen“ näher erläutert. Eine andere Berechnungsmethode wird von Maxent implementiert, hierbei wird die Eignung der Gebiete nicht Binär wiedergegeben, sondern durch einen Verlauf von höchster Eignung zu niedrigster Eignung. Hierbei sind durch diese Darstellung und die Abstufung der Habitateignung (von 0 - 
100\%) in den Ergebnissen mehr Informationen enthalten als in der SRE Darstellung, die nur 0 oder $100 \%$ als Ergebnis zulässt (Abbildung 16). Um dieser binären Darstellung in Projekt I entgegenzuwirken und um auf die bedeutende Stichprobenverzerrung (Kapitel Datenqualität und Methodenkritik) aufmerksam zu machen, modellierten wir drei Verbreitungen mit unterschiedlichem Informationsgehalt, einmal 90\%, 95\% und 100\% der gesammelten, bereits bereinigten, Fundpunkte. Die Stichprobenverzerrung wird vor allem bei den Arten Chrysops caecutiens, Chrysops relictus und Haematopota pluvialis sichtbar (Projekt I, Fig 1.). Die Nichtberücksichtigung von lediglich 5\% der Daten reduziert das geeignete, modellierte Gebiet um etwa $80 \%$. Ein weiteres geeignetes Beispiel ist Tabanus sudeticus, hierbei entstehen bei der Nichteinbeziehung von 5\% der Daten große Lücken innerhalb sonst geeigneter Gebiete (z.B. große Teile Polens, Tchechien).

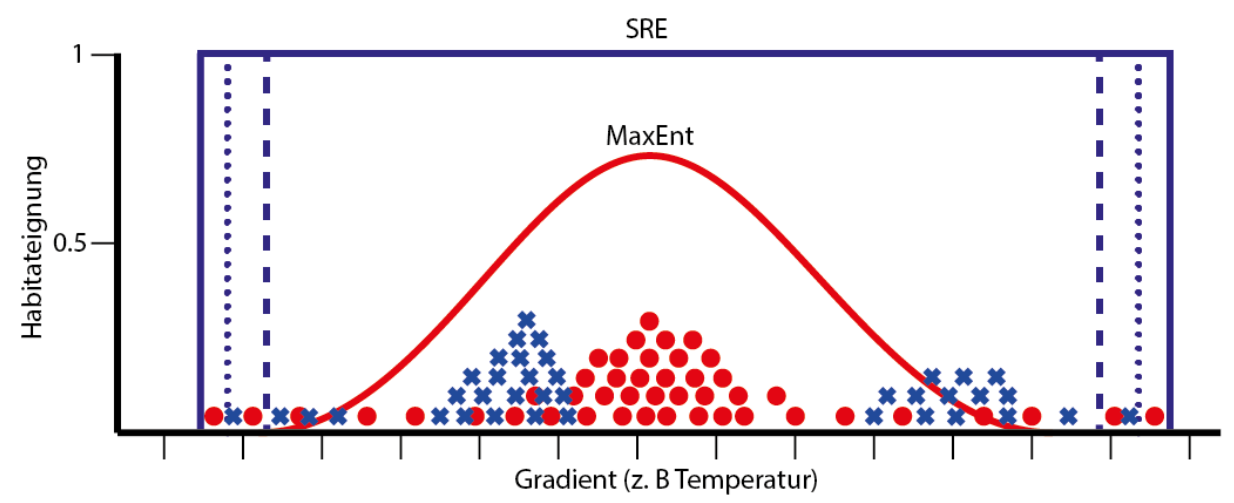

Abbildung 16: Schematische Darstellung und Vergleich der Modellierungsansätze SRE und MaxEnt. Rote Punkte stellen fiktive Datenpunkte entlang eines Umgebungsgradienten (z. B. Temperatur, Niederschlag) dar, die in diesem Falle entlang einer Optimumskurve verlaufen sind. Es wäre MaxEnt hierbei das geeignetere Modell, die Habitateignung zu berechnen. Bei anderer Verteilung (durch Verzerrung, Lücken im Gradienten, Blaue Kreuze) wäre das SRE die geeignetere Variante. Angepasste SRE Modelle sind z. B. 95\%-Modell (gepunktete Linie) oder 90\%-Modell (gestrichelte Linie).

Die Modelle wurden anhand der Datenlage gewählt und besitzen eine unterschiedliche Sensitivität gegenüber Extremwerten. Die in Projekt II verwendete Methode eignet sich hervorragend für Arten, deren Beobachtungspunkte einer Optimumskurve folgen und deren bisherige Verbreitungen gut beobachtet sind. Dies wären beispielsweise entweder bedrohte Arten oder invasive Spezies, die ein neues Habitat besiedeln und dies bekannt ist. Ebenfalls implementiert auch MaxEnt nur gesicherte Fundpunkte, erfordert also für die Berechnung keine gesicherten Punkte, an denen die Art nicht vorkommt, dies ist besonders im Hinblick auf invasive Arten, die sich noch nicht im Gleichgewicht mit den Umweltbedingungen befinden 
(Elith und Franklin 2013). Im Falle der Stechmücke Aedes albopictus handelt es sich um eine invasive Art, die erst seit wenigen Jahren in Deutschland auftritt. Die bisherige mögliche Verbreitung beschreibt sich durch 96 Fundpunkte, die in die Berechnung eingeflossen sind und begrenzt sich auf kleine und wenige Gebiete in Westdeutschland (Projekt II, Fig. 1, 20112013). Die Zukunftsprognosen, in Abhängigkeit von verschiedenen Klimavorhersagen, zeigen eine Ausbreitung der Art. Die Darstellung der Ergebnisse ist ebenfalls binär möglich, würde jedoch den Informationsgehalt senken und es nicht ermöglichen, potentielle zukünftige Ausbreitungswege zu interpretieren. Dies Informationen sind jedoch wichtig für sich ausbreitende Arten wie Aedes albopictus, im Falle der bereits etablierten und großen Flugstrecken zurücklegenden Tabanidenarten wäre die Darstellung für prozentuale Habitateignung eher abkömmlich. In Projekt III wurde aufgrund der Datenlage keine Habitateignungsmodellierung durchgeführt. In Hessen kommen die untersuchten Arten Culex pipiens pipiens und Culex torrentium ohne Ausnahme flächendeckend vor. Beide Arten sind autochthon in Hessen und in unseren Ergebnissen gibt es keine Muster der Verbreitung innerhalb der Überwinterungshabitate, beide Arten kamen in den meisten Habitaten gleichzeitig vor und durch die geringe Höhe hessischer Gebirge (höchster Berg Wasserkuppe, 950m) sind klimatisch bedingte Verbreitungsgrenzen innerhalb Hessens unwahrscheinlich.

\section{Klimabedingungen}

Als Hauptaspekt für Artverbreitung und deren Vorhersage sind im großen Rahmen die Klimabedingungen und Auswirkungen des Wetters auf die Arten wichtig. Die Auswirkungen von Klima auf das Artvorkommen wurde daher in allen drei Projekten untersucht (Projekt I, Fig. 2; Projekt II, Fig. 2; Projekt III, Fig. 3). In Projekt I und II wurden verschiedene Klimavariablen zur Berechnung von Artverbreitung und Ausbreitung genutzt. In Projekt I wurden folgende Variablen genutzt: Bio5 (höchste Temperatur des wärmsten Monats), Bio6 geringste Temperatur des kältesten Monats), Bio13 (Niederschlag des niederschlagsreichsten Monats), Bio 14 (Niederschlag des niederschlagärmsten Monats), Bio18 (Niederschlag des wärmsten Quartals) und Bio19 (Niederschlag des kältesten Quartals). Die genutzten Variablen in Projekt II waren Bio01 (Jährliche Durchschnittstemperatur), Bio10 (Durchschnittstemperatur des wärmsten Quartals), Bio11 (Durchschnittstemperatur des kältesten Quartals) und Bio12 (Jährlicher Niederschlag). Die Auswahl der Variablen erfolgte auf Basis der ökologischen Relevanz auf das Auftreten der Arten. Variablen mit nur geringfügigem Erklärungsgehalt für die Ergebnisse wurden nicht genutzt. In Projekt III 
analysierten wir innerhalb des GLM den Einfluss von Temperaturen und den Niederschlag in den Quartalen Frühling, Sommer und Herbst auf die Abundanz der Stechmücken innerhalb der Überwinterungsquartiere im Winterquartal. In Projekt I wurden verschiedene Darstellungsformen der Nischen, basierend auf den Modellen, gewählt. Für das SRE wurden Balkengrafiken gewählt (Projekt I, Fig.2), die in Kombination mit den drei Modellen (90\%, 95\%, 100\%) einen Ansatz für eine Verteilung aufzeigt. Durch Nutzung nur eines Modelles wäre lediglich eine binäre Darstellung der Ergebnisse möglich, durch die Darstellung der drei Modelle können jedoch Rückschlüsse gezogen werden, in welchen Bereichen die Arten hauptsächlich vorkommen, hierbei muss jedoch berücksichtigt werden, dass weiterhin eine Stichprobenverzerrung vorhanden ist. Im Vergleich dazu gleicht die Darstellung der Auftretenswahrscheinlichkeit des Modells aus Projekt II (Fig. 2) einer Optimumskurve. Diese Verteilung wird dabei auch in der Darstellung der Ergebnisse (Projekt I und Projekt II, Fig. 1) ersichtlich. In Projekt I war das Ziel, über eine große Fläche eine generelle Verbreitung zu modellieren, aus der Hinweise auf bisherig unbekannte aber klimatisch geeignete Gebiete gezogen werden können. Eine Optimumsverteilung von Bremsen, entlang eines Gradienten (z. B. Temperatur) oder räumlich, kann vorausgesetzt werden, da die Gruppe unter normalen Umständen weitverbreitet ist und generell keine Inselhabitate besetzt. Darauf und auf den Klimavariablen basierend konnte das SRE effektiv angewandt werden. In Projekt III wurde, auf kleinskaliger Ebene von den Klimavariablen abgeleitet, untersucht, wie sich die Stechmückenanzahlen über mehrere Monate innerhalb von Überwinterungshabitaten ändern.

\begin{tabular}{|c|c|c|c|}
\cline { 2 - 4 } & Projekt I & Projekt II & Projekt III \\
\cline { 2 - 4 } Niederschlag & $\begin{array}{c}\text { Sommer (Bio18) } \\
\text { Winter (Bio19) }\end{array}$ & Jahr (Bio12) & $\begin{array}{c}\text { Frühling } \\
\text { Sommer (Bio18*) } \\
\text { Herbst (Bio17*) }\end{array}$ \\
\cline { 2 - 4 } Temperatur & $\begin{array}{c}\text { Sommer (Bio05) } \\
\text { Winter (Bio06) }\end{array}$ & $\begin{array}{c}\text { Sommer (Bio10) } \\
\text { Winter (Bio11) } \\
\text { Jahr (Bio01) }\end{array}$ & $\begin{array}{c}\text { Fommer (Bio10*) } \\
\text { Herbst (Bio09*) }\end{array}$ \\
\cline { 2 - 4 } & Globcover & - & CLC \\
\hline
\end{tabular}

Abbildung 17: Übersicht der untersuchten Faktoren innerhalb der Projekte. Die Markierung * bedeutet, dass die untersuchten Daten mit den genannten Klimavariablen vergleichbar sind. 
Durch die Gleichmäßigkeit der Hessischen Landschaft gibt es nur wenige räumliche Unterschiede und in Kombination mit den breiten Nischen der untersuchten Arten sind Rückschlüsse auf Beeinflussung durch klimatische Faktoren und der direkten Umgebung zu erwarten. Die untersuchten Zeiträume Frühling, Sommer und Herbst entsprechen in diesem Falle den in den Klimavariablen genutzten Quartalen. Somit lässt sich die Abhängigkeit des Auftretens in Hessen als Bio10 (Durchschnittstemperatur des wärmsten Quartals; hier Temperatur Sommer) oder Bio8 (Durchschnittstemperatur des niederschlagreichsten Quartals, diese wären hierbei identisch), Bio18 (Niederschlag des wärmsten Quartals; Niederschlag Sommer, identisch hierbei mit Bio16), Bio9 (Durchschnittstemperatur des trockensten Quartals, Temperatur Herbst) und Bio17 (Niederschlag des trockensten Quartals, Niederschlag Herbst) ausdrücken. Hierbei wurde ein großer Einfluss von Temperatur und Niederschlag auf die überwinternden Mücken festgestellt. Insbesondere in den Aktivitätsmonaten der heimischen Stechmücken wirken sich höhere Temperaturen und höherer Niederschlag stark positiv auf die Individuendichte in den Winterquartieren aus. Verglichen mit Projekt II wirkt sich die Variable Bio10 mit 25,9\% auf die Vorhersage aus, während Bio01 (Jährliche Durchschnittstemperatur) ebenfalls das Auftreten mit 8,4\% erklärt. Zusammengefasst lässt sich darauf schließen, dass Stechmücken in Deutschland eine starke Abhängigkeit der Klimavariable Bio11 (Durchschnittstemperatur des kältesten Quartals) aufzeigen, also der Durchschnittstemperatur im Winter. In der Modellierung von Aedes albopictus erklärte diese Variable $49,3 \%$ des Auftretens oder der Abwesenheit der Art, während die in Projekt III untersuchten Arten durch ihre Überwinterungsphase diesem Einfluss ausweichen. Generell lässt sich dadurch ebenfalls genauer erkennen, dass Stechmücken durch ihre Ektothermie am stärksten durch den Winter und damit einhergehende Gefriertemperaturen, limitiert sind. Generell sind Jährliche Minimal- und Maximaltemperaturen, die damit korrelierte Durchschnittstemperatur und Niederschlagsmenge die Faktoren, die, je höher sie sind, Stechmücken am positivsten beeinflussen. Nur in Kombination mit darauffolgenden Frosttemperaturen (Projekt III, Fig. 3) und der einhergehende Zwang für eine Ruhephase haben sie eine negative Auswirkung und können Arten entweder an der Ausbreitung hindern oder sie dezimieren, wenn sie bereits den Reproduktionszyklus begonnen haben. Ein weiterer Faktor, der in Projekt II und Projekt III untersucht wurde ist der Einfluss der Höhenlage auf das Vorkommen der Arten. Das Auftreten von Aedes albopictus wird durch die Höhenlage zu 9,3\% erklärt, hierbei nimmt die Eignung des 
Habitats für die invasive Stechmücke mit zunehmender Höhe stetig ab bis sie ab $750 \mathrm{~m}$ in Deutschland nicht mehr vorkommt (Projekt II, Fig. 2). Hierbei ist zu beachten, dass die Höhenlage direkt mit der Temperatur korreliert und die an der Fundstelle vorgefundene Temperatur wahrscheinlich der einschränkende Faktor ist und somit keine Rückschlüsse auf Vorkommen in Höhenlagen innerhalb anderer Gebiete gezogen werden können. Zusätzlich lässt sich sagen, dass die Höhe des Geländes sich nicht auf die von uns untersuchten Tabaniden auswirkte und sie, modelliert, teilweise in Gebieten vorkommen, die beinahe zur Permafrostzone gehören. Da die Temperatur der entscheidende Faktor für die Hauptverbreitung ist und direkt mit der Höhe korreliert, wurde auf der Eurasischen Skala nur mit der Temperatur modelliert und die Höhe nicht miteinbezogen. Trotzdem ist es, aufgrund von nicht in die Berechnung mit eingeflossenen Abhängigkeiten wie Pflanzenbewuchs und damit einhergehenden Großsäugern, unwahrscheinlich, dass sie auf hohen Gebirgen vorkommen können, die in unserer Modellierung als geeignete Gebiete in Zentralasien markiert wurden. In Projekt III jedoch konnten wir durch Datenaufbereitung hinsichtlich Autokorrelationen aufzeigen, dass für die einheimischen Stechmücken die Altitude eine förderliche Auswirkung zeigt. Für Aedes albopictus ist die Höhenlage zusätzlich der einzige Faktor, der nicht entlang einer Optimumskurve verteilt ist, sondern monoton abfällt. Hinweise auf eine solche Verteilung der Datenpunkte lassen sich durch die Methodenwahl ebenfalls in die Ergebnisse aus Projekt I interpretieren, so erscheinen die Ergebnisse für Bio5 eher einer Optimumskurve zu folgen, während Bio6, Bio13 und Bio19, zumindest bei den meisten Arten, verzerrt sind. Insbesondere bei Bio6 wird ersichtlich, dass sich der Hauptteil der Vorkommensdaten nicht in Gebieten befindet, in denen es sehr niedrige Wintertemperaturen gibt. Dieses Ergebnis basiert auf der Datenlage und zeigt gleichzeitig die extreme Anpassungsfähigkeit der Tabanidenarten, die, im Gegensatz zu den untersuchten Stechmückenarten, unter diesen Umständen noch vorkommen können. Die untersuchten Tabaniden weisen eine deutlich größere Toleranz für verschiedene klimatische Bedingungen auf als Stechmücken. Vergleichbar zwischen den Projekten sind die Faktoren der Sommertemperaturen (Projekt I: Bio05, Projekt II: Bio10, Projekt III: Bio10* (vergleichbare Daten)). Eine höhere Sommertemperatur hat für alle untersuchten Arten eine förderliche Wirkung auf das Vorkommen. Diese Ergebnisse entsprechen, basierend auf dem bisherigen Wissen über diese Tiere, den Erwartungen. Zwischen den Tabaniden und den untersuchten Culiciden in Projekt III ist die Variable Bio18 vergleichbar, hier scheinen die Tabaniden deutlich 
resistenter gegen Trockenheit (abgebildet in den Faktoren durch niedrige Niederschlagsmengen) zu sein. Erklärbar ist dies durch die verschiedenen Anpassungen des Lebenszyklus der Gruppen, während Stechmücken in allen Stadien abhängig von Wasseransammlungen ohne Prädatoren sind, haben Tabaniden oftmals prädatorisch lebende Larven, die je nach Art, nicht oder nur begrenzt von Wasservorkommen abhängig sind. Insbesondere wirkt sich dies auf die Verbreitung innerhalb trockenerer Gebiete aus, die von Stechmücken aufgrund von Regenmangel nicht mehr besiedelt werden können. Die dritte Gruppe vergleichbarer Faktoren sind Bio06 in Projekt I und Bio11 in Projekt II. Bei Aedes albopictus zeigen sich, durch die knapp 50\% der Habitateignungserklärung dieses Faktors, starke Auswirkungen der Wintertemperatur auf die Ausbreitung der Art, dies ist besonders im Hinblick auf die bisher mangelnde Anpassung der Art auf diese klimatische Zone zurückzuführen, hierbei wurde die Durchschnittstemperatur des kältesten Quartals für die Modellierung genutzt, daher ist ein absoluter Vergleich mit dem Faktor der absoluten Minimaltemperatur in Projekt I nicht möglich. Jedoch zeigt sich, dass die Tabaniden deutlich toleranter für Temperaturen unter dem Gefrierpunkt sind, sodass Tabanus sudeticus, als anfälligste Art für diesen Faktor, in Gebieten mit einer Minimumtemperatur von $-17^{\circ} \mathrm{C}$ vorkommt, während Chrysops caecutiens, Chrysops relictus und Haematopota pluvialis bis zu $-52^{\circ} \mathrm{C}$ tolerieren. Dies ist wohl darauf zurückzuführen, dass diese Arten, im Vergleich zu Aedes albopictus schon eine deutlich längere Zeit in diesen Gebieten vorkommen und an die Gegebenheiten angepasst sind.

\section{Landschaftspräferenzen}

Neben den klimatischen Bedingungen wirken sich weitere, abiotische und biotische, Faktoren auf das Vorkommen der Arten aus. In Projekt I (Fig. 4) und Projekt III (Fig. 6) wurden, basierend auf den vorhandenen Vorkommensdaten, Landschaftspräferenzen und den Vorkommenshäufigkeiten innerhalb der Überwinterungsquartiere, für die beiden einheimischen Steckmückenarten und für alle sechs untersuchten Tabanidenarten generiert. Da beide Arten, sowohl Culex torrentium als auch Culex pipiens pipiens, ubiquitär und gleichzeitig auftreten, konnten hierbei keinerlei Unterschiede in den Präferenzen aufgedeckt werden. Es kann davon ausgegangen werden, dass beide Arten die gleiche oder zumindest sehr ähnliche Nische besetzen und damit ein fast deckungsgleiches Vorkommen haben, allerdings aufgrund ausreichenden Nahrungsangebotes und genügend Brutmöglichkeiten nicht miteinander konkurrieren und durch andere Faktoren wie z. B. Prädation limitiert 
werden. Für die Analyse der Landschaftspräferenzen wurden um die Fundpunkte herum an die Fluggeschwindigkeit und Reichweite der betreffenden Arten angepasste Radien gezogen und Areale generiert, die mithilfe Daten der Corine Land Cover in dominierende Landschaftstypen kategorisiert wurden. Hierbei wurden für die Stechmücken mehrere Radien $(200,400,800$ und $1600 \mathrm{~m})$ erstellt, um eventuell abweichende Auswirkungen durch einen größeren Umkreis zu erfassen. Für die Bremsen wurde, auch abhängig von mangelnden Informationen zu den Aktionsräumen der einzelnen Arten, der häufigste Landschaftstyp innerhalb für die Berechnung genutzten Fläche von 5x5 Bogenminuten (im untersuchten Gebiet ungefähr eine Fläche von $10 \times 10$ km) für diese Analyse genutzt. Beide Gruppen zeigten bei der Analyse eine Präferenz für nahgelegene menschliche Einflüsse, also Ortschaften oder andere, von Menschen regelmäßig genutzte Flächen wie Gartenanlagen. Dieser Effekt war jedoch bei den Stechmücken im kleinen Radius (200 und $400 \mathrm{~m}$ ) auffallend und verkehrte sich bei 1600 m ins Gegenteil, sodass signifikant weniger Stechmücken in den Höhlen anzutreffen waren, die als Hauptlandschaftstyp anthropogen genutzte Flächen im Umkreis hatten. Die Tabaniden zeigten eine deutliche Bevorzugung von anthropogen genutzten Flächen (als „Artificial“ bezeichnet) und es lagen zwischen 2,5 bis über 5-mal so häufig Fundpunkte in diesen Gebieten als bei einer gleichmäßigen Verteilung erwartet werden würde. Dies zeigte sich bei allen untersuchten Tabanidenarten, ist zumindest zum Teil jedoch auf die Stichprobenverzerrung zurückzuführen, der den Daten zugrunde liegt. Bei beiden Gruppen konnte aufgedeckt werden, dass zwischen Nadelwald und Laubwald keinerlei Unterschiede hinsichtlich der Bevorzugung durch die Arten vorhanden ist, bei den beiden heimischen Stechmücken ergab sich in keinem Landschaftsradius ein signifikanter Unterschied der Waldtypen. Auch die Tabaniden kamen nur geringfügig vom Erwartungswert abweichend in beiden Waldtypen und Mischwald vor, hierbei konnte jedoch noch gezeigt werden, dass lichter Nadelwald vor dicht gewachsenem Nadelwald bevorzugt wurde. Die Stechmücken zeigten in den Entfernungen 200 - 800 m ein, im Verhältnis zu anthropogen genutzten oder Landwirtschaftlichen Flächen, signifikant verringertes Vorkommen in von Laubwald dominiertem Gebiet. Dies ist ein Bild, dass bei den Tabaniden, zumindest im direkten Vergleich zwischen Laubwald und anthropogenen Flächen, ebenfalls sichtbar wird. Anbauflächen jedoch zeigen für Bremsen einen stark negativen Effekt auf die Vorkommenswahrscheinlichkeit, ein Bild, das sich von den Stechmücken ebenfalls unterscheidet. Hier steigt die Vorkommenshäufigkeit, je mehr Fläche in der Umgebung agrikulturell geprägt ist. Eine 
Erklärung hierfür wäre eine, durch die Fähigkeit der Besiedlung von kleinsten Wasseransammlungen, geringere Abhängigkeit der Stechmücken von Brutgebieten wie Gewässer oder Feuchtgebieten, die für Bremsen relevant sind, jedoch innerhalb von Agrarlandschaften häufig von Pestizidrückständen oder Überdüngung stark geschädigt sind. Für beide Arten sind höchstwahrscheinlich genug Wirtstiere wie z. B. Weidetiere, Pferde, Schweine oder auch Wildtiere auf Agrarflächen vorhanden, sodass dies als limitierender Faktor unwahrscheinlich ist. Für Aedes albopictus wurden bisherig keine Untersuchungen hinsichtlich der Landschaftspräferenzen der Art durchgeführt, sodass potentielle Zusammenhänge für diese Art unbekannt sind. Es wurden jedoch Analysen zu meteorologischen Auswirkungen auf das Vorkommen der Art sowie Abhängigkeiten innerhalb von städtischen Gebieten durchgeführt, die jedoch einen direkten Vergleich mit den Ergebnissen von Projekt I und Projekt III schwierig machen und keine direkten Rückschlüsse zulassen.

\section{Unterirdische Mikrohabitate}

Von großflächiger Verbreitung über regionale Begrenzungen kann man ebenfalls Auswirkungen diverser abiotischer Faktoren auf die direkte Verbreitung in kleinen Gebieten erfassen und Vorhersagen treffen, die auf andere Gebiete projiziert werden können. In Projekt III wurden, mithilfe einer großen und über Jahrzehnte gepflegten Datenbank, Informationen gesammelt und Rückschlüsse hingehend der Präferenz und Eignung von unterirdischen Mikrohabitaten als Überwinterungsquartier der beiden einheimischen Stechmückenarten Culex pipiens pipiens und Culex torrentium gezogen. Die genutzte Datenbank beinhaltet viele Daten über die mitaufgenommen unterirdischen Objekte und eine Vielzahl von eingetragenen und stetig aktualisierten Tierarten über die Jahrzehnte hinweg und bot eine gute Möglichkeit einen Langzeitdatensatz auszuwerten. In der Datenbank wurde im Katalogisierungsverfahren das Umgebungsgestein der Überwinterungsquartiere mitaufgenommen.

Aufgrund der Vielzahl der verschiedenen Gesteinstypen und der im Verhältnis dazu begrenzten Datenlage wurden nicht einzelne Gesteinstypen miteinander verglichen, sondern die Gesteine nach ihren chemischen Auswirkungen auf den $\mathrm{pH}$-Wert des Wassers gruppiert und die beiden Gruppen „sauer“ und „basisch“ gegeneinander verglichen. Hierbei ergab sich ein signifikantes Ergebnis innerhalb mittelmäßig feuchter oder trockener Höhlen, deren Gestein als sauer klassifiziert wurde. Die Anzahl an innerhalb der Höhle auffindbaren Mücken 
nahm, über den Datensatz, mit fortschreitender Zeit über die Wintermonate ab und war im Februar signifikant weniger Mücken auffindbar als im Dezember (Projekt III, Fig. 4). Ein Ergebnis, welches auch in feuchten und nassen Höhlen ansatzweise erkennbar war, jedoch noch keine Signifikanz zeigte.

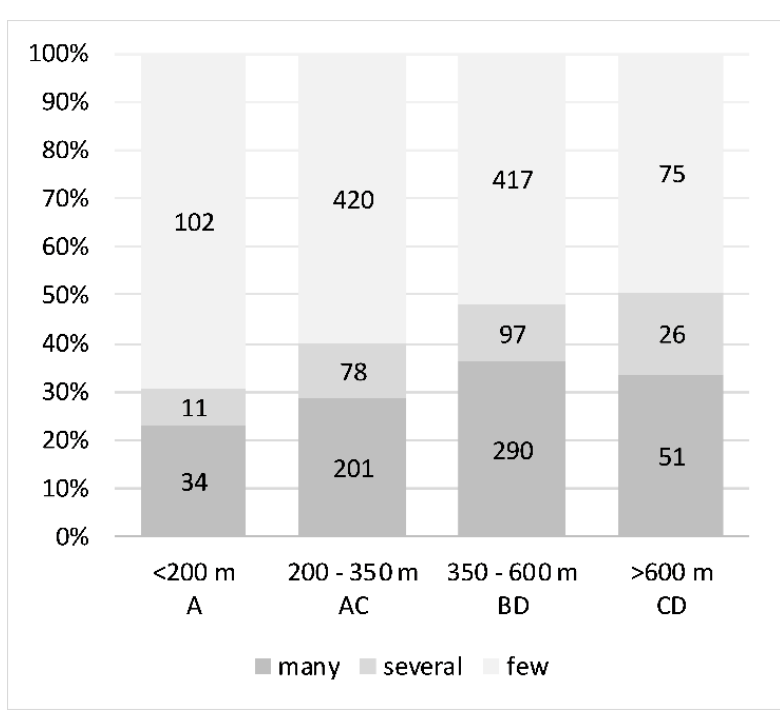

Abbildung 18: Abundanz der überwinternden Mücken in Abhängigkeit der Höhenlage der Überwinterungsquartiere

Im Gegenzug dazu war innerhalb der alkalinen Höhlen keinerlei Verringerung der Mückenzahl feststellbar. Auch konnten wir zeigen, dass, entgegen der bisherigen punktuellen Beobachtungen und Vermutungen, überwinternde Stechmücken eher die Dunkelzone innerhalb einer Höhle als Überwinterungsplatz nutzen. Zwei weitere Ergebnisse, die aufgrund des Umfanges in der Publikation ausgelassen wurden, sind Einflüsse der Höhenlage (Abbildung 18) und die Länge der unterirdischen Habitate (Abbildung 19).

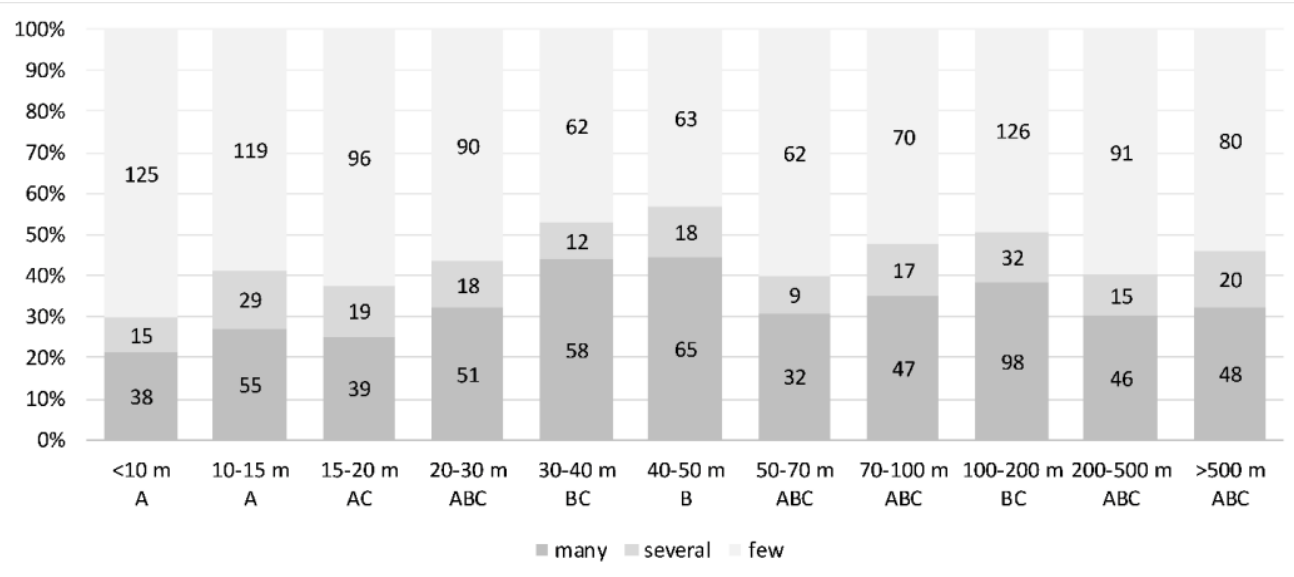

Abbildung 19: Abundanz der überwinternden Mücken in Abhängigkeit der Länge der Überwinterungsquartiere 
Wir konnten mit der Analyse zeigen, dass in Höhlen in einer Höhenlage zwischen 350 und 600 m eine signifikant höhere Abundanz überwinternder Stechmücken, im Vergleich zu Höhlen die darunterliegen, auffindbar ist. Auch gibt es signifikant mehr Mücken in Höhlen, die über 600 m ü. N. N. liegen im Vergleich zu Höhlen deren Lage unter 200 m ü. N. N. ist. Ebenfalls ein interessantes Ergebnis war, dass die untersuchten Culex-Stechmücken, entgegen bisheriger Vermutungen, Höhlen bevorzugen, die zwischen 40 und 50 Metern lang sind.

Dies deckt sich mit dem Ergebnis, dass die Dunkelzone innerhalb der Höhlen bevorzugt wird (Projekt III, Fig. 5). Höhlen jedoch, die 20 m oder weniger lang waren, wurden, im Verhältnis zu 40-50 m signifikant weniger als Überwinterungsquartier aufgesucht, ein Ergebnis, dass sich mit der Bevorzugung der Dunkelzone deckt, die in den meisten Höhlen erst nach einigen Metern beginnt und für die Stechmücken überlebenswichtige Vorteile, wie konstante Temperaturen, Luftfeuchtigkeit und wenig bis keine Luftbewegungen, für die Überwinterung präsentiert.

\section{Datenqualität und Methodenkritik}

Im Zuge unserer Berechnungen mussten die vorliegenden Datensätze von Projekt I und Projekt III stark bereinigt werden. Um Autokorrelationen wie z. B. doppelt aufgenommene Tiere innerhalb zweier benachbarter Habitate oder Einflüsse von Habitaten aufeinander und die Auswirkungen auf die Ergebnisse der Studien zu vermeiden, wurden bei verschiedenen Modellierungsansätzen bestimmte Mechanismen zur Qualitätskontrolle angewandt. Diese Notwendigkeit bestand nicht in Projekt II, da hierbei ein kleinerer Datensatz von 92 unabhängigen Fundpunkten, verteilt über Europa, für die Berechnung verwendet wurde.

In Projekt I wurden insgesamt 25701 Fundpunkte, verteilt auf die sechs untersuchten Arten, genutzt, um die Artverbreitungen und Landnutzung abzuschätzen und vorherzusagen. Basierend auf der ausgeprägten Stichprobenverzerrung wurden die Fundpunkte auf ein 5 Längenminuten-Raster übertragen und mehrfache Funde innerhalb eines Rasterfeldes auf einen Fundpunkt reduziert. Insgesamt wurden dadurch $76 \%$ der Fundpunkte aus dem Datensatz entfernt und die Modellierungen hinsichtlich der klimatischen Eignung basieren auf 6183 verbleibenden über Eurasien verteilten Fundpunkten. In Projekt III wurden, basierend auf Autokorellationswahrscheinlichkeiten, Stichprobenverzerrung und Probenqualität insgesamt 271 Nutzbare Datensätze für die Hauptanalyse verwendet. Durch die umfangreichen Maßnahmen zur statistischen Absicherung wurden von den 1827 verfügbaren 
Datensätzen fast $85 \%$ der Daten nicht für die Berechnungen der $\mathrm{pH}$-Auswirkungen und der umgebenden Landschaft verwendet. Der volle Datensatz konnte jedoch, da bei Beobachtung dieser Faktoren keine Autokorrelation möglich war, für Rückschlüsse auf die Eigenschaften innerhalb der unterirdischen Mikrohabitate herangezogen werden. Für die Analyse der umgebenden Landschaft konnten, abhängig von teilweise mangelnder Anzahl an Beprobungen innerhalb einer Kategorie und damit einhergehender statistischer Unsicherheit, erneut Daten nicht verwendet werden, sodass beim Vergleich der Umgebung in $1600 \mathrm{~m}$ Umkreis nur 170 Datensätze (9,3\%) in die Berechnung einflossen. Für die Genauigkeit der Analysen und Signifikanz der Ergebnisse, besonders für die oberirdischen Modellierungen, ist die Sicherung der Datenqualität sehr wichtig. Zur Vermeidung künstlicher Fehlerquellen in der Analyse war es notwendig, den Datensatz, basierend auf verschiedenen Qualitätssicherungsmaßnahmen, teilweise stark zu verringern.

Informationen zu den umliegenden Habitaten wirken sich, durch die Probennahme innerhalb der Höhlen, indirekt auf die Höhlenwahl zur Überwinterung aus. Es können, basierend auf der Untersuchung, hierbei keine sicheren Rückschlüsse auf die Landschaftspräferenzen hinsichtlich des kompletten Lebenszyklus getroffen werden, wie z. B. Präferenzen für die Eiablage, Paarungsschwärme oder Larvalhabitate.

Es können desweiteren beispielsweise in großflächigen Berechnungen innerhalb kleinerer Gebiete mikroklimatische Effekte auftreten, die ein Vorkommen einer Art in einem kleinen Habitat nicht zulässt, die Art jedoch um dieses Gebiet herum vorkommt. Aufgrund der fehlenden Miteinbeziehung in die Berechnung der Ergebnisse (Rasterzellen meist größer als $1 \mathrm{~km}^{2}$ ) ist dieses ausgesparte Gebiet jedoch nicht sichtbar. Um eine Überschätzung der Artverbreitung vorzubeugen kann in der Berechnung ein Prozentsatz der am meisten vom Durchschnitt abweichenden Datenpunkte von der Berechnung ausgeschlossen werden. Da das Modell hier besonders anfällig ist, wird es empfohlen die „Ausreißer“ zu entfernen. Dies kann aber besonders bei schlechter Datenlage in einigen Gebieten von großem Nachteil für die Berechnung sein. In der Analyse wurden diverse Faktoren, aufgrund ihrer fehlenden oder nur geringen Auswirkung auf die Modelle, nicht mit einbezogen. Die Sonnenscheindauer wurde nicht in die Analyse mit einbezogen, da sie bei Aedes albopictus keinen Effekt auf das Vorkommen hat (Cunze et al. 2016) und bei Voranalysen für Projekt I \& III sehr stark mit der Temperatur korreliert war. Ebenfalls ist die Höhenlage grundsätzlich stark mit der Temperatur 
korreliert, sodass in Projekt I keinerlei Aussage über Höhenpräferenzen getroffen wurde. In Projekt II konnte ein geringfügiger Zusammenhang zwischen Höhenlage und Habitateignung geschaffen werden, der jedoch auch auf die Temperatur zurückzuführen sein kann. In Projekt III konnte durch die intensive Fehlerquellenbereinigung und einem Herausfiltern der Korrelation mit der Temperatur ein Zusammenhang zwischen Höhe und Abundanz der Mücken gefunden werden. Die Auswirkungen der Parameter im Herbst wurden bei Projekt II nicht untersucht, da die Extremwerte einzelner Monatsparameter das Auftreten der Art gut beschrieben und es im Herbst keinerlei Extremwerte dahingehend gab. Auch die Wintertemperaturen wirken sich unterschiedlich auf alle drei untersuchten Gruppen aus, sodass wir keine Analyse der Wintertemperaturen und des Niederschlages bei Projekt III durchführten, da die untersuchten Arten während dieser Jahreszeit durch diese Faktoren weder beeinträchtigt noch gefördert werden.

Die Qualität der Ergebnisse dieser Modelle steht immer in direkter Abhängigkeit der Qualität der genutzten Daten. Die Ergebnisse der Modellierungen können dadurch bedingt nicht die absoluten Tatsachen widerspiegeln, sondern geben eine Einschätzung, wie die abiotischen oder auch biotischen Faktoren die Verbreitung der Arten beeinflussen. Die Wahl der Modelle, Datenaufbereinigung und anschließende Modellierungen basierten in den Projekten auf den gesammelten oder verfügbaren Datensätzen. Der Datensatz in Projekt I war behaftet mit einer starken Stichprobenverzerrung, die unter Einsatz eines SRE größtenteils ausgeglichen werden konnte. Insbesondere die Einbeziehung von an der Modellierungsgrenze liegenden Fundpunkten sind förderlich für eine verlässliche Vorhersage der tatsächlichen Verbreitung. Der Datensatz in Projekt II bestand aus weniger als 100 Fundpunkten für eine Art, die invasiv in Deutschland ist, sich weiterhin ausbreitet und noch nicht in einem ökologischen Gleichgewicht befindet. Darauf basierend ermöglichte die Nutzung von MaxEnt, trotz der geringen Fundpunktzahl, eine gute Einschätzung der aktuellen und zukünftigen Verbreitung dieser Art, deren Modellierung zukünftig mithilfe von weiteren Fundpunkdaten verbessert werden kann. Der Datensatz in Projekt III wurde angemessen mit Methoden zur statistischen Absicherung behandelt und es wurden auf den Datensatz passende und statistisch sichere Tests zur Überprüfung der Auswirkungen genutzt. Deshalb bot dieser Datensatz, obwohl er nicht auf einem Projektplan basierend gesammelt und angelegt wurde, einen großen Informationsgehalt für unsere Untersuchungen. 


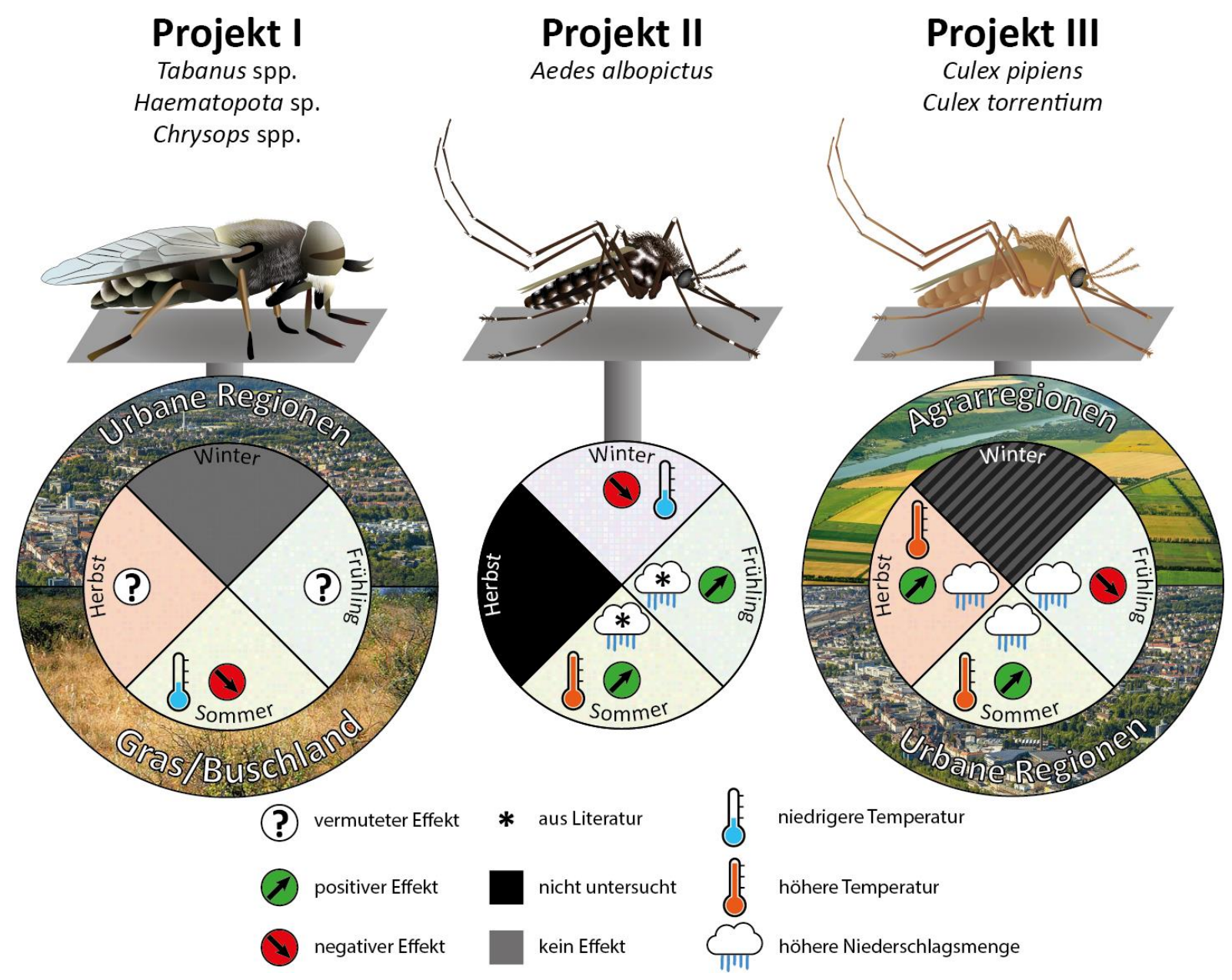

Abbildung 20: Übersicht über die Ergebnisse des Einflusses von Landschaft und Klima/Wetter aller drei Projekte. Projekt I: Die untersuchten Bremsen bevorzugen, Eurasienweit, in Reihe der Wichtigkeit, Urbane Regionen und Grasland/Buschland* (* nicht $T$. bovinus). Wintertemperaturen haben keine begrenzende Wirkung auf die untersuchten Arten. Wir vermuten Temperatur- und/oder Niederschlagsabhängigkeiten in Frühling sowie Herbst, konnten diese jedoch nicht nachweisen. Kältere Temperaturen haben im Sommer einen Ausbreitungsbegrenzenden Effekt, dieser ist jedoch, je nach Art, verschieden stark ausgeprägt. Projekt II: Niedrige Wintertemperaturen haben, in Deutschland, eine stark begrenzende Wirkung auf Aedes albopictus. Höhere Niederschlagsmengen haben im Frühling und Sommer einen positiven Effekt auf das Vorkommen der Art (Cunze et al. 2016). Höhere Sommertemperaturen haben ebenfalls einen positiven Effekt auf das Vorkommen der Art. Auswirkungen von Niederschlag und Temperatur wurden im Herbst nicht untersucht. Projekt III: Die beiden untersuchten Stechmückenarten bevorzugen, innerhalb Hessens, Agrarregionen und Urbane Regionen. Wintertemperaturen haben durch die Überwinterungsquartiere keine Auswirkungen und wurden aufgrund dessen nicht untersucht. Höhere Niederschläge haben im Frühling eine negative Auswirkung auf das Vorkommen, im Sommer und Herbst jedoch eine positive. Höhere Temperaturen haben im Sommer und Herbst eine positive Auswirkung. 


\section{Zusammenfassung}

Viele Gruppen der Lebewesen, insbesondere Insekten breiten sich durch steigende Temperaturen zunehmend in Gebieten aus, in denen sie ursprünglich nicht vorkommen (Novikov und Vaulin 2014; Bebber 2015). Hierbei ist die steigende Temperatur in verschiedenen Gebieten der Hauptfaktor für Expansionen dieser Arten in Richtung des nördlichen Polarkreises. Einige dieser Arten sind sehr tolerant für verschiedene Variablen und können damit ihr Verbreitungsgebiet deutlich nach Norden hin ausdehnen. Aufgrund steigender Temperaturen werden jedoch andere Arten in ihrem Verbreitungsgebiet eingeschränkt oder ihre Verbreitung verschiebt sich in nördliche Richtung (Ogden und Lindsay 2016; Lawler et al. 2009). Auch für die Verbreitung von Krankheiten spielen Temperaturen, Ausbreitungen oder Verbreitungsverschiebungen eine wichtige Rolle (Mordecai et al. 2019). So können, durch die Etablierung der passenden Vektoren, bisher nur in wärmeren Gebieten auftretende Krankheiten zukünftig auch in unseren Breitengraden eingeschleppt und verbreitet werden. Bremsen, invasive Stechmücken aber auch einheimische Mücken tragen alle ein Potential, verschiedenste Krankheitserreger zu verbreiten, auch wenn die Eignung als Vektor für jede Art unterschiedlich groß ausfällt und manche Arten daher kaum beobachtet und untersucht werden. Mit dem Augenmerk auf sich ändernde Verbreitungsgebiete hinsichtlich zukünftigen klimatischen Veränderungen und sich wandelnden anthropogenen Einflüssen sollten jedoch auch Arten mit bisher geringem Vektorpotential mit in Beobachtungsprogramme aufgenommen werden.

Wir untersuchten in Projekt I auf kontinentaler Skala die Verbreitung von sechs verschiedenen Bremsenarten und konnten sowohl Rückschlüsse auf eine mangelhafte Beobachtung der Arten ziehen als auch Artpräferenzen hinsichtlich der Landschaftsnutzung, Auswirkungen des Klimas auf die Verbreitung der Art und bisher unbekannte Toleranzen hinsichtlich tiefen Temperaturen und äußerst verkürzten Wärmeperioden aufdecken. Eine Größenordnung niedriger wurde in Projekt II, basierend auf aktuellen und Vergangenen Klimadaten, die zukünftige und aktuelle Verbreitung einer invasiven, sich zukünftig ausbreitenden Stechmückenart innerhalb Deutschlands modelliert. Durch bisherig im Untersuchungsgebiet nur begrenztes Auftreten konnten noch keine Rückschlüsse auf die unterschiedlichen Präferenzen für das Habitat gezogen werden, es können jedoch für zukünftige Berechnungen Habitatpräferenzen aus anderen Gebieten hinzugezogen werden um die Art und ihre fortschreitende Ausbreitung genauer zu beobachten. Auf der kleinsten untersuchten Ebene 
konnten in Projekt III innerhalb eines Mikrohabitates verschiedenste Rückschlüsse auf limitierende oder förderliche abiotische Faktoren, die teilweise bisherig nicht oder nur geringfügig beobachtet wurden, gezogen werden. Ebenfalls konnten Auswirkungen der umgebenden Landschaft auf die Abundanzen der Tiere beobachtet werden. Mithilfe von verschiedenen Modellen und in Abhängigkeit von Klimakarten, Landbedeckungsdaten und Landnutzung sowie Eigenschaften und Toleranzen der untersuchten Arten lassen sich in verschiedenen Größenordnungen geeignete Habitate von einheimischen sowie invasiven Arten identifizieren und zukünftige Verbreitungen effizient vorhersagen.

Insgesamt können, basierend auf all diesen Daten, dadurch für alle untersuchten Faktoren Modelle auf andere Gebiete übertragen werden um somit potentielle Verbreitungen dort vorherzusagen. Auf unseren Daten basierend können so zum Beispiel Modellierungen für die potentielle Ausbreitung der untersuchten Tabaniden innerhalb anderer Kontinente berechnet werden und Monitoringprogramme können die Ergebnisse unserer Studie als Startpunkt aufgreifen, um durch Beprobung an modellierten Standorten die Korrektheit unserer Modelle zu überprüfen und sowohl Landschaftstypen als auch Artzusammensetzung aufzunehmen um das Modell zu bestätigen oder zu verbessern. Die Modellierung der invasiven Art Aedes albopictus bietet die Möglichkeit, diese Art in Zukunft innerhalb der möglichen Ausbreitungskorridore genauer $\mathrm{zu}$ beobachten um ihre fortschreitende Verbreitung $\mathrm{zu}$ verifizieren oder eventuelle Änderungen des klimatischen Verlaufes mit einzubinden und das Modell anzupassen. Die Untersuchung des Mikrohabitats von Culex pipiens pipiens und Culex torrentium bietet, auch hinsichtlich anderer Arten in diesem Habitat, eine potente Methode, Vorhersagen für Artvorkommen innerhalb anderer Unterirdischen Objekte zu berechnen. Hier können, bei ausreichend großer Datenlage, eine Vielzahl von Faktoren in die Auswertung mit einfließen.

Die durchgeführten Studien bestätigen die Notwendigkeit für verbesserte Monitoringkonzepte für alle vektorkompetenten Tiergruppen hinsichtlich der sich ändernden klimatischen Bedingungen, des globalen Handels und die sich wandelnde Nutzung der Landschaften durch den Menschen und darin begründete Veränderungen der Artenzusammensetzung eines Habitates, zeigen Möglichkeiten, diese Konzepte mit bisher ungenutzten Daten aufzubauen und zu verbessern und können gleichzeitig zu deren Verbesserung herangezogen werden. 


\section{Literaturverzeichnis}

Adhami, J; Reiter, P (1998): Introduction and establishment of Aedes (Stegomyia) albopictus Skuse (Diptera: Culicidae) in Albania. In: Journal of the American Mosquito Control Association 14, S. 340.

Al-Jaran, TK; Katbeh-Bader, AM (2001): Laboratory Studies on the Biology of Culiseta longiareolata (Macquart) (Diptera: Culicidae). In: Aquatic Insects 23 (1), S. 11-22. DOI: 10.1076/aqin.23.1.11.4928.

Alto, BW; Juliano, SA (2001): Precipitation and temperature effects on populations of Aedes albopictus (Diptera: Culicidae): implications for range expansion. In: Journal of Medical Entomology 38 (5), S. 646-656. DOI: 10.1603/0022-2585-38.5.646.

Alvarez-García, G; Frey, CF; Mora, LMO; Schares, G (2013): A century of bovine besnoitiosis: an unknown disease re-emerging in Europe. In: Trends in Parasitology 29 (8), S. 407-415. DOI: 10.1016/j.pt.2013.06.002.

Amara Korba, R; Alayat, MS; Bouiba, L; Boudrissa, A; Bouslama, Z et al. (2016): Ecological differentiation of members of the Culex pipiens complex, potential vectors of West Nile virus and Rift Valley fever virus in Algeria. In: Parasites \& Vectors 9 (1), S. 1405. DOI: 10.1186/s13071-016-1725-9.

Andreadis, TG (2012): The contribution of Culex pipiens complex mosquitoes to transmission and persistence of West Nile virus in North America. In: Journal of the American Mosquito Control Association 28 (4 Suppl), S. 137-151. DOI: 10.2987/8756-971X-28.4s.137.

Andreadis, TG; Huang, S; Molaei, G (2011): Reexamination of Culex pipiens Hybridization Zone in the Eastern United States by Ribosomal DNA-Based Single Nucleotide Polymorphism Markers. In: The American Journal of Tropical Medicine and Hygiene 85 (3), S. 434-441. DOI: 10.4269/ajtmh.2011.10-0679.

Andreeva, R; Altunsoy, F; Kılıç, YA (2009): New contribution to information about Tabanidae (Diptera) adult and larvae from West Anatolia. In: Journal of the Entomological Research Society 11 (3), S. 19-30.

Andreeva, RV (1982): On ecologo-morphological typing of tabanid larvae (Diptera, Tabanidae). In: Entomological Review 64, S. 49-54.

Andreeva, RV (1990): Opredelitel lichinok slepnei (Evropeiskaya chast SSSR, Kavkaz i Srednaya Azia). Kiev: Naukova Dumka.

Aranda, C; Eritja, R; Roiz, D (2006): First record and establishment of the mosquito Aedes albopictus in Spain. In: Medical and Veterinary Entomology 20 (1), S. 150-152. DOI: 10.1111/j.1365-2915.2006.00605.x.

Arino, O (2010): GlobCover 2009. 
Arthur, BJ; Emr, KS; Wyttenbach, RA; Hoy, RR (2014): Mosquito (Aedes aegypti) flight tones: frequency, harmonicity, spherical spreading, and phase relationships. In: The Journal of the Acoustical Society of America 135 (2), S. 933-941. DOI: 10.1121/1.4861233.

Aubry, KB; Raley, CM; McKelvey, KS (2017): The importance of data quality for generating reliable distribution models for rare, elusive, and cryptic species. In: PloS one 12 (6), e0179152. DOI: 10.1371/journal.pone.0179152.

Austin, MP; Nicholls, AO; Margules, CR (1990): Measurement of the Realized Qualitative Niche: Environmental Niches of Five Eucalyptus Species. In: Ecological Monographs 60 (2), S. 161-177. DOI: 10.2307/1943043.

Awasthi, AK; Wu, C-H; Hwang, J-S (2012): Diving as an anti-predator behavior in mosquito pupae. In: Zoological Studies 51 (8), S. 1225-1234.

Azari-Hamidian, S; Harbach, RE (2009): Keys to the adult females and fourth-instar larvae of the mosquitoes of Iran (Diptera: Culicidae). In: Zootaxa 2078 (1), S. 1-33. DOI:

10.11646/zootaxa.2078.1.1.

Badino, G (2004): Cave temperatures and global climatic change. In: International Journal of Speleology 33 (1/4), S. 103-113. DOI: 10.5038/1827-806X.33.1.10.

Bagnarelli, P; Marinelli, K; Trotta, D; Monachetti, A; Tavio, M et al. (2011): Human case of autochthonous West Nile virus lineage 2 infection in Italy, September 2011. In:

Eurosurveillance 16 (43), S. 20002.

Bailey, NS (1948): The Hovering and Mating of Tabanidae: a Review of the Literature with Some Original Observations. In: Annals of the Entomological Society of America 41 (4), S. 403-412. DOI: 10.1093/aesa/41.4.403.

Baldacchino, F; Desquesnes, M; Mihok, S; Foil, LD; Duvallet, G et al. (2014a): Tabanids: neglected subjects of research, but important vectors of disease agents! In: Infection, Genetics and Evolution 28, S. 596-615. DOI: 10.1016/j.meegid.2014.03.029.

Baldacchino, F; Krčmar, S; Bernard, C; Manon, S; Jay-Robert, P (2017): The impact of land use and climate on tabanid assemblages in Europe. In: Agriculture, Ecosystems \& Environment 239, S. 112-118. DOI: 10.1016/j.agee.2017.01.003.

Baldacchino, F; Puech, L; Manon, S; Hertzog, LR; Jay-Robert, P (2014b): Biting behaviour of Tabanidae on cattle in mountainous summer pastures, Pyrenees, France, and effects of weather variables. In: Bulletin of Entomological Research 104 (4), S. 471-479. DOI: 10.1017/S0007485314000170.

Barashkova, Al; Reshetnikov, AD (2014): Investigation into the Practical Use of Means and Methods for Protection of Farm Animals from Blood-Sucking Dipterous Insects in Yakutia. In: Барашкова, Решетников 36 (3), S. 7-13.

Barashkova, Al; Reshetnikov, AD (2017): Traps effectiveness in the fight against Horse Flies (Diptera, Tabanidae) on Alas pastures. In: Асрарныц весмнцк Урала 155 (1), S. 4-7.

Barr, AR (1967): Occurrence and distribution of the Culex pipiens complex. In: Bulletin of the World Health Organization 37 (2), S. 293-296. 
Bebber, DP (2015): Range-expanding pests and pathogens in a warming world. In: Annual review of phytopathology 53, S. 335-356. DOI: 10.1146/annurev-phyto-080614-120207.

Becker, N (2008): Influence of climate change on mosquito development and mosquitoborne diseases in Europe. In: Parasitology Research 103 Suppl 1 (S1), S19-28. DOI: 10.1007/s00436-008-1210-2.

Becker, N; Geier, M; Balczun, C; Bradersen, U; Huber, K et al. (2013): Repeated introduction of Aedes albopictus into Germany, July to October 2012. In: Parasitology Research 112 (4), S. 1787-1790. DOI: 10.1007/s00436-012-3230-1.

Becker, N; Petric, D; Zgomba, M; Boase, C; Madon, M; Dahl, C; Kaiser, A (2010): Mosquitoes and Their Control. 2nd ed. Heidelberg: Springer.

Belkin, JN (1962): The Mosquitoes of the South Pacific (Diptera, Culicidae), Vol. 2: Cambridge University Press.

Bellmann, H (1999): Der neue Kosmos-Insektenführer. Extra: die wichtigsten Spinnentiere. Stuttgart: Kosmos (Kosmos-Naturführer).

Benedict, MQ; Levine, RS; Hawley, WA; Lounibos, LP (2007): Spread of the tiger: global risk of invasion by the mosquito Aedes albopictus. In: Vector-Borne and Zoonotic Diseases 7 (1), S. 76-85. DOI: 10.1089/vbz.2006.0562.

Benelli, G (2015): The best time to have sex: mating behaviour and effect of daylight time on male sexual competitiveness in the Asian tiger mosquito, Aedes albopictus (Diptera: Culicidae). In: Parasitology Research 114 (3), S. 887-894. DOI: 10.1007/s00436-014-4252-7.

Benelli, G; Mehlhorn, H (2016): Declining malaria, rising of dengue and Zika virus: insights for mosquito vector control. In: Parasitology Research 115 (5), S. 1747-1754. DOI: 10.1007/s00436-016-4971-z.

Benoit, JB; Denlinger, DL (2007): Suppression of water loss during adult diapause in the northern house mosquito, Culex pipiens. In: The Journal of Experimental Biology 210 (Pt 2), S. 217-226. DOI: 10.1242/jeb.02630.

Bentley, MD; Day, JF (1989): Chemical ecology and behavioral aspects of mosquito oviposition. In: Annual Review of Entomology 34 (1), S. 401-421. DOI:

10.1146/annurev.en.34.010189.002153.

Benton, TG; Bryant, DM; Cole, L; Crick, HQP (2002): Linking agricultural practice to insect and bird populations: a historical study over three decades. In: Journal of Applied Ecology 39 (4), S. 673-687. DOI: 10.1046/j.1365-2664.2002.00745.x.

Böse, R; Friedhoff, KT; Olbrich, S; Büscher, G; Domeyer, I (1987): Transmission of Trypanosoma theileri to cattle by Tabanidae. In: Parasitology Research 73 (5), S. 421-424. DOI: $10.1007 /$ bf00538199.

Bowman, Rl; Billeb, SL (1965): Blood-eating in a Galápagos finch. In: Living Bird 4, S. 29-44. Brady, OJ; Golding, N; Pigott, DM; Kraemer, MUG; Messina, JP et al. (2014): Global temperature constraints on Aedes aegypti and Ae. albopictus persistence and competence for dengue virus transmission. In: Parasites \& Vectors 7 (1), S. 1-17. 
Briegel, H (1969): Untersuchungen zum Aminosäuren- und Proteinstoffwechsel während der autogenen und anautogenen Eireifung von Culex pipiens. In: Journal of Insect Physiology 15 (7), S. 1137-1166. DOI: 10.1016/0022-1910(69)90225-x.

Briegel, H; Waltert, A; Kuhn, AR (2001): Reproductive physiology of Aedes (Aedimorphus) vexans (Diptera: Culicidae) in relation to flight potential. In: Journal of Medical Entomology 38 (4), S. 557-565. DOI: 10.1603/0022-2585-38.4.557.

Brogdon, WG (1994): Measurement of flight tone differences between female Aedes aegypti and A. albopictus (Diptera: Culicidae). In: Journal of Medical Entomology 31 (5), S. 700-703. DOI: 10.1093/jmedent/31.5.700.

Buffington, JD (1972): Hibernaculum Choice in Culex Pipiens. In: Journal of Medical Entomology 9 (2), S. 128-132. DOI: 10.1093/jmedent/9.2.128.

Burgess, NRH; Shuttleworth, AE; Chetwyn, KN (1978): The Immature Stages of the Common Cleg Haematopota pluvialis L. (Diptera: Tabanidae): In the Field and in the Laboratory. In: Journal of the Royal Army Medical Corps 124 (1), S. 27-30. DOI: 10.1136/jramc-124-01-07.

Byers, JE (2009): Including parasites in food webs. In: Trends in Parasitology 25 (2), S. 55-57. DOI: 10.1016/j.pt.2008.11.003.

Carey, PD (1996): DISPERSE: A Cellular Automaton for Predicting the Distribution of Species in a Changed Climate. In: Global Ecology and Biogeography Letters 5 (4/5), S. 217. DOI: $10.2307 / 2997790$.

Catalogue of Life (2019): Species 2000 \& ITIS Catalogue of Life, zuletzt aktualisiert am 2019. Cator, LJ; Arthur, BJ; Harrington, LC; Hoy, RR (2009): Harmonic convergence in the love songs of the dengue vector mosquito. In: Science 323 (5917), S. 1077-1079. DOI:

10.1126/science.1166541.

Catts, EP; Olkowski, W (1972): Biology of Tabanidae (Diptera): Mating and Feeding Behavior of Chrysops fuliginosus. In: Environmental Entomology 1 (4), S. 448-453. DOI:

10.1093/ee/1.4.448.

Celis-Murillo, A; Schelsky, W; Benson, TJ; Louder, MIM; Ward, MP (2017): Patterns, correlates, and paternity consequences of extraterritorial foray behavior in the field sparrow (Spizella pusilla): an automated telemetry approach. In: Behavioral Ecology and Sociobiology 71 (2). DOI: 10.1007/s00265-017-2273-9.

Charlwood, JD; Pinto, J; Sousa, CA; Madsen, H; Ferreira, C et al. (2002): The swarming and mating behaviour of Anopheles gambiae s.s. (Diptera: Culicidae) from São Tomé Island. In: Journal of Vector Ecology 27, S. 178-183.

Cheng, TC (1986): General Parasitology. 2nd ed. Oxford: Elsevier Science. Online verfügbar unter http://site.ebrary.com/lib/alltitles/docDetail.action?doclD=10697255.

Chippaux, J-P; Bouchité, B; Demanou, M; Morlais, I; Le Goff, G (2000): Density and dispersal of the loaiasis vector Chrysops dimidiata in southern Cameroon. In: Medical and Veterinary Entomology 14 (3), S. 339-344. DOI: 10.1046/j.1365-2915.2000.00249.x. 
Chvála, M; Ježek, J (1997): Diptera, Tabanidae, Horse flies. In: Anders Nilsson (Hg.): Odonata, Diptera. Stenstrup: Apollo Books (Aquatic insects of North Europe, a taxonomic handbook / ed. by Anders Nilsson; Vol. 2).

Chvála, M; Lyneborg, L; Moucha, J (1972): The Horse Flies of Europe (Diptera, Tabanidae). Copenhagen: Entomological Society of Copenhagen.

Clark, CG; Diamond, LS (2002): Methods for cultivation of luminal parasitic protists of clinical importance. In: Clinical Microbiology Reviews 15 (3), S. 329-341. DOI:

10.1128/CMR.15.3.329-341.2002.

Copernicus Land Monitoring Service (2019): Corine Land Cover Data: European Environment Agency (EEA).

Coquillett, DW (1898): Report on a collection of Japanese Diptera, presented to the U.S. national museum by the Imperial University of Tokyo. In: Proceedings of the United States National Museum 21, S. 301-340.

Costa, GC; Nogueira, C; Machado, RB; Colli, GR (2010): Sampling bias and the use of ecological niche modeling in conservation planning: a field evaluation in a biodiversity hotspot. In: Biodiversity and Conservation 19 (3), S. 883-899. DOI: 10.1007/s10531-0099746-8.

Cunze, S; Kochmann, J; Koch, LK; Klimpel, S (2016): Aedes albopictus and Its Environmental Limits in Europe. In: PloS one 11 (9), e0162116. DOI: 10.1371/journal.pone.0162116.

Czihak, G; Langer, H; Ziegler, H; Blüm, V (Hg.) (1984): Biologie. Ein Lehrbuch ; mit 1235 zum Teil mehrfarbarbigen Abbildungen und 2 Falttafel. 3., völlig neubearb. Aufl.; korr. und erg. Nachdr. Berlin: Springer.

Dalla Pozza G, Majjori G (1992): First record of Aedes albopictus establishment in Italy. J Am Mosq Control Assoc 8:318-320. In: Journal of the American Mosquito Control Association 8, S. 318.

Danasekaran, R; Mani, G; Annadurai, K; Ramasamy, J (2014): Small Bite, Big Threat: The Burden of Vector-borne Diseases. In: Iranian Journal of Public Health 43 (7), S. 1014-1015.

Day, JF (2016): Mosquito Oviposition Behavior and Vector Control. In: Insects 7 (4), S. 65. DOI: $10.3390 /$ insects 7040065 .

Denlinger, DL; Armbruster, PA (2014): Mosquito diapause. In: Annual Review of Entomology 59, S. 73-93. DOI: 10.1146/annurev-ento-011613-162023.

Dennis, RL; Thomas, CD (2000): Bias in butterfly distribution maps: the influence of hot spots and recorder's home range. In: Journal of Insect Conservation 4 (2), S. 73-77.

Deplazes, P; Eckert, J; Samson-Himmelstjerna, G von; Zahner, H (2013): Lehrbuch der Parasitologie für die Tiermedizin. 3., überarbeitete Auflage. Stuttgart: Enke Verlag.

Deslongchamps, P; Tourneur, JC (1980): Head capsule growth and early sexual dimorphism in Culex quinquefasciatus Say (Diptera: Culicidae). In: Mosquito News 40, S. 351-355.

Di Luca, M; Toma, L; Severini, F; Boccolini, D; D'Avola, S et al. (2017): First record of the invasive mosquito species Aedes (Stegomyia) albopictus (Diptera: Culicidae) on the 
southernmost Mediterranean islands of Italy and Europe. In: Parasites \& Vectors 10 (1), S. 543. DOI: 10.1186/s13071-017-2488-7.

Dirie, MF; Bornstein, S; Wallbanks, KR; Stiles, JK; Molyneux, DH (1990): Zymogram and lifehistory studies on trypanosomes of the subgenus Megatrypanum. In: Parasitology Research 76 (8), S. 669-674. DOI: 10.1007/bf00931085.

Downes, JA (1966): Observations on the Mating Behaviour of the Crab Hole Mosquito Deinocerites cancer (Diptera: Culicidae). In: The Canadian Entomologist 98 (11), S. 11691177. DOI: 10.4039/ent981169-11.

ECDC (2015a): Aedes albopictus - Factsheet for experts. Online verfügbar unter http://ecdc.europa.eu/en/healthtopics/vectors/mosquitoes/Pages/aedes-albopictus.aspx, zuletzt geprüft am Mi, 06, 01, 2021.

ECDC (2015b): Surveillance and disease data for disease vectors. Online verfügbar unter http://ecdc.europa.eu/en/healthtopics/vectors/vector-maps/Pages/VBORNET_maps.aspx, zuletzt geprüft am Mi, 06, 01, 2021.

Edwards, FW; Oldroyd, H; Smart, J (1939): British Blood-Sucking Flies. In: British BloodSucking Flies.

Egri, Á; Blahó, M; Sándor, A; Kriska, G; Gyurkovszky, M et al. (2012): New kind of polarotaxis governed by degree of polarization: attraction of tabanid flies to differently polarizing host animals and water surfaces. In: Die Naturwissenschaften 99 (5), S. 407-416. DOI: 10.1007/s00114-012-0916-2.

Elith, J; Franklin, J (2013): Species Distribution Modeling. In: Encyclopedia of Biodiversity: Second Edition, S. 692-705. DOI: 10.1016/B978-0-12-384719-5.00318-X.

Elith, J; H. Graham, C; P. Anderson, R; Dudík, M; Ferrier, S et al. (2006): Novel methods improve prediction of species' distributions from occurrence data. In: Ecography 29 (2), S. 129-151. DOI: 10.1111/j.2006.0906-7590.04596.x.

Ellenberg, H; Dierschke, H (2010): Vegetation Mitteleuropas mit den Alpen. In ökologischer, dynamischer und historischer Sicht; 203 Tabellen. Unter Mitarbeit von Christoph Leuschner. 6., vollständig neu bearbeitete und stark erweiterte Auflage. Stuttgart: Verlag Eugen Ulmer (UTB Botanik, Ökologie, Agrar- und Forstwissenschaften, Geographie, 8104).

Engelhardt, W (1989): Was lebt in Tümpel, Bach und Weiher? Pflanzen und Tiere unserer Gewässer; eine Einführung in die Lehre vom Leben der Binnengewässer. 13. Aufl. Stuttgart: Franckh (Kosmos-Naturführer).

Environmental Systems (2019): ArcGIS Desktop. Version 10.7. Redlands, CA.

Eritja, R; Escosa, R; Lucientes, J; Marquès, E; Roiz, D et al. (2005): Worldwide invasion of vector mosquitoes: present European distribution and challenges for Spain. In: Biological Invasions 7 (1), S. 87-97. DOI: 10.1007/s10530-004-9637-6.

Fairchild, GB (1969): Climate and the Phylogeny and Distribution of Tabanidae. In: Bulletin of the Entomological Society of America 15 (1), S. 7-11. DOI: 10.1093/besa/15.1.7. 
Falkowski, P; Knoll, AH (2011): Evolution of Primary Producers in the Sea. San Diego: Elsevier Science.

Faraji, A; Egizi, A; Fonseca, DM; Unlu, I; Crepeau, T et al. (2014): Comparative host feeding patterns of the Asian tiger mosquito, Aedes albopictus, in urban and suburban Northeastern USA and implications for disease transmission. In: PLoS Neglected Tropical Diseases 8 (8), e3037. DOI: 10.1371/journal.pntd.0003037.

Farnesi, LC; Vargas, HCM; Valle, D; Rezende, GL (2017): Darker eggs of mosquitoes resist more to dry conditions: Melanin enhances serosal cuticle contribution in egg resistance to desiccation in Aedes, Anopheles and Culex vectors. In: PLOS Neglected Tropical Diseases 11 (10), e0006063. DOI: 10.1371/journal.pntd.0006063.

Fawaz, EY; Allan, SA; Bernier, UR; Obenauer, PJ; Diclaro, JW (2014): Swarming mechanisms in the yellow fever mosquito: aggregation pheromones are involved in the mating behavior of Aedes aegypti. In: Journal of Vector Ecology 39 (2), S. 347-354. DOI: 10.1111/jvec.12110.

Ficetola, GF; Lunghi, E; Canedoli, C; Padoa-Schioppa, E; Pennati, R et al. (2018): Differences between microhabitat and broad-scale patterns of niche evolution in terrestrial salamanders. In: Scientific Reports 8 (1), S. 10575. DOI: 10.1038/s41598-018-28796-x.

Fick, SE; Hijmans, RJ (2017): Worldclim 2: New 1-km spatial resolution climate surfaces for global land areas. International Journal of Climatology.

Fischer, D; Thomas, SM; Neteler, M; Tjaden, NB; Beierkuhnlein, C (2014): Climatic suitability of Aedes albopictus in Europe referring to climate change projections: comparison of mechanistic and correlative niche modelling approaches. In: Eurosurveillance 19 (6), S. 20696.

Fischer, D; Thomas, SM; Niemitz, F; Reineking, B; Beierkuhnlein, C (2011): Projection of climatic suitability for Aedes albopictus Skuse (Culicidae) in Europe under climate change conditions. In: Global and Planetary Change 78 (1-2), S. 54-64. DOI:

10.1016/j.gloplacha.2011.05.008.

Flint, SJ (2000): Principles of virology. Molecular biology, pathogenesis, and control. Washington, DC: ASM Press.

Foil, LD (1989): Tabanids as vectors of disease agents. In: Parasitology Today 5 (3), S. 88-96. DOI: 10.1016/0169-4758(89)90009-4.

Foil, LD; Hogsette, JA (1994): Biology and control of tabanids, stable flies and horn flies. In: Revue Scientifique et Technique 13 (4), S. 1125-1158. DOI: 10.20506/rst.13.4.821.

Fonseca, DM; Keyghobadi, N; Malcolm, CA; Mehmet, C; Schaffner, F et al. (2004): Emerging vectors in the Culex pipiens complex. In: Science 303 (5663), S. 1535-1538. DOI: 10.1126/science.1094247.

Forskål, P (1775): Flora ÆEgyptiaco-Arabica sive descriptiones plantarum quas per ægytum inferiorem et arabiam felicem detexit, illustravit Petrus Forskål. Post mortem auctoris edidit Carsten Niebuhr. 
Fourcade, Y; Engler, JO; Rödder, D; Secondi, J (2014): Mapping species distributions with MAXENT using a geographically biased sample of presence data: a performance assessment of methods for correcting sampling bias. In: PloS one 9 (5), e97122. DOI:

10.1371/journal.pone.0097122.

Frouz, J (2001): Use of soil dwelling Diptera (Insecta, Diptera) as bioindicators: a review of ecological requirements and response to disturbance. In: Maurizio G. Paoletti ( $\mathrm{Hg}$.): Invertebrate biodiversity as bioindicators of sustainable landscapes. Practical use of invertebrates to assess sustainable land use. 1. ed., 2. impr. Amsterdam: Elsevier (Agriculture ecosystems \& environment Special issue, 74,1/3), S. 167-186.

Giatropoulos, A; Emmanouel, N; Koliopoulos, G; Michaelakis, A (2012): A study on distribution and seasonal abundance of Aedes albopictus (Diptera: Culicidae) population in Athens, Greece. In: Journal of Medical Entomology 49 (2), S. 262-269. DOI:

10.1603/ME11096.

Gjenero-Margan; B Aleraj; D Krajcar; V Lesnikar; A Klobučar et al. (2011): Autochthonous dengue fever in Croatia, August-September 2010. In: Eurosurveillance 16 (9), S. 19805. DOI: 10.2807/ese.16.09.19805-en.

Gjullin, CM; Yates, WW; Stage, HH (1950): Studies on Aedes vexans (Meig.) and Aedes sticticus (Meig.), Flood-Water Mosquitoes, in the Lower Columbia River Valley. In: Annals of the Entomological Society of America 43 (2), S. 262-275. DOI: 10.1093/aesa/43.2.262.

Gomes, B; Sousa, CA; Novo, MT; Freitas, FB; Alves, R et al. (2009): Asymmetric introgression between sympatric molestus and pipiens forms of Culex pipiens (Diptera: Culicidae) in the Comporta region, Portugal. In: BMC Evolutionary Biology 9 (1), S. 262. DOI: 10.1186/14712148-9-262.

Gomes, B; Sousa, CA; Vicente, JL; Pinho, L; Calderón, I et al. (2013): Feeding patterns of molestus and pipiens forms of Culex pipiens (Diptera: Culicidae) in a region of high hybridization. In: Parasites \& Vectors 6, S. 93. DOI: 10.1186/1756-3305-6-93.

Gould, EA; Gallian, P; Lamballerie, X de; Charrel, RN (2010): First cases of autochthonous dengue fever and chikungunya fever in France: from bad dream to reality! In: Clinical Microbiology and Infection 16 (12), S. 1702-1704. DOI: 10.1111/j.1469-0691.2010.03386.x.

Graham, NL; Stoffolano, JG (1983): Relationship between Female Size, Type of Egg Mass Deposited, and Description of the Oviposition Behavior of the Sibling Species Tabanus nigrovittatus and T. simulans (Diptera: Tabanidae). In: Annals of the Entomological Society of America 76 (4), S. 699-702. DOI: 10.1093/aesa/76.4.699.

Grulet, O; Humphery-Smith, I; Sunyach, C; Le Goff, F; Chastel, C (1993): 'Spiromed': a rapid and inexpensive Spiroplasma isolation technique. In: Journal of Microbiological Methods 17 (2), S. 123-128. DOI: 10.1016/0167-7012(93)90005-3.

Guagliardo, SA; Barboza, JL; Morrison, AC; Astete, H; Vazquez-Prokopec, G et al. (2014): Patterns of geographic expansion of Aedes aegypti in the Peruvian Amazon. In: PLOS Neglected Tropical Diseases 8 (8), e3033. DOI: 10.1371/journal.pntd.0003033. 
Guarneri, F; Pugliese, A; Giudice, E; Guarneri, C; Giannetto, S et al. (2005): Trombiculiasis: clinical contribution. In: European Journal of Dermatology: EJD 15 (6), S. 495-496.

Guisan, A; Thuiller, W (2005): Predicting species distribution: offering more than simple habitat models. In: Ecology Letters 8 (9), S. 993-1009. DOI: 10.1111/j.1461-

0248.2005.00792.x.

Gunn, J (Hg.) (2004): Encyclopedia of caves and karst science. New York: Fitzroy Dearborn.

Gutierrez-Velez, VH; Wiese, D (2020): Sampling bias mitigation for species occurrence modeling using machine learning methods. In: Ecological Informatics 58, S. 101091. DOI: 10.1016/j.ecoinf.2020.101091.

Hackett, KJ; Whitcomb, RF; French, FE; Tully, JG; Gasparich, GE et al. (1996): Spiroplasma corruscae sp. nov., from a Firefly Beetle (Coleoptera: Lampyridae) and Tabanid Flies (Diptera: Tabanidae. In: International journal of systematic bacteriology 46 (4), S. 947-950. DOI: 10.1099/00207713-46-4-947.

Hallmann, CA; Sorg, M; Jongejans, E; Siepel, H; Hofland, N et al. (2017): More than 75 percent decline over 27 years in total flying insect biomass in protected areas. In: PLOS ONE 12 (10), e0185809. DOI: 10.1371/journal.pone.0185809.

Hannah, L; Flint, L; Syphard, AD; Moritz, MA; Buckley, LB et al. (2014): Fine-grain modeling of species' response to climate change: holdouts, stepping-stones, and microrefugia. In: Trends in Ecology \& Evolution 29 (7), S. 390-397. DOI: 10.1016/j.tree.2014.04.006.

Hansens, EJ (1979): Review: Tabanidae of the East Coast as an Economic Problem. In: Journal of the New York Entomological Society 87 (4), S. 312-318. Online verfügbar unter www.jstor.org/stable/25009178.

Harbach, RE (2020): Mosquito Taxonomic Inventory - Valid Species List. Online verfügbar unter http://mosquito-taxonomic-inventory.info/, zuletzt geprüft am 26.12.2020.

Harbach, RE; Dahl, C; White, GB (1985): Culex (Culex) pipiens Linnaeus (Diptera: Culicidae): Concepts, Type Designations, and Description. In: Proceedings of the Entomological Society of Washington 87 (1), S. 24.

Harbach, RE; Harrison, BA; Gad, AM (1984): Culex (Culex) molestus Forskal (Diptera: Culicidae): neotype designation, description, variation, and taxonomic status. In: Proceedings of the Entomological Society of Washington 86 (3), S. 521-542.

Harbach, RE; Kitching, IJ (1998): Phylogeny and classification of the Culicidae (Diptera). In: Systematic Entomology 23 (4), S. 327-370. DOI: 10.1046/j.1365-3113.1998.00072.x.

Haupt, J; Haupt, H (1998): Fliegen und Mücken. Beobachtung, Lebensweise. Augsburg: Naturbuch-Verl.

Hayes, CG (2001): West Nile virus: Uganda, 1937, to New York City, 1999. In: Annals of the New York Academy of Sciences 951 (951), S. 25-37.

Hellmann, JJ; Byers, JE; Bierwagen, BG; Dukes, JS (2008): Five potential consequences of climate change for invasive species. In: Conservation Biology 22 (3), S. 534-543. DOI: 10.1111/j.1523-1739.2008.00951.x. 
Helmuth, BS; Hofmann, GE (2001): Microhabitats, thermal heterogeneity, and patterns of physiological stress in the rocky intertidal zone. In: The Biological Bulletin 201 (3), S. 374384. DOI: 10.2307/1543615.

Hendrix, CM; Robinson, E (2016): Diagnostic Parasitology for Veterinary Technicians. 5th ed. St Louis: Elsevier Health Sciences.

Hesson, JC; Rettich, F; Merdić, E; Vignjević, G; Ostman, O et al. (2014): The arbovirus vector Culex torrentium is more prevalent than Culex pipiens in northern and central Europe. In: Medical and Veterinary Entomology 28 (2), S. 179-186. DOI: 10.1111/mve.12024.

Hijmans, RJ; Cameron, SE; Parra, JL; Jones, PG; Jarvis, A (2005): Very high resolution interpolated climate surfaces for global land areas. In: International Journal of Climatology 25 (15), S. 1965-1978. DOI: 10.1002/joc.1276.

Hijmans, RJ; Graham, CH (2006): The ability of climate envelope models to predict the effect of climate change on species distributions. In: Global Change Biology 12 (12), S. 2272-2281. DOI: $10.1111 / \mathrm{j} .1365-2486.2006 .01256 . x$.

Hinton, HE (1968): Structure and protective devices of the egg of the mosquito Culex pipiens. In: Journal of Insect Physiology 14 (2), S. 145-161. DOI: 10.1016/0022-1910(68)90027-9. Hirzel, AH; Le Lay, G (2008): Habitat suitability modelling and niche theory. In: Journal of Applied Ecology 45 (5), S. 1372-1381. DOI: 10.1111/j.1365-2664.2008.01524.x.

Hocking, B (1953): The intrinsic range and speed of flight of insects. In: Transactions of the Royal Entomological Society of London 104 (Pt. 8), S. 223-345.

Honomichl, K; Bellmann, H (1996): Biologie und Ökologie der Insekten. CD-ROM Lexikon. Stuttgart: Fischer.

Hornok, S; Micsutka, A; Meli, ML; Lutz, H; Hofmann-Lehmann, R (2011): Molecular investigation of transplacental and vector-borne transmission of bovine haemoplasmas. In: Veterinary microbiology 152 (3-4), S. 411-414. DOI: 10.1016/j.vetmic.2011.04.031.

Huang, S; Hamer, GL; Molaei, G; Walker, ED; Goldberg, TL et al. (2009): Genetic Variation Associated with Mammalian Feeding in Culex pipiens from a West Nile Virus Epidemic Region in Chicago, Illinois. In: Vector-Borne and Zoonotic Diseases 9 (6), S. 637-642. DOI:

10.1089/vbz.2008.0146.

Hubálek, Z (2008): Mosquito-borne viruses in Europe. In: Parasitology Research 103 (S1), S. 29-43. DOI: 10.1007/s00436-008-1064-7.

Hubálek, Z; Halouzka, J (1999): West Nile Fever-a Reemerging Mosquito-Borne Viral Disease in Europe. In: Emerging Infectious Diseases 5 (5), S. 643-650. DOI: 10.3201/eid0505.990505. Huey, RB (1991): Physiological Consequences of Habitat Selection. In: The American Naturalist 137, S91-S115. DOI: 10.1086/285141.

Huey, RB; Peterson, CR; Arnold, SJ; Porter, WP (1989): Hot Rocks and Not-So-Hot Rocks: Retreat-Site Selection by Garter Snakes and Its Thermal Consequences. In: Ecology 70 (4), S. 931-944. DOI: 10.2307/1941360. 
Hutchinson, GE (1957): The multivariate niche. In: Cold Spring Harbor Symposia on Quantitative Biology, Bd. 22, S. 415-421.

Issel, CJ; Foil, LD (1984): Studies on equine infectious anemia virus transmission by insects. In: Journal of the American Veterinary Medical Association 184 (3), S. 293-297.

Jacobs, W; Renner, M; Honomichl, K (1998): Biologie und Ökologie der Insekten. Ein Taschenlexikon. 3. Aufl. Stuttgart: G. Fischer.

Jin, L; Luo, J; Fu, Y; Xu, S (2006): Prey and Feeding Behavior of Larval Culex (Lutzia ) fuscanus (Diptera: Culicidae) in Shantou, Guangdong Province, China : Table 1. In: Journal of Medical Entomology 43 (4), S. 785-786. DOI: 10.1093/jmedent/43.4.785.

Johnson, KP; Yoshizawa, K; Smith, VS (2004): Multiple origins of parasitism in lice. In: Proceedings. Biological sciences 271 (1550), S. 1771-1776. DOI: 10.1098/rspb.2004.2798.

Joshi, PP; Shegokar, VR; Powar, RM; Herder, S; Katti, R et al. (2005): Human trypanosomiasis caused by Trypanosoma evansi in India: the first case report. In: The American journal of tropical medicine and hygiene 73 (3), S. 491-495.

Kampen, H; Kronefeld, M; Zielke, D; Werner, D (2013): Further specimens of the Asian tiger mosquito Aedes albopictus (Diptera, Culicidae) trapped in southwest Germany. In: Parasitology Research 112 (2), S. 905-907. DOI: 10.1007/s00436-012-3128-y.

Kampen, H; Werner, D (2015): Die wiederkehrende Notwendigkeit von StechmückenSurveillance und -Forschung. In: Bundesgesundheitsblatt - Gesundheitsforschung Gesundheitsschutz 58 (10), S. 1101-1109. DOI: 10.1007/s00103-015-2218-2.

Kamura, T; Bekku, H (1959): Studies on the Culex pipiens group of Japan. IV. Ecological studies on the Nagasaki molestus. In: Endemic Diseases Bulletin of Nagasaki University (1), S. 51-59.

Karolyi, F; Colville, JF; Handschuh, S; Metscher, BD; Krenn, HW (2014): One proboscis, two tasks: adaptations to blood-feeding and nectar-extracting in long-proboscid horse flies (Tabanidae, Philoliche). In: Arthropod Structure \& Development 43 (5), S. 403-413. DOI: 10.1016/j.asd.2014.07.003.

Kaufmann, C; Briegel, H (2004): Flight performance of the malaria vectors Anopheles gambiae and Anopheles atroparvus. In: Journal of Vector Ecology 29 (1), S. 140-153.

Kearney, M; Porter, W (2009): Mechanistic niche modelling: combining physiological and spatial data to predict species' ranges. In: Ecology Letters 12 (4), S. 334-350. DOI: 10.1111/j.1461-0248.2008.01277.x.

Kempe, S; Rosendahl, W (2008): Höhlen. Verborgene Welten. 1. Aufl. Darmstadt: Primus. Kent, RJ; Harrington, LC; Norris, DE (2007): Genetic Differences Between Culex pipiens f. molestus and Culex pipiens pipiens (Diptera: Culicidae) in New York. In: Journal of Medical Entomology 44 (1), S. 50-59. DOI: 10.1603/0022-2585(2007)44[50:gdbcpf]2.0.co;2.

Kilpatrick, AM (2011): Globalization, land use, and the invasion of West Nile virus. In: Science 334 (6054), S. 323-327. DOI: 10.1126/science.1201010. 
Kjærandsen J. (1993): Diptera in mines and other cave systems in southern Norway. In: Entomologica Fennica 4 (4), S. 151-160.

Kniepert, F-W (1980): Blood-feeding and nectar-feeding in adult tabanidae (Diptera). In: Oecologia 46 (1), S. 125-129. DOI: 10.1007/bf00346976.

Knight, KL (1951): A Review of the Culex pipiens complex in the Mediterranean Subregion (Diptera, Culicidae). In: Transactions of the Royal Entomological Society of London 102 (7), S. 354-364. DOI: 10.1111/j.1365-2311.1951.tb00754.x.

Kormondy, EJ (1969): Concepts of ecology: Prentice-Hall. Online verfügbar unter https://tamug-ir.tdl.org/handle/1969.3/23744.

Kozel, P; Pipan, T; Mammola, S; Culver, DC; Novak, T (2019): Distributional dynamics of a specialized subterranean community oppose the classical understanding of the preferred subterranean habitats. In: Invertebrate Biology 138 (3). DOI: 10.1111/ivb.12254.

Kraemer, MUG; Sinka, ME; Duda, KA; Mylne, AQN; Shearer, FM et al. (2015): The global distribution of the arbovirus vectors Aedes aegypti and Ae. albopictus. In: Elife 4, e08347. DOI: $10.7554 /$ eLife.08347.

Krämer, B; Kämpf, I; Enderle, J; Poniatowski, D; Fartmann, T (2012): Microhabitat selection in a grassland butterfly: a trade-off between microclimate and food availability. In: Journal of Insect Conservation 16 (6), S. 857-865. DOI: 10.1007/s10841-012-9473-4.

Krinsky, WL (1976): Animal disease agents transmitted by horse flies and deer flies (Diptera: Tabanidae). In: Journal of Medical Entomology 13 (3), S. 225-275. DOI:

10.1093/jmedent/13.3.225.

Kumar, S; Stohlgren, TJ (2009): Maxent modeling for predicting suitable habitat for threatened and endangered tree Canacomyrica monticola in New Caledonia. In: Journal of Ecology and The Natural Environment 1 (4), S. 94-98. DOI: 10.5897/JENE.9000071.

La Rocque, S de; Balenghien, T; Halos, L; Dietze, K; Claes, F et al. (2011): A review of trends in the distribution of vector-borne diseases: is international trade contributing to their spread? In: Revue Scientifique et Technique 30 (1), S. 119-130. DOI: 10.20506/rst.30.1.2018.

La Ruche, G; Souarès, Y; Armengaud, A; Peloux-Petiot, F; Delaunay, P et al. (2010): First two autochthonous dengue virus infections in metropolitan France, September 2010. In: Euro surveillance 15 (39), S. 19676. DOI: 10.2807/ese.15.39.19676-en.

Lafferty, KD; Allesina, S; Arim, M; Briggs, CJ; Leo, G de et al. (2008): Parasites in food webs: the ultimate missing links. In: Ecology Letters 11 (6), S. 533-546. DOI: 10.1111/j.14610248.2008.01174.x.

Lane, RP (Hg.) (2012): Medical insects and arachnids. Softcover repr. of the hardcover 1. ed. 1993. Dordrecht: Springer Netherlands.

Lane, RS; Anderson, JR; Philip, CB (1983): Biology of Autogenous Horse Flies Native to Coastal California: Apatolestes actites (Diptera: Tabanidae). In: Annals of the Entomological Society of America 76 (4), S. 559-571. DOI: 10.1093/aesa/76.4.559. 
Lapshin, DN; Vorontsov, DD (2017): Frequency organization of the Johnston's organ in male mosquitoes (Diptera, Culicidae). In: Journal of Experimental Biology 220 (Pt 21), S. 39273938. DOI: $10.1242 /$ jeb.152017.

Lawler, JJ; Shafer, SL; White, D; Kareiva, P; Maurer, EP et al. (2009): Projected climateinduced faunal change in the Western Hemisphere. In: Ecology 90 (3), S. 588-597. DOI: 10.1890/08-0823.1.

Le Goff, F; Marjolet, M; Humphery-Smith, I; Leclercq, M; Hellas, C et al. (1993): Tabanid spiroplasmas from France: characterization, ecology and experimental study. In: Annales de Parasitologie Humaine et Comparée 68 (3), S. 150-153. DOI: 10.1051/parasite/1993683150. Li, Q; Ren, H; Zheng, L; Cao, W; an Zhang et al. (2017): Ecological Niche Modeling Identifies Fine-Scale Areas at High Risk of Dengue Fever in the Pearl River Delta, China. In: International Journal of Environmental Research and Public Health 14 (6), S. 619. DOI: 10.3390/ijerph14060619.

Liberato, C de; Magliano, A; Autorino, GL; Di Domenico, M; Sala, M et al. (2019): Seasonal succession of tabanid species in equine infectious anaemia endemic areas of Italy. In: Medical and Veterinary Entomology 33 (3), S. 431-436. DOI: 10.1111/mve.12360.

Liebisch, A (1987): Vector Biology of Flies on Grazing Cattle in Germany. In: G. Thomas, H. J. Over, U. Vecht und P. Nansen (Hg.): Summer Mastitis. Dordrecht: Springer Netherlands, S. 109-115.

Linnaeus, C (1758): Systema naturae. Vol. 1. No. part 1. Stockholm: Laurentii Salvii. Livdahl, TP; Edgerly, JS (1987): Egg hatching inhibition: field evidence for population regulation in a treehole mosquito. In: Ecological Entomology 12 (4), S. 395-399. DOI: 10.1111/j.1365-2311.1987.tb01020.x.

Lõhmus, M; Lindström, A; Björklund, M (2012): How often do they meet? Genetic similarity between European populations of a potential disease vector Culex pipiens. In: Infection Ecology \& Epidemiology 2 (1), S. 12001. DOI: 10.3402/iee.v2i0.12001.

Lord, RD (1993): A taste for blood: the highly specialized vampire bat will dine on nothing else. In: Wildlife Conservation 96, S. 32-38.

Low-Décarie, E; Kolber, M; Homme, P; Lofano, A; Dumbrell, A et al. (2015): Community rescue in experimental metacommunities. In: Proceedings of the National Academy of Sciences 112 (46), S. 14307-14312. DOI: 10.1073/pnas.1513125112.

Lucius, R; Loos-Frank, B; Lane, RP (2018): Biologie von Parasiten. 3., aktualisierte und überarbeitete Auflage. Berlin, Heidelberg: Springer Spektrum.

Lühken, R; Steinke, S; Leggewie, M; Tannich, E; Krüger, A et al. (2015): Physico-Chemical Characteristics of Culex pipiens sensu lato and Culex torrentium (Diptera: Culicidae) Breeding Sites in Germany. In: Journal of Medical Entomology 52 (5), S. 932-936. DOI: 10.1093/jme/tjv070.

Lundström, JO (1999): Mosquito-borne viruses in western Europe: a review. In: Journal of Vector Ecology 24 (1), S. 1-39. 
MacAlpine, JF (Hg.) (1981): Manual of Nearctic Diptera. Hull, Que.: Canadian Gornvment Publ. Centre (Monograph / Agriculture Canada, 27).

Maharaj, R (2003): Life table characteristics of Anopheles arabiensis (Diptera: Culicidae) under simulated seasonal conditions. In: Journal of Medical Entomology 40 (6), S. 737-742. DOI: 10.1603/0022-2585-40.6.737.

Mahmood, F; Crans, WJ; Savur, NS (1997): Larval competition in Aedes triseriatus (Diptera: Culicidae): effects of density on size, growth, sex ratio, and survival. In: Journal of Vector Ecology 22 (1), S. 90-94.

Maramorosch, K (Hg.) (1962): Biological Transmission of Disease Agents. Burlington: Elsevier Science.

Martini, R (1925): Zwei bemerkenswerte Culiciden von einem eigenartigen Biotop. In: International Review of Hydrobiology 12, S. 333-337.

Mattingly, PF (1976): Mosquito eggs XXVIII. In: Culex subgenera Melanoconion and Mochlostyrax. Mosq. Syst 8, S. 223-231.

Mays, HL; Hung, C-M; Shaner, P-J; Denvir, J; Justice, M et al. (2018): Genomic Analysis of Demographic History and Ecological Niche Modeling in the Endangered Sumatran Rhinoceros Dicerorhinus sumatrensis. In: Current Biology 28 (1), 70-76.e4. DOI: 10.1016/j.cub.2017.11.021.

Mazoyer, M; Roudart, L (2017): Histoire des agricultures du monde. Du néolithique à la crise contemporaine: Le Seuil.

McAlpine, JF; Munroe, DD (1968): Swarming of Lonchaeid Flies and other insects, with descriptions of four new species of Lonchaeidae (Diptera). In: The Canadian Entomologist 100 (11), S. 1154-1178. DOI: 10.4039/Ent1001154-11.

McKeever, S; French, FE (1997): Fascinating, Beautiful Blood Feeders. In: American Entomologist 43 (4), S. 217-226. DOI: 10.1093/ae/43.4.217.

Medlock, JM; Avenell, D; Barrass, I; Leach, S (2006): Analysis of the potential for survival and seasonal activity of Aedes albopictus (Diptera: Culicidae) in the United Kingdom. In: Journal of Vector Ecology 31 (2), S. 292-304. DOI: 10.3376/1081-

1710(2006)31[292:AOTPFS]2.0.CO;2.

Medlock, JM; Hansford, KM; Versteirt, V; Cull, B; Kampen, H et al. (2015): An entomological review of invasive mosquitoes in Europe. In: Bulletin of Entomological Research 105 (6), S. 637-663. DOI: 10.1017/S0007485315000103.

Mehlhorn, H; Benelli, G (Hg.) (2018): Mosquito-borne Diseases. Implications for Public Health. 1st edition 2019. Cham: Springer International Publishing (Parasitology Research Monographs, 10).

Mehrabi, Z; Slade, EM; Solis, A; Mann, DJ (2014): The importance of microhabitat for biodiversity sampling. In: PloS one 9 (12), e114015. DOI: 10.1371/journal.pone.0114015. 
Meigen, JW; Wiedemann, CRW (1828): Aussereuropäische Zweiflügelige Insekten / beschrieben von Christ. Rud. Wilh. Wiedemann; als Fortsetzung des Meigenischen Werkes. DOI: 10.5962/bhl.title.14603.

Melaun, C; Werblow, A; Cunze, S; Zotzmann, S; Koch, LK et al. (2015): Modeling of the putative distribution of the arbovirus vector Ochlerotatus japonicus japonicus (Diptera: Culicidae) in Germany. In: Parasitology Research 114 (3), S. 1051-1061. DOI: 10.1007/s00436-014-4274-1.

Merdić, E; Vujičić-Karlo, S (2005): Two types of Hibernation of Culex pipiens complex (Diptera: Culicidae) in Croatia. In: Entomology Croatia 9, S. 71-76.

Merritt, RW; Dadd, RH; Walker, ED (1992): Feeding behavior, natural food, and nutritional relationships of larval mosquitoes. In: Annual Review of Entomology 37 (1), S. 349-376. DOI: 10.1146/annurev.en.37.010192.002025.

Middlekauff, WW; Lane, RS (1980): Adult and immature Tabanidae (Diptera) of California. Berkeley: Univ. of California Press (Bulletin of the California Insect Survey, 22).

Millar, JG; Chaney, JD; Beehler, JW; Mulla, MS (1994): Interaction of the Culex quinquefasciatus egg raft pheromone with a natural chemical associated with oviposition sites. In: Journal of the American Mosquito Control Association 10 (3), S. 374-379. Online verfügbar unter https://www.ncbi.nlm.nih.gov/pubmed/7807079.

Molaei, G; Andreadis, TG; Armstrong, PM; Diuk-Wasser, M (2008): Host-Feeding Patterns of Potential Mosquito Vectors in Connecticut, USA: Molecular Analysis of Bloodmeals from 23 Species of Aedes, Anopheles, Culex, Coquillettidia, Psorophora, and Uranotaenia. In: Journal of Medical Entomology 45 (6), S. 1143-1151. DOI: 10.1093/jmedent/45.6.1143.

Mordecai, EA; Caldwell, JM; Grossman, MK; Lippi, CA; Johnson, LR et al. (2019): Thermal biology of mosquito-borne disease. In: Ecology Letters 22 (10), S. 1690-1708. DOI: 10.1111/ele.13335.

Morita, SI; Bayless, KM; Yeates, DK; Wiegmann, BM (2016): Molecular phylogeny of the horse flies: a framework for renewing tabanid taxonomy. In: Systematic Entomology 41 (1), S. 56-72. DOI: 10.1111/syen.12145.

Mota, MM; Pradel, G; Vanderberg, JP; Hafalla, JC; Frevert, U et al. (2001): Migration of Plasmodium sporozoites through cells before infection. In: Science 291 (5501), S. 141-144. DOI: 10.1126/science.291.5501.141.

Moutailler, S; Barré, H; Vazeille, M; Failloux, A-B (2009): Recently introduced Aedes albopictus in Corsica is competent to Chikungunya virus and in a lesser extent to dengue virus. In: Tropical Medicine \& International Health 14 (9), S. 1105-1109. DOI: 10.1111/j.13653156.2009.02320.x.

Mullen, GR (Hg.) (2019): Medical and Veterinary Entomology: Elsevier.

Mustapha, J; Hill, SB (1974): Short-term effects of diazinon on soil arthropods. In: Revue d Ecologie et de Biologie du Sol 11, S. 197-200. 
Nawrocki, SJ; Hawley, WA; others (1987): Estimation of the northern limits of distribution of Aedes albopictus in North America. In: Journal of the American Mosquito Control Association 3 (2), S. 314-317.

Novikov, YM; Vaulin, OV (2014): Expansion of Anopheles maculipennis s.s. (Diptera: Culicidae) to northeastern Europe and northwestern Asia: causes and consequences. In: Parasites \& Vectors 7, S. 389. DOI: 10.1186/1756-3305-7-389.

Ogden, NH; Lindsay, LR (2016): Effects of Climate and Climate Change on Vectors and VectorBorne Diseases: Ticks Are Different. In: Trends in Parasitology 32 (8), S. 646-656. DOI: 10.1016/j.pt.2016.04.015.

Olsufjev, NG; Golovd, A (1936): Horse Flies as Transmitters and Conservators of Tularaemia. In: Animaux Pathogen, S. 187-226.

Onyeka, JOA; Boreham, PFL (1987): Population studies, physiological state and mortality factors of overwintering adult populations of females of Culex pipiens L. (Diptera: Culicidae). In: Bulletin of Entomological Research 77 (01), S. 99. DOI: 10.1017/S0007485300011585.

Padgett, JJ; Jacobsen, KH (2008): Loiasis: African eye worm. In: Transactions of the Royal Society of Tropical Medicine and Hygiene 102 (10), S. 983-989. DOI:

10.1016/j.trstmh.2008.03.022.

Pape, T; Thompson, FC (2019): Systema Dipterorum (version 2.0, Jan 2011). In: Y. Roskov, G. Ower, T. Orrell, D. Nicolson, N. Bailly, P. M. Kirk et al. (Hg.): Species 2000 \& ITIS Catalogue of Life, 2019 Annual Checklist: Naturalis.

Parker, BM (1986): Hatchability of Eggs of Aedes taeniorhynchus (Diptera: Culicidae): Effects of Different Temperatures and Photoperiods during Embryogenesis. In: Annals of the Entomological Society of America 79 (6), S. 925-930. DOI: 10.1093/aesa/79.6.925.

Paupy, C; Delatte, H; Bagny, L; Corbel, V; Fontenille, D (2009): Aedes albopictus, an arbovirus vector: from the darkness to the light. In: Microbes and Infection 11 (14-15), S. 1177-1185. DOI: 10.1016/j.micinf.2009.05.005.

Paz, S; Albersheim, I (2008): Influence of warming tendency on Culex pipiens population abundance and on the probability of West Nile fever outbreaks (Israeli Case Study: 20012005). In: EcoHealth 5 (1), S. 40-48. DOI: 10.1007/s10393-007-0150-0.

Peng, C (2000): From static biogeographical model to dynamic global vegetation model: a global perspective on modelling vegetation dynamics. In: Ecological Modelling 135 (1), S. 3354. DOI: 10.1016/s0304-3800(00)00348-3.

Peterson, AT; Soberón, J (2012): Species distribution modeling and ecological niche modeling: getting the concepts right. In: Natureza \& Conservação 10 (2), S. 102-107.

Phillips, SJ; Dudík, M (2008): Modeling of species distributions with Maxent: new extensions and a comprehensive evaluation. In: Ecography 31 (2), S. 161-175. DOI: 10.1111/j.09067590.2008.5203.x.

Phillips, SJ; Dudík, M; Schapire, RE (2004): A maximum entropy approach to species distribution modeling. In: Proceedings of the 41st annual Design Automation Conference. 
Twenty-first international conference on Machine learning - ICML '04. The 41st Annual Design Automation Conference 2004; ACM Special Interest Group on Design Automation. New York, NY: ACM.

Pluskota, B; Storch, V; Braunbeck, T; Beck, M; Becker, N (2008): First record of Stegomyia albopicta (Skuse) (Diptera : Culicidae) in Germany. In: European Mosquito Bulletin 26, S. 1. Poulin, R (2006): Evolutionary Ecology of Parasites. (Second Edition). Princeton: Princeton University Press.

Press, M; Graves, J (1995): Parasitic plants. 1. ed. London: Chapman \& Hall.

Pucat, AM (1965): The functional morphology of the mouthparts of some mosquito larvae. In: Quaestiones Entomologicae 1, S. 41-86.

Pulliam, HR (2000): On the relationship between niche and distribution. In: Ecology Letters 3 (4), S. 349-361. DOI: 10.1046/j.1461-0248.2000.00143.x.

Qin, D; Plattner, GK; Tignor, M; Allen, SK; Boschung, J et al. (2014): Climate change 2013: the physical science basis. In: Intergovernmental Panel on Climate Change (Hg.): Climate Change 2013 - The Physical Science Basis. The physical science basis : Working Group I contribution to the Fifth assessment report of the Intergovernmental Panel on Climate Change.

Cambridge: Cambridge University Press, S. 5-14.

R Core Team (2013): R. A language and environment for statistical computing.: R Foundation for Statistical Computing, Vienna, Austria.

Randin, CF; Dirnböck, T; Dullinger, S; Zimmermann, NE; Zappa, M et al. (2006): Are nichebased species distribution models transferable in space? In: Journal of Biogeography 33 (10), S. 1689-1703. DOI: 10.1111/j.1365-2699.2006.01466.x.

Reisen, WK; Lothrop, HD; Lothrop, B (2003): Factors influencing the outcome of markrelease-recapture studies with Culex tarsalis (Diptera: Culicidae). In: Journal of Medical Entomology 40 (6), S. 820-829. DOI: 10.1603/0022-2585-40.6.820.

Reiss, H; Cunze, S; König, K; Neumann, H; Kröncke, I (2011): Species distribution modelling of marine benthos: a North Sea case study. In: Marine Ecology Progress Series 442, S. 71-86. DOI: 10.3354/meps09391.

Rezza, G; Nicoletti, L; Angelini, R; Romi, R; Finarelli, AC et al. (2007): Infection with chikungunya virus in Italy: an outbreak in a temperate region. In: The Lancet 370 (9602), S. 1840-1846. DOI: 10.1016/S0140-6736(07)61779-6.

Rodríguez-Prieto, I; Fernández-Juricic, E; Martín, J (2006): Anti-Predator Behavioral Responses of Mosquito Pupae to Aerial Predation Risk. In: Journal of Insect Behavior 19 (3), S. 373-381. DOI: 10.1007/s10905-006-9033-4.

Rohde, K (2005): Marine Parasitology. Melbourne: CSIRO Publishing. Online verfügbar unter https://rune.une.edu.au/web/handle/1959.11/9373.

Rolff, J; Johnston, PR; Reynolds, S (2019): Complete metamorphosis of insects. In: Philosophical transactions of the Royal Society of London. Series B, Biological sciences 374 (1783), S. 20190063. DOI: 10.1098/rstb.2019.0063. 
Rowland, M (1989): Changes in the circadian flight activity of the mosquito Anopheles stephensi associated with insemination, blood-feeding, oviposition and nocturnal light intensity. In: Physiological Entomology 14 (1), S. 77-84. DOI: 10.1111/j.13653032.1989.tb00939.x.

Rudolf, M; Czajka, C; Börstler, J; Melaun, C; Jöst, H et al. (2013): First nationwide surveillance of Culex pipiens complex and Culex torrentium mosquitoes demonstrated the presence of Culex pipiens biotype pipiens/molestus hybrids in Germany. In: PloS one 8 (9), e71832. DOI: 10.1371/journal.pone.0071832.

Rueda, LM (2007): Global diversity of mosquitoes (Insecta: Diptera: Culicidae) in freshwater. In: Freshwater Animal Diversity Assessment, Bd. 198: Springer, Dordrecht, S. 477-487. Online verfügbar unter https://link.springer.com/chapter/10.1007/978-1-4020-8259-7_48. Salgado-Maldonado, G; García Aldrete, AN; Vidal-Martínez, VM (2000): Metazoan parasites in the neotropics. A systematic and ecological perspective. 1st ed. México, D.F.: Universidad Nacional Autónoma de México, Instituto de Biología.

Sallum, MAM; Obando, RG; Carrejo, N; Wilkerson, RC (2020): Identification keys to the Anopheles mosquitoes of South America (Diptera: Culicidae). II. Fourth-instar larvae. In: Parasites \& Vectors 13 (1), S. 582. DOI: 10.1186/s13071-020-04299-5.

Say, $T$ (1823): Descriptions of dipterous insects of the United States. In: Journal of the Academy of Natural Sciences of Philadelphia 3, S. 9-54.

Schäfer, ML; Lundström, JO (2006): Different responses of two floodwater mosquito species, Aedes vexans and Ochlerotatus sticticus (Diptera: Culicidae), to larval habitat drying. In: Journal of Vector Ecology 31 (1), S. 123-128. DOI: 10.3376/10811710(2006)31[123:DROTFM]2.0.CO;2.

Schaffner, F; Boulétreau, B; Guillet B.; Guilloteau J.; Krach S. (2001): Aedes albopictus (Skuse, 1894) established in metropolitan France. In: European Mosquito Bulletin 9, S. 1.

Schaffner, F; van Bortel, W; Coosemans, M (2000): First record of Aedes (Stegomyia) albopictus in Belgium. In: Journal of the American Mosquito Control Association 20, S. 201.

Schnieder, T; Boch, J; Supperer, R; Bauer, C (2006): Veterinärmedizinische Parasitologie. 6., vollst. überarb. und erw. Aufl. Stuttgart: Parey. Online verfügbar unter http://www.thieme.de/ebooklibrary/nutzungsrechte_vel.html?3830441359/index.php.

Scholte, E-J; Jacobs, F; Linton, Y-M; Dijkstra, E; Fransen, J et al. (2007): First record of Aedes (Stegomyia) albopictus in the Netherlands. In: European Mosquito Bulletin 22 (5), S. 9.

Schönborn, W; Risse-Buhl, U (2013): Lehrbuch der Limnologie. 2., vollständig überarbeitete Auflage. Stuttgart: Schweizerbart.

Schreiber, ET (2007): Toxorhynchites. In: Journal of the American Mosquito Control Association 23 (sp2), S. 129-132. DOI: 10.2987/8756-971X(2007)23[129:T]2.0.CO;2.

Schwardt, HH (1934): Biological Notes on Goniops chrysocoma (OS)(Diptera: Tabanidae). In: Journal of the Kansas Entomological Society 7 (3), S. 73-79. 
Service, MW (1978): A short history of early medical entomology. In: Journal of Medical Entomology 14 (6), S. 603-626. DOI: 10.1093/jmedent/14.6.603.

Service, MW (Hg.) (2008): Medical entomology for students. Fourth edition. Cambridge: Cambridge University Press.

Shahhosseini, N; Kayedi, MH; Sedaghat, MM; Racine, T; P Kobinger, G et al. (2018): DNA barcodes corroborating identification of mosquito species and multiplex real-time PCR differentiating Culex pipiens complex and Culex torrentium in Iran. In: PloS one 13 (11), e0207308. DOI: 10.1371/journal.pone.0207308.

Shelton, RM (1973): The effect of temperatures on development of eight mosquito species. In: Mosquito News 33 (1), S. 1-12.

Sheppard, C; Wilson, BH (1976): Flight Range of Tabanidae in a Louisiana Bottomland Hardwood Forest. In: Environmental Entomology 5 (4), S. 752-754. DOI: 10.1093/ee/5.4.752.

Sih, A (1986): Antipredator Responses and the Perception of Danger by Mosquito Larvae. In: Ecology 67 (2), S. 434-441. DOI: 10.2307/1938587.

Sillero, N (2011): What does ecological modelling model? A proposed classification of ecological niche models based on their underlying methods. In: Ecological Modelling 222 (8), S. 1343-1346. DOI: 10.1016/j.ecolmodel.2011.01.018.

Sillero, N; Barbosa, AM (2021): Common mistakes in ecological niche models. In: International Journal of Geographical Information Science 35 (2), S. 213-226. DOI: 10.1080/13658816.2020.1798968.

Smith, SM; Turnbull, DA; Taylor, PD (1994): Assembly, mating, and energetics of Hybomitra arpadi (Diptera: Tabanidae) at Churchill, Manitoba. In: Journal of Insect Behavior 7 (3), S. 355-383. DOI: 10.1007/bf01989741.

Soberón, J (2007): Grinnellian and Eltonian niches and geographic distributions of species. In: Ecology Letters 10 (12), S. 1115-1123. DOI: 10.1111/j.1461-0248.2007.01107.x.

Souza, RS; Virginio, F; Riback, TIS; Suesdek, L; Barufi, JB et al. (2019): Microorganism-Based Larval Diets Affect Mosquito Development, Size and Nutritional Reserves in the Yellow Fever Mosquito Aedes aegypti (Diptera: Culicidae). In: Frontiers in Physiology 10, S. 152. DOI: 10.3389/fphys.2019.00152.

Spielman, A (1964): Studies on Autogeny in Culex pipiens Populations in Nature. I. Reproductive Isolation between Autogenous and Anautogenous Populations. In: American Journal of Hygiene 80, S. 175-183.

Spielman, A; D'Antonio, M (2004): Mosquito. The story of man's deadliest foe. 1st paperback ed. New York: Hyperion.

Stabach, JA; Laporte, N; Olupot, W (2009): Modeling habitat suitability for Grey Crownedcranes (Balearica regulorum gibbericeps) throughout Uganda. In: International Journal of Biodiversity and Conservation 1 (5), S. 177-186. DOI: 10.5897/IJBC.9000096.

Steinbach, G; Reichholf-Riehm, H; Kühbandner, R (Hg.) (1996): Insekten. Mit Anhang Spinnentiere. Neue, bearb. Sonderausg. München: Mosaik-Verl. (Steinbachs Naturführer). 
Stocker, TF; Qin, D; Plattner, G-K; Tignor, M; Allen, SK et al. (2013): Climate Change 2013. The Physical Science Basis. Working Group I Contribution to the Fifth Assessment Report of the Intergovernmental Panel on Climate Change-Abstract for decision-makers

Sulaiman, S; Service, MW (1983): Studies on hibernating populations of the mosquito Culex pipiens L. in southern and northern England. In: Journal of Natural History 17 (6), S. 849-857. DOI: $10.1080 / 00222938300770661$.

Tandon, N; Ray, S (2000): Host Feeding Pattern of Aedes aegypti and Aedes albopictus in Kolkata India. In: Dengue Bulletin.

Thavara, U; Tawatsin, A; Chompoosri, J (2004): Evaluation of attractants and egg-laying substrate preference for oviposition by Aedes albopictus (Diptera: Culicidae). In: Journal of Vector Ecology 29, S. 66-72.

Thomas, SM; Obermayr, U; Fischer, D; Kreyling, J; Beierkuhnlein, C (2012): Low-temperature threshold for egg survival of a post-diapause and non-diapause European aedine strain, Aedes albopictus (Diptera: Culicidae). In: Parasites \& Vectors 5 (1), S. 100. DOI: 10.1186/1756-3305-5-100.

Thomson, RCM (1938): The Reactions of Mosquitoes to Temperature and Humidity. In: Bulletin of Entomological Research 29 (02), S. 125. DOI: 10.1017/S0007485300026158.

Thornhill, AR; Hays, KL (1972): Dispersal and Flight Activities of Some Species of Tabanus (Diptera: Tabanidae). In: Environmental Entomology 1 (5), S. 602-606. DOI: 10.1093/ee/1.5.602.

Thorson, RE; Noble, ER; Noble, GA (1963): Parasitology, The Biology of Animal Parasites. In: American Midland Naturalist 69 (1), S. 252. DOI: 10.2307/2422862.

Thuiller, W; Georges, D; Engler, R; Breiner, F; Georges, MD; Thuiller, CW (2016): Package biomod2: Ensemble platform for species distribution modeling.

Tjaden, NB; Caminade, C; Beierkuhnlein, C; Thomas, SM (2018): Mosquito-Borne Diseases: Advances in Modelling Climate-Change Impacts. In: Trends in Parasitology 34 (3), S. 227-245. DOI: 10.1016/j.pt.2017.11.006.

Townsend, CR; Begon, M; Harper, JL (2014): Ökologie. 2., vollständig überarbeitete und aktualisierte Auflage. Berlin, Heidelberg: Springer Spektrum (Lehrbuch).

Tremlett, JG (1964): Mud cylinders formed by larvae of Tabanus biguttatus Wied. (Diptera: Tabanidae) in Kenya. In: Proceedings of the Royal Entomological Society of London. Series A, General Entomology 39 (1-3), S. 23-24. DOI: 10.1111/j.1365-3032.1964.tb00779.x.

Tripet, F; Dolo, G; Traoré, S; Lanzaro, GC (2004): The "wingbeat hypothesis" of reproductive isolation between members of the Anopheles gambiae complex (Diptera: Culicidae) does not fly. In: Journal of Medical Entomology 41 (3), S. 375-384. DOI: 10.1603/0022-2585-41.3.375.

Trisurat, Y; Alkemade, JR; Arets, E (2009): Projecting forest tree distributions and adaptation to climate change in northern Thailand. In: Journal of Ecology and The Natural Environment 1 (3), S. 55-63. 
Trpis, M (1972): Development and Predatory Behavior of Toxorhynchites brevipalpis (Diptera: Culicidae) in Relation to Temperature 1. In: Environmental Entomology 1 (5), S. 537-546. DOI: 10.1093/ee/1.5.537.

Turkington, C; Ashby, B (2007): The Encyclopedia of Infectious Diseases. 3rd ed. New York: Facts On File (Facts on File library of health and living).

Valerio, L; Marini, F; Bongiorno, G; Facchinelli, L; Pombi, M et al. (2010): Host-feeding patterns of Aedes albopictus (Diptera: Culicidae) in urban and rural contexts within Rome province, Italy. In: Vector-Borne and Zoonotic Diseases 10 (3), S. 291-294. DOI: 10.1089/vbz.2009.0007.

Vazeille, M; Jeannin, C; Martin, E; Schaffner, F; Failloux, A-B (2008): Chikungunya: a risk for Mediterranean countries? In: Acta Tropica 105 (2), S. 200-202. DOI:

10.1016/j.actatropica.2007.09.009.

Veraldi, S; Esposito, L (2017): Skin lesions caused by Tabanus bovinus bites. In: Journal of Travel Medicine 24 (5), S. 1-3. DOI: 10.1093/jtm/tax049.

Verdonschot, PF; Besse-Lototskaya, AA (2014): Flight distance of mosquitoes (Culicidae): A metadata analysis to support the management of barrier zones around rewetted and newly constructed wetlands. In: Limnologica 45, S. 69-79. DOI: 10.1016/j.limno.2013.11.002.

Vezzani, D; Rubio, A; Velázquez, SM; Schweigmann, N; Wiegand, T (2005): Detailed assessment of microhabitat suitability for Aedes aegypti (Diptera: Culicidae) in Buenos Aires, Argentina. In: Acta Tropica 95 (2), S. 123-131. DOI: 10.1016/j.actatropica.2005.03.010.

Vilcinskas, A; Götz, P (1999): Parasitic Fungi and their Interactions with the Insect Immune System. In: John R. Baker, Ralph Muller und D. Rollinson (Hg.): Advances in Parasitology. 1. Aufl. s.l.: Elsevier textbooks (Advances in Parasitology, v.43), S. 267-313.

Villiard, A; Gaugler, R (2015): Long-term Effects of Carbohydrate Availability on Mating Success of Newly Eclosed Aedes albopictus (Diptera: Culicidae) Males. In: Journal of Medical Entomology 52 (3), S. 308-314. DOI: 10.1093/jme/tjv030.

Vinogradova, EB (2000): Culex pipiens pipiens mosquitoes. Taxonomy, distribution, ecology, physiology, genetics, applied importance and control. Sofia: Pensoft (Pensoft Series Parasitologica, no. 2).

Vinogradova, EB (2007): Diapause in Aquatic Insects, with Emphasis on Mosquitoes. In: Viktor Rostislovovič Alekseev, Bart T. DeStasio und John J. Gilbert (Hg.): Diapause in aquatic invertebrates. Theory and human use. Dordrecht: Springer (Monographiae biologicae, 84), S. 83-113.

Vinogradova, EB; Shaikevich, EV (2007): Morphometric, physiological and molecular characteristics of underground populations of the urban mosquito Culex pipiens Linnaeus $f$. molestus Forskål (Diptera: Culicidae) from several areas of Russia. In: European Mosquito Bulletin 22 (22), S. 17-24.

Walsh, MG; Webb, C (2018): Hydrological features and the ecological niches of mammalian hosts delineate elevated risk for Ross River virus epidemics in anthropogenic landscapes in Australia. In: Parasites \& Vectors 11 (1), S. 192. DOI: 10.1186/s13071-018-2776-x. 
Weitzel, T; Jawień, P; Rydzanicz, K; Lonc, E; Becker, N (2015): Culex pipiens s.I. and Culex torrentium (Culicidae) in Wrocław area (Poland): occurrence and breeding site preferences of mosquito vectors. In: Parasitology Research 114 (1), S. 289-295. DOI: 10.1007/s00436014-4193-1.

Werblow, A; Bolius, S; Dorresteijn, AWC; Melaun, C; Klimpel, S (2013): Diversity of Culex torrentium Martini, 1925 - a potential vector of arboviruses and filaria in Europe. In: Parasitology Research 112 (7), S. 2495-2501. DOI: 10.1007/s00436-013-3418-z.

Werblow, A; Klimpel, S; Bolius, S; Dorresteijn, AWC; Sauer, J et al. (2014): Population Structure and Distribution Patterns of the Sibling Mosquito Species Culex pipiens and Culex torrentium (Diptera: Culicidae) Reveal Different Evolutionary Paths. In: PloS one 9 (7), e102158. DOI: 10.1371/journal.pone.0102158.

Werner, D; Kampen, H (2015): Aedes albopictus breeding in southern Germany, 2014. In: Parasitology Research 114 (3), S. 831-834. DOI: 10.1007/s00436-014-4244-7.

Werner, D; Kronefeld, M; Schaffner, F; Kampen, H (2012): Two invasive mosquito species, Aedes albopictus and Aedes japonicus japonicus, trapped in south-west Germany, July to August 2011. In: Euro surveillance 17 (4). DOI: 10.2807/ese.17.04.20067-en.

Werren, JH; Zhang, W; Guo, LR (1995): Evolution and phylogeny of Wolbachia: reproductive parasites of arthropods. In: Proceedings. Biological sciences 261 (1360), S. 55-63. DOI: 10.1098/rspb.1995.0117.

Westheide, W; Rieger, R; Dohle, W (1996): Spezielle Zoologie. Stuttgart, New York: G. Fischer.

WHO (2020): Fact Sheet on Vector-borne diseases. Online verfügbar unter https://www.who.int/news-room/fact-sheets/detail/vector-borne-diseases, zuletzt geprüft am 10.01.2021.

Wiens, JA; Stralberg, D; Jongsomjit, D; Howell, CA; Snyder, MA (2009): Niches, models, and climate change: assessing the assumptions and uncertainties. In: Proceedings of the National Academy of Sciences 106 (Supplement 2), S. 19729-19736. DOI: 10.1073/pnas.0901639106.

Wiesenhütter, E (1975): Research into the relative importance of Tabanidae (Diptera) in mechanical disease transmission. In: Journal of Natural History 9 (4), S. 385-392. DOI: 10.1080/00222937500770281.

Wilkerson, RC; Butler, JF (1984): The Immelmann Turn, a Pursuit Maneuver Used by Hovering Male Hybomitra hinei wrighti (Diptera: Tabanidae). In: Annals of the Entomological Society of America 77 (3), S. 293-295. DOI: 10.1093/aesa/77.3.293.

Wilkerson, RC; Butler, JF; Pechuman, LL (1985): Swarming, hovering and mating behavior of male horse flies and deer flies (Diptera: Tabanidae). In: Myia 3 (5), S. 546.

Winegard, TC (2019): Mosquito. A human history of our deadliest predator: Text Publishing. Wittig, R; Streit, B (2004): Ökologie: UTB (2542).

Wunderer, H; Smola, U (1986): Functional morphology of the retina of Chrysops caecutiens L. and Haematopota pluvialis L. (Diptera : Tabanidae): Region around eye equator. In: 
International Journal of Insect Morphology and Embryology 15 (4), S. 311-319. DOI: 10.1016/0020-7322(86)90048-6.

Yates, KL; Bouchet, PJ; Caley, MJ; Mengersen, K; Randin, CF et al. (2018): Outstanding challenges in the transferability of ecological models. In: Trends in Ecology \& Evolution 33 (10), S. 790-802.

Yee, DA; Kesavaraju, B; Juliano, SA (2004): Larval feeding behavior of three co-occurring species of container mosquitoes. In: Journal of Vector Ecology 29 (2), S. 315.

Yee, TW (2015): Vector generalized linear and additive models: with an implementation in R: Springer.

Yee, TW; Wild, CJ (1996): Vector generalized additive models. In: Journal of the Royal Statistical Society: Series B (Methodological) 58 (3), S. 481-493.

Yuval, B; Fritz, GN (1994): Multiple mating in female mosquitoes - evidence from a field population of Anopheles freeborni (Diptera: Culicidae). In: Bulletin of Entomological Research 84 (1), S. 137-139. DOI: 10.1017/s0007485300032326.

Yuval, B; Wekesa, JW; Washino, RK (1993): Effect of body size on swarming behavior and mating success of male Anopheles freeborni (Diptera: Culicidae). In: Journal of Insect Behavior 6 (3), S. 333-342. DOI: 10.1007/bf01048114.

Zgomba, M; Petric, D; others (2008): Risk assessment and management of mosquito-born diseases in the European region. In: ICUP (Hg.): Sixth International Conference of Urban Pests. ICUP. Budapest, S. 29-39.

Zillikens, A; Sousa Gorayeb, I de; Steiner, J; Marcondes, CB (2005): Aquatic larvae and pupae of Fidena (Laphriomyia) rufopilosa (Ricardo)(Diptera: Tabanidae) developing in bromeliad phytotelmata in the Atlantic forest of southern Brazil. In: Journal of the Kansas Entomological Society 78 (4), S. 381-386.

Zimmer, C; Curths, M (2001): Parasitus Rex. In der bizarren Welt der gefährlichsten Geschöpfe der Natur. Frankfurt am Main: Umschau/Braus.

Zittra, C; Flechl, E; Kothmayer, M; Vitecek, S; Rossiter, H et al. (2016): Ecological characterization and molecular differentiation of Culex pipiens complex taxa and Culex torrentium in eastern Austria. In: Parasites \& Vectors 9, S. 197. DOI: 10.1186/s13071-0161495-4.

Zittra, C; Moog, O; Christian, E; Fuehrer, H-P (2019): DNA-aided identification of Culex mosquitoes (Diptera: Culicidae) reveals unexpected diversity in underground cavities in Austria. In: Parasitology Research 118 (5), S. 1385-1391. DOI: 10.1007/s00436-019-06277-y.

Zittra, C; Vitecek, S; Obwaller, AG; Rossiter, H; Eigner, B et al. (2017): Landscape structure affects distribution of potential disease vectors (Diptera: Culicidae). In: Parasites \& Vectors 10 (1), S. 205. DOI: 10.1186/s13071-017-2140-6. 


\title{
Incompletely observed: niche estimation for six frequent European horsefly species (Diptera, Tabanoidea, Tabanidae)
}

Dorian D. Dörge ${ }^{1 *}$, Sarah Cunze ${ }^{1}$ and Sven Klimpel ${ }^{1,2}$

\begin{abstract}
Background: More than 170 species of tabanids are known in Europe, with many occurring only in limited areas or having become very rare in the last decades. They continue to spread various diseases in animals and are responsible for livestock losses in developing countries. The current monitoring and recording of horseflies is mainly conducted throughout central Europe, with varying degrees of frequency depending on the country. To the detriment of tabanid research, little cooperation exists between western European and Eurasian countries.

Methods: For these reasons, we have compiled available sources in order to generate as complete a dataset as possible of six horsefly species common in Europe. We chose Haematopota pluvialis, Chrysops relictus, C. caecutiens, Tabanus bromius, T. bovinus and T. sudeticus as ubiquitous and abundant species within Europe. The aim of this study is to estimate the distribution, land cover usage and niches of these species. We used a surface-range envelope (SRE) model in accordance with our hypothesis of an underestimated distribution based on Eurocentric monitoring regimes.

Results: Our results show that all six species have a wide range in Eurasia, have a broad climatic niche and can therefore be considered as widespread generalists. Areas with modelled habitat suitability cover the observed distribution and go far beyond these. This supports our assumption that the current state of tabanid monitoring and the recorded distribution significantly underestimates the actual distribution. Our results show that the species can withstand extreme weather and climatic conditions and can be found in areas with only a few frost-free months per year. Additionally, our results reveal that species prefer certain land-cover environments and avoid other land-cover types.

Conclusions: The SRE model is an effective tool to calculate the distribution of species that are well monitored in some areas but poorly in others. Our results support the hypothesis that the available distribution data underestimate the actual distribution of the surveyed species.
\end{abstract}

Keywords: Tabanidae, Tabanus, Haematopota, Chrysops, Niche, Climate, Land cover, Surface range, Model, Envelope

*Correspondence: Doerge@bio.uni-frankfurt.de

1 Institute for Ecology, Evolution and Diversity, Goethe-University,

Max-von-Laue-Str. 13, 60439 Frankfurt/Main, Germany

Full list of author information is available at the end of the article

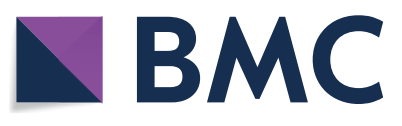

(c) The Author(s) 2020. This article is licensed under a Creative Commons Attribution 4.0 International License, which permits use, sharing, adaptation, distribution and reproduction in any medium or format, as long as you give appropriate credit to the original author(s) and the source, provide a link to the Creative Commons licence, and indicate if changes were made. The images or other third party material in this article are included in the article's Creative Commons licence, unless indicated otherwise in a credit line to the material. If material is not included in the article's Creative Commons licence and your intended use is not permitted by statutory regulation or exceeds the permitted use, you will need to obtain permission directly from the copyright holder. To view a copy of this licence, visit http://creativeco mmons.org/licenses/by/4.0/. The Creative Commons Public Domain Dedication waiver (http://creativecommons.org/publicdomain/ zero/1.0/) applies to the data made available in this article, unless otherwise stated in a credit line to the data. 


\section{Background}

Common throughout the world, tabanids are hematophagous dipterans. Worldwide there are about 4400 known species [1, 2] of which more than 170 occur in Europe [3]. Female horseflies can cause severe skin lesions $[4,5]$ and are able to effectively transmit different diseases [6-8] due to their excessive feeding behavior [9]. These include the eye worm Loa loa (sausing loaiasis) [2, 7, 10, 11], the equine infectious anemia virus [12-14], Trypanosoma theileri $[15,16]$ and $T$. evansi (Surra) which mainly infect livestock [2] but can also infect humans [17]. Further transmittable pathogens are Spiroplasma [18-20], Bacillus tularensis (causing tularemia) [21], Bacillus anthrax (Anthrax) [12], bovine mycoplasma [22], Elaeophora schneideri (causing elk and deer filariosis) [23] as well as Besnoitia besnoiti (causing bovine besnoitiosis) [24].

Many species require slow flowing or stagnant water with shallow zones for egg-laying and for the migration of larvae between land and water. The larvae live predatorily or feed on detritus at the edge of the water, seeking dry ground to pupate. Other species, however, are specialized in drier areas and do not require bodies of water but only moist soil or dung from grazing animals [2, 3, 25-27]. As a result of the draining of many of Europe's wetlands [28, 29], the number of susceptive horseflies has fallen sharply [30]. Current insecticide- and land-use changes are further reducing the numbers [31-34]. However, especially in poorer countries, cattle and other livestock continue to suffer due to lack of protection or control options, resulting in anemia or severe skin damage to the affected animals $[2,35,36]$.

Recent research within Europe is focused mainly on monitoring points within a few countries for the occurrence of horseflies and potential control measures [37] as well as ecological and anthropogenic effects on their populations [38]. To date, there are no standardized and repeatedly executed monitoring protocols for horseflies in Eurasia (and other continents as well), which makes it difficult to acquire, compile and utilize existing data for calculations and projections. Due to the different monitoring schemes within different countries, occurrences are either over- or underestimated and combining these datasets is complicated. Based on the lack of monitoring in many countries, not much is known about horsefly complete distribution. Finally, since only sites in western Europe have been extensively recorded, the distribution in the rest of Eurasia is most likely greatly underestimated.

Six species commonly observed in central Europe were used for our study: Chrysops relictus (Meigen 1820) and the morphologically similar species Chrysops caecutiens (Linnaeus, 1758), Haematopota pluvialis (Linnaeus, 1758), Tabanus bromius (Linnaeus, 1758), Tabanus bovinus (Linnaeus, 1758) and Tabanus sudeticus (Zeller, 1842). Tabanus spp. and Haematopota spp. are relatively eurytopic and do not require stagnant water but moist soil for egg-laying and larval development [25, 39-43], while Chrysops belongs to the hydrophilous ecological group and depends on ponds, rivers or lakes [44].

To find a realistic dispersal of the species, we calculated the climatic niche and the land cover allocation of occurrence points using available literature and database data ranging back to 1990 . We used the ecological niche model (ENM) with a surface-range envelope (SRE) to project the potential distribution within Europe and Asia. In order to counteract the present sampling bias, we used this method, as it is particularly resistant to over- and under-representation of species in databases and literature. We also compared the modelled niches (climatic envelopes), as well as the preferred type of land cover and the number of frost-free months required for the six species to exist.

\section{Methods}

For our analysis, we compiled data collected from an extensive literature research [37, 45-113] as well as the GBIF-Database [114-120]. Occurrence data were adjusted to the spatial resolution (5 arc-minutes) of the environmental raster data and reduced to one occurrence per grid cell.

\section{Estimation of the potential distribution}

For the niche range analysis, 8 bioclimatic variables provided by Worldclim [121] were downloaded at a spatial resolution of 5 arc-minutes. The variables Bio5, Bio6, Bio13, Bio14, Bio18 and Bio19 were used. We computed SREs (as implemented in the biomod2 R-package [122] for each tabanid species and considered three models: the full model (yellow in the depictions), 95\% (orange) and $90 \%$ (red) of all occurrence points. Maps were created in Esri ArcGIS [123].

\section{Comparison of requirements}

Data were acquired from ESA GlobCover [124] for the activity phases, as well as for the land-cover preference comparisons. For the activity comparison, the amount of frost-free months was derived from the monthly minimum temperature, provided by Worldclim [121]. The type of land cover was obtained from GlobCover at the respective sites for the land-cover comparison and the relative frequencies of individual LC-types were compared with the availability of the LC-type (relative frequency in the study area). The range of the study area is reduced to $-10^{\circ} \mathrm{W}, 45^{\circ} \mathrm{E}, 79^{\circ} \mathrm{N}$ and $35^{\circ} \mathrm{S}$ based on the lack of data from more eastern areas. Land cover categories were combined when adequate, resulting in 11 
categories: Cropland > 50\% (11, 14); Grass/Shrubland $(110,120,130,140)$; Broadleaf Forest $(40,50,60)$; Mixed Forest (100); Dense Evergreens (70); Light Evergreens (90); Mosaic Vegetation (20, 30); Sparse Vegetation (150); Artificial (190); Water Bodies (210); and Other (160, 170, 180, 195, 215).

\section{Results}

Figure 1 shows three different models of all six surveyed species. The $90 \%$ and $95 \%$ models for C. caecutiens showed a very fragmented distribution with the center of these models lying in the northern part of Europe. The full model extended from central Spain over all European countries, including Turkey and Russia, as far as the eastern part of Siberia. A very similar picture emerged for $C$. relictus and $H$. pluvialis, where only the areas in Spain and Turkey are missing in the comparison. Incorporating the niches' climatic variables (Fig. 2), all three species showed very similar patterns: the $90 \%$ and $95 \%$ model mostly made up less than $50 \%$ of the full model and were skewed in one direction. In climatic variable Bio18, C. caecutiens showed a higher tolerance for low precipitation than C. relictus and H. pluvialis.

For T. bovinus, T. bromius and T. sudeticus, the $90 \%$ and 95\% models were closer to the full model. The full model closed gaps in central Europe as well as added areas in (northeastern) Finland and central Russia. For T. sudeticus, the full model closed most gaps within the original distribution. The climatic variables (Fig. 2) were relatively similar for these three species. For T. sudeticus, the 95\% model incorporated most of the niche when considering only the variables.

Figure 3 shows that most species (except T. sudeticus) occur in small numbers in areas with two frost-free months. Most occurrences are within 9 months for $C$. relictus, C. caecutiens and H. pluvialis. Haematopota pluvialis also had a slightly decreased occurrence rate of 11 months. The highest numbers of individuals of T. bovinus occured at 5 and 6 months. Tabanus bromius showed a steady distribution at 5, 6, 7, 9 and 11 months. Tabanus sudeticus showed the most individual occurrences at 7 and 11 months. The data from 5 months on (except for 10 months) showed a slightly lower frequency. No species demonstrated more than $3 \%$ of their occurrences in areas with 10 frost-free months.

The comparison of land cover type and species occurrence (Fig. 4) shows that in the Cropland category, all the species occured at a frequency between half and a quarter of the expected value. Tabanids occured in areas with the category Grass/Shrubland between 2-3.5 times the expected frequency, except for T. bovinus, which occured only slightly more frequently. In Broadleaf Forest, there were only minor deviations from the expected value, with $H$. pluvialis occurring slightly less frequently and $T$. bromius occurring slightly more frequently. Similarly, in Mixed Forest there was only a slightly higher value for $T$. bovinus. In the category Dense Evergreens, C. caecutiens, C. relictus and $T$. bovinus showed a negative deviation from the expected value between $60 \%$ and $90 \%$ while $T$. bromius (30\%) and T. sudeticus (80\%) were more common. Except for the values, this effect was exactly the opposite in the category Light Evergreens. Mosaic vegetation shows no fundamental difference. Sparse Vegetation showed a slight increase in occurrence of T. bovinus, but a reduction of the other species between $60-180 \%$. The Artificial category showed the largest deviations from the expected value by far, with positive deviations between $260 \%$ ( 2.6 times the expected value) and $510 \%$ (5.1 times the expected value). In the Water Bodies category, the values were slightly negative for $C$. caecutiens, C. relictus and T. bovinus, while they are more pronounced for the species T. bromius $(130 \%)$ and T. sudeticus (80\%). The category Other showed medium to strong negative deviations for all species except for T. bovinus.

\section{Discussion}

We modelled the potential distribution of six common horsefly species in Eurasia and compared their niches. An SRE model was used because no extensive monitoring with standardized methods exists. Hence, the available data show a strong bias with large regions being severely underrepresented or not considered at all. Due to the very dense sampling in western Europe, a skewed picture emerges, although several of the species also occur about $6000 \mathrm{~km}$ further east. The investigated species require moist soil (Tabanus, Haematopota) or lakes, ponds and rivers (Chrysops) for egg deposition and larval development [25, 39-42]. In addition, the larvae are often detrivorous or can feed predatorily on small insects or worms [125]. The species are relatively common and widespread in Europe and are therefore likely to appear in many surveys, making them adequate examples for this methodology. For the model, we counteracted the sampling bias as much as possible by reducing the number of samples to one per grid cell. It is therefore likely that all species can truly fill most of the niche (full model) calculated in the analysis.

When comparing the areas of the $90 \%$ model, it becomes apparent that the distribution area is very small due to a dense monitoring in western and central Europe and a very similar distribution for all six species could be expected. When taking the full model into account, a different picture emerges. Three species, i.e. C. caecutiens, $C$. relictus and $H$. pluvialis, have a much larger niche than evident from the data. Here, C. caecutiens has the largest distribution and the distribution 

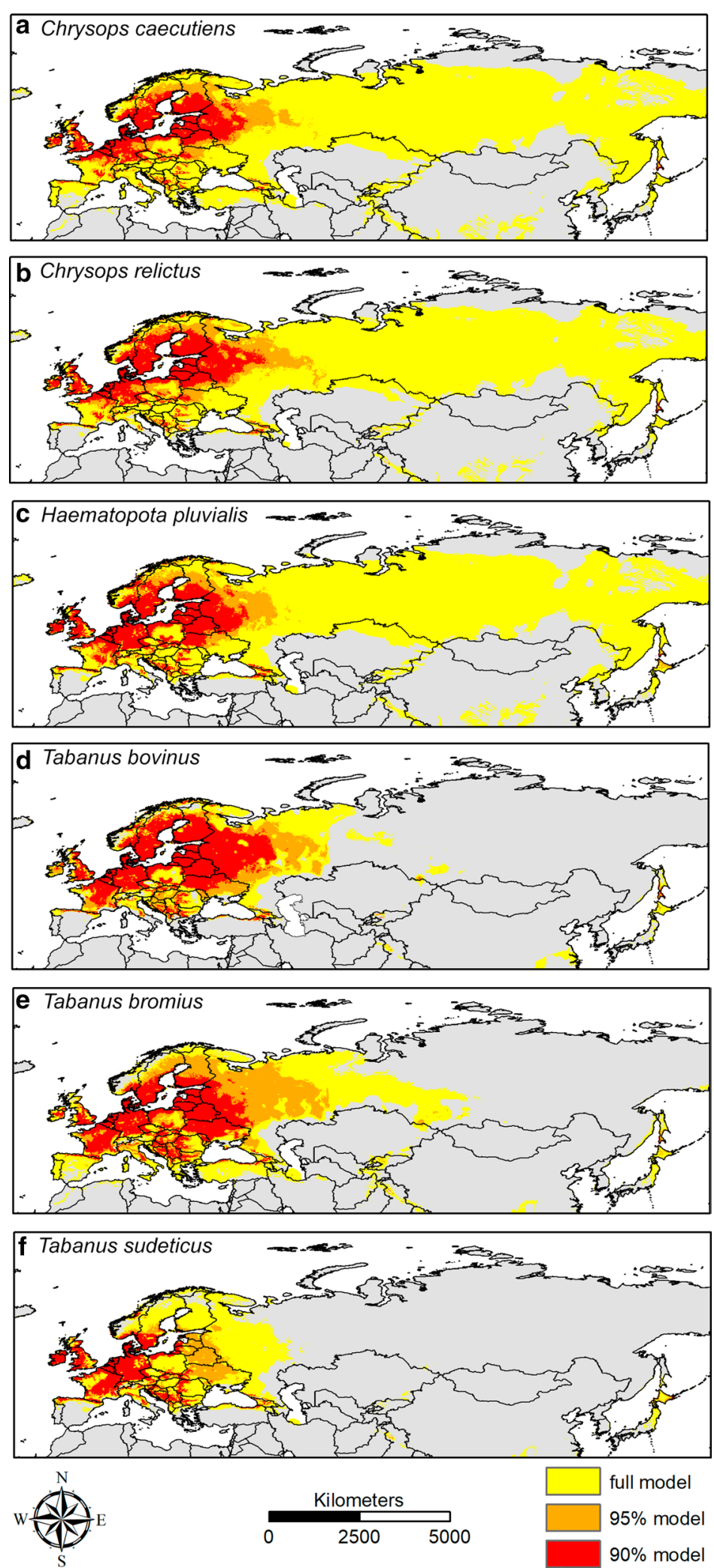

Fig. 1 Modelled distribution of the six species. Key: yellow, full model; orange, $95 \%$ model ( $5 \%$ outliers removed); red, $90 \%$ model (10\% outliers removed). Figure created with Esri ArcGIS [123] 

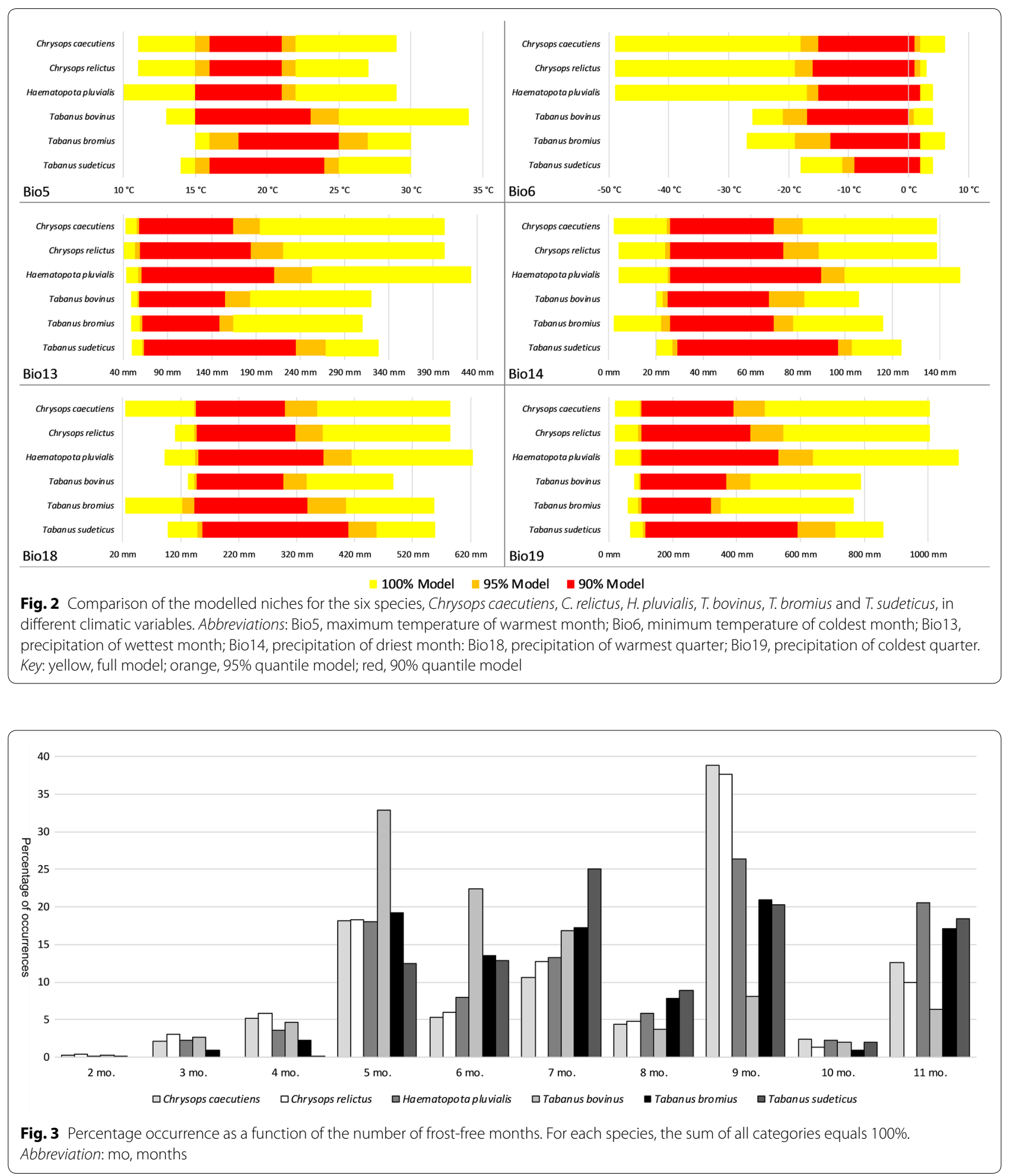

areas of the other three species overlap even in the eastern areas, where only few surveys have been made. Tabanus bovinus and T. bromius have similarly large niches which are mostly overlapping and are supported by data collection in Europe. Tabanus sudeticus has the smallest distribution. The distribution of collected sightings of T. bovinus and the results of our calculation 


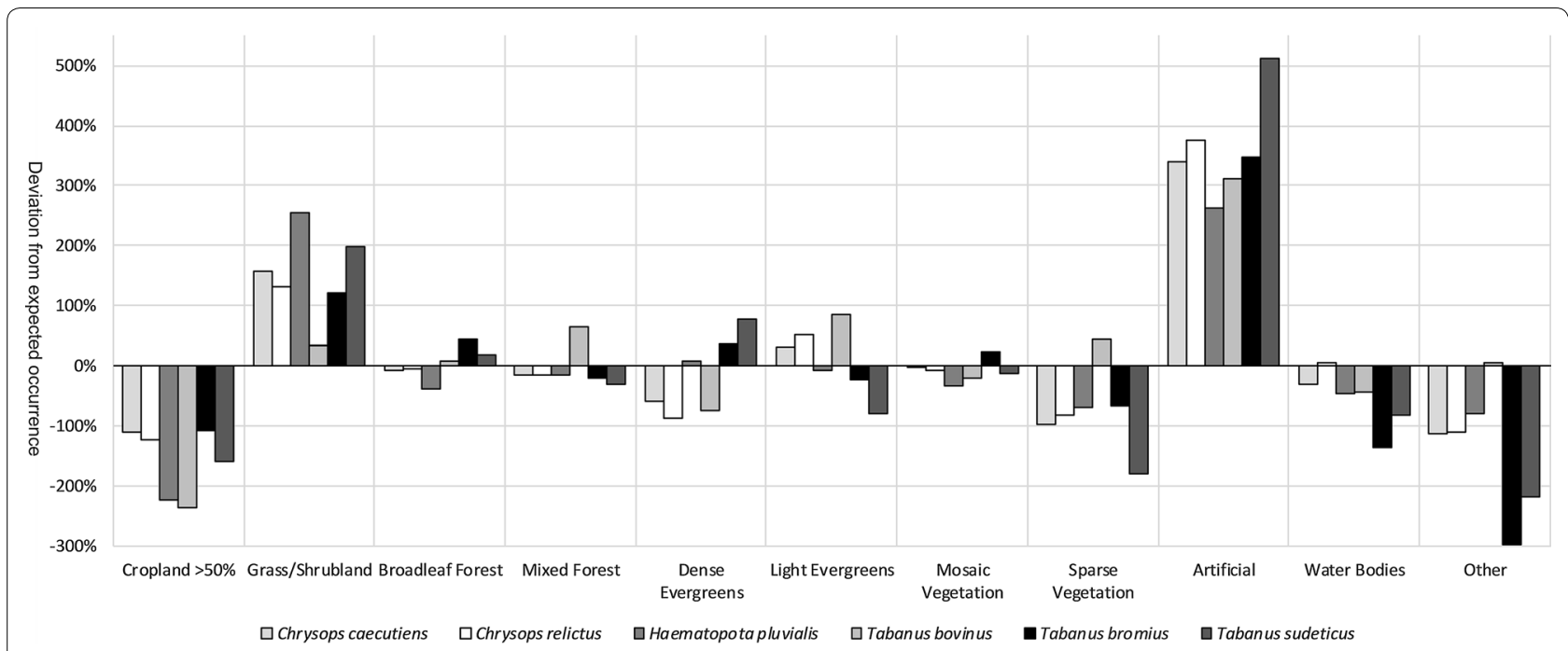

Fig. 4 Deviation of occurrence of the species compared to available land cover. A positive value of $100 \%$ shows that the species occurs twice as often as expected in the respective areas. Conversely, a negative value of $100 \%$ indicates an abundance that is only half as high as expected

are very close to the known distribution which is shown in Fig. 1.

\section{Activity phases}

When comparing the frequency of occurrence as a function of the number of frost-free months, it is apparent that five of the six species can occur in areas with only two frost-free months, albeit with only a few individuals. This frequency gradually increases up to five months, with $T$. sudeticus appearing in areas with at least four frost-free months. The remaining numbers show the direct influence of the sampling bias towards central and western Europe. The extreme peak at nine months is mainly due to heavy sampling in central Europe, while the increased numbers at 11 months are almost entirely due to the inclusion of England and Ireland. It is known that horseflies hibernate as larvae and may require several years for their development [126]. In central Europe, development spans between one and three years. However, assuming an area with only two frost-free months per year, this number could increase significantly. The most cold-tolerant species are C. caecutiens, $C$. relictus and $H$. pluvialis with occurrences in areas that plunge below $-58{ }^{\circ} \mathrm{C}$.

\section{Land-cover comparison}

As expected, monoculture cropland was avoided by all six species. This may be due to pesticide use, lack of hosts and lack of areas for egg-laying and larval development and lack of adequate sites for mating behavior, as well as a shortage of sugar sources [127-129]. It is also not surprising that grassland and scrubland are preferred. Since Grasslands, or areas with some lowland scrub, are mostly used as grazing land for livestock [130], tabanids can easily find the hosts they need. Broadleaf forest, mixed forest and mosaic vegetation show no particular effect on tabanid preference or aversion. However, Dense Evergreen and Light Evergreen showed an interesting pattern on preference and aversion, which largely balances out when the two categories are combined. We remark that $C$. relictus, $C$. caecutiens and $T$. bovinus avoid dense evergreen, while at least T. sudeticus prefers it. Sparse vegetation is avoided by all species except for $T$. bovinus. This can be explained by the fact that within these areas, significantly fewer animals can serve as hosts. An interesting result is that all species have an extreme preference for Artificial areas category. This is most likely due to the fact that populated areas harbor domestic animals, grazing animals, livestock and, ultimately, people in the immediate vicinity. It is important to note that although the dataset has been adjusted and reduced to one point per grid cell, a sampling bias is still present towards heavily populated as well as frequently surveyed areas. This would explain at least part of the extreme values of the Artificial category. Baldacchino et al. [38] were able to show parts of the current horsefly diversity of western and southern European countries in a large-scale study of almost 80,000 captured animals. In comparison to other areas, a significantly lower diversity of species could be found on pastureland, with larger, well-flying species preferring these areas for host searching. Another study by Baldacchino et al. [113] also suggested a preference for mosaic landscape and light forest. Our analysis cannot 
confirm this result since our dataset does not support any preference for mosaic landscape. On the other hand, our analyses show that forest cover presents mixed results for aversion or preference by the examined species. The land-cover analysis also shows that tabanids equally colonize water bodies if they are available. However, the numbers mostly show an underrepresentation, which is explained by the fact that the available land cover is taken with a resolution of 300 meters, so most water bodies are not presented in the dataset. The category "Other" consists of several land-cover types with very few occurrences and should therefore, be considered carefully if at all. Overall, we have reduced the influence of sampling biases as much as possible, but the effects still shift our results. A standardized monitoring programme is needed to clarify these results and enable future calculations to be more exact.

\section{Quality of the model}

Our envelope model included Japan as a suitable area for all species. This is highly unlikely, at least for the three Tabanus species. According to the GBIF database, H. pluvialis occurs in Japan. However, this isolated occurrence was not included in the calculation due to the extreme distance to other sites but is a realistic occurrence point for this species after calculating the model. Other remote areas such as the Asian Highlands (Pamir, Hindukush, Himalaya) were additionally estimated as suitable sites by our model. We doubt that these mountain ranges are actually suitable areas for tabanid habitation and that an exclusionary factor is lacking in the model. For the three Tabanus species specifically, it is very unlikely that they can be found in these areas. For Chrysops species and $H$. pluvialis, however, the areas are within the range of the main distribution spectrum but are discontinuous. We considered temperature and precipitation as important climatic factors. There can also be other factors that are not considered in this study, but which locally exclude the occurrence of these species (e.g. snow cover, humidity). Our model is based on a continental scale, where climatic factors are the most important to show rough distribution patterns [131]. Fine-scale models could go into more detail and include microclimatic effects, but due to the continental scale and the lack of available data, this is beyond the scope of this study. The delimited parts of the model (e.g. southern China, mountain ranges of Asia) in which some species could occur due to a calculated suitable habitat, but either do not occur or it is unknown, show possible distribution areas, which, however, have not been colonized due to dispersal barriers or a missing limiting factor.

\section{Conclusions}

The distribution of most tabanids is not monitored enough in many areas. The SRE model is an effective tool to calculate the distribution of species that are well monitored in some areas but poorly in others. Our results support the hypothesis that the available distribution data underestimate the actual distribution of the surveyed species. Especially C. relictus, C. caecutiens and H. pluvialis have a much larger calculated niche than the collated observations represent. Our results also show that five of the six species occur in areas with only two frost-free months per year, revealing a strong resistance against temperatures up to $-58{ }^{\circ} \mathrm{C}$. We found that the six species of horseflies strongly prefer populated areas, as well as grassland and scrubland and avoid arable land and regions of sparse vegetation. Our results reveal that only the observed distribution of T. bovinus closely resembles the calculated niche while the other species are most likely not monitored enough. Both Chrysops species have almost the same observed distribution and calculated niche, as well as land-cover preferences. We also suggest a standardized monitoring programme, which can improve and validate this methodology for tabanids and other species. With the help of predictions from this model, further monitoring can be planned in areas where few or no observations have been recorded to confirm and extend our model.

\section{Acknowledgements \\ We thank Dr. Adrienne Jochum for proofreading the manuscript. \\ Authors' contributions \\ DDD designed and conceptualized the study, wrote the main manuscript text, executed the statistical analysis, interpreted the data and prepared Figs. 2, 3, \\ 4. SC executed the statistical analysis, interpreted the data and prepared Fig. 1. SK designed and conceptualized the study. All authors read and approved the final manuscript.}

\section{Funding}

Open access funding provided by Projekt DEAL. This research was funded by the German Federal Ministry of Food and Agriculture (BMEL) through the Federal Office for Agriculture and Food (BLE) (Grant Numbers 2819104415 and 2819105115) and by the Uniscientia Foundation (P 121-2017).

\section{Availability of data and materials \\ The data are available through the cited references as stated in the Methods section.}

Ethics approval and consent to participate

Not applicable.

\section{Consent for publication}

Not applicable.

\section{Competing interests}

The authors declare that they have no competing interests.

\section{Author details}

${ }^{1}$ Institute for Ecology, Evolution and Diversity, Goethe-University, Max-von-Laue-Str. 13, 60439 Frankfurt/Main, Germany. ${ }^{2}$ Senckenberg Biodiversity and Climate Research Centre, Senckenberg Gesellschaft für Naturforschung, Senckenberganlage 25, 60325 Frankfurt/Main, Germany. 
Received: 22 June 2020 Accepted: 24 August 2020

Published online: 10 September 2020

\section{References}

1. Pape T, Thompson FC. Systema Dipterorum (version 2.0, Jan 2011). In: Roskov Y, Ower G, Orrell T, Nicolson D, Bailly N, Kirk PM, et al., editors. Species 2000 \& ITIS Catalogue of Life, 2019 Annual Checklist. Leiden: Naturalis; 2019.

2. Cheng TC. General parasitology. 2nd ed. Oxford: Elsevier Science; 1986.

3. Chvála M, Lyneborg L, Moucha J. The horse flies of Europe (Diptera, Tabanidae). Copenhagen: Entomological Society of Copenhagen; 1972

4. Veraldi S, Esposito L. Skin lesions caused by Tabanus bovinus bites. J Travel Med. 2017;24:5.

5. Smith SM. Tabanus bovinus in Bolivia? J Travel Med. 2018:25:1.

6. Baldacchino F, Desquesnes M, Mihok S, Foil LD, Duvallet G, Jittapalapong S. Tabanids: neglected subjects of research, but important vectors of disease agents! Infect Genet Evol. 2014;28:596-615.

7. Chippaux J-P, Bouchité B, Demanou M, Morlais I, Le Goff G. Density and dispersal of the loaiasis vector Chrysops dimidiata in southern Cameroon. Med Vet Entomol. 2000;14:339-44.

8. Foil LD. Tabanids as vectors of disease agents. Parasitol Today. 1989:5:88-96

9. Wiesenhütter E. Research into the relative importance of Tabanidae (Diptera) in mechanical disease transmission. J Nat Hist. 1975;9:385-92.

10. Turkington C, Ashby B. The encyclopedia of infectious diseases. 3rd ed. New York: Facts On File; 2007.

11. Padgett JJ, Jacobsen KH. Loiasis: African eye worm. Trans R Soc Trop Med Hyg. 2008;102:983-9.

12. Krinsky WL. Animal disease agents transmitted by horse flies and deer flies (Diptera: Tabanidae). J Med Entomol. 1976;13:225-75.

13. Issel CJ, Foil LD. Studies on equine infectious anemia virus transmission by insects. J Am Vet Med Assoc. 1984;184:293-7.

14. De Liberato C, Magliano A, Autorino GL, Di Domenico M, Sala M, Baldacchino F. Seasonal succession of tabanid species in equine infectious anaemia endemic areas of Italy. Med Vet Entomol. 2019;33:431-6.

15. Böse R, Friedhoff KT, Olbrich S, Büscher G, Domeyer I. Transmission of Trypanosoma theileri to cattle by Tabanidae. Parasitol Res. 1987:73:421-4.

16. Dirie MF, Bornstein S, Wallbanks KR, Stiles JK, Molyneux DH. Zymogram and life-history studies on trypanosomes of the subgenus Megatrypanum. Parasitol Res. 1990;76:669-74.

17. Joshi PP, Shegokar VR, Powar RM, Herder S, Katti R, Salkar HR, et al. Human trypanosomiasis caused by Trypanosoma evansi in India: the first case report. Am J Trop Med Hyg. 2005;73:491-5.

18. Le Goff F, Marjolet M, Humphery-Smith I, Leclercq M, Hellas C, Supplisson F, et al. Tabanid spiroplasmas from France: characterization, ecology and experimental study. Ann Parasitol Hum Comp. 1993;68:150-3.

19. Grulet O, Humphery-Smith I, Sunyach C, Le Goff F, Chastel C. 'Spiromed': a rapid and inexpensive Spiroplasma isolation technique. J Microbio Methods. 1993;17:123-8.

20. Hackett KJ, Whitcomb RF, French FE, Tully JG, Gasparich GE, Rose DL, et al. Spiroplasma corruscae sp. nov., from a firefly beetle (Coleoptera: Lampyridae) and tabanid flies (Diptera: Tabanidae). Int J Syst Bacteriol. 1996:46:947-50

21. Olsufiev NG, Golovd A. Horse flies as transmitters and conservators of tularaemia. Animaux Pathog. 1936;2:187-226.

22. Hornok S, Micsutka A, Meli ML, Lutz H, Hofmann-Lehmann R. Molecular investigation of transplacental and vector-borne transmission of bovine haemoplasmas. Vet Microbiol. 2011;152:411-4.

23. Mullens BA. Horse flies and deer flies (Tabanidae). In: Mullen GR, editor. Medical and veterinary entomology. New York: Elsevier; 2019. p. 327-43.

24. Alvarez-García G, Frey CF, Ortega Mora LM, Schares G. A century of bovine besnoitiosis: an unknown disease re-emerging in Europe. Trends Parasitol. 2013;29:407-15.

25. Der Bellmann H. neue Kosmos-Insektenführer: extra: die wichtigsten Spinnentiere. Stuttgart: Kosmos; 1999.
26. Liebisch A. Vector biology of flies on grazing cattle in Germany. In: Thomas G, Over HJ, Vecht U, Nansen P, editors. Summer mastitis. Dordrecht: Springer; 1987. p. 109-15.

27. Chvála M, Ježek J. Diptera, Tabanidae, Horse flies. In: Nilsson A, editor. Aquatic insects of Northern Europe A taxonomic handbook, Vol. 2: Odonata. Diptera. Vester Skerninge: Apollo Books; 1997.

28. Ellenberg $H$, Dierschke H. Vegetation Mitteleuropas mit den Alpen: In ökologischer, dynamischer und historischer Sicht; 203 Tabellen. 6th ed. Stuttgart: Verlag Eugen Ulmer; 2010

29. Schönborn W, Risse-Buhl U. Lehrbuch der Limnologie. 2nd ed. Stuttgart: Schweizerbart; 2013.

30. Frouz J. Use of soil dwelling Diptera (Insecta, Diptera) as bioindicators: a review of ecological requirements and response to disturbance. In: Paoletti MG, editor. Invertebrate biodiversity as bioindicators of sustainable landscapes: practical use of invertebrates to assess sustainable land use. Amsterdam: Elsevier; 2001. p. 167-86.

31. Mustapha J, Hill SB. Short-term effects of diazinon on soil arthropods. Rev Ecol Biol Sol. 1974:11:197-200.

32. Hallmann CA, Sorg M, Jongejans $E$, Siepel H, Hofland N, Schwan H, et al. More than 75 percent decline over 27 years in total flying insect biomass in protected areas. PLOS ONE. 2017;12:e0185809.

33. Benton TG, Bryant DM, Cole L, Crick HQP. Linking agricultural practice to insect and bird populations: a historical study over three decades. J Appl Ecol. 2002;39:673-87.

34. Mazoyer M, Roudart L. Histoire des agricultures du monde. Du néolithique à la crise contemporaine. Paris: Le Seuil; 2017.

35. Hansens EJ. Review: Tabanidae of the east coast as an economic problem. J NY Entomol Soc. 1979;87:312-8.

36. Maramorosch K, editor. Biological transmission of disease agents Burlington: Elsevier Science; 1962.

37. Barashkova Al, Reshetnikov AD. Traps effectiveness in the fight against horse flies (Diptera, Tabanidae) on Alas pastures. Agrar Vestn Urala. 2017:155:4-7.

38. Baldacchino F, Krčmar S, Bernard C, Manon S, Jay-Robert P. The impact of land use and climate on tabanid assemblages in Europe. Agric Ecosyst Environ. 2017;239:112-8.

39. Edwards FW, Oldroyd H, Smart J. British blood-sucking flies. London: British Museum (Natural History); 1939.

40. Burgess NRH, Shuttleworth AE, Chetwyn KN. The immature stages of the common cleg Haematopota pluvialis L. (Diptera: Tabanidae): in the field and in the laboratory. J Roy Army Med Cps. 1978;124:27-30.

41. Steinbach $\mathrm{G}$, Reichholf-Riehm H, Kühbandner R, editors. Insekten: Mit Anhang Spinnentiere. München: Mosaik-Verl; 1996.

42. Haupt J, Haupt H. Fliegen und Mücken: Beobachtung, Lebensweise. Augsburg: Naturbuch-Verl; 1998.

43. Andreeva RV. On ecologo-morphological typing of tabanid larvae (Diptera, Tabanidae). Entomol Rev. 1982;64:49-54.

44. Andreeva RV. Keys to horsefly larvae. European part of the USSR, Caucasus, Central Asia. Kiev: Naukova Dumka; 1990.

45. Agapitova AV, Balakhonova VA. To fauna of gadflies (Diptera, Tabanidae) in Kurgan region. Vestnik KGU. 2011:2:35-9.

46. Aibulatov SV. Bloodsucking dipterans (Diptera: Ceratopogonidae, Culicidae, Simuliidae, Tabanidae) of the Kurgala Peninsula, Leningrad Province. Entmol Rev. 2009;89:645-58.

47. Aibulatov SV, Chetverikova T, Chetverikov P. List of horseflies (Diptera: Tabanidae) from Belgrade neighbourhoods (Serbia). Acta Ent Serbica. 2012:17:167-9.

48. Aistleitner E. Zur Kenntnis der Bremsenfauna der Iberischen Halbinsel (Diptera, Brachycera, Tabanidae). Entomofauna. 2008;29:281-92.

49. Akbaev RM, Cherednichenko DA. Species composition of flies of the Chekhov district of the Moscow region. Sov Pro Parasitol. 2017:21-3.

50. Altunsoy F, Ercan I, Ocakoglu G. Analysis of morphometric characteristics of different populations of Tabanus bromius Linne 1758 (Diptera: Tabanidae). Pak J Zool. 2017:49:1013-8.

51. Aspöck H. Durch Arthropoden übertragene Erreger von Infektionen des Menschen in Mitteleuropa - ein Update. Mitt Dtsch Ges Allg Angew Entomol. 2008;16:371-92.

52. Balashov YS. Harmfulness of parasitic insects and acarines to mammals and birds. Entmol Rev. 2007:87:1300-16. 
53. Baldacchino F, Gardès L, De Stordeur E, Jay-Robert P, Garros C. Bloodfeeding patterns of horse flies in the French Pyrenees. Vet Parasitol. 2014;199:283-8

54. Barashkova Al. Fauna of the flies (Diptera, Tabanidae) in the agrocenoses of central Yakutia. Agrar Vestn Urala. 2017;161:12-5.

55. Barashkova Al, Reshetnikov AD. Investigation into the practical use of means and methods for protection of farm animals from blood-sucking dipterous insects in Yakutia. Bar Resh. 2014;36:7-13.

56. Beron P, editor. Biodiversity of Bulgaria. 3. Biodiversity of western Rhodopes (Bulgaria and Greece) I. Pensoft: Sofia; 2006.

57. Blahó M, Egri Á, Barta A, Antoni G, Kriska G, Horváth G. How can horseflies be captured by solar panels? A new concept of tabanid traps using light polarization and electricity produced by photovoltaics. Vet Parasitol. 2012;189:353-65.

58. Budaeva IA, Prisniy YA, Vlasova EV, Vislevskaya EY. To the study of the fauna gadflies (Diptera, Tabanidae) of areas of reserve "Belogorie" "Yamskaya Step" and "Lysiye Gory. Sci Bull BelSU. 2013;153:83-6.

59. Budaeva IA, Ruchin AB. To the fauna of horseflies (Diptera: Tabanidae) of the Republic Mordovia (Russia). Nauchn Ved Belgorod Gos Univ Ser. Estestv Nauki. 2016:232:85-93

60. Dementev MS. Biodiversity horseflies (Tabanidae) Ciscaucasia central and adjacent mountain areas. Nauka Innovatsii Tekhnologii. 2014;4:184-90.

61. Drees M. Die Bremsen des Hagener Raumes (Diptera: Tabanidae). Nat u Hei. 2012;72:77-89

62. Dvořák L. Some data to horsefly fauna (Diptera: Tabanidae) in southeastern part of the Bohemian forest, Czech Republic, with notes to Hybomitra arpadi (Szilády, 1923). Silva Gabreta. 2011;17:73-81.

63. Egorov SV. Fauna of gadflies (Diptera, Tabanidae) in the central area of Nonchernozem zone of Russia. Ross Parazitol Zhurnal. 2010;4:19-21.

64. Egorov SV, Belyaev DK. Gadfly ecology peculiarities (Diptera, Tabanidae) in the central region of the Non-Chernozem zone of Russia. Theory Pract Animal Parasitic Dis. 2012;3:164-6.

65. Egri Á, Blahó M, Száz D, Kriska G, Majer J, Herczeg T, et al. A horizontally polarizing liquid trap enhances the tabanid-capturing efficiency of the classic canopy trap. Bull Entomol Res. 2013;103:665-74.

66. Egri Á, Blahó M, Száz D, Barta A, Kriska G, Antoni G, Horváth G. A new tabanid trap applying a modified concept of the old flypaper: linearly polarising sticky black surfaces as an effective tool to catch polarotactic horseflies. Int J Parasitol. 2013;43:555-63.

67. El-Hawagry MS, Abdel-Dayem MS, Elgharbawy AA, Dhafer HMA. A preliminary account of the fly fauna in Jabal Shada al-A'la Nature Reserve, Saudi Arabia, with new records and biogeographical remarks (Diptera, Insecta). ZooKeys. 2016;636:107-39.

68. Falck M. The horse flies (Diptera, Tabanidae) of Norway. Nor J Entomol. 2014:61:219-64.

69. Ganeva D. The tabanids fauna (Tabanidae, Diptera) of Stara Planina (Bulgaria). In: Gruev B, Nikolova M, Donev A, editors. Balkan Scientific Conference of Biology; 19-21 May 2005. Plovdiv: Bulgaria; 2005. p. 397-403.

70. Ganeva D. The tabanid fauna (Diptera: Tabanidae) of the Saint Ilijski Eminences (Bulgaria). Acta Zool Bulg. 2008;2:19-24.

71. Ganeva D. The tabanids (Diptera: Tabanidae) from the Belassitsa Mountain, Bulgaria. J Agric Sci Technol. 2009;1:30-2.

72. Ganeva D. Horse flies (Diptera, Tabanidae) of Surnena Sredna Gora Mountain, Bulgaria. Trakia J Sci. 2011;9:13-6.

73. Ganeva D. Horse flies (Diptera: Tabanidae) of Vrachanska Planina Mountains. ZooNotes. 2016:3:181-4.

74. Ganeva D. Horse flies (Diptera: Tabanidae) in the Rila Mts., Bulgaria. Acta Zool Bulg. 2017:8:131-8.

75. Grayson A. The horseflies of Yorkshire: A.D. 2000 update. Larger Brachycera recording scheme 2000:18:7-15

76. Herczeg T, Száz D, Blahó M, Barta A, Gyurkovszky M, Farkas R, et al. The effect of weather variables on the flight activity of horseflies (Diptera: Tabanidae) in the continental climate of Hungary. Parasitol Res. 2015;114:1087-97.

77. Isimbekov JM, Nurlina AB. Distribution and landscape occurrence of horseflies (Diptera, Tabanidae) in the Pavlodar Irtysh region. Bull AGAU. 2008:7:46-7.
78. Ježek J, Vonicka P, Preisler J. Tabanidae (Diptera) of the Jizerské hory Mts and Frýdlant region (northern Bohemia, Czech Republic). Sborník Severočeského Muzea, Liberec. 2008:26:187-200.

79. Kiliç AY. Investigations on Tabanidae (Diptera) fauna of Bartın, Karabük and Zonguldak provinces of Turkey. Türk Entomol Derg. 2005;29:151-60.

80. Kofler A, Schacht W. Zum Vorkommen von Bremsen in Osttirol und Kärnten und angrenzenden Gebieten (Diptera, Tabanidae). Entomofauna. 2009:30:353-64.

81. Kolbeck H. Bemerkenswerte Funde von Schwebfliegen, Bremsen und Waffenfliegen aus dem Bodenwöhrer Becken (Diptera: Syrphidae, Tabanidae, Stratiomyidae). Beitr Bayer Ent. 1995;1:159-68.

82. Kozlova GG, Minina NN, Onina SA, Usmanov SM. The Ecology of the Lake Podvornoe in the Birsk District the Republic of Bashkortostan. Zdorov'e XXI Veke. 2016;18:8-11.

83. Krčmar S. Seasonal abundance of horse flies (Diptera: Tabanidae) from two locations in eastern Croatia. J Vector Ecol. 2005;30:316-21.

84. Krčmar S. Preliminary list of horse flies (Diptera, Tabanidae) of Serbia. ZooKeys. 2011;117:73-82.

85. Krčmar S, Durbesic P. Ecological niches of horse flies and the selectivity of Malaise traps (Diptera: Tabanidae). Period Biol. 2000;102:269-72.

86. Krčmar S, Mikuška A, Jasika M. Horsefly fauna of three different forest communities in the Danube river floodplain in Croatia (Diptera: Tabanidae). Entomol Gener. 2009;32:23-34.

87. Martens C, de Blauwe H, Dekoninck W, Kekenbosch R, Lock K, Menten J, et al. Resultaten van een Malaisevalcampagne in de vallei van de Zeverenbeek (Deinze, Oost-Vlaanderen, België). Bull Soc Roy Belge Entomol. 2014;150:111-31.

88. Martens C, Mortelmans J, Pollet M, Beuk P, Dekoninck W, de Blauwe H, et al. Resultaten van een Malaisevalcampagne langs een brakke sloot in de Jeronimuspolder (Sint-Laureins, Oost-Vlaanderen, België). Bull Soc Roy Belge Entomol. 2013;149:117-30.

89. Medvedev SG. The fauna of bloodsucking insects of the gnus complex (Diptera) of Northwest Russia. Analysis of distribution. Entomol Rev. 2011:91:1092-107.

90. Medvedev SG. Organization of studies of the gnus complex of bloodsucking dipterans (Diptera: Culicidae, Ceratopogonidae, Tabanidae) by Yu. S. Balashov. Entomol Rev. 2013:93:1218-27.

91. Mikuška A, Krčmar S, Mikuska J. Horse flies (Tabanidae) of Bosnia and Herzegovina. J Vector Ecol. 2008;33:365-9.

92. Mikuška A, Mlinaric S, Begovic L, Curran E. Comparative efficiency of traps for horse fly (Diptera: Tabanidae) survey in riparian oak-ash forests in Danube floodplain. Eur J Entomol. 2016;113:531-6.

93. Mirzaeva AG, Glushchenko NP. Bloodsucking diptera in the foreststeppe regions of Novosibirsk province. Entomol Rev. 2009;89:659-71.

94. Pavlova RP, Khlyzova TA, Latkin SV. The faunistic review of horse flies (Diptera: Tabanidae) on pastures of the southern zone of the Tyumen region. Ross Parazitol Zhurnal. 2012;2:34-41.

95. Pavlova RP, Sivkova El. Faunal overview of horseflies (Diptera, Tabanidae) of Tyumen region. Ukr J Ecol. 2019;9:57-67.

96. Pestov SV, Dolgin MM. Horse-flies (Diptera, Tabanidae): fauna of European North-East of Russia. Horse-flies, vol. XI. St. Petersburg: Nauka; 2013.

97. Pestov SV, Panjukova EV. Landscape and zonal distribution of bloodsucking mosquitoes and horseflies (Diptera: Culicidae, Tabanidae) in the northeastern Russian Plain. Entomol Rev. 2013;93:1129-37.

98. Peterson AM, Chirov PA. Fauna review of horse-flies (Diptera, Tabanidae) collection from zoological museum of Saratov State University. Entomol i parazitol issledovaniya v Povolzh'e. 2008;7:33-5.

99. Petrov JF, Abarykova OL, Egorov SV, Smirnov AA. Bioecological particularities of horse flies (Diptera: Tabanidae) in east upper Volga region and defence methods of animals from their attack. Ross Parazitol Zhurnal. 2008;2:1-6.

100. Potapova NK, Aibulatov SV. The horsefly fauna (Diptera, Tabanidae) of Yakutia. Entomol Rev. 2018;98:1105-12.

101. Prisniy YA. Distribution of bloodsucking dipterous (Diptera) of the families mosquitoes (Culicidae) and horseflies (Tabanidae) on the territory of Belgorod region. Vet Meditsina. 2016;232:393-4.

102. Reichholf JH. Flugzeiten und Häufigkeit von Bremsen und Stechmücken an der Isar südlich von München. Entomofauna. 2006:27:125-32. 
103. Reshetnikov AD, Barashkova Al. Database "Epizootic monitoring of parasitic diseases of animals in Yakutia" created according NVU program. Ross parazitol ž. 2015;3:23-8.

104. Rudzinski H-G, Flügel H-J. Fliegen (Diptera excl. Conopidae et Syrphidae) aus Barberfallen und Netzfängen vom Halberg bei Neumorschen (Nordhessen, Fuldatal). Philippa. 2007;13:59-70.

105. Scharr J. Spektrum potentieller Vektoren für die mechanische Übertragung von Besnoitia besnoiti beim Rind: Entomologische Untersuchungen zum Vorkommen von Insektenspezies der Familien Tabanidae und Muscidae (Diptera) im Landkreis Erding, Bayern. München: PhD Thesis, Ludwig-Maximilians-Universität; 2012.

106. Šikutova S, Halouzká J, Baruš V. Mermithid nematode parasitizing in Tabanidae (Diptera) in South Moravia, Czech Republic. Helminthologia. 2004;41:113-4.

107. Smirnov AA, Agarikova OL, Philippov RV. Horsefly fauna (Diptera, Tabanidae) in the upper Volga region. AVU. 2006;34:51-3.

108. Takken W, Verhulst N, J. Scholte E, H. H. Jacobs F, Jongema $Y$, van lammeren $\mathrm{R}$, et al. Distribution and dynamics of arthropod vectors of zoonotic disease in the Netherlands in relation to risk of disease transmission. Wageningen University; 2007

109. Vaduva G. A study on bloodsucking Tabanidae and Stomoxys calcitrans (Diptera) attacking horses and cows in northern Scania, Sweden. J Biol Life Sci. 2015;7:19.

110. Vonička P. Results of the entomological survey in the Jizerské hory mts and Frýdlant region I. Liberec: Severočeské Muzeum; 2008.

111. Zaspel D. Insektizidhaltige Netze zum Schutz von Pferden gegen Bremsen und Lästlingsinsekten aufWeiden in Brandenburg. Berlin: Mensch und Buch-Verl; 2008.

112. Ganeva D. Tabanids (Tabanidae, Diptera) of the Bulgarian part of the Rhodopes. In: Beron P, editor. Biodiversity of Bulgaria. 3. Biodiversity of western Rhodopes (Bulgaria and Greece) I. Sofia: Pensoft; 2006. p. 719-27.

113. Baldacchino F, Puech L, Manon S, Hertzog LR, Jay-Robert P. Biting behaviour of Tabanidae on cattle in mountainous summer pastures, Pyrenees, France, and effects of weather variables. Bull Entomol Res. 2014:104:471-9.

114. occdownload gbif.org. GBIF Occurrence Download 2018. https://doi. org/10.15468/dl.sv8nuo

115. occdownload gbif.org. GBIF Occurrence Download 2019. https://doi. org/10.15468/dl.lo3roa

116. occdownload gbif.org. GBIF Occurrence Download 2019. https://doi. org/10.15468/dl.vokawg

117. occdownload gbif.org. GBIF Occurrence Download 2019. https://doi. org/10.15468/dl.zadec1
118. occdownload gbif.org. GBIF Occurrence Download 2019. https://doi. org/10.15468/dl.iolv1k

119. occdownload gbif.org. GBIF Occurrence Download 2019. https://doi. org/10.15468/dl.6ucnt3

120. occdownload gbif.org. GBIF Occurrence Download 2019. https://doi. org/10.15468/dl.pkutyu

121. Fick SE, Hijmans RJ. Worldclim 2: New 1-km spatial resolution climate surfaces for global land areas. Int J Climatol. 2017;12:4302-15.

122. Thuiller W, Georges $D$, Engler R, Breiner F, Georges MD, Thuiller CW. Package biomod2: ensemble platform for species distribution modeling; 2016. https://cran.r-project.org/web/packages/biomod2/biomo d2.pdf

123. Environmental Systems Research Institute. ArcGIS Desktop. Redlands: ESRl; 2019.

124. Arino O, Ramos Perez JJ, Kalogirou V, Bontemps S, Defourny P, Van Bogaert E. Global Land Cover Map for 2009 (GlobCover 2009). () European Space Agency (ESA) \& Université catholique de Louvain (UCL), Pangaea. https://doi.org/10.1594/PANGAEA.787668

125. Puig MÀ, Benito G. Els macroinvertebrats dels rius catalans: guia il.lustrada. Barcelona: Generalitat de Catalunya; 1999.

126. Schnieder T, Boch J, Supperer R, Bauer C. Veterinärmedizinische Parasitologie. 6th ed. Stuttgart: Parey; 2006.

127. Smith SM, Turnbull DA, Taylor PD. Assembly, mating, and energetics of Hybomitra arpadi (Diptera: Tabanidae) at Churchill, Manitoba. J Insect Behav. 1994;7:355-83.

128. Hunter FF, Ossowski AM. Honeydew sugars in wild-caught female horse flies (Diptera: Tabanidae). J Med Entomol. 1999;36:896-9.

129. Robertson BA, Porter C, Landis DA, Schemske DW. Agroenergy crops influence the diversity, biomass, and guild structure of terrestrial arthropod communities. Bioenergy Res. 2012;5:179-88.

130. Varga A, Molnár Z, Biró M, Demeter L, Gellény K, Miókovics E, et al. Changing year-round habitat use of extensively grazing cattle, sheep and pigs in east-central Europe between 1940 and 2014: consequences for conservation and policy. Agric Ecosyst Environ. 2016;234:142-53.

131. Peterson AT, Soberón J. Species distribution modeling and ecological niche modeling: getting the concepts right. Nat Conserv. 2012;10:102-7.

\section{Publisher's Note}

Springer Nature remains neutral with regard to jurisdictional claims in published maps and institutional affiliations.
Ready to submit your research? Choose BMC and benefit from:

- fast, convenient online submission

- thorough peer review by experienced researchers in your field

- rapid publication on acceptance

- support for research data, including large and complex data types

- gold Open Access which fosters wider collaboration and increased citations

- maximum visibility for your research: over $100 \mathrm{M}$ website views per year

At BMC, research is always in progress.

Learn more biomedcentral.com/submissions 


\title{
Modeling the habitat suitability for the arbovirus vector Aedes albopictus (Diptera: Culicidae) in Germany
}

\author{
Lisa K. Koch ${ }^{1}$ • Sarah Cunze ${ }^{1}$ - Antje Werblow ${ }^{1}$ - Judith Kochmann ${ }^{1}$. \\ Dorian D. Dörge $^{1} \cdot$ Heinz Mehlhorn ${ }^{2} \cdot$ Sven Klimpel $^{1}$
}

Received: 20 August 2015 / Accepted: 10 November 2015 / Published online: 4 December 2015

(C) Springer-Verlag Berlin Heidelberg 2015

\begin{abstract}
Climatic changes raise the risk of re-emergence of arthropod-borne virus outbreaks globally. These viruses are transmitted by arthropod vectors, often mosquitoes. Due to increasing worldwide trade and tourism, these vector species are often accidentally introduced into many countries beyond their former distribution range. Aedes albopictus, a wellknown disease vector, was detected for the first time in Germany in 2007, but seems to have failed establishment until today. However, the species is known to occur in other temperate regions and a risk for establishment in Germany remains, especially in the face of predicted climate change. Thus, the goal of the study was to estimate the potential distribution of Ae. albopictus in Germany. We used ecological niche modeling in order to estimate the potential habitat suitability for this species under current and projected future climatic conditions. According to our model, there are already two areas in western and southern Germany that appear suitable for Ae. albopictus under current climatic conditions. One of these areas lies in Baden-Wuerttemberg, the other in NorthRhine Westphalia in the Ruhr region. Furthermore, projections under future climatic conditions show an increase of the modeled habitat suitability throughout Germany. Ae. albopictus is supposed to be better acclimated to colder temperatures than other tropical vectors and thus, might become,
\end{abstract}

Lisa K. Koch

lisa.koch@senckenberg.de

1 Institute for Ecology, Evolution and Diversity; Senckenberg Biodiversity and Climate Research Centre (BiK-F); Senckenberg Gesellschaft für Naturforschung (SGN), Goethe-University (GU), Max-von-Laue-Str. 13, 60438 Frankfurt/ M., Germany

2 Institute for Parasitology, Heinrich Heine University, Universitätsstr. 1, 40225 Düsseldorf, Germany triggered by climate change, a serious threat to public health in Germany. Our modeling results can help optimizing the design of monitoring programs currently in place in Germany.

Keywords Asian tiger mosquito $\cdot$ Climate change · Ecological niche modeling $\cdot$ Maxent $\cdot$ Species distribution modeling

\section{Introduction}

All over the world mosquitoes are known as nuisance biters. Due to the ongoing climate change the potential range of more and more species may shift northwards. Due to global trade and tourism species are passively transported over large distances (Becker 2008) and may thus be able to reach sites outside the old range with newly suitable habitat conditions. The re-emergence of arthropod-borne viruses in Europe is considered one of the consequences of species redistributions, with tropical mosquitoes functioning as vectors for serious diseases. Tropical mosquitoes often belong to the genera Anopheles or Aedes. One mosquito species that gained attention in Europe over the last decades is the Asian tiger mosquito Aedes albopictus (Ae. albopictus). This species is indigenous to Asia and possesses strong invasion ability (Paupy et al. 2009). First records from Europe date back to 1979 in Albania where it was most likely introduced with goods on ships from Chinas (Adhami and Reiter 1998).

Today, the species has established populations at least in 12 European countries including Italy, Spain, France, and Greece (Dalla Pozza and Majjori 1992; ECDC 2015a, b; Schaffner et al. 2001; Aranda et al. 2006; Giatropoulos et al. 2012). Ae. albopictus has already been introduced into the Netherlands, Belgium, and Germany, presumably with "lucky bamboo" from China to horticultural companies in the Netherlands, 
with used tires from the US and Japan to Belgium, and with tourism from southern Europe to Germany (Schaffner et al. 2000; Scholte et al. 2007; Becker 2008; Pluskota et al. 2008; Kampen et al. 2013; Werner and Kampen 2015). However, despite multiple findings, it is still unclear whether the species managed to establish in these countries (Pluskota et al. 2008; Werner et al. 2012; Becker et al. 2013; Kampen et al. 2013).

The changing climate is assumed to increase the risk of an establishment of Ae. albopictus in northern Europe, e.g., in Germany. Generally, the species is susceptible to infections with many arthropod-borne viruses and some nematode species (see Table 1) and can also function as a transmitter of those. For instance, Ae. albopictus is thought to be responsible for a recent outbreak of chikungunya in Italy and dengue in France and Croatia (Rezza et al. 2007; La Ruche et al. 2010; Gjenero-Margan et al. 2011). Given the species' high medical importance, it could also become a major threat to human health in Germany. In 2011, Becker et al. (2013) initiated a first surveillance network including international airports, harbors, and train stations as sampling sites. However, the authors did not account for environmental factors that might promote an establishment of the species. Despite a predicted global rise in temperature, there will certainly be differences in the habitat suitability for mosquitoes depending on, for instance, altitude or precipitation levels.

Due to expected future climatic changes, we assume that Ae. albopictus will be able to extent its European range northward and thus could establish permanently in Germany. Against this background, we used ecological niche modeling (ENM) in order to project the current and future habitat suitability for Ae. albopictus in Germany. Our results should lead to a better understanding of the species' potential distribution and may identify areas with a high risk of an establishment of Ae. albopictus in Germany. Furthermore, the modeling results will help optimizing the monitoring in the frame of a surveillance program to hinder the species spread.

Table 1 Overview of vector competence of Aedes albopictus. Data from Mitchell (1991). Paupy et al. (2009) and Cancrini et al. (2003a, b)

\begin{tabular}{|c|c|c|c|c|c|}
\hline \multirow[t]{2}{*}{ Disease } & & \multirow[t]{2}{*}{ Family } & \multirow{2}{*}{$\begin{array}{l}\text { Field-caught infected } \\
\text { mosquito }\end{array}$} & \multicolumn{2}{|c|}{ Vector competence (laboratory experiment) } \\
\hline & & & & Infection (of the mosquito) & Transmission (to host) \\
\hline Cache Valley virus & CVV & Bunyaviridae & + & & \\
\hline Potosi virus & POTV & & + & + & + \\
\hline Tensaw virus & TENV & & + & & \\
\hline Jamestown Canyon virus & $\mathrm{JCV}$ & & + & + & + \\
\hline La Crosse virus & LACV & & + & + & + \\
\hline San Angelo virus & SAV & & & + & + \\
\hline Keystone virus & KEYV & & + & + & \\
\hline Trivittatus virus & TVT & & & + & \\
\hline Oropouche virus & OROV & & & + & \\
\hline Rift-Valley-Fever virus & RVFV & & & + & + \\
\hline Dengue virus $1,2,3,4$ & DENV & Flaviviridae & + & + & + \\
\hline Japanese encephalitis virus & JEV & & + & + & + \\
\hline St. Louis encephalitis virus & SLEV & & & + & + \\
\hline West Nile virus & WNV & & + & + & + \\
\hline Yellow fever virus & YEV & & + & + & + \\
\hline Chikungunya virus & CHIKV & Togaviridae & + & + & + \\
\hline Eastern equine encephalitis virus & EEEV & & + & + & + \\
\hline Mayaro virus & MAYV & & & + & + \\
\hline Ross-River virus & RRV & & & + & + \\
\hline Sindbis virus & SINV & & & + & + \\
\hline Venezuelan equine encephalitis virus & VEEV & & & + & + \\
\hline Western equine encephalitis virus & WEEV & & & + & + \\
\hline Getah virus & GETV & & & + & + \\
\hline Orungo virus & ORUV & Reoviridae & & + & + \\
\hline Nodamura virus & NOV & Nodaviridae & & + & \\
\hline Dirofiliaria immitis & D. immitis & Onchocercida & + & & \\
\hline Dirofiliaria repens & D. repens & & + & & \\
\hline
\end{tabular}




\section{Methods}

\section{Occurrence data}

Based on an intensive literature research using references named in Benedict et al. (2007). Fischer et al. (2011) and the European Centre for Disease Prevention and Control (ECDC 2015b). we compiled an occurrence database for Europe. Records of individuals that were not established or with unclear status were not taken into account. For modeling we used 96 occurrence points for Ae. albopictus in Europe.

\section{Environmental data}

For selection of environmental variables we followed the "expert knowledge-based model" by Fischer et al. (2011). Thus, four climatic variables (namely bio01: annual mean temperature, bio10: mean temperature of the warmest quarter, bio11: mean temperature of the coldest quarter, and bio12: annual precipitation) and altitude provided by WorldClim (http://www.worldclim.org/) were chosen.

\section{Model training}

In order to train our model we used variables representing the climatic conditions between 1950 and 2000 and considered the following spatial extent: latitude: $35^{\circ} \mathrm{N}-79^{\circ} \mathrm{N}$, longitude: $10^{\circ} \mathrm{W}-45^{\circ} \mathrm{E}$ and a spatial resolution of 5 arc $\min (\sim 10 \mathrm{~km})$. The time period of the climatic data used for training (19502000) widely matches the time period of the occurrence data. For instance in Italy, many of the occurrence records date back to the early 1990s. A maximum entropy approach was used and implemented in the software Maxent (Phillips et al. 2004; Phillips and Dudík 2008). This correlative and presence-only ENM-method is a good-performing tool (Elith et al. 2006). which is commonly applied to model potential distributions of species under current or future climatic conditions (Hijmans and Graham 2006; Kumar and Stohlgren 2009; Stabach et al. 2009; Trisurat et al. 2009; Reiss et al. 2011; Melaun et al. 2015).

\section{Habitat suitability maps}

WorldClim data representing the period between 1950 and 2000 was used to map the habitat suitability for Ae. albopictus in Germany under current climatic conditions. Additionally, we used data from the Deutscher Wetterdienst (DWD) representing the average climatic conditions (empirical data) between 2011 and 2013 in Germany (see Melaun et al. 2015 for further details on these data). Assuming that climate change has already taken place, these data better reflect the current climatic conditions prevailing in Germany. We did not use the DWD data for model training as they were only available for Germany. In order to display the potential habitat suitability for Ae. albopictus under future climatic condition in Germany, we projected the habitat suitability for the time periods 2021-2040, 2041-2060, and 2061-2080. For data on future climatic conditions, four Representative Concentration Pathways (RCP) scenarios were available at CIAT (http://www.ccafs-climate.org/data/): RCP2.6, RCP4.5, RCP 6.0, and RCP 8.5 (5th Assessment report, IPCC 2013). We used the data based on the global circulation model CSIRO-Mk3.6.0. For projections, a spatial resolution of 30 arc sec $(\sim 1 \mathrm{~km})$ was applied.

\section{Results}

\section{Modeled habitat suitability under current and future climatic conditions (Fig. 1)}

According to our model (AUC value $=0.944$, average over 10 runs), there are already two areas in Germany that are suitable for Ae. albopictus under current climatic conditions (20112013). One area lies in western Baden-Wuerttemberg around Freiburg and northwards. The other area is the Ruhr region in North Rhine-Westphalia. Other parts of Germany are modeled to be currently unsuitable for the species. The projections for all considered future time periods under different RCPs indicate an enlargement of area with suitable habitat conditions and show a similar pattern over all Germany. With regard to the future, best climatic conditions for Ae. albopictus are modeled to prevail in northern Germany and the southeastern (Bavaria) and southwestern parts (around Freiburg). Considering the RCP 2.6 scenario, the modeled habitat suitability increases the least compared to the other RCPs, followed by the RCP 6.0 and the RCP 4.5. The highest increase of modeled habitat suitability for Ae. albopictus in Germany is projected under the RCP 8.5.

\section{Variable importance (Table 2)}

All five variables used for modeling were investigated according to their relative contributions to the model by reevaluating the model on permuted data (Table 2). The mean temperature of the coldest quarter (bio11) was identified as the variable contributing the most to the model, followed by the mean temperature of the warmest quarter (bio10), with a permutation importance of nearly $75 \%$ (bio10 and bio11 together). The other three variables contributed to a lesser extent to the model. 
$1950-2000$

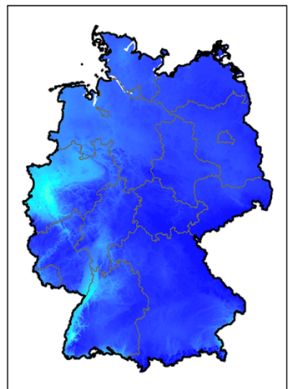

emp. data
2011 - 2013

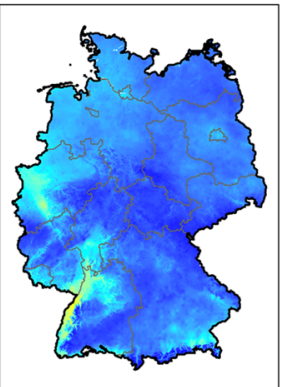

emp. data
$2021-2040$

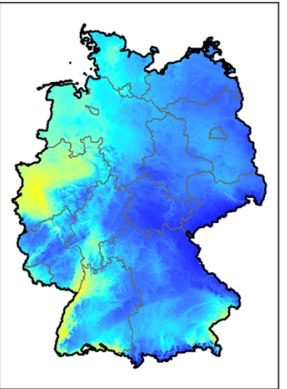

RCP 2.6

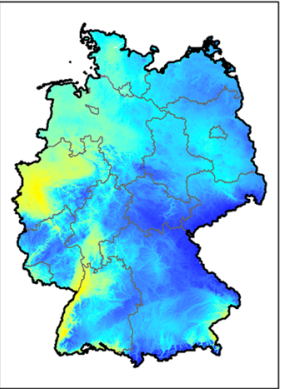

RCP 4.5

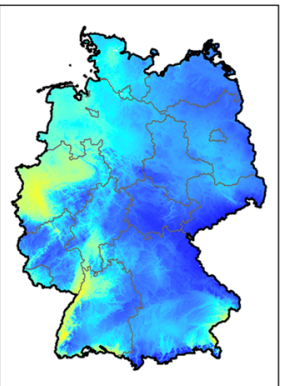

RCP 6.0

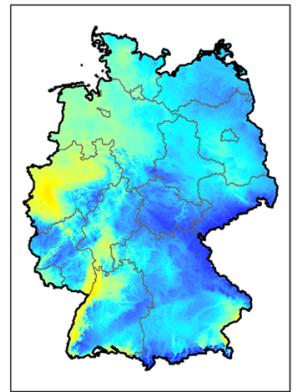

RCP 8.5
2041 - 2060

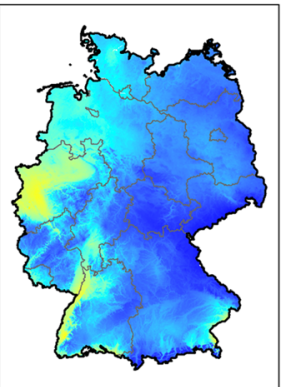

RCP 2.6

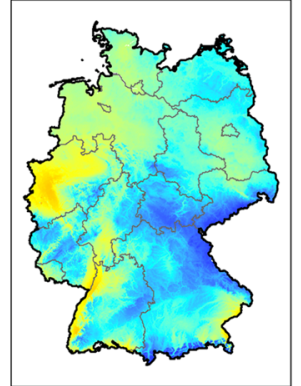

RCP 4.5

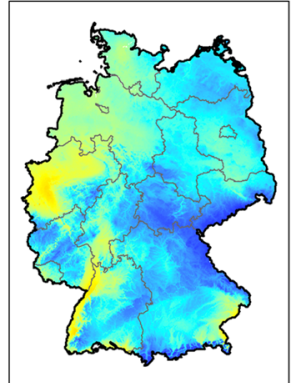

RCP 6.0

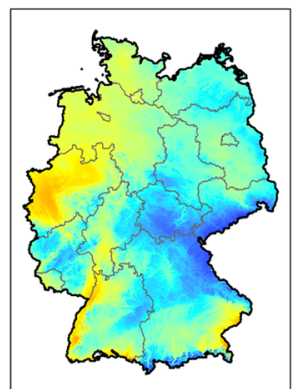

RCP 8.5
2061 - 2080

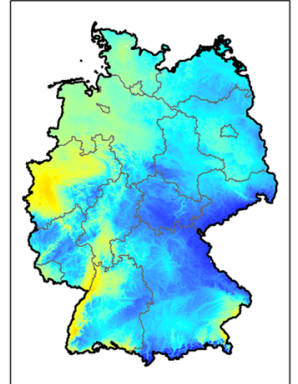

RCP 2.6

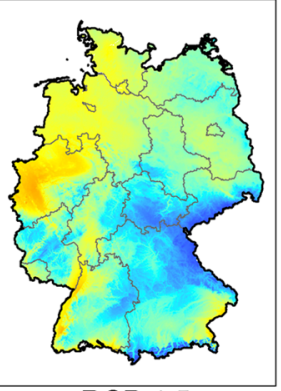

RCP 4.5

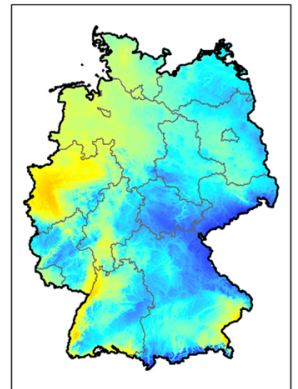

RCP 6.0

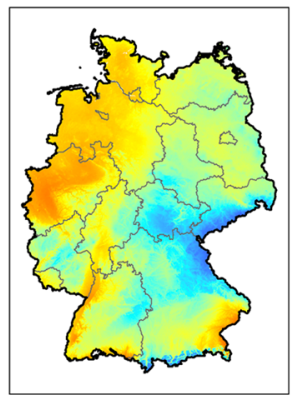

RCP 8.5

Fig. 1 Modeling results for Aedes albopictus in Germany. Continuous modeling results: warmer colors (on a scale from blue to red) indicate areas with higher modeled habitat suitability

\section{One-variable response curves for Ae. albopictus within Europe (Fig. 2)}

The one-variable response curves show the modeled habitat suitability for Ae. albopictus depending on only one variable. Considering the variable bio11, Ae. albopictus is modeled to find suitable conditions up to a mean temperature of the coldest quarter of $0{ }^{\circ} \mathrm{C}$ if a threshold of $22.15 \%$ is applied. This is the threshold that minimizes the difference between sensitivity and specificity and is a commonly applied threshold in order to transform the continuous modeling output into a binary format. Considering the mean temperature of the coldest quarter the optimum is modeled to be around $6.5^{\circ} \mathrm{C}$. Regarding the mean temperature of the warmest quarter (bio10), the species is modeled to presumably occur in regions with temperatures between 17 and $30{ }^{\circ} \mathrm{C}$ according to the above mentioned threshold, with a modeled optimum 
Table 2 Permutation importance for the variables used in the ecological niche modeling for Ae. albopictus considering the range of the respective environmental variable within Europe

\begin{tabular}{lll}
\hline Variable & $\begin{array}{l}\text { Permutation } \\
\text { importance [\%] }\end{array}$ \\
\hline bio11 & Mean temperature of coldest quarter $\left[0.1^{\circ} \mathrm{C}\right]$ & 49.3 \\
bio10 & Mean temperature of warmest quarter $\left[0.1^{\circ} \mathrm{C}\right]$ & 25.9 \\
bio01 & Annual mean temperature $\left[0.1^{\circ} \mathrm{C}\right]$ & 8.4 \\
bio12 & Annual precipitation $[\mathrm{mm}]$ & 7.1 \\
alt & Altitude $[\mathrm{m}]$ & 9.3 \\
\hline
\end{tabular}

around $24{ }^{\circ} \mathrm{C}$. In terms of the annual mean temperature (bio01) and the annual precipitation (bio12), the species is modeled to be present in regions with a mean annual temperature between 10 and $18{ }^{\circ} \mathrm{C}$ with a modeled optimum around $14.5^{\circ} \mathrm{C}$ and between $160-1700 \mathrm{~mm}$ with a modeled optimum around $1200 \mathrm{~mm}$, respectively. The modeled habitat suitability decreases with increasing altitude. Applying the equal training sensitivity and specificity threshold of $22.15 \%$, the species is modeled to occur in areas up to $750 \mathrm{~m}$ above mean sea level (mamsl).

\section{Discussion}

The aim of the present study was to investigate the habitat suitability for the well-known disease vector Ae. albopictus in Germany under current and future climate conditions. Our results underline the assumption that Ae. albopictus will find, promoted by climate change, more and more suitable habitats and has the potential to become established in Germany in the future. The overall increase in modeled habitat suitability in Germany as well as the regions where Ae. albopictus can be expected corroborates other previous niche modeling results on a global and European scale (e.g., Benedict et al. 2007; Fischer et al. 2011, 2014; Kraemer et al. 2015). Small-scale differences in the modeled distribution patterns between the current study and other studies can be explained by the use of different subsets of occurrence data, environmental variables, and climate scenarios.

Different projections of future climate conditions exist that largely differ in their underlying socioeconomic assumptions. Here, we tried to aim for a robust assessment of $A e$. albopictus' potential future range and to account for some uncertainties. Thus, we chose to apply four different models on future climatic conditions provided by the Intergovernmental Panel on Climate Change (IPCC). The different models (RCPs) chosen resulted in a range of potential distributional patterns for Ae. albopictus in Germany under future climatic conditions.
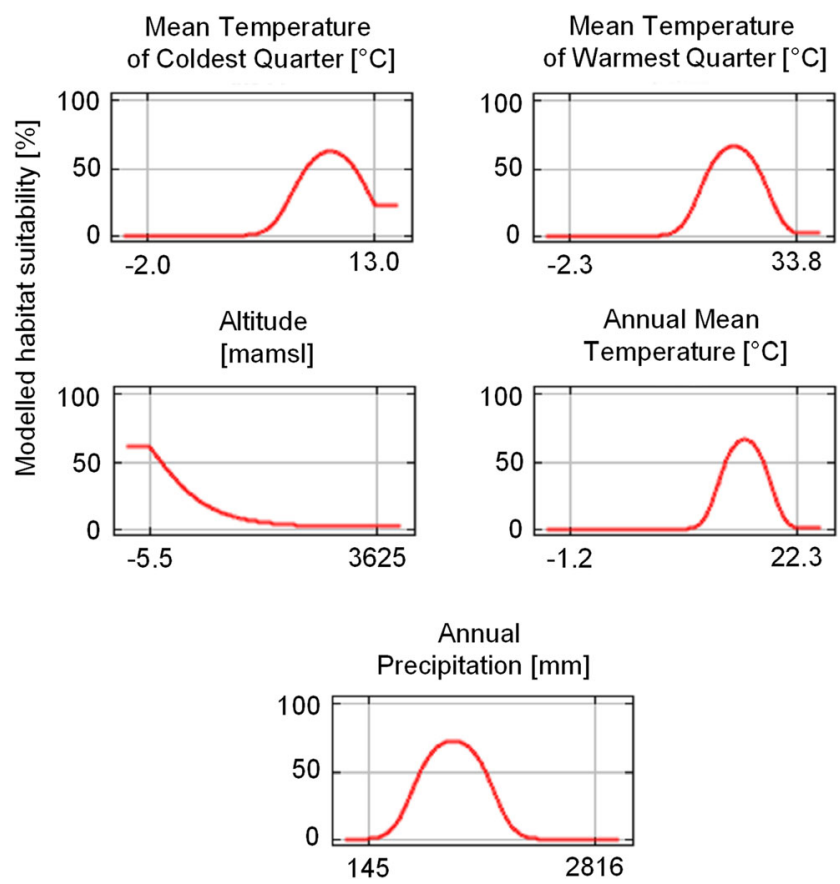

Fig. 2 Response curves for the one-variable-models indicate the ecological requirements of Ae. albopictus in Europe

Whereas all the RCP scenarios agree in projecting a temperature rise until 2100 , the rise of them is not always linear and could stagnate or even decrease in some scenarios and varies between regions. This might explain why projected habitat suitability does not generally increase from RCP 2.6 via RCP 4.5 and RCP 6.0 to RCP 8.5 .

Under current climatic conditions, our model revealed two suitable areas for the mosquito in Germany, one around the Ruhr region in North Rhine-Westphalia and another in an even larger area in western Baden-Wuerttemberg. The latter is currently monitored and individuals are regularly recorded, particularly in southwest Baden-Wuerttemberg which is evidence that the species is likely to get or even has been established in this region already (Werner et al. 2012; Kampen et al. 2013; Werner and Kampen 2015). The sites where Ae. albopictus individuals have been found in southwest Baden-Wuerttemberg are located near the highways, a main road toward southern Europe. In North RhineWestphalia the species has not been found yet as far as we know. This could be explained by the fact that the species has not been introduced there.

Under future climatic conditions Ae. albopictus was modeled to find more suitable habitat conditions in Germany. According to our results, the suitability for the species will increase markedly in northern Germany, whereas the suitability in southern Germany will increase as well but more slowly except for an area in southeast of Bavaria. This pattern was present in all of the modeling results based on the four different RCPs. Although it seems tempting to argue that the future distribution of the species will be restricted to lower 
altitudes, the modeled pattern might rather reflect a correlation of altitude with the mean temperature of the coldest quarter; the latter being the variable with the highest influence in the model. This means that the regions identified as potentially suitable habitats in northern and southern Germany will presumably have milder winters due to their lower altitudes. Furthermore, our findings are in accordance with the commonly known establishment thresholds of the ECDC for $A e$. albopictus (ECDC 2015a, b; Medlock et al. 2015). These thresholds are based on previous research that estimated the species potential distribution or distribution limits using fieldcaught specimen. According to these thresholds, the species may occur in regions with mean winter temperature higher than $0{ }^{\circ} \mathrm{C}$ and mean annual temperatures of higher than $11^{\circ} \mathrm{C}$ (Medlock et al. 2015). It seems likely that such climatic conditions will match with lower altitudes first. Moreover, for optimal development, including breeding sites for egg deposition, the mosquito species requires at least $500 \mathrm{~mm}$ of annual rainfall and a summer temperature of $25-30{ }^{\circ} \mathrm{C}$ (Medlock et al. 2015). This is supported by the results of one-variable response curves, where similar ranges for rainfall and summer temperature were identified.

Results of the model suggest that habitat conditions will become more and more suited to fit Ae. albopictus requirements, in different parts of Germany, in the future. However, does this consequently mean that the species will establish self-recruiting populations in all of these specific regions? Although Ae. albopictus does not actively spread over large distances, females are likely to be transported passively, given that female mosquitoes sometimes follow humans into their cars for a blood meal (Paupy et al. 2009; Werner and Kampen 2015). Another common way of introduction of this species is trade, e.g., the transport of used tires (Deblauwe et al. 2015). As tourism and also trading are both not assumed to decrease in the near future, further introductions to Germany, e.g., by travel tourism (e.g., from southern Europe) of the species seem very likely. Thus, further introductions of the species in Germany are likely to continue. Considering the risk of establishment after successful introductions, recent findings of eggs suggest that this might indeed be possible (Kampen et al. 2013).

The Asian tiger mosquito is a species with a high competitive ability and ecological plasticity (Paupy et al. 2009). In some countries, Ae. albopictus even started to displace other famous vector species like the yellow fever mosquito Aedes aegypti or exploit other species (e.g., Culex pipiens) habitats (Paupy et al. 2009). Generally, the species can deal with a wide range of conditions and adapt very fast (Paupy et al. 2009) which might allow Ae. albopictus to survive colder winters in areas with cooler climate. Some laboratory experiments showed that populations from southern Europe can overcome freeze periods of up to $-10{ }^{\circ} \mathrm{C}$ (Thomas et al. 2012; Kampen and Werner 2015). Furthermore, preadaptations to colder temperatures in the source locations might also facilitate a faster establishment in colder regions. Nawrocki and Hawley (1987) already demonstrated that Ae. albopictus populations of the temperate zone in Asia have dormancy during their egg stage which separates them from Ae. albopictus populations from the tropical zone of Asia. Another example is populations in southern Europe, which are assumed to be secondary introductions from Northern America. Thus, populations introduced into Europe might have already adapted to temperate climate during their establishment in another nonnative range. Due to this kind of overwintering adaptation, the species might be able to spread further northwards in Europe and even further than other important disease vectors (e.g., Ae. aegypti). In support of this, a recent review on invasive aedine mosquito species called attention to Ae. albopictus species, suggesting that apart from Ae. aegypti, this species would be the most detrimental invader in Europe and should, therefore, be monitored (Zgomba and Petric 2008; Medlock et al. 2015).

Our model projects a clear enlargement of the area modeled to be suitable for Ae. albopictus in Germany under future climatic conditions. Thus, our results suggest that an establishment (overwintering, breeding, eggs) of the species in Germany seems likely in the future, and regular records of the species, particularly in southwest Baden-Wuerttemberg, are evidence that the species might get or even has been established in Germany already (Werner et al. 2012; Kampen et al. 2013; Werner and Kampen 2015).

A successful establishment bears the risk of health risks in Germany. Various characteristics of Ae. albopictus could facilitate a successful transmission of diseases in Germany. Although Ae. albopictus is often considered a minor vector for dengue and yellow fever virus (Tandon and Ray 2000; Eritja et al. 2005; Moutailler et al. 2009; Paupy et al. 2009; Valerio et al. 2010). studies by Brady et al. (2014) revealed that Ae. albopictus not only has similar virus dissemination rates of dengue virus but will even exceed the primary vector Ae. aegypti if the longer lifespan of Ae. albopictus is taken into account. Furthermore, Ae. albopictus can act as a bridge vector (Medlock et al. 2006) due to its striking biting behavior. Several former studies detected avian blood besides a high amount of mammalian blood (including human blood) in the mosquito's blood meals, thus, the species is not dependent on an obligatory host (Medlock et al. 2006; Valerio et al. 2010; Faraji et al. 2014). Based on recent autochthonous outbreaks of diseases transmitted by Ae. albopictus in other European countries, such as Italy, France, and Croatia (Vazeille et al. 2008; Paupy et al. 2009; Gould et al. 2010; Gjenero-Margan et al. 2011), the Asian tiger mosquito could also become a major threat to human health in Germany. 


\section{Conclusion}

The disease-transmitting vector species Ae. albopictus has successfully established in large parts of southern Europe. With ongoing climate change the species is likely to extent its range northwards and thus, may be able to get established in Germany. As the species is of high medical importance due to its vector competency for various diseases, it could become a major threat for human health in Germany. Our results can help supporting other surveillance programs (e.g., Becker et al. 2013) already in place pointing out areas that have to be checked more intensively, such as Baden-Wuertemberg and North Rhine Westphalia. Thus, we strongly suggest monitoring these areas more intensively, but also put in place a Germany-wide monitoring in order to prevent the further spread of the species and its associated diseases using an early preventive strategy.

Acknowledgments This research was funded by the ERA-Net BiodivERsA, with the national funders German Research Foundation (DFG KL 2087/6-1), Austrian Science Fund (FWF I-1437), and The French National Research Agency (ANR-13-EBID-0007-01), part of the 2013 BiodivERsA call for research proposals, by the research funding program "LOEWE-Landes-Offensive zur Entwicklung Wissenschaftlich-ökonomischer Exzellenz" of Hesse's Ministry of Higher Education, Research, and the Arts, and by the Senate Competition Committee grant (SAW-2014-SGN-3) of the Leibniz Association.

\section{References}

Adhami J, Reiter P (1998) Introduction and establishment of Aedes (Stegomyia) albopictus Skuse (Diptera: Culicidae) in Albania. J Am Mosq Control Assoc 14:340-343

Aranda C, Eritja R, Roiz D (2006) First record and establishment of the mosquito Aedes albopictus in Spain. Med Vet Entomol 20:150-152. doi:10.1111/j.1365-2915.2006.00605.x

Becker N (2008) Influence of climate change on mosquito development and mosquito-borne diseases in Europe. Parasitol Res 103(Suppl 1): $19-28$

Becker N, Geier M, Balczun C, Bradersen U, Huber K, Kiel E, Krueger A, Luehken R, Orendt C, Plenge-Boenig A, Rose A, Schaub GA, Tannich E (2013) Repeated introduction of Aedes albopictus into Germany, July to October 2012. Parasitol Res 112:1787-1790. doi: 10.1007/s00436-012-3230-1

Benedict MQ, Levine RS, Hawley WA, Lounibos LP (2007) Spread of the tiger: global risk of invasion by the mosquito Aedes albopictus. Vector-Borne Zoonotic Dis 7:76-85. doi:10.1089/vbz.2006.0562

Brady OJ, Golding N, Pigott DM et al (2014) Global temperature constraints on Aedes aegypti and Ae. albopictus persistence and competence for dengue virus transmission. Parasit Vectors 7:338. doi:10. 1186/1756-3305-7-338

Cancrini G, Frangipane Di Regalbono A, Ricci I, Tessarin C, Gabrielli S, Pietrobelli M (2003a) Aedes albopictus is a natural vector of Dirofilaria immitis in Italy. Vet Parasitol 118:195-202. doi:10. 1016/j.vetpar.2003.10.011

Cancrini G, Romi R, Gabrielli S, Toma L, Di Paolo M, Scaramozzino P (2003b) First finding of Dirofilaria repens in a natural population of Aedes albopictus. Med Vet Entomol 17:448-451. doi:10.1111/j. 1365-2915.2003.00463.x
Dalla Pozza G, Majjori G (1992) First record of Aedes albopictus establishment in Italy. J Am Mosq Control Assoc 8:318-320

Deblauwe I, Demeulemeester J, De Witte J, Hendy A, Sohier C, Madder M (2015) Increased detection of Aedes albopictus in Belgium: no overwintering yet, but an intervention strategy is still lacking. Parasitol Res. doi:10.1007/s00436-015-4575-Z

ECDC (European Centre for Disease Prevention and Control) (2015a) Vector maps. Mosquito maps. Aedes albopictus. Stockholm, Sweden. http://ecdc.europa.eu/en/healthtopics/vectors/vector-maps/ Pages/VBORNET_maps.aspx. Accessed 31 July 2015

ECDC (European Centre for Disease Prevention and Control) (2015b) Mosquitoes. Aedes albopictus. Stockholm, Sweden.http://ecdc. europa.eu/en/healthtopics/vectors/mosquitoes/Pages/aedesalbopictus.aspx. Accessed 31 July 2015

Elith J, Graham CH, Anderson RP, Dudík M, Ferrier S, Guisan A, Hijmans RJ, Huettmann F, Leathwick JR, Lehmann A, Li J, Lohmann LG, Loiselle BA, Manion G, Moritz C, Nakamura M, Nakazawa Y, McC. M. Overton J, Townsend Peterson A, Phillips SJ, Richardson K, Scachetti-Pereira R, Schapire RE, Soberón J, Williams S, Wisz MS, Zimmermann NE (2006) Novel methods improve prediction of species' distributions from occurrence data. Ecography (Cop) 29:129-151. doi:10.1111/j.2006.0906-7590. 04596.x

Eritja R, Escosa R, Lucientes J, Marquès E, Molina R, Roiz D, Ruiz S (2005) Worldwide invasion of vector mosquitoes: present European distribution and challenges for Spain. Biol Invasions 7:87-97

Faraji A, Egizi A, Fonseca DM, Unlu I, Crepeau T, Healy SP, Gaugler R (2014) Comparative host feeding patterns of the Asian tiger mosquito, Aedes albopictus, in urban and suburban northeastern USA and implications for disease transmission. PLoS Negl Trop Dis 8: e3037. doi:10.1371/journal.pntd.0003037

Fischer D, Thomas SM, Niemitz F, Reineking B, Beierkuhnlein C (2011) Projection of climatic suitability for Aedes albopictus Skuse (Culicidae) in Europe under climate change conditions. Glob Planet Chang 78:54-64. doi:10.1016/j.gloplacha.2011.05.008

Fischer D, Thomas SM, Neteler M, Tjaden NB, Beierkuhnlein C (2014) Climatic suitability of Aedes albopictus in Europe referring to climate change projections: comparison of mechanistic and correlative niche modelling approaches. Eurosurveillance 19:1-13

Giatropoulos A, Emmanouel N, Koliopoulos G, Michaelakis A (2012) A study on distribution and seasonal abundance of Aedes albopictus (Diptera: Culicidae) population in Athens, Greece. J Med Entomol 49:262-269

Gjenero-Margan I, Aleraj B, Krajcar D, Lesnikar V, Klobučar A, PemNovosel I, Kurečić-Filipović S, Komparak S, Martić R, Đuričić S, Betica-Radić L, Okmadžić J, Vilibić-Čavlek T, Babić-Erceg A, Turković B, Avšić-Županc T, Radić I, Ljubić M, Šarac K, BenićN M-GG (2011) Autochthonous dengue fever in Croatia, AugustSeptember 2010. Eurosurveillance 16:1-4

Gould EA, Gallian P, De Lamballerie X, Charrel RN (2010) First cases of autochthonous dengue fever and chikungunya fever in France: from bad dream to reality! Clin Microbiol Infect 16:1702-1704. doi:10. 1111/j.1469-0691.2010.03386.x

Hijmans RJ, Graham CH (2006) The ability of climate envelope models to predict the effect of climate change on species distributions. Glob Chang Biol 12:2272-2281. doi:10.1111/j.1365-2486.2006.01256.x

IPCC (2013) Climate Change 2013: the physical science basis: contribution of working group I to the Fifth Assessment Report of the Intergovernmental Panel on Climate Change, IPCC Fifth Assessment Report: Climate Change 2013 (AR5). Cambridge University Press, Cambridge, New York

Kampen H, Werner D (2015) Die wiederkehrende Notwendigkeit von Stechmücken-Surveillance und -Forschung. Bundesgesundheitsbl Gesundheitsforsch Gesundheitsschutz 58:1101-1109. doi:10.1007/ s00103-015-2218-2 
Kampen H, Kronefeld M, Zielke D, Werner D (2013) Further specimens of the Asian tiger mosquito Aedes albopictus (Diptera, Culicidae) trapped in southwest Germany. Parasitol Res 112:905-907. doi:10. 1007/s00436-012-3128-y

Kraemer MUG, Sinka ME, Duda KA, Mylne AQN, Shearer FM, Barker CM, Moore CG, Carvalho RG, Coelho GE, Bortel WV, Hendrickx G, Schaffner F, Elyazar IRF, Teng H-J, Brady OJ, Messina JP, Pigott DM, Scott TW, Smith DL, Wint GRW, Golding N, Hay SI (2015) The global distribution of the arbovirus vectors Aedes aegypti and Ae. albopictus. Elife 4:1-18. doi:10.7554/eLife.08347

Kumar S, Stohlgren TJ (2009) Maxent modeling for predicting suitable habitat for threatened and endangered tree Canacomyrica monticola in New Caledonia. J Ecol Nat Environ 1:94-98. doi:10.3390/ d1020118

La Ruche G, Souarès Y, Armengaud A, Peloux-Petiot F, Delaunay P, Desprès $\mathrm{P}$, Lenglet A, Jourdain F, Leparc-Goffart I, Charlet F, Ollier L, Mantey K, Mollet T, Fournier JP, Torrents R, Leitmeyer K, Hilairet P, Zeller H, Van Bortel W, Dejour-Salamanca D, Grandadam M, Gastellu-Etchegorry M (2010) First two autochrhonous dengue virus infections in metropolitan France, September 2010. Eurosurveillance 15(39):19676

Medlock JM, Avenell D, Barrass I, Leach S (2006) Analysis of the potential for survival and seasonal activity of Aedes albopictus (Diptera: Culicidae) in the United Kingdom. J Vector Ecol 31: 292-304

Medlock JM, Hansford KM, Versteirt V, Cull B, Kampen H, Fontenille D, Hendrickx G, Zeller H, Van Bortel W, Schaffner F (2015) An entomological review of invasive mosquitoes in Europe. doi: 10. 1017/S0007485315000103

Melaun C, Werblow A, Cunze S, Zotzmann S, Koch LK, Mehlhorn H, Doerge DD, Huber K, Tackenberg O, Klimpel S (2015) Modeling of the putative distribution of the arbovirus vector Ochlerotatus japonicus japonicus (Diptera: Culicidae) in Germany. Parasitol Res. doi:10.1007/s00436-014-4274-1

Mitchell CJ (1991) Vector competence of North and South American strains of Aedes albopictus for certain arboviruses: a review. J Am Mosq Control Assoc 7:446-451

Moutailler S, Barré H, Vazeille M, Failloux AB (2009) Recently introduced Aedes albopictus in Corsica is competent to chikungunya virus and in a lesser extent to dengue virus. Trop Med Int Heal 14: 1105-1109. doi:10.1111/j.1365-3156.2009.02320.x

Nawrocki SJ, Hawley WA (1987) Estimation of the northern limits of distribution of Aedes albopictus in North America. J Am Mosq Control Assoc 3:314-317

Paupy C, Delatte H, Bagny L, Corbel V, Fontenille D (2009) Aedes albopictus, an arbovirus vector: from the darkness to the light. Microbes Infect 11:1177-1185. doi:10.1016/j.micinf.2009.05.005

Phillips SJ, Dudík M (2008) Modeling of species distribution with Maxent: new extensions and a comprehensive evaluation. Ecograpy 31:161-175. doi:10.1111/j.2007.0906-7590.05203.x

Phillips SJ, Dudik M, Schapire RE (2004) A maximum entropy approach to species distribution modeling. Proceedings of the Twenty-First International Conference on Machine learning. 655-662
Pluskota B, Storch V, Braunbeck T, Beck M, Becker N (2008) First record of Stegomyia albopicta (Skuse) (Diptera : Culicidae) in Germany. Eur Mosq Bull 26:1-5

Reiss H, Cunze S, Koenig K, Neumann H, Kroencke I (2011) Species distribution modelling of marine benthos: a North Sea case study. Mar Ecol Prog Ser 442:71-86. doi:10.3354/meps09391

Rezza G, Nicoletti L, Angelini R, Romi R, Finarelli AC, Panning M, Cordioli P, Fortuna C, Boros S, Magurano F, Silvi G, Angelini P, Dottori M, Ciufolini MG, Majori GC, Cassone A (2007) Infection with chikungunya virus in Italy: an outbreak in a temperate region. Lancet 370:1840-1846. doi:10.1016/S0140-6736(07)61779-6

Schaffner F, Van Bortel W, Coosemans M (2000) First record of Aedes (Stegomyia) albopictus in Belgium. J Am Mosq Control Assoc 20: 201-203

Schaffner F, Boulétreau B, Guillet B, Guilloteau J, Krach S (2001) Aedes albopictus (Skuse, 1894) established in metropolitan France. Eur Mosq Bull 9:1-3

Scholte EJ, Jacobs F, Linton YM, Dijkstra E, Fransen J, Takken W (2007) First record of Aedes (Stegomyia) albopictus in the Netherlands. 22: 5-9

Stabach JA, Laporte N, Olupot W (2009) Modeling habitat suitability for Grey crowned-cranes (Balearica regulorum gibbericeps) throughout Uganda. Int J Biodivers Conserv 1:177-186

Tandon N, Ray S (2000) Host feeding pattern of Aedes aegypti and Aedes albopictus in Kolkata, India. Denuge Bull 24:117-120

Thomas S, Obermayr U, Fischer D et al (2012) Low-temperature threshold for egg survival of a post-diapause and non-diapause European aedine strain, Aedes albopictus (Diptera: Culicidae). Parasit Vectors 5:100. doi:10.1186/1756-3305-5-100

Trisurat Y, Alkemade R, Arets E (2009) Projecting forest tree distributions and adaptation to climate change in northern Thailand. J Ecol Nat Environ 1:55-63

Valerio L, Marini F, Bongiorno G, Facchinelli L, Pombi M, Caputo B, Maroli M, della Torre A (2010) Host-feeding patterns of Aedes albopictus (Diptera: Culicidae) in urban and rural contexts within Rome province, Italy. Vector Borne Zoonotic Dis 10:291-294. doi: 10.1089/vbz.2009.0007

Vazeille M, Jeannin C, Martin E, Schaffner F, Failloux AB (2008) Chikungunya: a risk for Mediterranean countries? Acta Trop 105: 200-202. doi:10.1016/j.actatropica.2007.09.009

Werner D, Kampen H (2015) Aedes albopictus breeding in southern Germany, 2014. Parasitol Res 114(3):831-834. doi:10.1007/ s00436-014-4244-7

Werner D, Kronefeld M, Schaffner F, Kampen H (2012) Two invasive mosquito species, Aedes albopictus and Aedes japonicus japonicus, trapped in southwest Germany, July to August 2011. Eurosurveillance 17:1-4

Zgomba M, Petric D (2008) Risk assessment and management of mosquito-borne diseases in the European region. Sixth Int Conf Urban Pests 29-39 


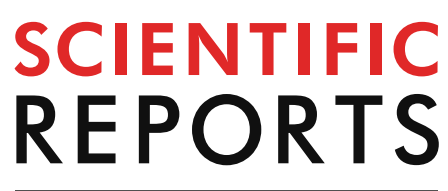

natureresearch

Check for updates

\title{
An investigation of hibernating
} members from the Culex pipiens complex (Diptera, Culicidae) in subterranean habitats of central Germany

\author{
Dorian D. Dörge ${ }^{1 \bowtie}$, Sarah Cunze ${ }^{1}$, Henrik Schleifenbaum ${ }^{1}$, Stefan Zaenker ${ }^{3}$ \& Sven Klimpel ${ }^{1,2}$
}

The Culex pipiens complex encompasses five species and subspecies of the genus Culex. Over time, a multitude of morphologically indistinguishable species has been assigned to this complex with several species being classified as important vectors for different diseases. Some species of this complex hibernate in subterranean habitats, and it has been proven that viruses can survive this phase of hibernation. However, studies focusing on the environmental requirements, ecology and spatial and temporal distribution patterns of mosquitos in underground habitats are sparse. Here, we investigate the main environmental factors and dependencies of Culex, considering the number of individuals and survival probabilities in underground habitats during the winter months. Methods. Since the State of Hesse, Germany harbors about 3500 to 4000 subterranean shelters ample availability of subterranean habitats there provides a good opportunity to conduct detailed investigations of the Culex pipiens complex. In this study, we identified a sample of 727 specimens of overwintering females within the Culex pipiens complex from 52 different underground sites collected over a period of 23 years using qPCR. A complete data set of samplings of hibernating mosquitos from 698 subterranean habitats in Central Germany over the same period was available to study the spatial and temporal patterns and the effect of temperature and precipitation conditions on these hibernating populations using a generalized linear model (GLM). Results. Our qPCR-results show, similar to aboveground studies of mosquitos, that Culex pipiens pipiens and Culex torrentium occur sympatrically. On the other hand, Culex pipiens molestus occurred very rarely. The GLM revealed no shifts in species composition over time, but different preferences for subterranean hibernacula, chemical effects on overwintering populations as well as effects of annual and seasonal mean temperature and precipitation during the active phase from March to November. $C x$. p. pipiens and $C x$. torrentium are the most common species within Hessian caves and other underground habitats during winter. They co-occur with different frequency without any patterns in species composition. Weather conditions influence the number of overwintering mosquitos during the activity phase. Depending on cave parameters, the number of mosquitos decreases during the winter months.

Culicidae members belonging to the Culex pipiens complex are difficult to distinguish morphologically. The most characteristic features include the male genitalia and the larval siphon ${ }^{1}$. According to Vinogradova ${ }^{1}$ the complex encompasses Culex pipiens pipiens var. pipiens ${ }^{2}$, its biotype Culex pipiens pipiens var. molestus ${ }^{3}$, Culex torrentium $^{4}$, Culex pipiens quinquefasciatus ${ }^{5}$, Culex pipiens pallens ${ }^{6}$, and Culex vagans ${ }^{7}$. The first three are abundant in Germany. While this complex is comprised largely of mosquitos inhabiting urban areas in temperate climates ${ }^{8}$, $C x$. pipiens, including its subspecies and biotypes, may be the most abundant mosquito species worldwide?

${ }^{1}$ Institute for Ecology, Evolution and Diversity, Goethe-University, Max-von-Laue-Str. 13, 60439 Frankfurt/Main, Germany. ${ }^{2}$ Senckenberg Biodiversity and Climate Research Centre, Senckenberg Gesellschaft für Naturforschung, Senckenberganlage 25, 60325 Frankfurt/Main, Germany. ${ }^{3}$ Hesse Federation for Cave and Karst Research, Königswarter Str. 2a, 36039 Fulda, Germany. ${ }^{\circledR}$ email: Doerge@bio.uni-frankfurt.de 
Like many other mosquito species, members of the Culex pipiens complex transmit different arthropodborne viruses (arboviruses). Notable is the West Nile Virus (WNV), which has triggered fatal infections and epidemics in Eastern and Central Europe $\mathrm{e}^{10-12}$ and is also known in Asia, Australia, Africa, the Caribbean and North America ${ }^{12}$. Several studies show that Culex species are competent vectors ${ }^{13-15}$. This may also be true for $C x$. torrentium which is widely distributed in Central Europe ${ }^{13,14}$. Since $C x$. $p$. pipiens is ornithophilic ${ }^{15,16}$, it plays a major role in the transmission of WNV within wild bird populations, except in the northern Central and Mid-Atlantic United States, where it shows higher than usual affinity for humans and becomes a bridge vector ${ }^{17}$. Andreadis ${ }^{17}$ attributes this alteration of host preference to potential genetic ancestry with Cx. p. molestus and is considered analogous to the assumed hybridization ${ }^{18}$. Cx. p. molestus is known to be mammophilic ${ }^{19}$ and found to have a very different behavior compared to $C x$. p. pipiens. However, $C x$. p. molestus has shown no difference in feeding behavior compared to $C x$. $p$. pipiens ${ }^{16}$ in a survey area in western Portugal. Today, it is commonly accepted that $C x$. p. molestus is adapted to a subterranean environment ${ }^{20-23}$ and is autogenous (requiring no blood meal prior to its first oviposition, due to a higher nutrient supply during the larval stage), stenogamous (mating in confined spaces) and homodynamous (non-diapausing). On the other hand, Cx. p. pipiens is anautogenous (requiring a blood meal prior to its first oviposition), eurygamous (mating in open spaces) and heterodynamous (diapausing) ) $^{1,20,21}$. The general autogeny and stenogamy of $C x$. p. molestus and the anautogamy and eurygamy of $C x$. p. pipiens respectively has been demonstrated in a breeding experiment ${ }^{23}$. Cx. p. pipiens is often seen as a subterranean form of $C x$. pipiens ${ }^{19,22,24,25}$ and could therefore be much more abundant in caves than in contrasting epigean habitats. Hybrids of $C x$. p. pipiens and $C x$. p. molestus were proposed to exist and could serve as bridge vectors for arboviruses from birds to humans since they would show a feeding strategy including mammals and birds $^{26}$. Hybrids of $C x$. p. molestus and $C x$. p. pipiens may therefore, play a key role in the distribution of certain zoonotic diseases such as WNV.

Depending on the species, mosquitos can survive winter in all three life stages ${ }^{27}$. Either eggs survive the cold season on dry ground, usually in floodplains, and hatch as soon as temperatures rise and a sufficient amount of water is available, or they overwinter as hatched larvae under the ice cover of low waters. Diapausing or hibernating females in underground systems such as caves or mines is the third option.

It is generally assumed that inseminated female $C x$. p. pipiens hibernate ${ }^{25,28}$ while $C x$. p. molestus does not need to ${ }^{29-31}$. Depending on the environmental conditions, the lack of diapause of $C x . p$. molestus may occur either as expressed or as suppressed homodynamy ${ }^{32}$. According to Kjærandsen ${ }^{33}, C x$. pipiens hibernates in caves and cave-like environments, however, the author did not distinguish between Cx. p. pipiens and Cx. p. molestus in his study. Caves are considered thermally insulated systems ${ }^{34}$, a frequent and established point of view, corroborating $\mathrm{Barr}^{35}$ in that the temperature in a cave is constant and close to the average annual temperature of the surrounding region. Caves are divided into three ecological zones: the entrance zone, twilight zone and depth zone ${ }^{36}$. Caves and other subterranean habitats not only have a relatively constant temperature mostly fluctuating in the entrance region, but also have a generally constant humidity gradient. There are several different categories of caves, ranging from caves that have running water to almost completely dry ones ${ }^{37}$. According to Buffington ${ }^{38}$, cave humidity is not a determining factor for choosing a site for diapausing. However, extensively tested reactions of $C x$. fatigans to different temperatures and humidity levels could prove the avoidance of subterranean habitats with greater than $95 \%$ and below $40 \%$ relative humidity ${ }^{39}$.

Considering the still unresolved structure of the Culex pipiens complex as well as the variability in their biological interactions and lack of knowledge within Germany, this is the first study to include hibernating mosquitos on a larger scale. Hesse is particularly suited to study the population structure and hibernation preferences of Culex due to its many subterranean habitats, the wide-ranging distribution of various Culex species and the temperate Central European climate in this region of Germany.

We examined the co-occurrence of the three Culex pipiens complex species present in Germany and tested whether spatial patterns within the study area occur. Furthermore, we examined if temperature and precipitation conditions in the preceding activity phases influence the number of mosquitos found during winter. We additionally investigated whether the abundance within the subterranean shelters decreases over the winter months and if this temporal pattern is dependent on certain subterranean parameters.

\section{Material and methods}

Sample material. A data set consisting of 1827 samples from 698 underground sites served as the basis for our investigations. A total of 8750 mosquitos from the Culex pipiens complex were collected from walls and ceilings of subterranean shelters by the Hesse Federation for Cave and Karst Research. Samples were collected during all months throughout the years 1991 to 2014 with a strong focus on winter months in caves, tunnels, cellars and other subterranean shelters. Collection was implemented during the regular inventories of Hessian underground structures. All samples were stored in small, 100\% ethanol-filled vials at room temperature until further examination. Specimens collected the same day in the same subterranean shelter were stored together in one vial and labelled as one sample accordingly. We genetically examined a subsample of 727 mosquitos from 52 of the 698 available sites (Table 1) and employed a modified version of the real-time qPCR (Table 2) developed by Rudolf et al. ${ }^{40}$ to gain comparable results. Regarding temporal and spatial patterns of the species' distribution, the whole dataset of 1827 samplings and species counts from 698 subterranean shelters was used. The spatial distribution patterns of the species compositions are shown in a Gis map (Fig. 1). The temperature and precipitation ratios of the years 2001 to 2014 are shown in comparison with the abundance distributions of the respective years (Fig. 2).

Effects of precipitation and temperature. In order to investigate effects of temperature and precipitation conditions on these hibernating populations we performed a generalized linear model (GLM). Since the 


\begin{tabular}{|c|c|c|c|c|c|}
\hline $\mathrm{Nr}$ & Shelter Type & Humidity & Dec. $\mathbf{N}$ & Dec. $\mathrm{E}$ & Sampling years \\
\hline 1 & Concrete tunnel & Moist & 50.7967 & 9.5485 & 2007,2013 \\
\hline 2 & BB tunnel & Very dry & 51.1948 & 9.0862 & 2011 \\
\hline 3 & BMC & Dry & 50.2387 & 9.5996 & 2011,2013 \\
\hline 4 & Rock cellar & Moist & 50.7540 & 9.2631 & 2008 \\
\hline 5 & Natural cave & Medium & 50.4896 & 8.0363 & 2010 \\
\hline 6 & Mine shaft & Wet & 51.2896 & 8.6955 & 2006,2008 \\
\hline 7 & Touristic mine & Moist & 51.3750 & 8.8005 & 2004,2006 \\
\hline 8 & Rock cellar & Moist & 51.0945 & 8.6287 & 2004 \\
\hline 9 & BMC & Moist & 50.9221 & 9.9102 & 2003,2006 \\
\hline 10 & Bunker in quarry & Dry & 51.1585 & 9.4466 & 2006 \\
\hline 11 & Bunker complex & Moist & 51.5189 & 9.3776 & 2006 \\
\hline 12 & Rock cellar & Dry & 50.6820 & 9.3776 & 2009 \\
\hline 13 & BB cellar & Medium & 50.6987 & 9.7299 & 2003 \\
\hline 14 & Mine shaft & Medium & 50.2439 & 8.1010 & 2008,2011 \\
\hline 15 & Rock cellar & Medium & 51.0323 & 8.9745 & 2001,2005 \\
\hline 16 & Rock cellar & Wet & 50.6401 & 9.4005 & 2007,2008 \\
\hline 17 & Rock cellar & Wet & 50.5010 & 9.1237 & 2008,2010 \\
\hline 18 & Mine shaft & MEDIUM & 50.1673 & 9.3542 & 2005,2006 \\
\hline 19 & Rock cellar & Wet & 51.1297 & 8.7965 & 2001,2014 \\
\hline 20 & Rock cellar & MOIST & 50.4867 & 9.8731 & $2003,2004,2005,2014$ \\
\hline 21 & Mine shaft & Dry & 51.0362 & 9.9002 & $2002,2004,2005,2006,2013$ \\
\hline 22 & Rock cellar & Medium & 50.5900 & 9.9984 & from 2003 to 2014 \\
\hline 23 & BB cellar & Dry & 50.4286 & 9.7630 & 2010 \\
\hline 24 & Natural cave & Medium & 50.1705 & 9.4033 & $2001,2007,2010,2011$ \\
\hline 25 & Mine shaft & Medium & 50.8330 & 8.5444 & 2003,2009 \\
\hline 26 & Mine shaft & Medium & 50.6164 & 8.3905 & 2005 \\
\hline 27 & Rock cellar & Medium & 50.1720 & 8.4602 & 2011 \\
\hline 28 & Mine shaft & Moist & 51.2733 & 9.8713 & 1994, 2004, 2005, 2007, 2009, 2011, 2012, 2013 \\
\hline 29 & Sand mine & Medium & 51.1166 & 10.1677 & 1996, 2000, 2002, 2004, 2006, 2008, 2011, 2012, 2013 \\
\hline 30 & Natural cave & Medium & 50.6852 & 8.2132 & $1995,1997,2005,2007$ \\
\hline 31 & Sand mine & Medium & 51.2148 & 10.0778 & $2003,2004,2009,2011,2013$ \\
\hline 32 & Mine shaft & Dry & 50.1016 & 7.9153 & 2011 \\
\hline 33 & Mine shaft & Medium & 50.3864 & 8.0706 & 2013 \\
\hline 34 & Mine shaft & Medium & 50.5896 & 8.6391 & 2008 \\
\hline 35 & BB tunnel & Dry & 50.3302 & 9.6025 & 2014 \\
\hline 36 & Mine shaft & Wet & 50.8598 & 9.7555 & $2001,2003,2007,2011$ \\
\hline 37 & Sand mine & Medium & 51.2150 & 10.0790 & 1994, 2003, 2004, 2009, 2011, 2013 \\
\hline 38 & Mine shaft & Moist & 50.0609 & 7.7813 & 2002,2005 \\
\hline 39 & Mine shaft & Wet & 51.1151 & 9.0086 & $2001,2004,2005,2008,2013,2014$ \\
\hline 40 & Mine shaft & Moist & 51.3177 & 9.3952 & $2003,2006,2012$ \\
\hline 41 & Natural cave & Moist & 51.2325 & 8.9012 & $2003,2004,2005,2007,2008,2010,2013,2014$ \\
\hline 42 & Mine shaft & Moist & 50.3665 & 8.6317 & 2011 \\
\hline 43 & Mine shaft & Wet & 50.5168 & 9.5344 & 2001, 2003, 2004, 2005, 2007, 2008, 2010, 2011, 2013, 2014 \\
\hline 44 & Mine shaft & Moist & 50.9963 & 8.5831 & $2003,2004,2005,2008,2011,2012,2013,2014$ \\
\hline 45 & Mine shaft & Medium & 50.1555 & 8.0817 & 2011 \\
\hline 46 & Sand mine & Dry & 51.3843 & 8.9929 & 2001 \\
\hline 47 & Mine shaft & Moist & 50.2259 & 8.2693 & 2005 \\
\hline 48 & BB tunnel & Dry & 50.9569 & 9.8046 & 2000, 2002, 2005, 2008, 2009, 2011, 2012, 2013 \\
\hline 49 & Natural cave & Medium & 50.5162 & 8.3752 & $2001,2002,2004$ \\
\hline 50 & Mine shaft & Moist & 49.6714 & 8.8525 & 2005 \\
\hline 51 & Mine shaft & Wet & 50.0075 & 7.9601 & 2007 \\
\hline 52 & Natural cave & Moist & 51.3209 & 9.8542 & 2007 \\
\hline
\end{tabular}

Table 1. Spatial pattern analysis $(\mathrm{BB}=$ brick-built, $\mathrm{BMC}=$ bridge maintenance chamber $)$ of subterranean sites. 


\begin{tabular}{|l|l|}
\hline Name of primer & Sequence \\
\hline PipF & 5'-GCGGCCAAATATTGAGACTT-3' \\
\hline PipR & 5'-CGTCCTCAAACATCCAGACA-3' \\
\hline TorrF & 5'-GACACAGGACGACAGAAA-3' \\
\hline TorrR & 5'-GCCTACGCAACTACTAAA-3' \\
\hline Name of Probe & Sequence \\
\hline PipPipProbe & 5'-GCTTCGGTGAAGGTTTGTGT-3' \\
\hline PipMolProbe & 5'-TGAACCCTCCAGTAAGGTATCAACTAC-3' \\
\hline TorrProbe & 5'-CGATGATGCCTGTGCTACCA-3' \\
\hline
\end{tabular}

Table 2. Primers and probes used (modified after Rudolf et al. 2013).

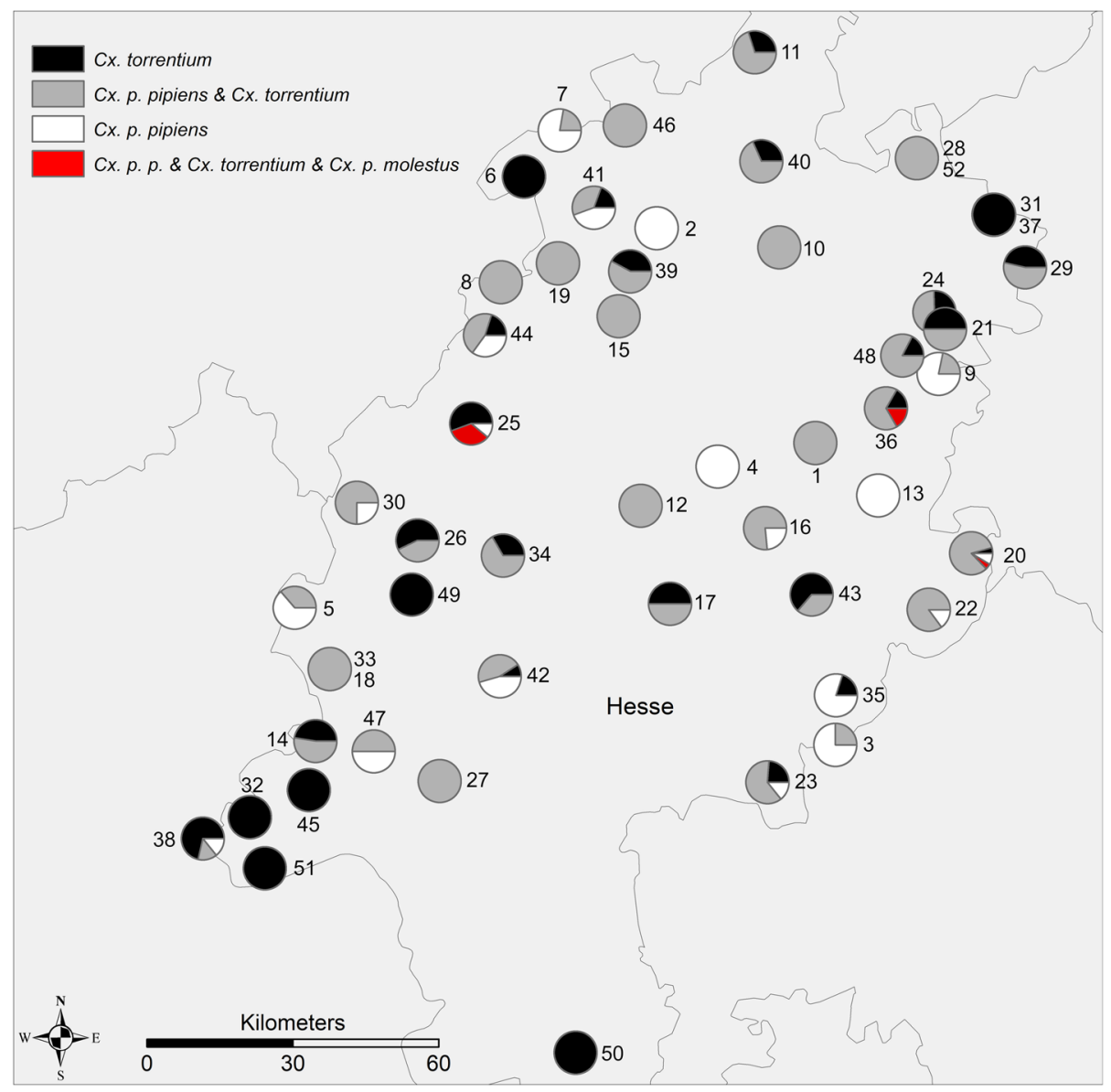

Figure 1. Overview of genetically assessed sample material. Numbers refer to the shelter numbers shown in Table 1. Figure created with ArcGIS Version $10.7^{46}$.

exact numbers of observed individuals were counted only up to 20 mosquitos in the original data collection we considered the number of hibernating mosquitos as a categorical variable of three classes: $f=f e w$ for counts between 1 and 10 individuals found within the subterranean shelter; $s=$ several for counts between 11 and 20 individuals; and $\mathrm{m}=$ many for counts more than 20 individuals. For this analysis we only considered hibernating mosquitoes found in the winter months (December to February).

To refine data quality and to reduce spatial autocorrelation we removed repeated samples from the same or nearby underground sites (within a radius of $600 \mathrm{~m}$ ). Among all data from sampling sites within a certain area and of the whole time period from 1991 to 2014 we chose only one sample at random but favoring a sampling date early in winter (i.e. December $>$ January $>$ February) in order to minimize the effect of potential die-off of the mosquitoes during winter. This procedure resulted in 390 samples when only taking one sample per cave into account and finally 271 samples when removing additional caves within a radius of $600 \mathrm{~m}$. 


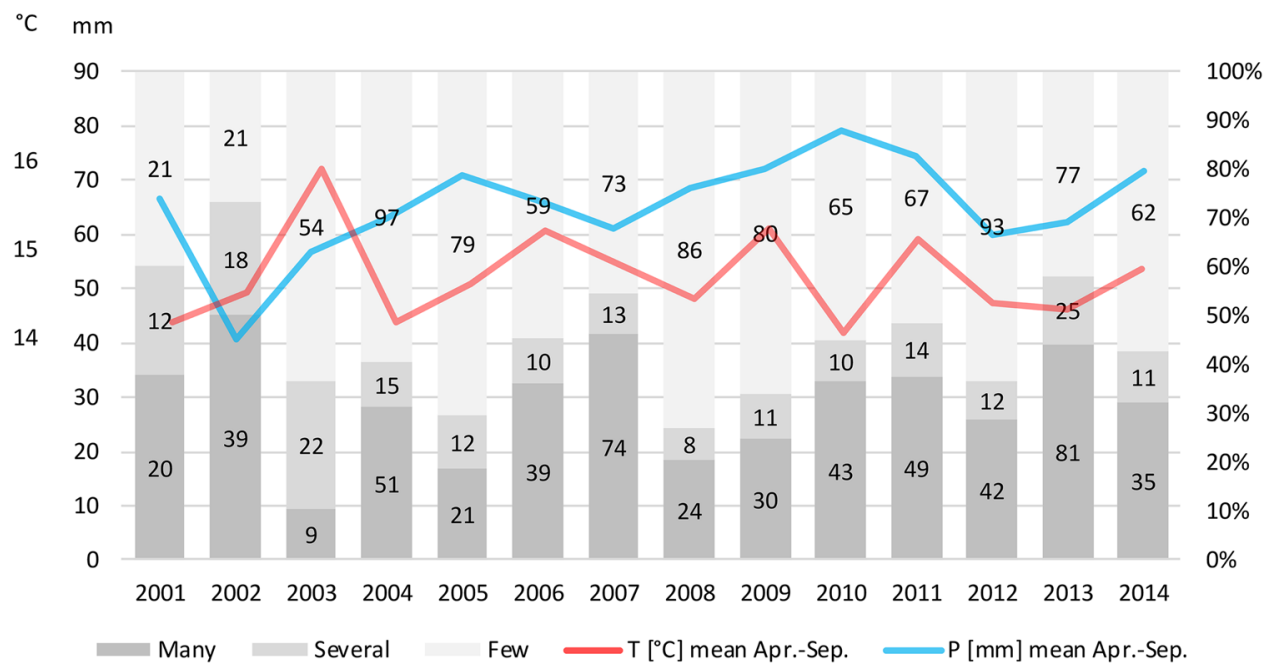

Figure 2. Abundance of hibernating mosquitos in comparison with the climate conditions during the previous activity phase. X-Axis: Year, left Y-Axis: temperature and precipitation, right Y-Axis: composition of categories within the sampling. The numbers in the bar graphs show the absolute frequency of categories in the respective years. Categories: many: $>20$ individuals, several: 10 to 20 individuals, few: $<10$ individuals found within the subterranean shelter.

As explaining variables, we considered temperature and precipitation during spring (i.e. March, April, May), Summer (i.e. June, July, August) and Fall (i.e. September, October, November). These variables were only little intercorrelated (see Table 1 in the supplementary). Additionally, we accounted for the sampling month during winter (coded as December $=1$, January $=2$ and February $=3$ ) and altitude. The altitude was taken into account as we used the regional averages of temperature and precipitation recorded for the State of Hesse by the Deutscher Wetterdienst (DWD = German weather service) as explaining variables in the GLM. Thus altitude was included in our model to account for the effect of decreasing temperature in higher altitudes. We assume that weather could have a different effect on mosquito abundance in different elevation (e.g. an extremely warm summer may have a positive effect in higher altitudes, while the differing temperature in lower altitudes is detrimental to mosquitoes). The inclusion of the sampling month was carried out due to the assumption that the number of mosquitoes in the caves tends to decrease over the winter months. Whether the number of mosquitoes in the caves decreases over the winter months will be examined below. The analysis was performed in $\mathrm{R}^{41}$ with package VGLM ${ }^{42,43}$.

Effects of surroundings. Since it is assumed that the number of mosquitos decreases over winter, the mosquito abundance was compared between the winter months as well. We tested for significant differences in the mosquito abundance frequencies between winter sampling month by means of a chi squared test.

Since we assume that a decrease in mosquito abundance may be influenced by cave parameters, we perform the test separately for source material and cave moisture. The main rock type of the shelter or of the walls and ceilings was recorded and shelters were divided into two categories, acidic or alkaline, according to the surrounding rock types and their influence on the $\mathrm{pH}$ of water. During site visits, the underground sites were also characterized by moisture level (very dry, dry, humid, wet, constant flow). Due to the paucity of extremes, the categories very dry/dry and constant flow/wet were combined. With a Chi square test, we tested for significance between the frequencies of recorded abundances of hibernating mosquitoes (few, several, many) and winter months (December to February, with GraphpadPrism 8.02 ${ }^{44}$ ) in the respective parameters and presented them as stacked bar charts.

Additionally, we performed further analysis on the surroundings of sampling sites. Different cave zones were also recorded whereby each mosquito specimen, as well as the counting or frequency estimation was attributed to a zone. Caves with several zones inhabited by mosquitos were also included in the calculation in the corresponding categories.

The surrounding environment of the caves was characterized to reveal potential associations with the number of mosquitos (categories based on numbers of individuals found and their frequency in the data set). For each cave, the percentages of different land cover types (using the Corine Land Cover data ${ }^{45}$ ) were calculated (using ArcGIS Version 10.7 ${ }^{46}$ ) within the surrounding $200 \mathrm{~m}, 400 \mathrm{~m}, 800 \mathrm{~m}$ and $1600 \mathrm{~m}$. The Land Cover data was compiled into four groups (coniferous forest (CLC category 312), broadleaf forest (CLC 311), anthropogenic (CLC categories 111, 112, 121, 122, 142), agriculture (CLC categories 211, 222, 231, 242, 243). Data that could not be effectively assigned to any category (less than $50 \%$ cover of a category) was omitted. These datasets were also tested for significance with a Chi squared test (GraphpadPrism 8.02 ${ }^{44}$ ) in the respective parameters and presented as stacked bar charts. 


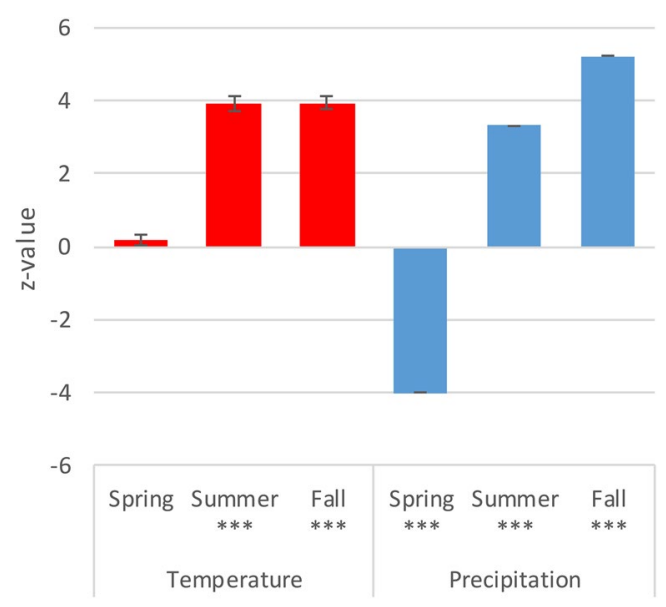

Figure 3. Effects of higher temperature and precipitation during activity and transition phases (March to November) on mosquito density in hibernacula during the hibernation phase (December through February). Depicted are the $\mathrm{z}$-values of the GLM and their standard errors ( $\mathrm{p}$-values: $\left.{ }^{* *}<0.001\right)$.

\section{Results}

Genetic species composition. The molecular species identification shows a sympatric occurrence of $C x$. p. pipiens and $C x$. torrentium in most of the cavernous habitats while there were no clear differences in species composition when comparing different sampling years (results not shown). Shown are the species proportions of the samples over the years (min years of sampling per cave $=1$, max sampling per cave $=13$ ) (Fig. 1 ). Numbers of $C x$. p. pipiens and Cx. torrentium caught were of similar size and distribution while the subspecies Cx. p. molestus occurred very rarely in our sampling (Pools with: only Cx. torrentium: 183 (25\%), only Cx. p. pipiens: 135 (19\%), both: 397 (55\%), both and Cx. p. molestus: 8 (1\%)). Our records also confirmed other mosquito species in Hessian caves: Aedes cinereus/geminus (1 female), Aedes rossicus (67 female,1 male), Anopheles maculipennis s.l. (3 female), Anopheles marteri (5 female), Culiseta annulata (204 female, 2 male).

Effects of precipitation and temperature. We first displayed temperature and precipitation conditions (yearly mean temperature and mean precipitation during the active phase from April through September) together with the observed mosquito abundances in the caves during winter months (Fig. 2). In comparatively hot and dry years such as 2003, a low percentage of caves with high abundances can be observed, whereas high abundances could be observed in comparatively cool, humid years such as 2010 or 2007. This is not the case in 2008, for example. Therefore, in the GLM we do not consider the temperature and precipitation ratios averaged over the whole activity phase but by quarters.

The GLM revealed that the abundance of hibernating mosquitoes is significantly affected by temperature in summer and fall as well as by precipitation of all three considered quarters (Supplementary). We illustrated the positive and negative effects of these variables in Fig. 3. Temperature in the spring months (March, April, May-T spring) had no significant effect while there was a significant increase during Summer (June, July, August) and Fall (September, October, November). Higher precipitation (P) had a significant negative effect during Spring and a significantly positive effect during Summer and Fall. A higher Altitude had a significant positive effect on the abundance as well (Supplementary model 1).

Effects of surroundings. There was a significant decrease in mosquito abundance during the winter months in subterranean environments surrounded by acidic rock composition in both, wet and dry underground shelters. On the other hand, the density of mosquitos within hibernacula classified as alkaline did not change during the winter months. The difference was strongest within the group of medium and dry underground shelters (Fig. 4).

A relationship between the abundance of mosquitos and the stated moisture levels of the underground habitats could not be established.

There is a significant difference between the number of mosquitos in the entrance and twilight zones compared to the dark zone (Fig. 5) in subterranean shelters. Dark zones seem to be favored be hibernating mosquitoes.

In addition, we considered the land cover characteristics of the surroundings of the underground sites. We found significant differences of the abundances of overwintering mosquitos between subterranean shelters surrounded by Broadleaf Forest and Conifer Forest and agricultural areas and Anthropogenic-purposed land (i.e. urbanization) (Fig. 6).

\section{Discussion}

Spatial patterns. No spatial pattern of species composition was detected in the subterranean shelters located in Hesse. However, the co-occurrence of the two species $C x$. p.pipiens and Cx. torrentium was confirmed (Fig. 1). Similar results were shown by Rudolf et al. ${ }^{40}$ with a sample set of mosquitos collected in Germany 


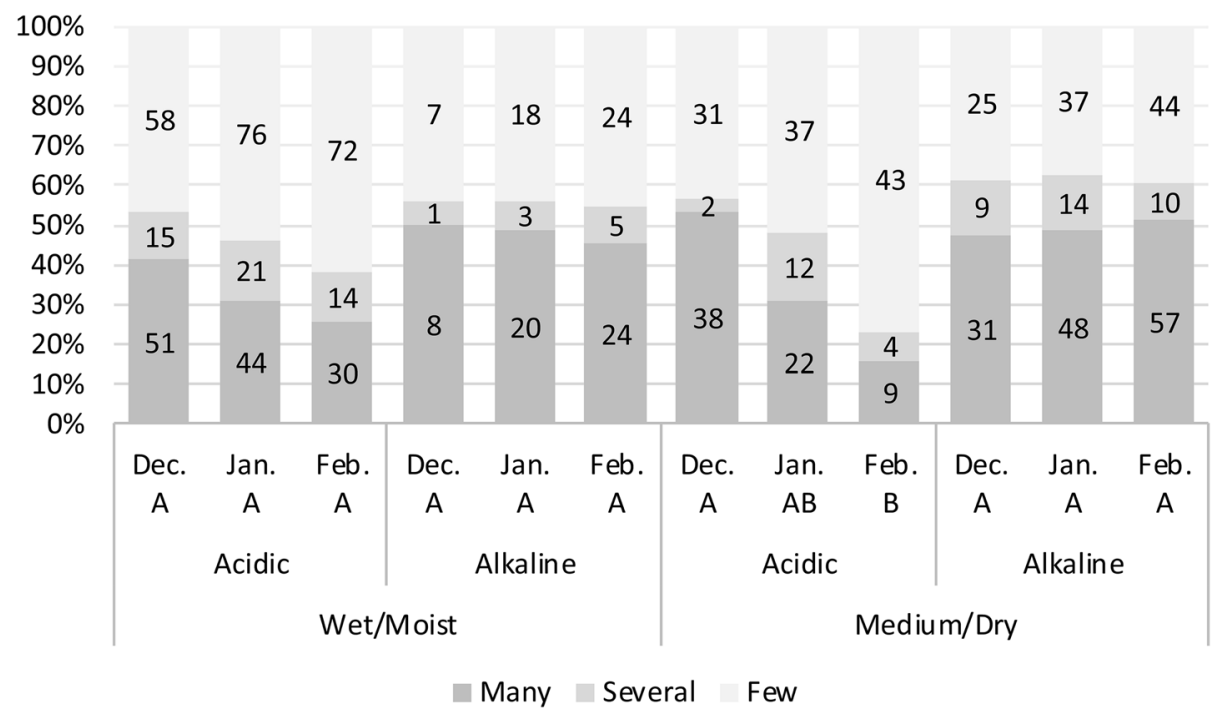

Figure 4. Comparison of mosquito abundance within hibernacles of alkaline and acidic surrounding rock combined with humidity levels. Statistical significance is symbolized with A, B and C, where non-matching letters are significantly different (Chi Square: $61.9,22 \mathrm{df}, \mathrm{p}=0.0002$; corrected min./max. value A against B: $\mathrm{p}=0.0004 / 0.0016)$. Y-Axis: composition of categories within the sampling. The numbers in the bar graphs show the absolute frequency of categories in the respective years. Categories: many: $>20$ individuals, several: 10-20 individuals, few: 1-10 individuals found within the subterranean shelter.

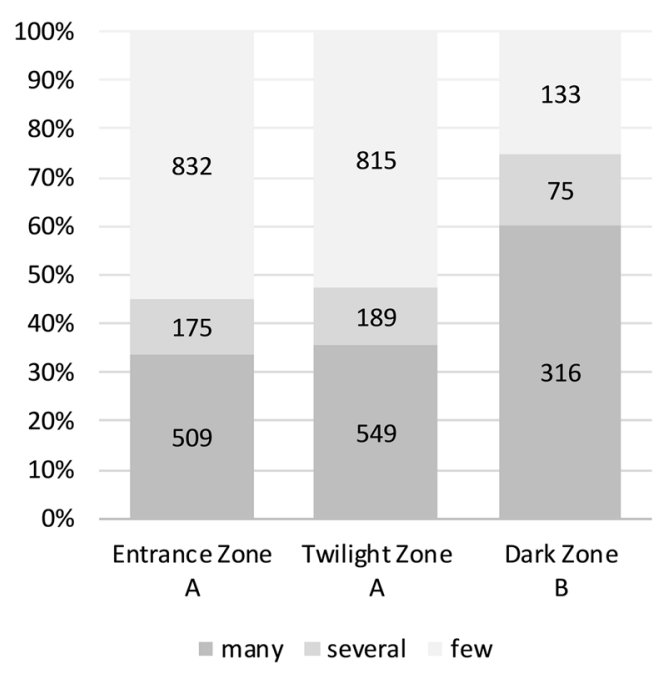

Figure 5. Comparison of mosquito abundance of the different depth zones within cavernous habitats during the hibernation period. Statistical significance is symbolized with A and B, where non-matching letters are significantly different (Chi Square: 154.3, $4 \mathrm{df}, \mathrm{p}<0.0001$; corrected value A against B: $\mathrm{p}<0.0001$ ). Y-Axis: composition of categories within the sampling. The numbers in the bar graphs show the absolute frequency of categories in the respective years. Categories: many: $>20$ individuals, several: 10-20 individuals, few: 1-10 individuals found within the cave.

above ground. For the State of Hesse, they found more $C x$. torrentium than $C x$. p. pipiens and no samples of $C x$. p. molestus. Werblow et al. ${ }^{47}$ detected a general pattern of fewer $C x$. torrentium than $C x$. pipiens. According to Hesson et al. ${ }^{14}, C x$. torrentium and $C x$. pipiens occur sympatrically with more $C x$. torrentium north of the Alps. In Central Europe and Austria, distributional patterns of both species are very similar ${ }^{48-50}$. Overall, it seems that $C x$. torrentium and $C x$. p. pipiens occur equally abundant in central Germany.

We could detect one hybridization event in our sampling. One pool of two collected specimens were molecularly flagged for all three subspecies. Although several authors already suggested hybridization between $C x$. p. pipiens and $C x$. p. molestus ${ }^{51-53}$, we were not able to determine which two out of the three sampled species hybridized. Since their genetic differences are overall very small ${ }^{22,24}$, it is questionable whether these two species should be distinguished as different subspecies. The authors suggested that the verification of gene flow between 


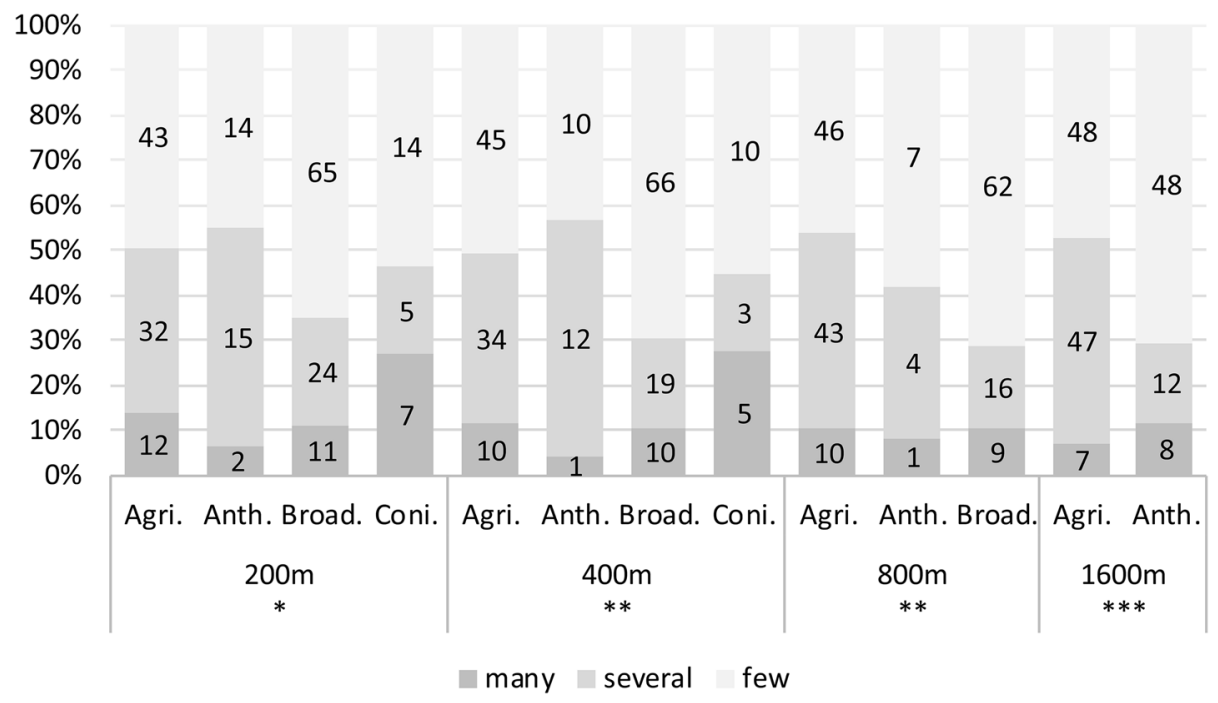

Figure 6. Comparison of mosquito abundance and different main land cover categories surrounding hibernacles in four different radiuses during the hibernation period. Abbreviations: Agri., agriculture and pastures; Anth., anthropogenic and urban; Broad., broadleaved forest; Coni., coniferous forest. p-values and Chi square statistics: $200 \mathrm{~m}$ : 0.02, 14.67, $6 \mathrm{df}$, Anth. against Coni.: 0.03, Anth. against Broad.: 0.03; $400 \mathrm{~m}$ : 0.004, 18.99, 6 df, Anth against Coni: 0.02, Anth. against Broad.: 0.007, Agri. against Broad.: 0.01; 800 m: 0.007, 14.8, 4 df, Agri. against Broad.: 0.007; 1600 m: 0.0007, 14.61, 2 df, Agri against Anth.: 0.0007. Omitted data from adjusted sample set of 263 sampling points: $200 \mathrm{~m}$ : 7\%, $400 \mathrm{~m}: 14 \%, 800 \mathrm{~m}: 25 \%, 1600 \mathrm{~m}$ : 35\%. Y-Axis: composition of categories within the sampling. The numbers in the bar graphs show the absolute frequency of categories in the respective years. Categories: many: $>20$ individuals, several: 10-20 individuals, few: 1-10 individuals found within the subterranean shelter.

both forms allows for two different interpretations: They could be two genetically distinct forms, which converge and hybridize where their distribution areas are overlapping. Otherwise, $C x$. p. molestus might just be a biotype that originated from $C x$. p. pipiens, and the two of them are not yet reproductively isolated whereby similarities in behavior and physiology suggest hybridization. This suggests that $C x$. p. molestus is a biotype of $C x$. pipiens and, at least in Germany, relatively rare. Amara Korba et al. ${ }^{23}$ could prove the stenogamy and autogamy of $C x$. p. molestus in $78.6 \%$ of their cases albeit this result does not account for all of the individuals. Another study revealed no prey choice preferences amongst birds and mammals regarding Cx. p. pipiens and Cx. p. molestus ${ }^{16}$. Overall, our findings corroborate those of other studies and point not to a picture of $C x$. p. molestus as a subterranean subspecies that feeds on cave-dwelling mammals, but rather, to it being a biotype of $C x$. pipiens that potentially has a shifted niche towards smaller enclosures like tree cavities or burrows of different animals that can also adapt to a surface habitat. If the two forms were only ecological varieties of one species, mixed forms should not be classified as hybrids.

The complete dataset contains 8750 Culex mosquitos, all collected within subterranean habitats. Of these samples, only 22 were male Culex mosquitos (collected in the months from May to December), of which 12 samples were classified as $C x$. torrentium and 10 as $C x$. p. pipiens, a finding which is supported by another study ${ }^{54}$. In light of the very low numbers of males and the lack of $C x$. p. molestus or hybrid males, and since hibernating females of $C x$. p. molestus collected in the subterranean shelters matched the percentage of those found by aboveground sampling, the surveyed Hessian $C x$. p. molestus show no sign of homodynamy. Similar results confirm our assumption that $C x$. p. molestus is not an underground biotype of $C x$. p. pipiens or that subterranean objects are particularly suitable for hybridization ${ }^{54}$.

All other species, except two, were collected between April and September within the subterranean shelters, and therefore, show no evidence of hibernation within subterranean shelters. Only Culiseta annulata and one specimen of Anopheles maculipennis were collected during the winter months, possibly using caves for hibernation. Compared to the other rarer mosquitos, higher individual numbers of $\mathrm{Cu}$. annulata underscore this consideration.

Effects of precipitation and temperature. We provide evidence that weather conditions during the previous activity phase as well as the time of sampling influence the abundance of species within the hibernacles in the following winter. Temperature in the Spring (March, April and May) had no significant effect. This can be explained by a previous finding that higher temperatures in March probably cause the mosquitos to exit their wintering grounds prematurely ${ }^{55}$, resulting in a negative effect that is cancelled out by the following two months.

Climate effects on mosquitos were studied from early May to mid-September in a north-western province in Italy ${ }^{56}$. Although the climate of northern Italy is not completely comparable with that of Hesse, partially similar patterns were observed. These results are somewhat different from our calculations whereby a higher temperature in Summer (June, July and August) as well as in the Fall (September, October and November) correlated with 
a significant increase of mosquitos within the hibernacles. Lack of information concerning Italian populations after September precludes further comparison. Higher temperatures in September potentially affect the behavior of mosquitos, which generally start migrating into shelters for the winter from the beginning of October. Higher temperatures in October and November could enable more mosquitos to find suitable shelter for the winter, which results in a positive effect for our "Fall" category. Our results show a negative effect in Spring and a positive one in Summer and Fall, corroborating a preference for higher precipitation that was reported before ${ }^{56,57}$. Another study detected a direct correlation between higher temperature and the number of mosquitos two weeks later ${ }^{58}$. Our calculation revealed a significant effect of sampling months on the number of mosquitos found inside the underground structure, i.e. the later the sampling in the winter, the fewer mosquitos were found inside the cave, which is corroborated by the study of Zittra et al. ${ }^{54}$.

Effects of surroundings. A decrease of mosquitos in January and February was detected. Smaller numbers are most prominent in underground habitats classified as dry/medium and acidic (Fig. 4). A similar, although not significant pattern is visible in wet/humid, acidic habitats. An attenuation of the impact on mosquito numbers with regard to increased humidity can be explained by the fact that contact more water weakens the $\mathrm{pH}$ lowering effect of the surrounding material. More acidic environments may simply not be conducive for mosquito hibernation whereby the mechanisms involved could merit further investigation.

Distribution within caves and the higher number of mosquitos in the deeper parts of the underground habitats was unexpected. It was previously assumed that mosquitos would hibernate mainly in the entrance and twilight zones $^{36}$. There might be a possible tradeoff reflected in the results in that overwintering in the deeper zones might guarantee better shelter against freezing outside temperatures and higher survival rates.

The effective flight distance for Culex mosquitos throughout their life span is between 600 to 2000 meters $^{59,60}$. For our analysis, we therefore set four different radiuses of 200, 400, 800 and $1600 \mathrm{~m}$ around the hibernation site to analyze land cover more closely. Overall, anthropogenic and agricultural surroundings have a positive effect on mosquito density within the hibernacles when compared to forests. Although coniferous forests in Germany are often monocultures for timber production that provide a suitable habitat for only a limited number of vertebrate species $^{61-63}$, we could not detect a significant difference between the two forest types. The increased proportion of the "many" and "several" categories in agricultural and anthropogenic areas might be explained by the fact that fields and pastures are frequently used by large grazing animals that serve as hosts for adult mosquitos. Water troughs as well as car tires, commonly used as weights on tarpaulins, are ideal breeding grounds for mosquito larvae. Most settlements within the flight radius of the surveyed hibernacles are small clusters of single-family houses with large gardens, which often also contain many small collections of water in rainwater barrels, plant pots or buckets. These breeding options as well as proximity to humans, pets and birds provide excellent living conditions for mosquitos. Our findings of greater abundancies of species in hibernacles surrounded by anthropogenic and agriculturally influenced terrains is a common pattern found in urban habitats ${ }^{15,48,50,57}$.

\section{Conclusion}

Germany and the State of Hesse lie in the temperate climate zone, where caves and other underground shelters offer an advantage for $C x$. pipiens and $C x$. torrentium, if not a necessity. Our study complements existing knowledge about the ecological requirements of this species complex. By using information about climate conditions and mosquito densities within caves the following winters, it might be possible to estimate which years witness a large mosquito density and thus create temporal pattern forecasts. The sites, their characteristics and surroundings are important for the occurrence of the species and create spatial patterns. Spatial and temporal patterns are particularly important for vector species as they allow the necessary precautions to be assessed and applied more quickly.

In summary, based on results of previous studies, we expected to find significantly higher proportions of $C x$. p. molestus inside the caves, but our results indicate a similar species composition of the Culex pipiens complex as that found outside the caves. We did not find any male specimens of $C x$. p. molestus, a fact that suggests that at least in our study area, $C x$. p. molestus lacks permanent underground populations and does not reproduce in subterranean environments. Our results also show that for Hesse, the previous theory that mosquitos hibernate primarily in the entrance zones of caves should be re-evaluated. We assume that the frequency of mosquitos within the caves is determined by the frequency of mosquitos on the surface. This assumption is supported by our results that the climate conditions during the activity phase have a significant effect on the frequency of hibernating mosquitos. Therefore, we argue that the number of hibernating mosquitos could be taken as a proxy for the overall density of the mosquito population but would require further investigation. The availability of suitable hibernation sites ensures the continuation of the species in the following year. Dependent on cave parameters, we could detect a decrease in the abundance of overwintering mosquitos during the winter months.

Received: 9 December 2019; Accepted: 3 June 2020

Published online: 24 June 2020

\section{References}

1. Vinogradova, E. B. Culex pipiens pipiens Mosquitoes. Taxonomy, Distribution, Ecology, Physiology, Genetics, Applied Importance and Control (Pensoft, Sofia, 2000).

2. Linnaeus, C. Systema naturae Vol. 1. No. part 1 (Laurentii-Salvii, Stockholm, 1758).

3. Forskål, P. Flora Agyptiaco-Arabica sive descriptiones plantarum quas per agytum inferiorem et arabiam felicem detexit, illustravit Petrus Forskål. Post mortem auctoris edidit Carsten Niebuhr (1775).

4. Martini, R. Zwei bemerkenswerte Culiciden von einem eigenartigen Biotop. Int Rev Hydrobiol 12, 333-337 (1925).

5. Say, T. Descriptions of dipterous insects of the United States. J. Acad. Nat. Sci. Philadelphia 3, 9-54 (1823). 
6. Coquillett, D. W. Report on a collection of Japanese Diptera, presented to the U.S. national museum by the Imperial University of Tokyo. Proc. US Natl. Museum 21, 301-340 (1898).

7. Meigen, J. W. \& Wiedemann, C. R. W. Aussereuropäische Zweiflügelige Insekten / beschrieben von Christ. Rud. Wilh. Wiedemann ; als Fortsetzung des Meigenischen Werkes.; 10.5962/bhl.title.14603 (1828).

8. Barr, A. R. Occurrence and distribution of the Culex pipiens complex. Bull. World Health Organ. 37, 293-296 (1967).

9. Hubálek, Z. \& Halouzka, J. West Nile Fever-a reemerging mosquito-borne viral disease in Europe. Emerg. Infect. Dis. 5, 643-650. https://doi.org/10.3201/eid0505.990505 (1999).

10. Lundström, J. O. Mosquito-borne viruses in western Europe: a review. J. Vector Ecol. 24, 1-39 (1999).

11. Hayes, C. G. West Nile virus: Uganda, 1937, to New York City, 1999. Ann. N. Y. Acad. Sci. 951, 25-37 (2001).

12. Hubálek, Z. Mosquito-borne viruses in Europe. Parasitol Res 103, 29-43. https://doi.org/10.1007/s00436-008-1064-7 (2008).

13. Werblow, A., Bolius, S., Dorresteijn, A. W. C., Melaun, C. \& Klimpel, S. Diversity of Culex torrentium Martini, 1925-a potential vector of arboviruses and filaria in Europe. Parasitol Res 112, 2495-2501. https://doi.org/10.1007/s00436-013-3418-z (2013).

14. Hesson, J. C. et al. The arbovirus vector Culex torrentium is more prevalent than Culex pipiens in northern and central Europe. Med. Vet. Entomol. 28, 179-186. https://doi.org/10.1111/mve.12024 (2014).

15. Becker, N. et al. Mosquitoes and Their Control 2nd edn. (Springer, Heidelberg, 2010).

16. Gomes, B. et al. Feeding patterns of molestus and pipiens forms of Culex pipiens (Diptera: Culicidae) in a region of high hybridization. Parasites Vectors 6, 93. https://doi.org/10.1186/1756-3305-6-93 (2013).

17. Andreadis, T. G. The contribution of Culex pipiens complex mosquitoes to transmission and persistence of West Nile virus in North America. J. Ame. Mosquito Control Assoc. 28, 137-151. https://doi.org/10.2987/8756-971X-28.4s.137 (2012).

18. Lõhmus, M., Lindström, A. \& Björklund, M. How often do they meet? Genetic similarity between European populations of a potential disease vector Culex pipiens. Infect. Ecol. Epidemiol. 2, 12001. https://doi.org/10.3402/iee.v2i0.12001 (2012).

19. Harbach, R. E., Harrison, B. A. \& Gad, A. M. Culex (Culex) molestus Forskal (Diptera: Culicidae): neotype designation, description, variation, and taxonomic status. Proc Entomol Soc Wash 86, 521-542 (1984).

20. Knight, K. L. A Review of the Culex pipiens complex in the Mediterranean Subregion (Diptera, Culicidae). Trans. R. Entomol. Soc. Lond. 102, 354-364. https://doi.org/10.1111/j.1365-2311.1951.tb00754.x (1951).

21. Kamura, T. \& Bekku, H. Studies on the Culex pipiens group of Japan. IV. Ecological studies on the Nagasaki molestus. Endemic Dis. Bull. Nagasaki Univ. 1(1), 51-59 (1959).

22. Kent, R. J., Harrington, L. C. \& Norris, D. E. Genetic Differences Between Culex pipiens f. molestus and Culex pipiens pipiens (Diptera: Culicidae) in New York. J. Med. Entomol. 44, 50-59. https://doi.org/10.1603/0022-2585(2007)44[50:gdbcpf]2.0.co;2 (2007).

23. Amara Korba, R. et al. Ecological differentiation of members of the Culex pipiens complex, potential vectors of West Nile virus and Rift Valley fever virus in Algeria. Parasites Vectors 9, 1405. https://doi.org/10.1186/s13071-016-1725-9 (2016).

24. Vinogradova, E. B. \& Shaikevich, E. V. Morphometric, physiological and molecular characteristics of underground populations of the urban mosquito Culex pipiens Linnaeus f. molestus Forskål (Diptera: Culicidae) from several areas of Russia. Eur Mosq Bull 22, 17-24 (2007)

25. Sulaiman, S. \& Service, M. W. Studies on hibernating populations of the mosquito Culex pipiens L. in southern and northern England. J. Nat. History 17, 849-857. https://doi.org/10.1080/00222938300770661 (1983).

26. Huang, S. et al. Genetic Variation Associated with Mammalian Feeding in Culex pipiens from a West Nile Virus Epidemic Region in Chicago Illinois. Vector-Borne Zoonotic Dis. 9, 637-642. https://doi.org/10.1089/vbz.2008.0146 (2009).

27. Denlinger, D. L. \& Armbruster, P. A. Mosquito diapause. Annu. Rev. Entomol. 59, 73-93. https://doi.org/10.1146/annurevento-011613-162023 (2014).

28. Onyeka, J. O. A. \& Boreham, P. F. L. Population studies, physiological state and mortality factors of overwintering adult populations of females of Culex pipiens L. (Diptera: Culicidae). BER 77, 99. https://doi.org/10.1017/S0007485300011585 (1987).

29. Spielman, A. Studies on Autogeny in Culex pipiens Populations in Nature. I. Reproductive isolation between autogenous and anautogenous populations. Am. J. Hygiene 80, 175-183 (1964).

30. Harbach, R. E., Harrison, B. A. \& Gad, A. M. Culex (Culex) molestus Forskal (Diptera: Culicidae): neotype designation, description, variation and taxonomic status. Proc Entomol 86, 521-542 (1984).

31. Harbach, R. E., Dahl, C. \& White, G. B. Culex (Culex) pipiens Linnaeus (Diptera: Culicidae): Concepts, type designations, and description. Proc. Entomol. Soc. Wash. 87, 24 (1985).

32. Merdić, E. \& Vujičić-Karlo, S. Two types of Hibernation of Culex pipiens complex (Diptera: Culicidae) in Croatia. Entomol. Croatia 9, 71-76 (2005).

33. Kjærandsen, J. Diptera in mines and other cave systems in southern Norway. Entomologica Fennica 4, 151-160 (1993).

34. Badino, G. Cave temperatures and global climatic change. IJS 33, 103-113. https://doi.org/10.5038/1827-806X.33.1.10 (2004).

35. Barr, R. A. Ocurrence and distribution of the Culex pipiens Complex. Bull. World Health Organ. 37, 293-296 (1967).

36. Gunn, J. (ed.) Encyclopedia of caves and karst science (Fitzroy Dearborn, New York, 2004).

37. Höhlen. Verborgene Welten. 1st ed. (Primus-Verl., Darmstadt, 2008).

38. Buffington, J. D. Hibernaculum choice in Culex Pipiens. J. Med. Entomol. 9, 128-132. https://doi.org/10.1093/jmedent/9.2.128 (1972).

39. Thomson, R. C. M. The reactions of mosquitoes to temperature and humidity. Bull. Entomol. Res. 29, 125. https://doi.org/10.1017/ S0007485300026158 (1938).

40. Rudolf, M. et al. First nationwide surveillance of Culex pipiens complex and Culex torrentium mosquitoes demonstrated the presence of Culex pipiens biotype pipiens/molestus hybrids in Germany. PLoS ONE 8, e71832. https://doi.org/10.1371/journ al.pone.0071832 (2013).

41. R Core Team. R. A Language and Environment for Statistical Computing (R Foundation for Statistical Computing, Vienna, 2013).

42. Yee, T. W. \& Wild, C. J. Vector generalized additive models. J. R. Stat. Soc. Ser. B (Methodol.) 58, 481-493 (1996).

43. Yee, T. W. Vector Generalized Linear and Additive Models: with an Implementation in R (Springer, Berlin, 2015).

44. GraphPad Software. GraphPad Prism (La Jolla California USA).

45. Copernicus Land Monitoring Service. Corine Land Cover Data (European Environment Agency (EEA), 2019).

46. Systems, E. ArcGIS Desktop (Redlands, CA, 2019).

47. Werblow, A. et al. Population structure and distribution patterns of the sibling mosquito species Culex pipiens and Culex torrentium (Diptera: Culicidae) reveal different evolutionary paths. PLoS ONE 9, e102158. https://doi.org/10.1371/journal.pone.01021 58 (2014).

48. Weitzel, T., Jawień, P., Rydzanicz, K., Lonc, E. \& Becker, N. Culex pipiens s.l. and Culex torrentium (Culicidae) in Wrocław area (Poland): occurrence and breeding site preferences of mosquito vectors. Parasitol Res 114, 289-295. https://doi.org/10.1007/s0043 6-014-4193-1 (2015)

49. Lühken, R. et al. Physico-chemical characteristics of Culex pipiens sensu lato and Culex torrentium (Diptera: Culicidae) breeding sites in Germany. J. Med. Entomol. 52, 932-936. https://doi.org/10.1093/jme/tjv070 (2015).

50. Zittra, C. et al. Ecological characterization and molecular differentiation of Culex pipiens complex taxa and Culex torrentium in eastern Austria. Parasites Vectors 9, 197. https://doi.org/10.1186/s13071-016-1495-4 (2016).

51. Fonseca, D. M. et al. Emerging vectors in the Culex pipiens complex. Science 303, 1535-1538. https://doi.org/10.1126/science.10942 47 (2004). 
52. Gomes, B. et al. Asymmetric introgression between sympatric molestus and pipiens forms of Culex pipiens (Diptera: Culicidae) in the Comporta region, Portugal. BMC Evol. Biol. 9, 262. https://doi.org/10.1186/1471-2148-9-262 (2009).

53. Andreadis, T. G., Huang, S. \& Molaei, G. Reexamination of Culex pipiens hybridization zone in the Eastern United States by Ribosomal DNA-based single nucleotide polymorphism markers. Am. J. Trop. Med. Hyg. 85, 434-441. https://doi.org/10.4269/ajtmh .2011.10-0679 (2011).

54. Zittra, C., Moog, O., Christian, E. \& Fuehrer, H.-P. DNA-aided identification of Culex mosquitoes (Diptera: Culicidae) reveals unexpected diversity in underground cavities in Austria. Parasitol. Res. 118, 1385-1391. https://doi.org/10.1007/s00436-019-06277 $-y(2019)$.

55. Ciota, A. T., Matacchiero, A. C., Kilpatrick, A. M. \& Kramer, L. D. The Effect of Temperature on Life History Traits of Culex Mosquitoes. J. Med. Entomol. 51, 55-62. https://doi.org/10.1603/ME13003 (2014).

56. Rosà, R. et al. Early warning of West Nile virus mosquito vector: climate and land use models successfully explain phenology and abundance of Culex pipiens mosquitoes in north-western Italy. Parasites Vectors 7, 269. https://doi.org/10.1186/1756-3305-7-269 (2014).

57. Zittra, C. et al. Landscape structure affects distribution of potential disease vectors (Diptera: Culicidae). Parasites Vectors 10, 205. https://doi.org/10.1186/s13071-017-2140-6 (2017).

58. Paz, S. \& Albersheim, I. Influence of warming tendency on Culex pipiens population abundance and on the probability of West Nile fever outbreaks (Israeli Case Study: 2001-2005). EcoHealth 5, 40-48. https://doi.org/10.1007/s10393-007-0150-0 (2008).

59. Verdonschot, P. F. M. \& Besse-Lototskaya, A. A. Flight distance of mosquitoes (Culicidae): A metadata analysis to support the management of barrier zones around rewetted and newly constructed wetlands. Limnologica 45, 69-79. https://doi.org/10.1016/j. limno.2013.11.002 (2014).

60. Ciota, A. T. et al. Dispersal of Culex mosquitoes (Diptera: Culicidae) from a wastewater treatment facility. J. Med. Entomol. 49, 35-42. https://doi.org/10.1603/me11077 (2012).

61. Otto, H.-J. Waldökologie (E. Ulmer, Stuttgart, 1994).

62. Brockerhoff, E. G., Jactel, H., Parrotta, J. A., Quine, C. P. \& Sayer, J. Plantation forests and biodiversity: oxymoron or opportunity?. Biodivers. Conserv. 17, 925-951. https://doi.org/10.1007/s10531-008-9380-x (2008).

63. Ellenberg, H., Leuschner, C. \& Dierschke, H. Vegetation Mitteleuropas mit den Alpen in ökologischer, dynamischer und historischer Sicht 6th edn. (E. Ulmer, Stuttgart, 2010).

\section{Acknowledgements}

This research was funded by the German Federal Ministry of Food and Agriculture (BMEL) through the Federal Office for Agriculture and Food (BLE), grant numbers 2819104415 and 2819105115 as well as by the Uniscientia Foundation (P 121-2017). We thank all members of the Hesse Federation for Cave and Karst Research for sample collection as well as Dr. Adrienne Jochum and Dr. Judith Kochmann for proofreading the manuscript.

\section{Author contributions}

Dorian D. Dörge designed and conceptionalized the study, wrote the main manuscript text, executed the statistical analysis, interpreted the data and prepared all figures. Sarah Cunze wrote the main manuscript text, executed the statistical analysis, interpreted the data and prepared all figures. Henrik Schleifenbaum executed the genetic data analysis and prepared Fig. 1. Stefan Zaenker acquired the samples and designed the study. Sven Klimpel designed and conceptionalized the study and wrote the main manuscript text. All authors reviewed the manuscript.

\section{Competing interests}

The authors declare no competing interests.

\section{Additional information}

Supplementary information is available for this paper at https://doi.org/10.1038/s41598-020-67422-7.

Correspondence and requests for materials should be addressed to D.D.D.

Reprints and permissions information is available at www.nature.com/reprints.

Publisher's note Springer Nature remains neutral with regard to jurisdictional claims in published maps and institutional affiliations.

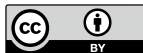

Open Access This article is licensed under a Creative Commons Attribution 4.0 International License, which permits use, sharing, adaptation, distribution and reproduction in any medium or format, as long as you give appropriate credit to the original author(s) and the source, provide a link to the Creative Commons license, and indicate if changes were made. The images or other third party material in this article are included in the article's Creative Commons license, unless indicated otherwise in a credit line to the material. If material is not included in the article's Creative Commons license and your intended use is not permitted by statutory regulation or exceeds the permitted use, you will need to obtain permission directly from the copyright holder. To view a copy of this license, visit http://creativecommons.org/licenses/by/4.0/.

(c) The Author(s) 2020 